Key Words:

Rotary Filter

Sludge

MST

Retention:

\#Permanent\#

\title{
TESTING OF A FULL-SCALE ROTARY MICROFILTER FOR THE ENHANCED PROCESS FOR RADIONUCLIDES REMOVAL
}

\author{
D.T. Herman \\ D.B. Stefanko \\ M.R. Poirier \\ S.D. Fink
}

JANUARY 2009

Savannah River National Laboratory

Savannah River Nuclear Solutions

Aiken, SC 29808

Prepared for the U.S. Department of Energy Under

Contract Number DE-AC09-08SR22470

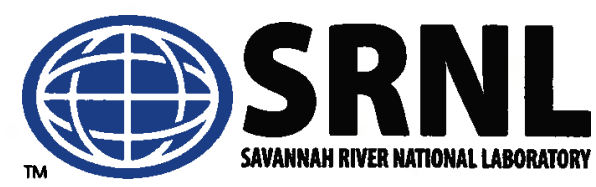




\section{DISCLAIMER}

This work was prepared under an agreement with and funded by the U.S. Government. Neither the U. S. Government or its employees, nor any of its contractors, subcontractors or their employees, makes any express or implied:

1. warranty or assumes any legal liability for the accuracy, completeness, or for the use or results of such use of any information, product, or process disclosed; or

2. representation that such use or results of such use would not infringe privately owned rights; or

3. endorsement or recommendation of any specifically identified commercial product, process, or service.

Any views and opinions of authors expressed in this work do not necessarily state or reflect those of the United States Government, or its contractors, or subcontractors.

Printed in the United States of America

Prepared for

U.S. Department of Energy 


\section{TABLE OF CONTENTS}

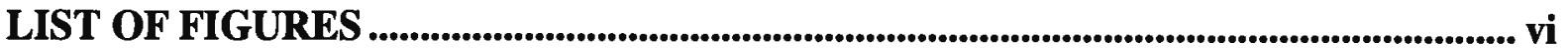

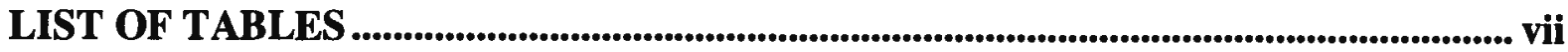

LIST OF ACRONYMS AND ABBREVIATIONS ........................................................ viii

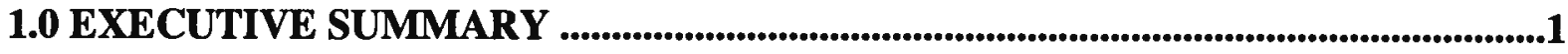

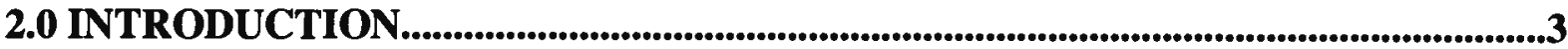

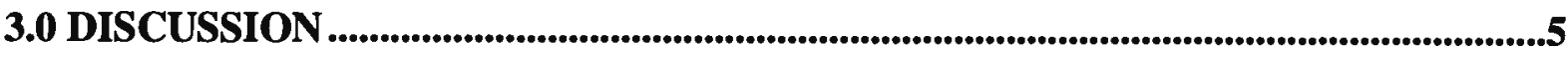

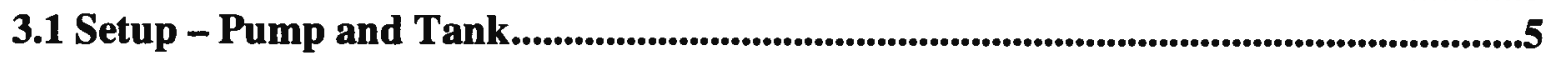

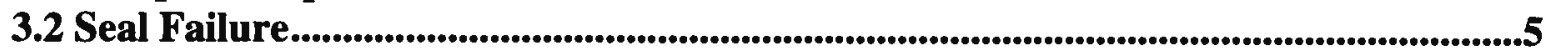

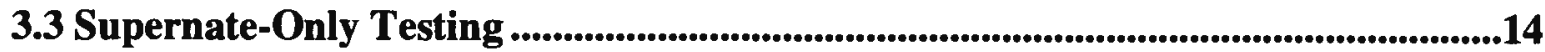

3.4 Testing with 0.06 wt \% Insoluble Solids................................................................15

3.5 Testing with 5 wt \% Insoluble Solids.....................................................................16

3.6 Particle Size Analysis of Test Feed..............................................................................22

3.7 Effect of Feed Pressure and Feed Flow on Filter Flux .....................................................22

3.8 Rotary Filter Power Requirements................................................................................24

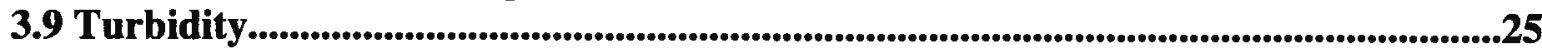

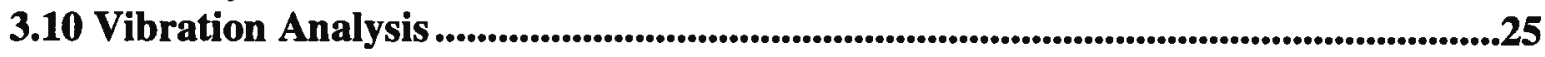

3.11 Cleaning .........................................................................................................................29

3.12 Disassembly. ......................................................................................................................35

3.12.1 Air Seal Inspection. ...................................................................................................35

3.12.2 Bushing Inspection ..............................................................................................38

3.12.3 Rotary Joint Inspection ...............................................................................40

3.12.4 Wear Part Summary .....................................................................................45

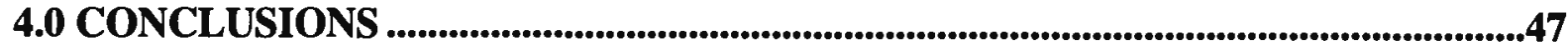

5.0 FUTURE WORK ...................................................................................................................49

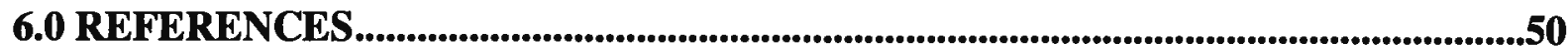

Attachment 1. Filter System Sketch

Attachment 2. John Crane Seal Analysis Report

Attachment 3. Test Data Sheets

Attachment 4. Initial Vibration Measurements

Attachment 5. Second Vibration Measurements 


\section{LIST OF FIGURES}

Figure 1. Rotary Filter Unit Diagram........................................... 4

Figure 2. Shaft Seal Carbon Face with Chipped Section Highlighted................. 6

Figure 3. Photo of Blisters on Carbon Seal Face........................................ 8

Figure 4. Radial Trace of Carbon Face of Failed Seal.............................. 9

Figure 5. Flatness Trace of Carbon Face of Air Seal............................... 10

Figure 6. Wear in Drive Tang of the Air Seal Carbon Face........................... 11

Figure 7. Shaft Seal Silicon-Carbide Face........................................ 11

Figure 8. Surface Trace of Silicon Carbide Air Seal Face at the Seal Dam............... 12

Figure 9. Radial Surface Trace of Silicon Carbide Air Seal Face...................... 13

Figure 10. Total Filter Flux with $6 \mathrm{M} \mathrm{Na}^{+}$Simulated Supernate after Initial Filter Disk Cleaning............................................................ 14

Figure 11. Total Filter Flux with 0.06 wt \% Insoluble Solids Simulated Tank 8F Sludge + MST ............................................................... 16

Figure 12. Total Filter Flux with Simulated Tank 8F Sludge + MST ................. 17

Figure 13. Comparison of 25-Disk Rotary Filter Testing with Sludge and Sludge + MST and 3-Disk Rotary Filter Testing with Sludge + MST at 0.06 wt \% Insoluble Solids..................................................... 18

Figure 14. Comparison of 25-Disk Rotary Filter Testing with Sludge and Sludge + MST and 3-Disk Rotary Filter Testing with Sludge + MST at 4.5-5 wt \% Insoluble Solids.

Figure 15. Relationship of Filtrate Flow per Square Foot of Filter Media vs. Net Pressure Drop across the Filter System................................. 20

Figure 16. Specific Flux versus Net Pressure Drop................................. 21

Figure 17. Specific Flux with Simulated Tank 8F Sludge + MST .................... 21

Figure 18. Comparison of Rotary Filter Feed Particle Size Analysis................... 22

Figure 19. Filtrate Flow Relative to Feed Pressure at all Insoluble Solids Loadings with

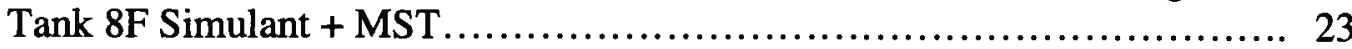

Figure 20. Filtrate Flow Relative to Feed Flow at all Insoluble Solids Loadings with Tank 8F Simulant + MST .......................................... 24

Figure 21. Filter Motor Power and Current Draw.................................. 24

Figure 22. Turbidity Analysis of Filtrate Samples................................. 25

Figure 23. Locations of Accelerometers for Vibration Measurements.................. 26

Figure 24. Baseline Vibration Measurements of the Rotary Filter................... 27

Figure 25. Summary Velocity Plot after the Incorporation of Shims and Support Arm... 28

Figure 26. Filter Stack after Rinsing with Inhibited Water............................ 29

Figure 27. Disk 24 after Rinsing with Inhibited Water (top face, left, and bottom face,

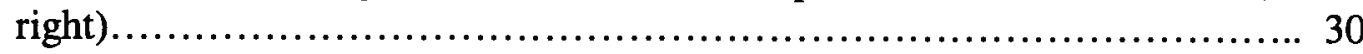

Figure 28. Filter Stack Comparison of IW Rinsed Filter (left photo) and Bottom Half Acid Washed (right photo) .............................................. 31

Figure 29. Disk \#24 Top (left photo) and Bottom (right photo) after First Acid Cleaning ............................................................. 32

Figure 30. Comparison of Disk \#24 after Acid Cleaning Steps........................ 33 
Figure 31. Comparison of Flux from Post Acid Cleaning to Original Data with $5 \mathrm{wt} \%$ Insoluble Solids (Time scale aligned for "post acid cleaning" data for comparison)

Figure 32. New Air Seal Silicon- Carbide Face Compared to Seal Face with 230 Hours of Operation....................................................... 35

Figure 33. Air Seal Carbide Face at the Interface of an Air Groove at the Seal Dam 10X Magnification................................................... 36

Figure 34. New Air Seal Carbon Face Compared to the Carbon Seal Face after 230 Hours of Operation................................................... 36

Figure 35. Air Seal Carbon Face at 4X Magnification.............................. 37

Figure 36. Photo of Seal Drive Tang after 230 Hours of Operation (top) Compare to a New Seal (bottom) ................................................. 38

Figure 37. Photo of Lower Shaft Bushing Rotating Part................................ 39

Figure 38. Photo of Lower Shaft Bushing Stationary Cup............................ 40

Figure 39. Rotary Joint at Test Completion............................................. 41

Figure 40. Photo of Upper Bearing from Rotary Joint................................ 41

Figure 41. Rotary Joint Carbon Face of Upper Seal.............................. 42

Figure 42. Carbon Seal Face from Top Seal of Rotary Joint at 4X Magnification........ 43

Figure 43. Rotary Joint Carbon Face of Lower Seal.................................. 43

Figure 44. Carbon Face from Bottom Seal of Rotary Joint at 4X Magnification.......... 44

Figure 45. Alumina Seal Face from Bottom Seal of Rotary Joint Showing Dried Salt Outside of Sealing Area................................................. 45

\section{LIST OF TABLES}

Table 1. Composition of the Simulated Supernate Used in Testing .................................14

Table 2. Simulated Tank 8F Sludge Target Composition...............................................15

Table 3. Summary of Wear Part Use in Each Rotary Filter Test Campaign ......................46 


\section{LIST OF ACRONYMS AND ABBREVIATIONS}

$\begin{array}{ll}\text { ACTL } & \text { Aiken County Technical Laboratory } \\ \text { CPVC } & \text { chlorinated polyvinyl chloride } \\ \text { DOE } & \text { Department of Energy } \\ \text { EPRR } & \text { Enhanced Processes for Radionuclide Removal } \\ \text { ips } & \text { inch per second } \\ \text { IW } & \text { inhibited water (0.01 M NaOH, 0.011 M NaNO } 2) \\ \text { gpm } & \text { gallons per minute } \\ \text { MCU } & \text { Modular Caustic Side Solvent Extraction Unit } \\ \text { MST } & \text { monosodium titanate } \\ \text { N/A } & \text { Not Applicable } \\ \text { NTU } & \text { Nephelometric turbidity units } \\ \text { psi } & \text { pounds per square inch } \\ \text { psid } & \text { pounds per square inch differential } \\ \text { pvc } & \text { polyvinyl chloride } \\ \text { Si-C } & \text { Silicon Carbide } \\ \text { SRNL } & \text { Savannah River National Laboratory } \\ \text { SRS } & \text { Savannah River Site } \\ \text { wt } \% & \text { weight percent }\end{array}$




\section{EXECUTIVE SUMMARY}

Savannah River National Laboratory (SRNL) researchers are investigating and developing a rotary microfilter for solid-liquid separation applications in the Department of Energy (DOE) complex. One application involves use in the Enhanced Processes for Radionuclide Removal (EPRR) at the Savannah River Site (SRS). To assess this application, the authors performed rotary filter testing with a full-scale, 25-disk unit manufactured by SpinTek Filtration with 0.5 micron filter media manufactured by Pall Corporation. The filter includes proprietary enhancements by SRNL. The most recent enhancement is replacement of the filter's main shaft seal with a John Crane Type 28LD gas-cooled seal. The feed material was SRS Tank $8 \mathrm{~F}$ simulated sludge blended with monosodium titanate (MST). Testing examined total insoluble solids concentrations of $0.06 \mathrm{wt} \%$ (126 hours of testing) and $5 \mathrm{wt} \%$ ( 82 hours of testing). The following are conclusions from this testing.

Operating Performance:

- During restart of the filter, the main air seal developed a leak. Evaluation of the seal led to the conclusion that the leak was a result of several small blisters that formed on the carbon seal face. The cause of the blisters is believed to be a contaminant being drawn between the seal faces and not an inherent flaw in the application of the air seal technology with the rotary filter. The change in wear pattern due to the prior disassembly of the seal allowed the contaminant to enter between the seal faces.

- The filter flux at $0.06 \mathrm{wt} \%$ solids reached a near constant value of approximately $0.090 \mathrm{gpm} / \mathrm{ft}^{2}$ (2.2 gpm total) at a net pressure drop of $40 \mathrm{psi}$ across the filter system.

- The filter flux at $5 \mathrm{wt} \%$ solids reached a near constant value of approximately $0.049 \mathrm{gpm} / \mathrm{ft}^{2}$ (1.2 gpm total) with a net pressure drop of $60 \mathrm{psi}$.

- Filtration rate has a linear relationship to the net pressure drop between 20 and 60 psid. The most productive net pressure for the tested slurry at low weight percent insoluble solids ( $\leq 5 \mathrm{wt} \%$ ) is $60 \mathrm{psi}$.

- Filtration rates are consistent with similar tests run previously using a pilot scale 3disk rotary filter using sludge + MST. The addition of MST results in a loss of flux versus filtering sludge only.

- Filtrate turbidity measured $<4$ Nephelometric Turbidity Units (NTU) for all samples collected.

Chemical Cleaning

- The rotary filter was successfully cleaned using approximately 50 liters of $4 \mathrm{M}$ nitric acid. Flux was restored to approximately $88 \%$ of the initial flux at $5 \mathrm{wt} \%$ insoluble solids.

Mechanical Wear

- Inspection of the faces of the main shaft seal after approximately 230 hours of operation showed an expected amount of initial wear, no passing of process fluid 
through the seal faces, and very little change in the air channeling grooves on the stationary face.

- The rotary joint showed signs of leakage in both upper and lower seals. Wear on the seals was primarily from vibration. The upper seal showed signs of running dry due to trapped air restricting liquid (coolant/lubricant) access to the seal for at least a portion of operational time.

- Evaluations of all mechanical seals show that vibration is a primary cause of component wear. Reduction of vibration in deployment of the rotary filter will greatly extend the lifetime of all seals and bearings.

- Measurements show that the mount of the filter in the test stand is the primary source of vibration to the rotary filter and requires improvement to allow for the accurate measurement of the vibration signature of the filter.

- Some polishing was observed at the bottom surface of the shaft bushing after a total operational time of approximately 380 hours.

\section{Recommended Improvements}

- Add a locking ring to restrain the bushing and incorporated grooves to provide additional cooling.

- Reduce trapped air in the rotary joint by raising the location of the discharge port thereby allowing the filtrate to lubricate and cool the seal.

- Install a forsheda ring (or similar) in the rotary joint to shield the lower bearing from filtrate that crosses the mechanical seal faces. Additionally, assure all bearings are stainless steel to reduce potential corrosion.

- Incorporate a motor stand to simplify alignment between the drive motor and the filter to reduce unit vibration.

- Reduce the open volume near the air seal to limit splashing of process fluid and maintain the gas pocket and the top of the filter.

- Reduce the tolerances of the filter disks and disk hubs to improve load balance on the shaft.

- Improve the alignment guides between the filter stack and the filter tank to reduce vibration. 


\subsection{INTRODUCTION}

Previously, SRNL received funding from DOE EM-21, Office of Engineering and Technology, Waste Processing (formerly Office of Cleanup Technologies) to develop the rotary microfilter for high-level radioactive service. That work focused on evaluating the performance of the rotary microfilter, redesigning the equipment for radioactive service, performing engineering studies to evaluate the risks, determining downstream impacts, assessing costs and benefits of deploying this technology, performing actual waste and pilotscale testing of the technology; and evaluating alternative filter media. The work led to the decision to design, fabricate and perform testing on a full-scale rotary microfilter for potential Savannah River Site (SRS) Tank Farm and Hanford Pretreatment applications. ${ }^{1,2}$

Because of the success of that testing, SRS is evaluating the use of the rotary microfilter for Enhanced Processes for Radionuclide Removal (EPRR). ${ }^{3}$ The EPRR is intended to provide a parallel processing path to the Modular Caustic Side Solvent Extraction Unit (MCU). ${ }^{4}$ EPRR is to be located at Tank $41 \mathrm{H}$ and is to process salt solution retrieved from SRS Tanks $1 \mathrm{~F}, 2 \mathrm{~F}$, $3 \mathrm{~F}$, and $37 \mathrm{H}$. It is to consist of two or more in-riser rotary microfilter units that feed ion exchange columns. Salt solutions from Tanks 1F, 2F, 3F, 37H, and $41 \mathrm{H}$ will feed the process and may contain up to $2 \mathrm{wt} \%$ solids. The process will add MST to the salt solution to sorb strontium and select actinides. The rotary filter will remove the MST and entrained sludge from the feed slurry.

The authors received funding from DOE EM- $21^{5}$ to modify the rotary microfilter, making it more robust and increasing the expected life from 1 to 3 years. The modifications include upgrading the mechanical seal and bushing, and tightening the manufacturing tolerances. SRNL has modified a prototypical unit with upgrades in the mechanical seal and bushing. This unit was used for the current testing.

The SpinTek Filtration high shear rotary filter used in this testing has 25 filter disks with each side covered with $0.5-\mu$ pore size (nominal) sheet membranes $(0.007$ inch thick) manufactured by Pall Corporation (PMM050). The filter area of each disk is $0.98 \mathrm{ft}^{2}$. The disks are physically mounted on and are hydraulically connected to a common hollow rotating shaft. The entire stack of membrane disks is enclosed within a vessel. Feed is fed into the filter vessel through the inlet on the side of the vessel wall. A pressure is set in the tank by restricting the outlet flow, typically by use of a gate valve on the concentrate piping. This applied pressure forces liquid through the filter membranes on the filter disks. Between each disk is a set of baffles (turbulence promoters). These turbulence promoters cause strong currents and eddies at the surface of the membranes inhibiting the formation of filter cake on the disks. Filtrate flows through the media and along a mesh inside the disk into the hollow shaft. The filtrate then flows through the shaft to the rotary joint which allows the spinning shaft to couple to stationary piping. The concentrated slurry exits the vessel through an outlet on the bottom of the filter tank.

SRNL made several enhancements to the commercial design targeting easier maintenance and operation for radioactive service. A patent application ${ }^{7}$ was filed covering 
enhancements, which are manufactured into the unit tested for this report. Figure 1 shows a cut-away of the rotary filter unit.

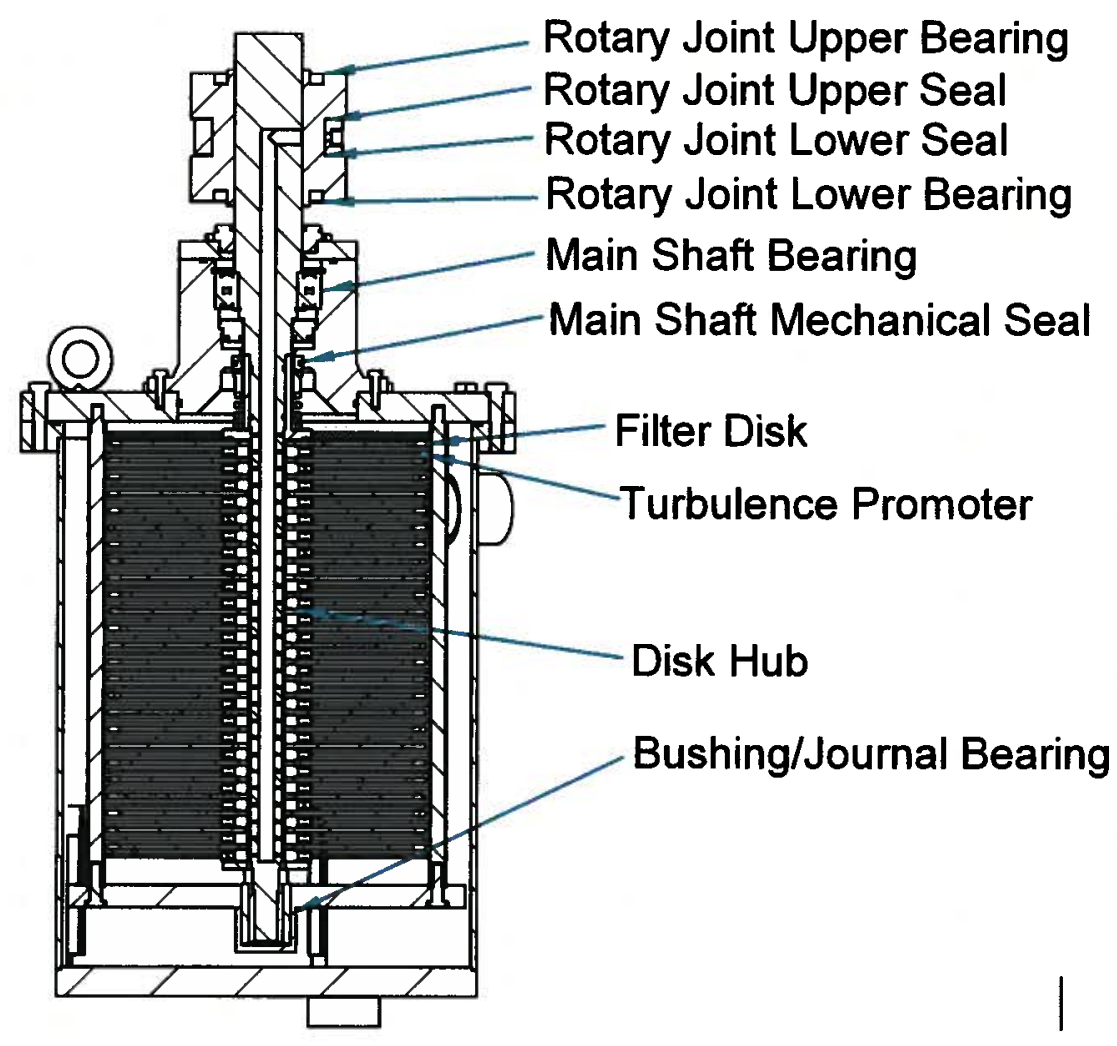

Figure 1. Rotary Filter Unit Diagram

To add to the database of knowledge on rotary filter testing, the SRNL performed the work presented in this report to continue to evaluate the rotary microfilter. A prototypic pump was installed as the feed pump for the rotary filter. The pump is capable of feeding two 25-disk rotary filter units with up to $5 \mathrm{wt} \%$ insoluble solids. The filter feed in this testing added MST to the sludge simulant (in the ratio of 0.4:0.6). The authors devised and demonstrated a filter cleaning protocol, which used $4 \mathrm{M}$ nitric acid, to clean the disks without removing the filter stack from the filter tank. This protocol can be easily adopted for use in the field. Additional evaluations were conducted on the primary seal and rotary joint. 


\subsection{DISCUSSION}

Testing included the use of the Tank $8 \mathrm{~F}$ simulated sludge (from the same batch ${ }^{8}$ used in previous testing) plus MST (MST Batch 00-QAB-417). The simulated sludge used in this testing had not been used in prior tests. Solids loadings used include $0.06 \mathrm{wt} \%$ insoluble solids and $5 \mathrm{wt} \%$ insoluble solids. The filter membranes used in testing were fabricated from nominal 0.5 micron stainless steel PMM050 membrane procured from Pall Corporation. Prior to solids testing the filter disks were individually cleaned using $4 \mathrm{M}$ nitric acid. The cleaned disks were tested using the simulated supernate solution without insoluble solids to obtain the baseline filtrate flow and demonstrate the adequacy of the cleaning.

\subsection{SETUP - PUMP AND TANK}

Testing included the use of a prototypic Grundfos model 150S150-6 well pump. This pump was selected for use in the Small Column Ion Exchange system for processing dissolved salt and entrained solids based on a calculation by Liquid Waste Engineering ${ }^{9}$. This pump is sufficient to provide feed for two rotary filter units. The maximum insoluble solids loading expected to be encountered by this pump is $5 \mathrm{wt} \%$. The use of the rotary filter in an application with higher solids concentration will require the use of a different pump.

The addition of the well pump required the use of a different feed tank system. A new feed tank was constructed from 16" polyvinylchloride (PVC) pipe to provide a tall, low volume feed tank to supply the test system. Maximum feed volume in the new tank is on the order of 80 gallons. All of the original system plumbing was replaced with chlorinated polyvinylchloride (CPVC) to allow for higher temperature and pressure testing. A sketch of the new test stand is shown as Attachment 1.

The pump was wired to an Allen Bradley PowerFlex70 variable frequency drive. The variable frequency drive allows for the control of pump output to set pressure and flow to meet testing requirements.

\subsection{SEAL FAILURE}

In preparation for the start of testing, the new plumbing was leak-checked using inhibited water (0.01 $\mathrm{M} \mathrm{NaOH}, 0.011 \mathrm{M} \mathrm{NaNO}_{2}$ ). Testing identified several minor plumbing leaks that were corrected. Due to poor filtration rates, a second cleaning of the filter disks was performed. Cleaning consisted of circulating $4 \mathrm{M}$ nitric acid through the filter tank and disks without removing the filter stack.

After rinsing with DI water, the filter system was restarted. Within the first few minutes of restart, a small leak was observed at the main shaft seal weep hole. Consultation with the seal vendor defined two possible remediation strategies.

The first strategy involved operating the filter to allow the seal faces to separate through the normal operation of the seal pumping air through the grooves and possibly clearing any 
material that may have been drawn between the faces. Under this assumed cause, operation of the seal should purge the trapped material and return to normal operation. Upon restarting the filter, the seal continued to leak as soon as the system pressure exceeded 15 psi.

The second strategy involved manually rotating the shaft in the opposite direction to back out any particulate that might be in the seal face grooves. The seal normally operates by channeling gas from the surrounding atmosphere (no filtering or pretreatment) through grooves cut into one seal face to focus at approximately the middle of the seal face. This gas forces the seal faces to separate while maintaining the seal for the process. By rotating the seal backwards, any material caught in the grooves is forced back out of the seal grooves thus returning the seal to normal operation and eliminating the leak.

Neither method slowed the leak rate. The leak continued after applying approximately $15 \mathrm{psi}$ on the system with the rotor either stopped or turning. Finally, with no improvement seen in the leak, the filter was disassembled and inspected by SRNL and a representative from John Crane International. Figure 2 shows a picture of the carbon face of the mechanical seal. The carbon face of the seal and the supporting assembly are mounted to the rotating shaft during operation. The chipped portion of the seal that is circled in the figure is the root cause of the seal leakage.

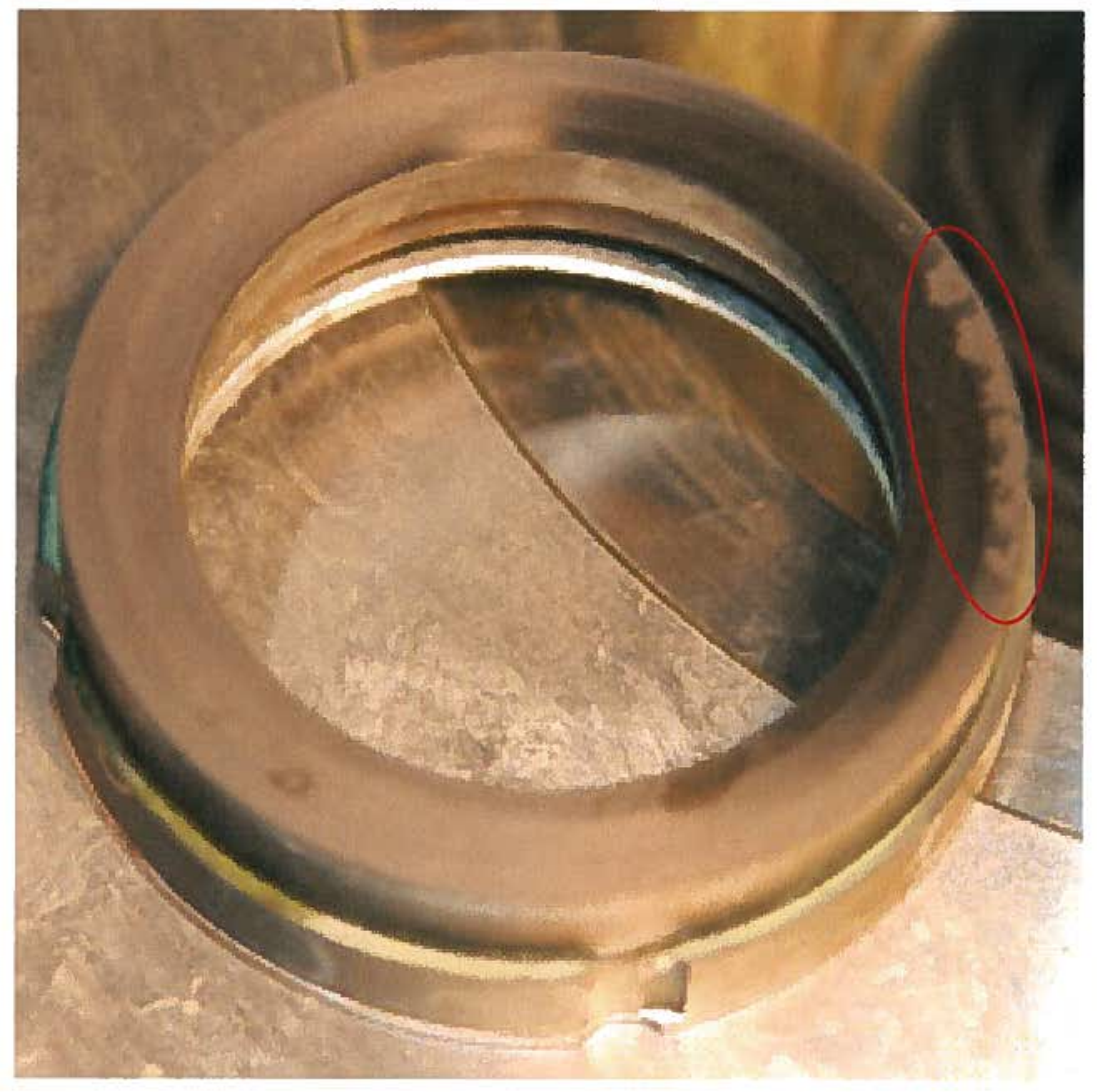

Figure 2. Shaft Seal Carbon Face with Chipped Section Highlighted 
The chipped features, shown enlarged in Figure 3, are commonly referred to as blisters and occur in much the same manner as galling of metal. According to the John Crane representative, this type of damage is typically caused when something of a viscous nature gets between the seal faces causing an adhesion that leads to the pullout of surface particles. However, damage is typically not localized. If the general process fluid had caused this we would expect the damage to be random in multiple quadrants rather than confined and excessive at just one point. In fact, none of the John Crane personnel who inspected the seal and have observed this type of damage have seen this effect as localized before. Inspection of the Carbon substructure shows that the material appears consistent with the original fabrication, and the nature of the damage makes the possibility of a defect in the material unlikely.

Prior to the leak, this air seal had seen service in a 150 hour test campaign. After that testing the seal was removed and inspected. No blisters were observed. The seal faces were wiped clean using a lint free towel with acetone and reassembled with the rest of the filter system. The seal was then operated without any signs of damage for approximately one hour. The filter system was then cleaned, in-situ, using nitric acid. During the cleaning, the seal remained assembled and static. Upon restarting the filter system after cleaning, the leak of feed slurry was observed.

Inspection and analysis of the seal components leads to the conclusion that the seal failure is an anomaly due to some foreign substance contaminating the seal faces. Within the first 1 or 2 seconds of startup, a momentary hotspot was created on the carbon face. The carbon expanded rapidly as it was not able to locally dissipate the heat. These high spots weakened the carbon locally and were sheared off, causing the blisters.

Three potential contamination methods are theorized. The first potential cause of the material between the seal faces is the previous disassembly of the seal. The seal faces were cleaned but not lapped to assure smoothness. During startup and shutdown, the seal faces come in contact and experience wear. Corresponding wear grooves are formed on the mating faces. These wear grooves typically are not aligned during reassembly. The offset caused by the wear grooves could allow enough space for material to be drawn between the faces by capillary action. By not disassembling the seal or by re-lapping the seal faces after a disassembly, the contact seal will be maintained and dramatically reduce the possibility of material being drawn between the seal faces.

The second method involves a contaminant contacting the seal face during assembly. Any such material would have to have not caused an issue in the initial startup and one-hour run of the filter. The contaminant viscosity may have increased due to heating during operation of the filter or decomposition by nitric acid or acid vapors that may have wicked between the seal faces during the cleaning, with the viscous material leading to the damage of the carbon face upon the subsequent startup.

The third method of contamination is the air seal drawing the contaminant from the atmospheric side of the filter seal, followed by the deposition of the material between the seal faces. 
It is unlikely that a viscous material passed between the seal faces from the process side during operation. Since the seal faces are designed as an air pump; they should not have been separated without a positive gas flow across the face of the seal.

It is believed that the re-assembly of the seal after the inspection at the conclusion of the previous testing caused an offset in the wear pattern of the two seal faces. This offset allowed a foreign material to come between the two faces due to capillary action. Disassembly of the seal in the field is extremely unlikely and therefore, this issue is not expected in field service.

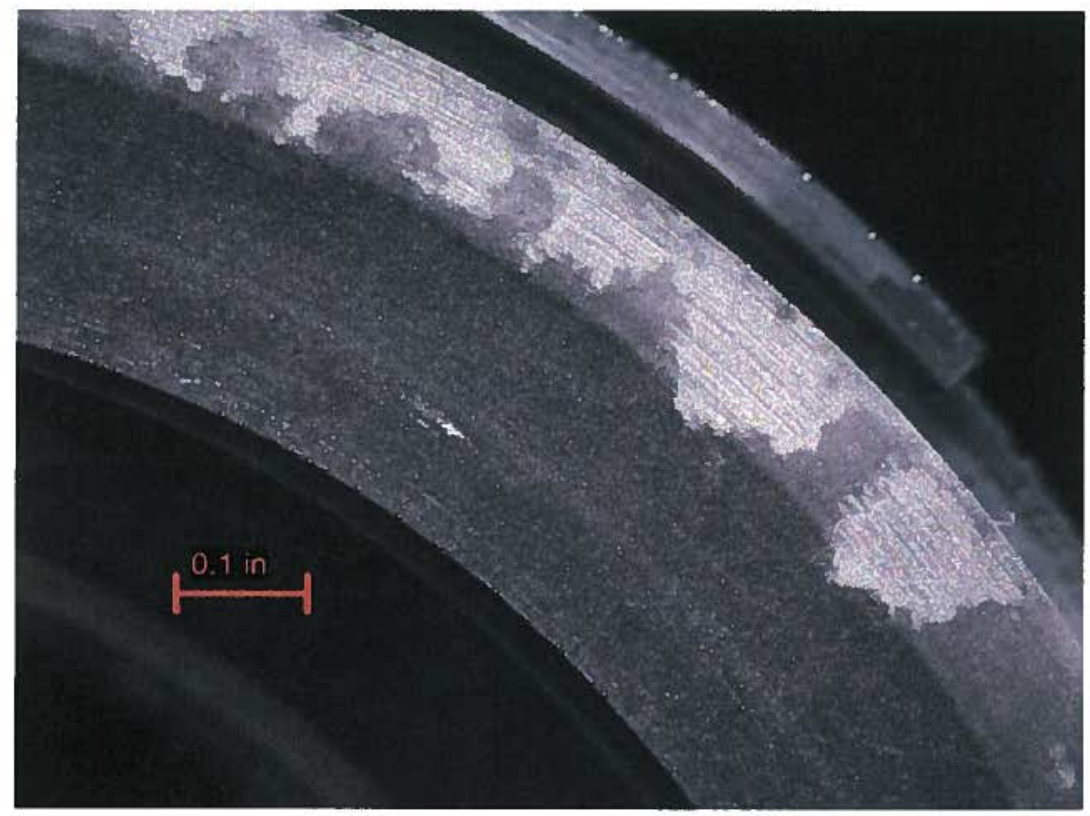

Figure 3. Photo of Blisters on Carbon Seal Face

John Crane International representatives performed finite element tracings of the seal faces using a radio profilometer and the tracing is shown in Figure 4. The tracing shows the surface profile of the carbon face taken in an area outside of the blisters. John Crane reported that the wear on these portions of the seal face are within their expectations and the mean deviation across the face is considered good. In the figure, the top portion shows the trace across a single diameter of the seal. The bottom portion shows an expanded version of one radial trace. 


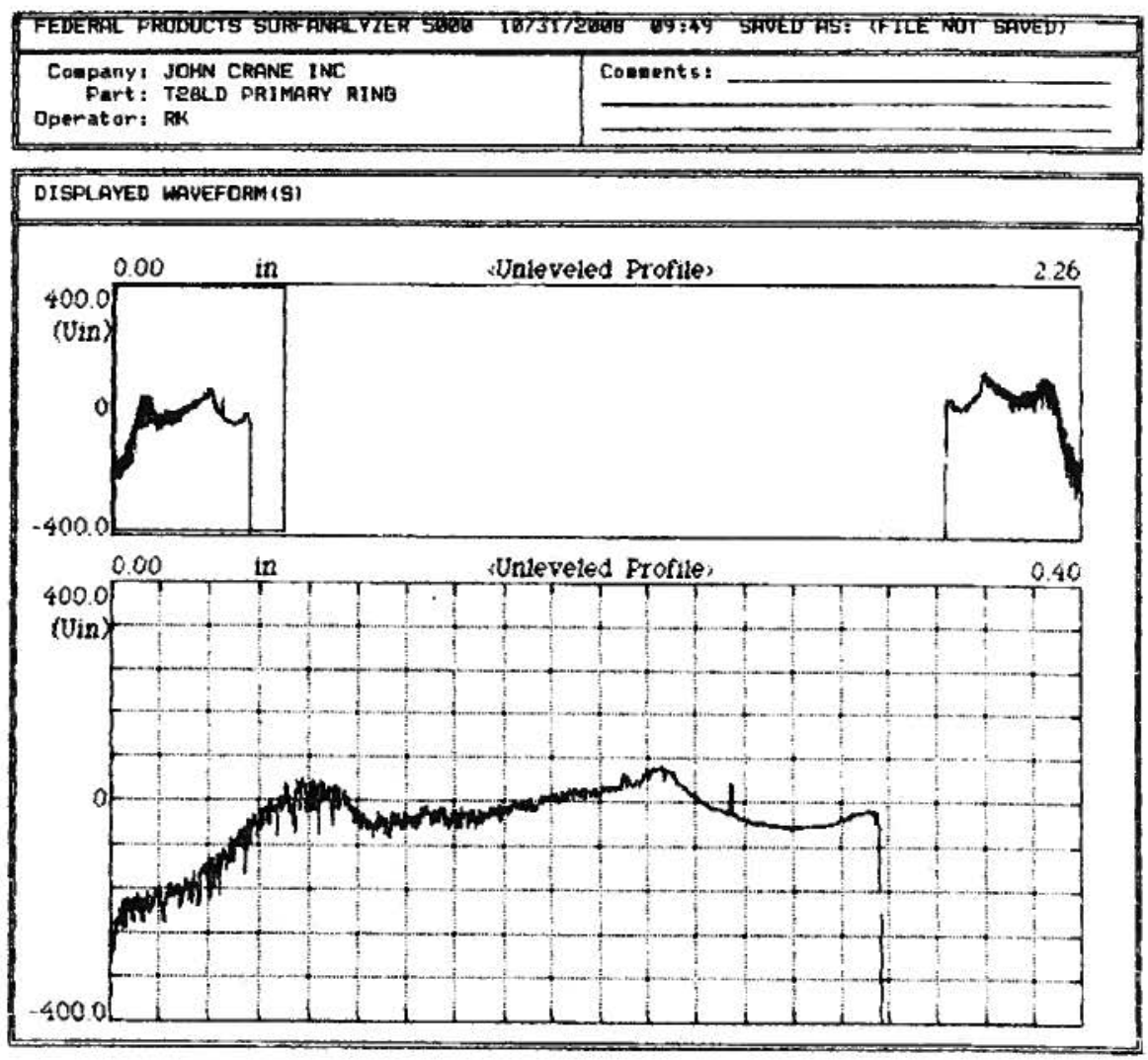

\begin{tabular}{|c|c|c|c|}
\hline $\begin{array}{l}\text { CUTOFF (r) } \\
\text { FILTER } \\
\text { DRQBE RANBE } \\
\text { EUALUATICN }\end{array}$ & $\begin{array}{l}\text { 9. } 630 \text { in } \\
\text { ANSI } 2 \sim R C \\
+1-560 \text { Uin (H) } \\
2.26 \text { in }\end{array}$ & $\begin{array}{l}\text { CUTOFF (W) } \\
\text { ORIVE SPEED } \\
\text { PROBE RATIO } \\
\text { TRAVERSE }\end{array}$ & $\begin{array}{l}0.030 \mathrm{in} \\
0.01 \mathrm{in} / \mathrm{sec} \\
1: 1 \\
\text { Uin }\end{array}$ \\
\hline
\end{tabular}

- Page 1 -

PE08-1929.max

Figure 4. Radial Trace of Carbon Face of Failed Seal

The second trace, Figure 5, is a circumferential trace of the carbon face just inboard of the blistering. This area is where the static sealing takes place. A flat surface would be indicated by a circular trace directly over the dashed circle in the figure. The trace shows a variation of 130 micro inches in a saddle pattern where the 12 and 6 o'clock positions are the low points and the 3 and 9 o'clock positions are the high points. On the left side of the trace, the 9:00 o'clock position, the spikes are where the needle grazed the blisters. The symmetric quality 
of this pattern is in line with a harmonic vibration causing increased wear at the 12 and 6 o'clock positions.
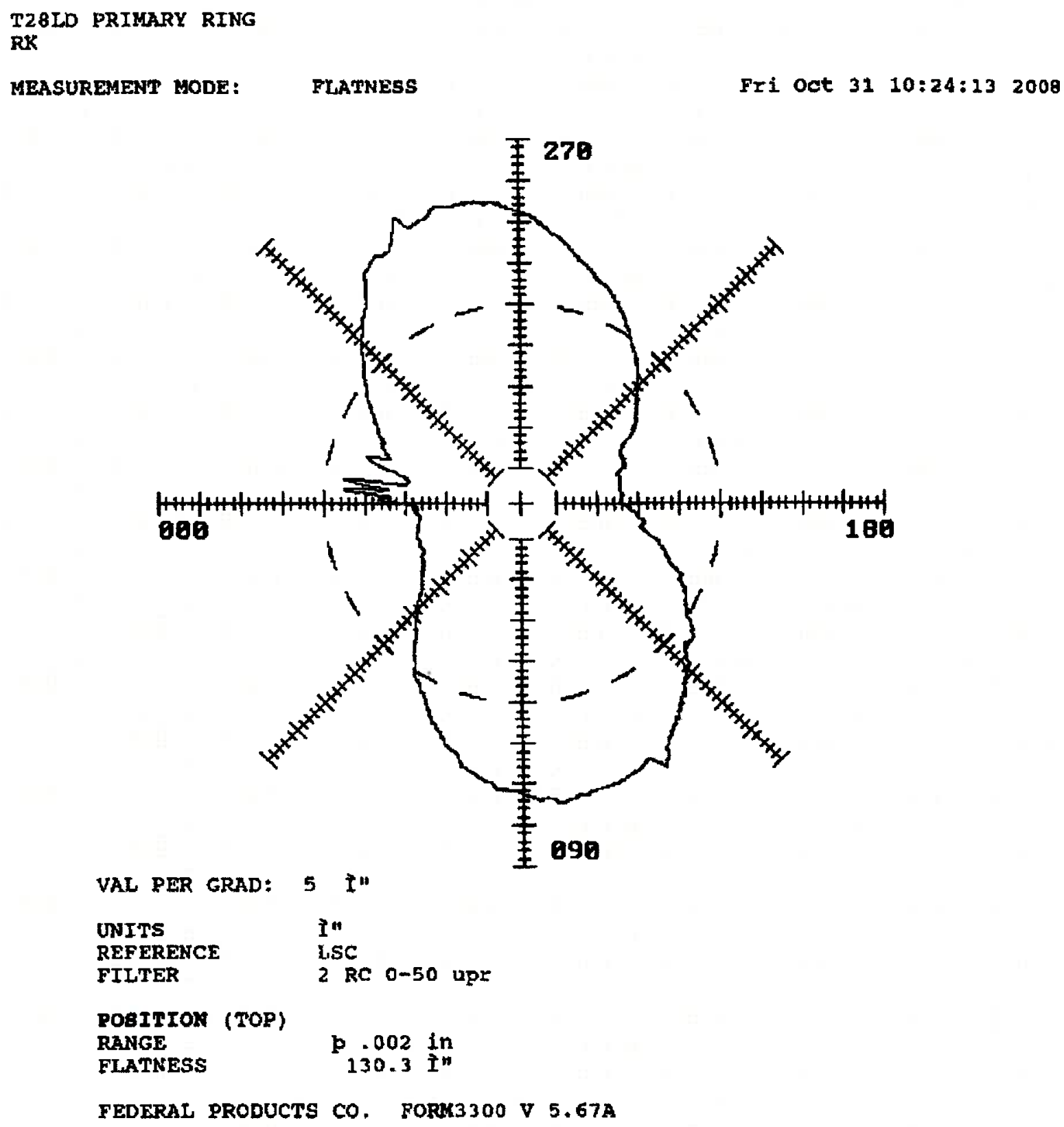

Figure 5. Flatness Trace of Carbon Face of Air Seal

There are four drive tangs on the seal; two of these become the primary drivers during operation. The seal will essentially rock on those positions due to the vibration and wear those grooves. Figure 6 shows the wear in one of the drive tangs. It is believed that the seal reached stability of wear, meaning that the saddle pattern had essentially maximized and would not ultimately cause the failure of the seal. The wear on the drive tangs would have continued, ultimately increasing wear on the carbon until the drive tangs would no longer 
drive (rotate) the seal face. All four drive tangs showed similar wear though two did not have the distinct scallop shown in the picture.

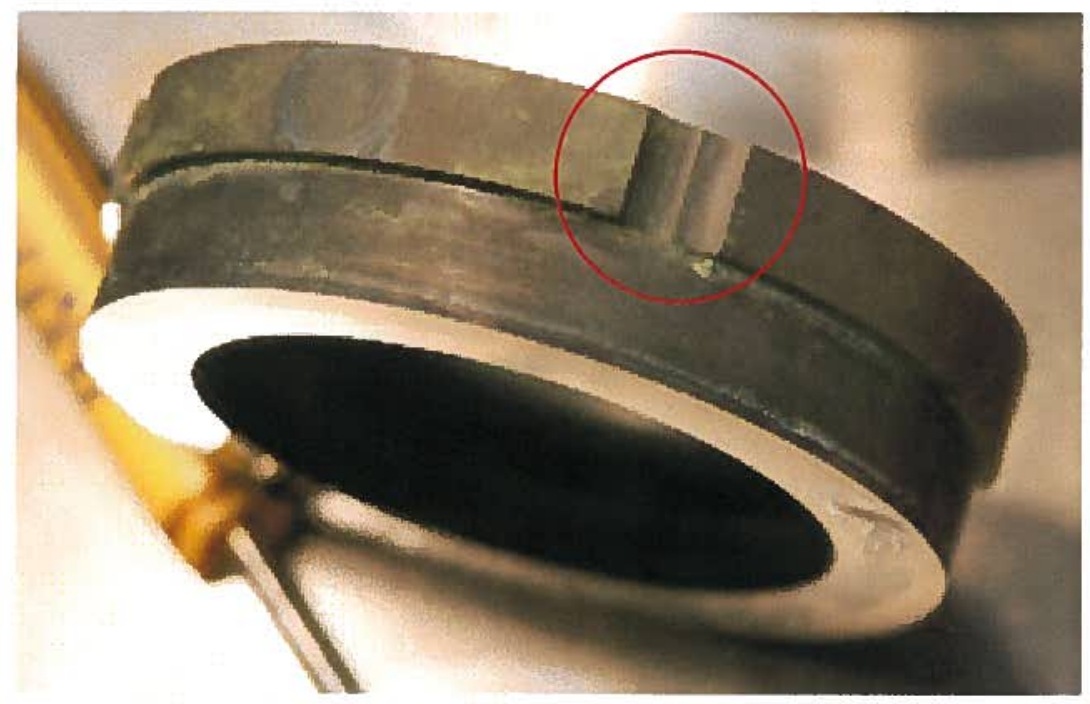

Figure 6. Wear in Drive Tang of the Air Seal Carbon Face

The stationary silicon-carbide face of the seal is shown in Figure 7. Inspection of this seal indicates that the seal face wore as expected with minor abrasion observed. Visual observation determined that the grooves appeared intact.

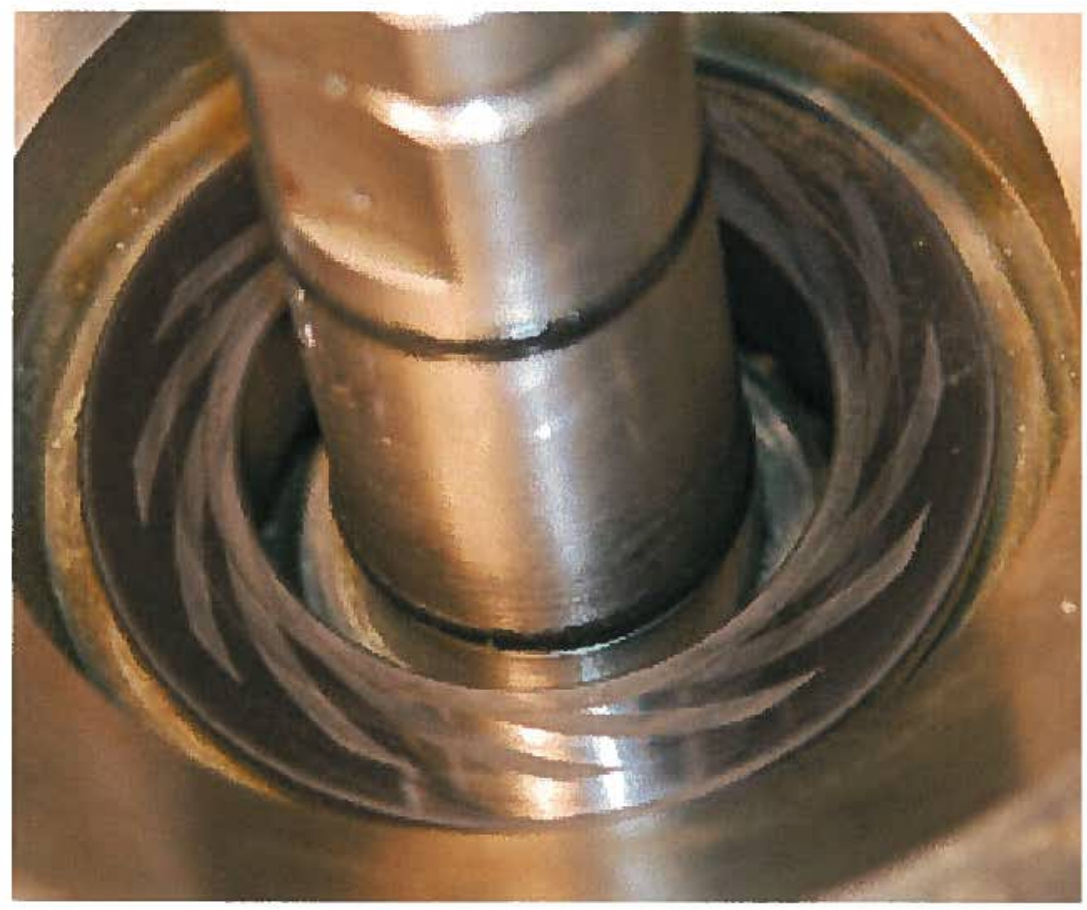

Figure 7. Shaft Seal Silicon-Carbide Face 
Figure 8 shows a surface trace of the silicon-carbide face on the seal dam (not including the grooves). This trace indicates the seal face is in good condition and shows no unusual signs of wear. The total indicated run-out measured 24 micro-inches. The original specification of the seal calls for the seal face to be within 22 micro-inches. A small amount of wear is indicated and is judged to be less than 5 micro-inches by the John Crane representative based on his experience.
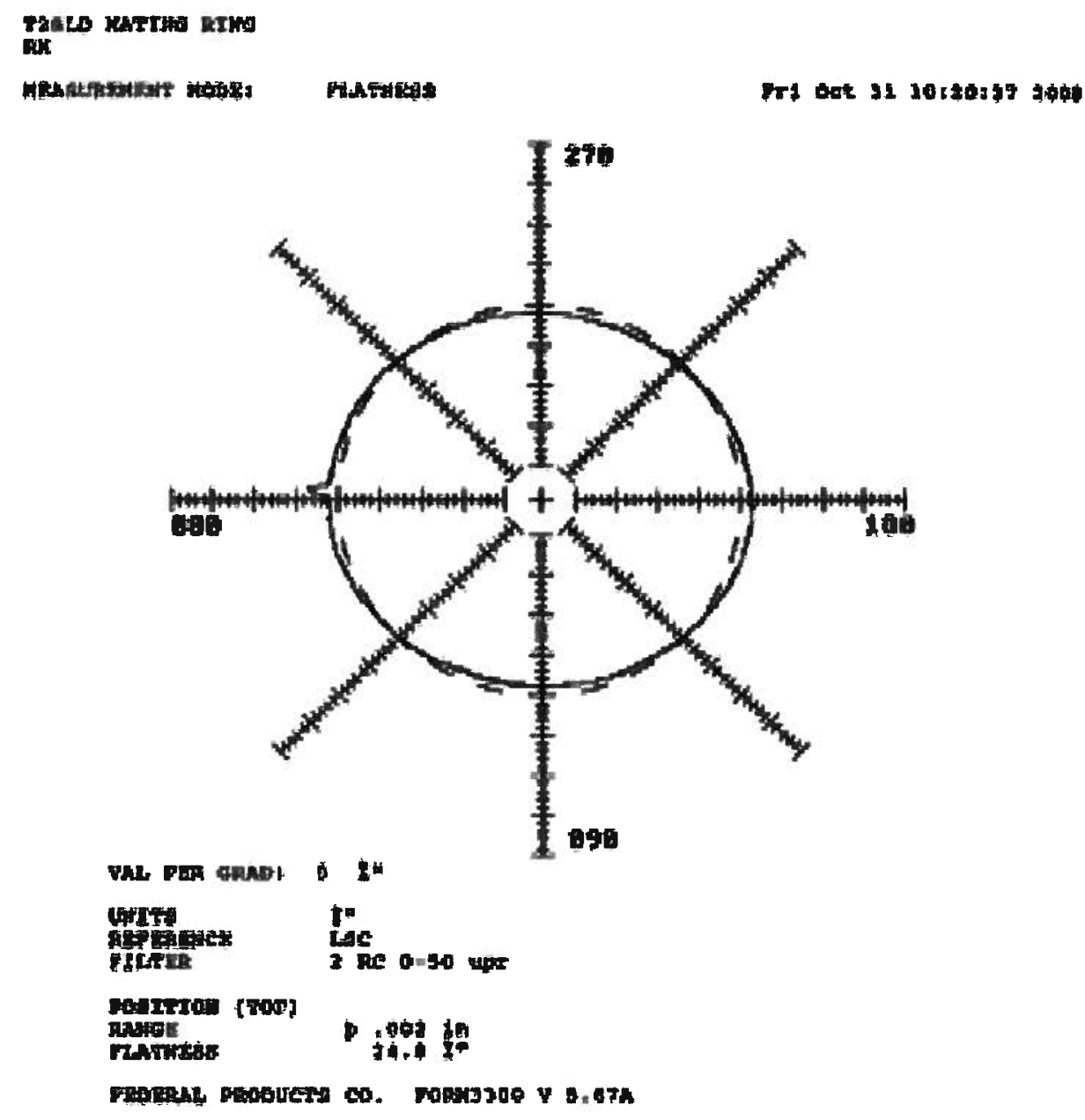

Figure 8. Surface Trace of Silicon Carbide Air Seal Face at the Seal Dam

Figure 9 is a surface trace of the silicon carbide face. Similar to Figure 4, the graph shows the measurement across the seal face diameter in the top portion of the figure and an enlarged radial trace in the lower portion of the figure. During the measurement, the grooves were crossed three times on each radius of the seal face. The trace shows that the groove depth is acceptable and shows no accelerated wear. 


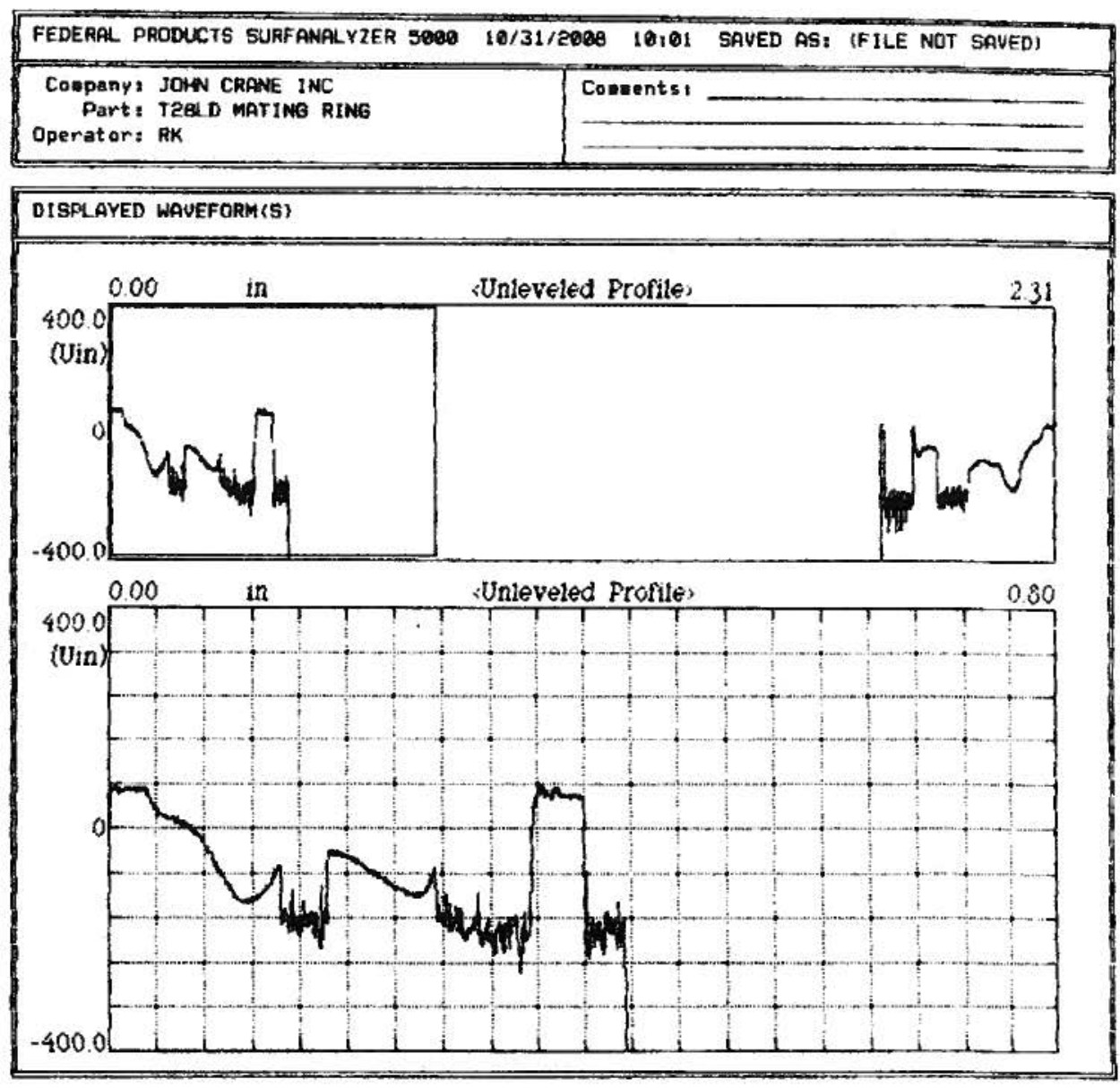

\begin{tabular}{|c|c|c|c|}
\hline \multicolumn{4}{|c|}{ TEST CONDITIONS } \\
\hline $\begin{array}{l}\text { CUTOFF ( } r) \\
\text { FILTER } \\
\text { PROBE RANGE } \\
\text { EVALUATION }\end{array}$ & $\begin{array}{l}\text { 0. } 390 \text { in } \\
\text { ANSI } 2-R C \\
+1-508 \text { Uin (H) } \\
2.31 \text { in }\end{array}$ & $\begin{array}{l}\text { CUTOFF (W) } \\
\text { DRIVE SPEED } \\
\text { PROBE RAT 10 } \\
\text { TRAUERSE }\end{array}$ & $\begin{array}{l}0.300 \text { in } \\
0.1 \mathrm{in} / \mathrm{sec} \\
1: 1 \\
\text { Uin }\end{array}$ \\
\hline
\end{tabular}

- Page 1 -

PE08-1929.max

Figure 9. Radial Surface Trace of Silicon Carbide Air Seal Face

The inspection report by John Crane is provided as Attachment 2 . 


\subsection{SUPERNATE-ONLY TESTING}

After the seal was replaced with a new seal of the same model, the system was re-assembled and prepared for testing. The $6 \mathrm{M} \mathrm{Na}^{+}$simulated salt solution was added to the feed tank.

Table 1 shows the recipe of the simulated salt solution used in this testing.

Table 1. Composition of the Simulated Supernate Used in Testing

\begin{tabular}{|c|c|}
\hline Ionic Species & Tank 2F, Molar \\
\hline $\mathrm{Na}^{+}$ & 6 \\
\hline $\mathrm{NO}_{3}$ & 4.19 \\
\hline $\mathrm{NO}_{2}{ }^{-}$ & 0.149 \\
\hline $\mathrm{OH}^{-}$ & 0.76 \\
\hline $\mathrm{AlO}_{2}{ }^{-}$ & 0.29 \\
\hline $\mathrm{CO}_{3}^{-2}$ & 0.13 \\
\hline $\mathrm{C}_{2} \mathrm{O}_{4}^{-2}$ & 0.0042 \\
\hline $\mathrm{SO}_{4}^{-2}$ & 0.032 \\
\hline $\mathrm{PO}_{4}^{-3}$ & 0.005 \\
\hline $\mathrm{Cl}^{-}$ & 0.003 \\
\hline $\mathrm{F}$ & $<0.0029$ \\
\hline $\mathrm{K}^{+}$ & 0.007 \\
\hline $\mathrm{Cs}^{+}$ & $1.70 \mathrm{E}-05$ \\
\hline $\mathrm{Rb}^{+}$ & $6.26 \mathrm{E}-06$ \\
\hline
\end{tabular}

The filter system was operated prior to the addition of solids to obtain a baseline flux measurement. Figure 10 shows the results of that testing.

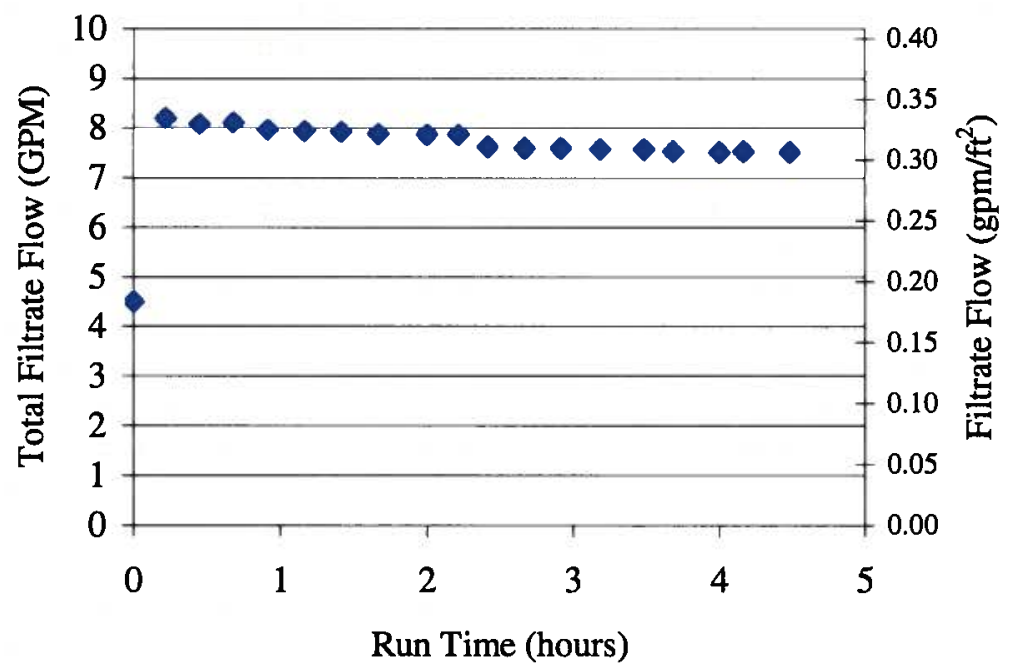

Figure 10. Total Filter Flux with $6 \mathrm{M} \mathrm{Na}^{+}$Simulated Supernate after Initial Filter Disk Cleaning 
Flux returned to approximately $8.2 \mathrm{gpm}$ and fell off to $7.5 \mathrm{gpm}$ after several hours. The original clean water flux for the newly procured unit measured was approximately $8.5 \mathrm{gpm}$ with water. ${ }^{1}$

\subsection{TESTING WITH 0.06 WT \% INSOLUBLE SOLIDS}

The first slurry filtration test used $0.06 \mathrm{wt} \%$ insoluble solids. The feed was made by combining $0.8 \mathrm{~kg}$ of $15 \mathrm{wt} \%$ insoluble solids of the simulated Tank $8 \mathrm{~F}$ sludge ${ }^{8}$, and $0.53 \mathrm{~kg}$ of $15 \mathrm{wt} \%$ MST to 70 gallons of simulated salt solution. The target composition of the sludge is given in Table 2 .

Table 2. Simulated Tank 8F Sludge Target Composition

\begin{tabular}{|l|c|l|c|}
\hline Component & Tank 8F (wt \%, dry) & Component & Tank 8F (wt \%, dry) \\
\hline Cations & & Anions & \\
\hline Aluminum, $\mathrm{Al}$ & 9.59 & Carbonate, $\mathrm{CO}_{3}{ }^{2-}$ & 5.13 \\
\hline Calcium, $\mathrm{Ca}$ & 2.11 & Nitrite, $\mathrm{NO}_{2}{ }^{-}$ & 5.87 \\
\hline Copper, $\mathrm{Cu}$ & 0.13 & Nitrate, $\mathrm{NO}_{3}{ }^{-}$ & 1.95 \\
\hline Iron, $\mathrm{Fe}$ & 24.34 & Total $\mathrm{Hydroxide}_{\mathrm{OH}} \mathrm{OH}^{-}$ & 24.7 \\
\hline Potassium, $\mathrm{K}$ & 0.005 & Oxide, $\mathrm{O}^{2-}$ & 11.4 \\
\hline Magnesium, $\mathrm{Mg}$ & 0.12 & Phosphate, $\mathrm{PO}_{4}{ }^{3-}$ & 0.13 \\
\hline Manganese, $\mathrm{Mn}$ & 2.73 & Sulfate, $\mathrm{SO}_{4}{ }^{2-}$ & 0.64 \\
\hline Sodium, $\mathrm{Na}$ & 7.20 & & \\
\hline Nickel, $\mathrm{Ni}$ & 2.79 & & \\
\hline Silicon, $\mathrm{Si}$ & 0.76 & & \\
\hline Strontium, $\mathrm{Sr}$ & 0.09 & & \\
\hline Zinc, $\mathrm{Zn}$ & 0.27 & & \\
\hline
\end{tabular}

The solids were added to the feed tank and mixed using the pump since the feed tank was too narrow to accommodate an external mixer. Feed flow was tested between 25 and $35 \mathrm{gpm}$, feed pressures ranged between 70 and 102 psi and the net pressure drop across the filters was held at 40 psid except for a brief test period at 30 psid. The filter operated for over 126 hours at the $0.06 \mathrm{wt} \%$ insoluble solids loading and the resulting flux is shown in Figure 11. 


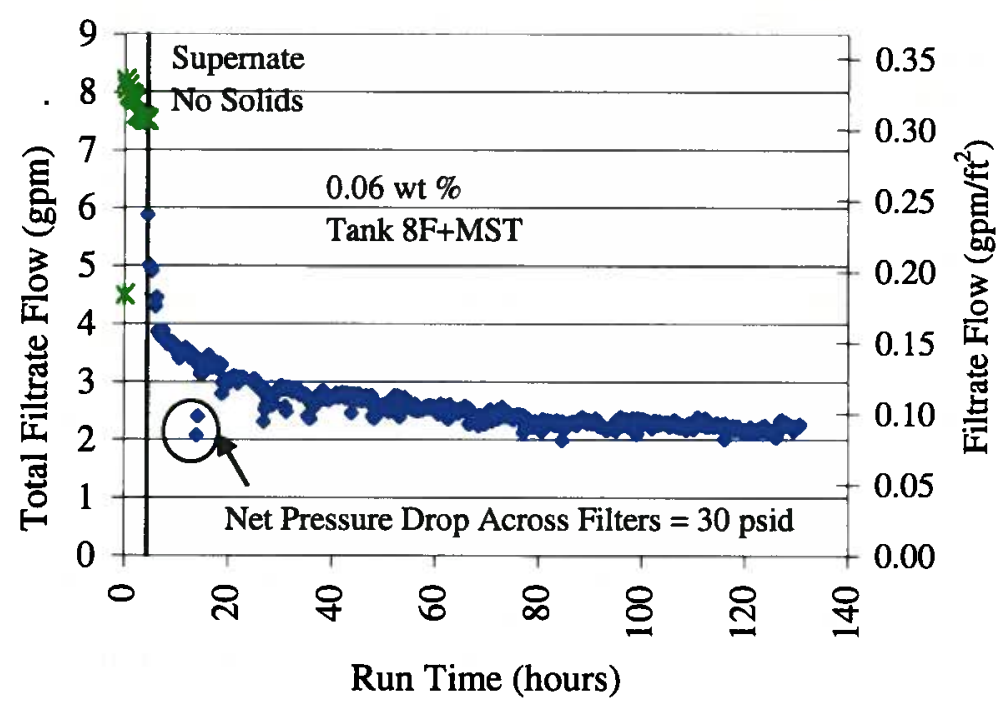

Figure 11. Total Filter Flux with 0.06 wt \% Insoluble Solids Simulated Tank 8F Sludge + MST

As can be seen from the graph, flux dropped rapidly with the introduction of the solids. In the previous testing using only the Tank 8F simulant, after 34 hours of filtration the flux was still approximately $5.25 \mathrm{gpm}^{1}$. For the sludge + MST, flux had dropped to $2.7 \mathrm{gpm}$ in 34 hours and by the end of testing at this solids loading, flux decayed to approximately $2.2 \mathrm{gpm}$.

\subsection{TESTING WITH 5 WT \% INSOLUBLE SOLIDS}

After the testing at $0.06 \mathrm{wt} \%$ was completed, additional solids were added to raise the insoluble solids concentration to $5.0 \mathrm{wt} \%$. This was done by adding $10 \mathrm{~kg}$ of sludge solids and $6.7 \mathrm{~kg}$ of MST solids to the simulated salt solution. The slurry was mixed using the feed pump prior to starting filter operation.

Feed flow was tested between approximately 29 and $42 \mathrm{gpm}$, feed pressures ranged between 75 and 100 psi. The net pressure drop across the filters was held at 40 and 60 psid, though short duration changes in the pressure drop ranging from 30 to 60 psid were tested and will be discussed later. The filter was operated for over 82 hours at the $5 \mathrm{wt} \%$ insoluble solids loading and the resulting flux is shown in Figure 12 along with the flux from the previous 0.06 wt \% solids loading. 


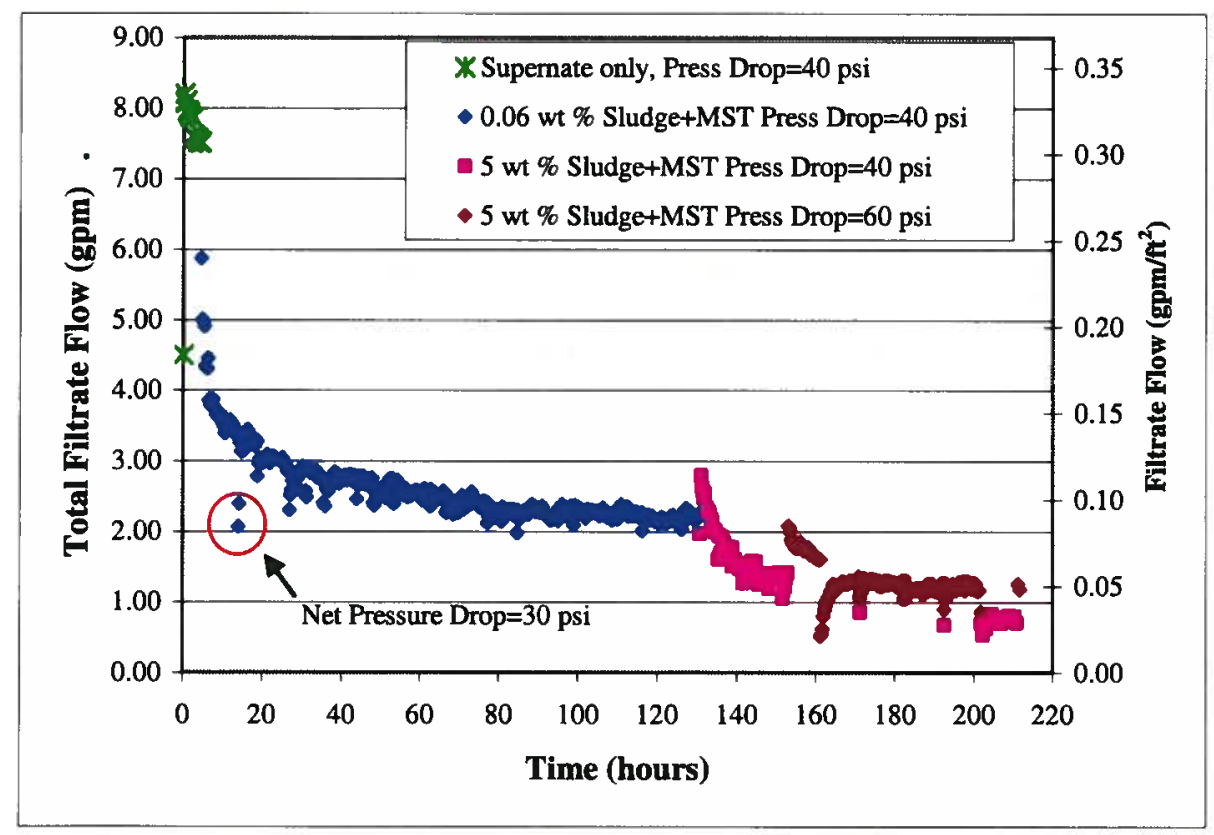

Figure 12. Total Filter Flux with Simulated Tank 8F Sludge + MST

At approximately 152 hours of total filtration time, the pressure drop was raised from 40 psid to $60 \mathrm{psid}$ to determine the effect on filtrate production. An immediate increase flux of 30 to $40 \%$ was recorded. Flux began to tail off, as typically occurs during operation.

One inconsistency in Figure 12, at approximately the 160 hour mark, shows a step change drop in the flux and a following increase back to expected filtration rates. The step change occurred after a shutdown at the end of a day's operation and the restart of the filter the following morning. This effect has been seen in past testing ${ }^{1}$ and has been attributed to the method of shutting the filter down. Typically, the filter is now shut down by decreasing the pressure drop prior to shutting down the rotor. By doing this, the membrane does not see a large pressure differential without the rotor in operation and thus minimizes the potential buildup of a filtercake. The cause in this instance is believed to be similar, with the pressure drop not reduced sufficiently and the pump allowed to continue to operate thus allowing the feed solids to form a sufficient filter cake to impede filter performance. The filter was not operated long enough to form a substantial filter cake and that which did form, was disrupted over several hours of filter operation.

The flux eventually reached a near steady state. When the pressure drop was returned to 40 psid approximately 50 hours later, a sudden drop in flux was recorded. The data indicates the flux drop is consistent with the normal flux decay at the 40 psid pressure drop.

Filtration rates in this testing are lower than previous 25 -disk rotary filter testing. One significant difference was the addition of MST to the sludge. Earlier testing completed with the 3-disk pilot scale rotary filter using a Sludge Batch-2 (SB2) simulant with MST added resulted in similar filtration rates on a per-square-foot of filter media basis. ${ }^{10}$ 
Figure 13 shows a comparison of the flux for tests with sludge only and sludge + MST with 0.5 micron filter membrane for the 25-disk unit, and sludge + MST using a 0.1 micron filter membrane for the 3-disk unit at $0.06 \mathrm{wt} \%$ insoluble solids ${ }^{10}$ It should also be noted that the sludge compositions were slightly different as well.

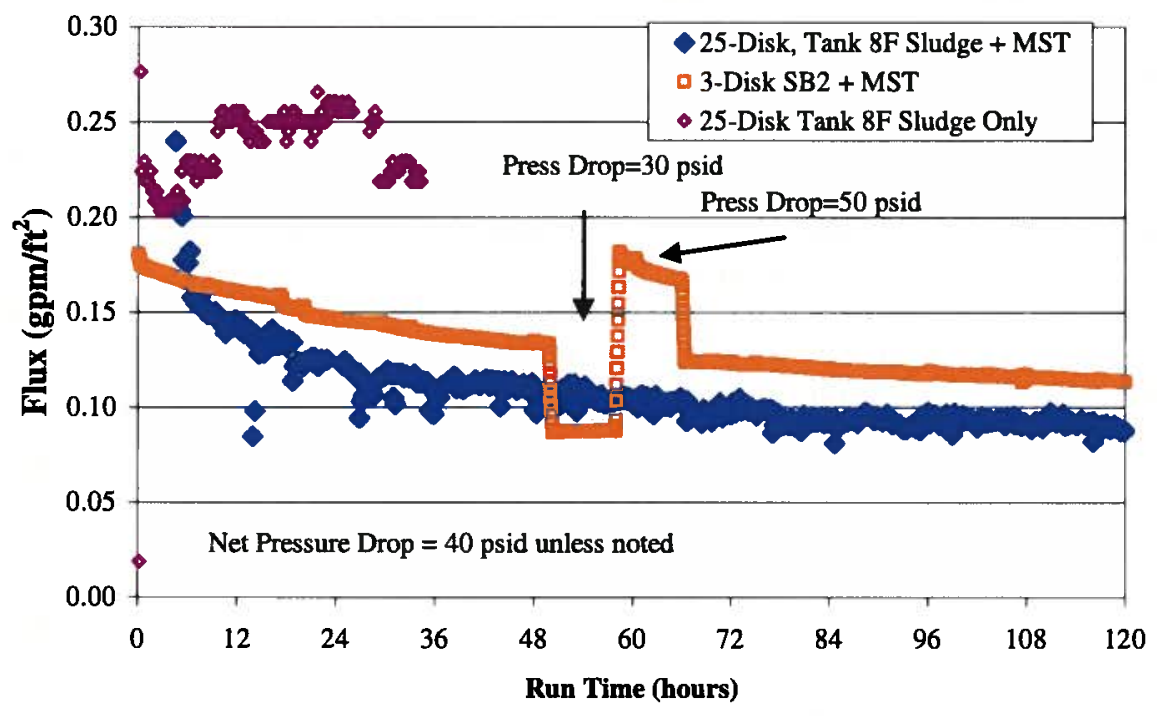

\section{Figure 13. Comparison of 25-Disk Rotary Filter Testing with Sludge and Sludge + MST and 3-Disk Rotary Filter Testing with Sludge + MST at 0.06 wt \% Insoluble Solids}

Figure 14 shows the same information but at the 4.5-5 wt \% insoluble solids for all tests. Data in both figures is primarily for a net pressure drop of 40 psid except where noted. 


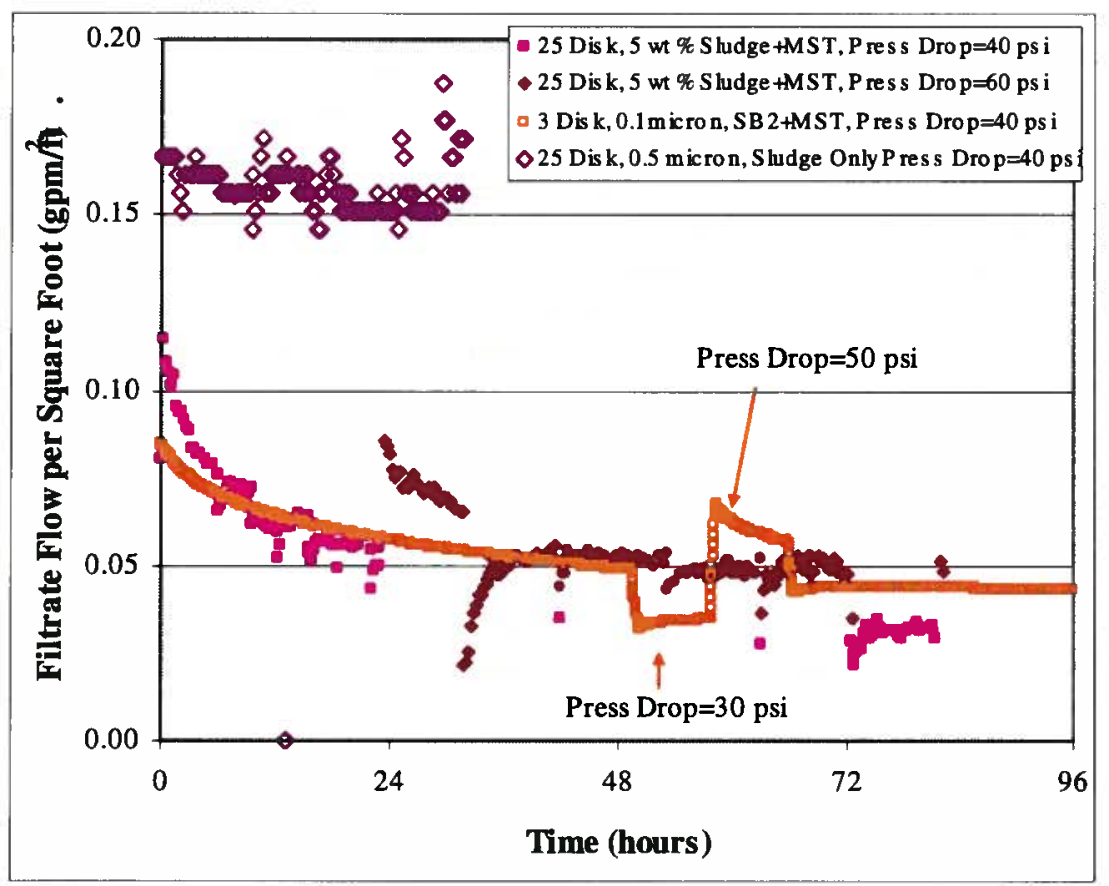

\section{Figure 14. Comparison of 25-Disk Rotary Filter Testing with Sludge and Sludge + MST and 3-Disk Rotary Filter Testing with Sludge + MST at 4.5-5 wt \% Insoluble Solids}

During various times of testing, the net pressure drop was adjusted to determine the effect on flux. The feed pressure was held constant and the filtrate pressure was adjusted in $5 \mathrm{psi}$ increments, the pressure held for less than 1 minute and the flux rate recorded. The chart shows when, during the total operating time of the test, the data was recorded and the pressure drop at which the filter was operating. The data are plotted in Figure 15. The results showed a linear relationship between net pressure drop and flux over a range of differential pressure from 30 to 60 psid. The slope of the line decreased as filter fouling occurred but the linear relationship is maintained.

Note that if a line is drawn through the data in Figure 15, the points would intersect at approximately $11 \mathrm{psi}$ for 0 filtrate flow. A pressure difference above $11 \mathrm{psi}$ is necessary with the rotor turning at $1170 \mathrm{rpm}$ to produce a net positive flow. A net pressure below $11 \mathrm{psi}$ will result in a net reverse flow of filtrate through the disks. The rotation of the disks results in a centrifugal force that pushes permeate towards the outer edge of the filter disks. This force increases as the radius of the disk increases. The inner radius of the disk may have a net positive pressure resulting in filtration; while the outer radius can have a net negative pressure resulting in permeate being pushed back out of the disk. At the rotor speed used throughout testing $(1170 \mathrm{rpm})$ the pressure drop at the outer edge of the disks is approximately 20 psi. A net pressure below 20 psi will result in a net reverse flow at the outer edge of the disk. A chart showing the relationship between pressure and rpm for the standard size rotary filter disk can be found in Reference 11. 


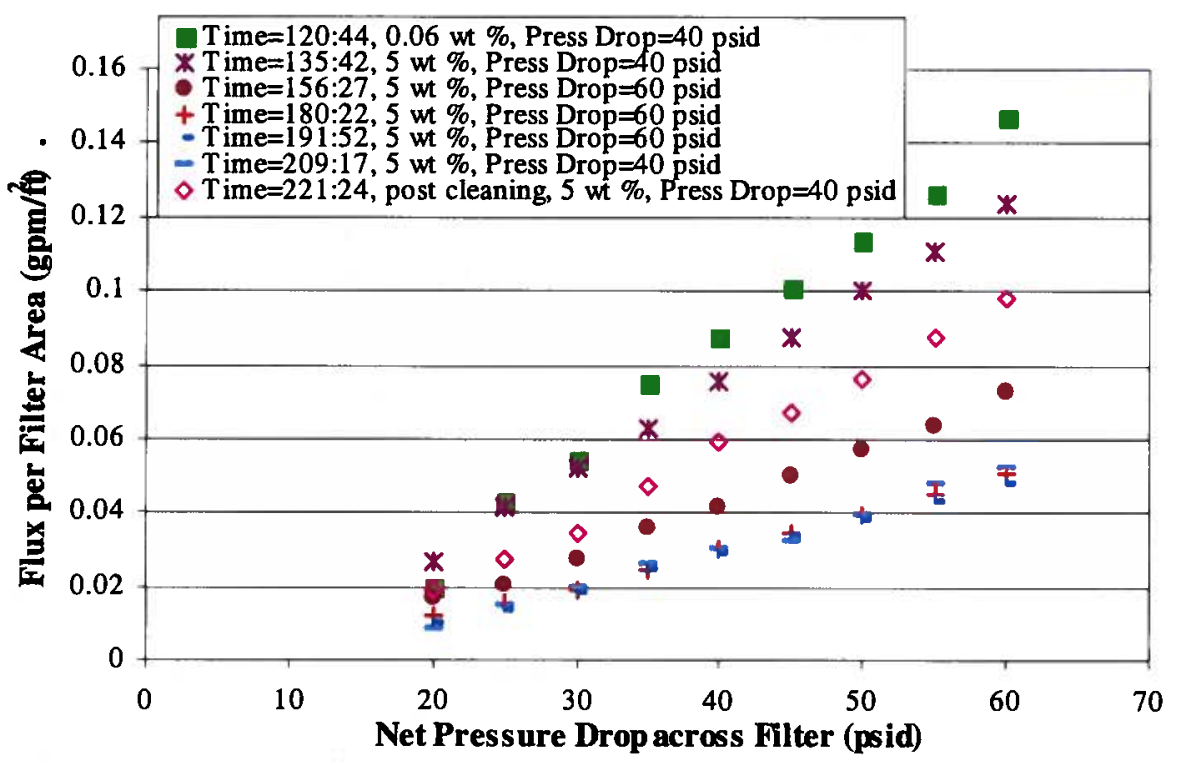

Figure 15. Relationship of Filtrate Flow per Square Foot of Filter Media vs. Net Pressure Drop across the Filter System

To obtain a comparison on an equal basis, specific flux is used. The specific flux is the filter flux per unit filter area divided by the net pressure drop across the filter system. The specific flux normalizes the productivity based on the applied pressure drop. Increasing the pressure drop across the filters causes absolute increases in the production of filtrate. But as the filtration rate increases, the slurry in the near proximity of the feed side of the membrane becomes more viscous thereby increasing its contribution to the hydrodynamic resistance of filtrate flow through the membrane. The higher the net pressure drop, the greater the filtrate flow. The more concentrated the slurry the more viscous the slurry becomes. This dissipates more of the hydrodynamic pressure available to push permeate through the membrane into "pushing" filtrate through the viscous slurry. ${ }^{11}$ Therefore, there may be a net increase in permeate by increasing the pressure drop, but it may come at the expense of efficiency and premature fouling of the membrane. Additionally, the increased pressure drop may cause particles to be pushed deeper into the pores of the membrane and making less likely that the particles can be transported from the membrane thereby increasing fouling. The resulting fouling will be shown as a decrease in specific flux.

The rate of filtration through the membrane will decrease as the membrane fouls. By comparing the specific flux at different pressure drops for this slurry, it has been determined that for the solids loading tested, increasing the net pressure drop continued to increase the rate of filtration per applied pressure differential. This is illustrated in Figure 16. As the net pressure drop was increased, the specific flux also continued to increase. The greatest improvement in specific flux is gained by increasing net pressure drop up to approximately 35 psid. At 35 psid and above, the specific flux begins to steady. For this simulant, the specific flux continued to increase as the pressure differential increased. Therefore, the most efficient net pressure drop tested is 60 psid. 


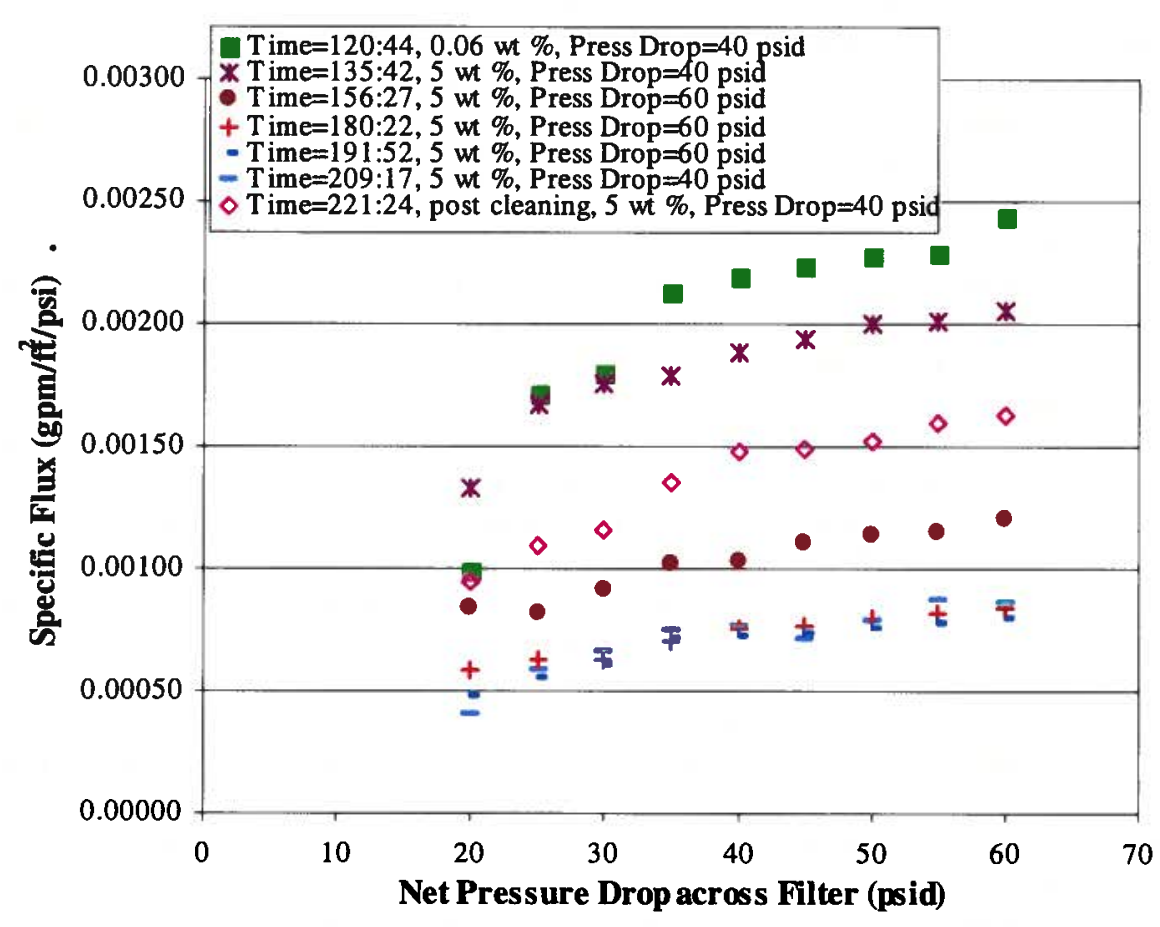

Figure 16. Specific Flux versus Net Pressure Drop

The specific flux for the entire test is shown as Figure 17. Note that there is little change in the specific flux when transitioning from 40 psid to $60 \mathrm{psid}$. There is also very little change in specific flux when transitioning back to 40 psid after 48 hours of filter operation at a $60 \mathrm{psi}$ net pressure drop.

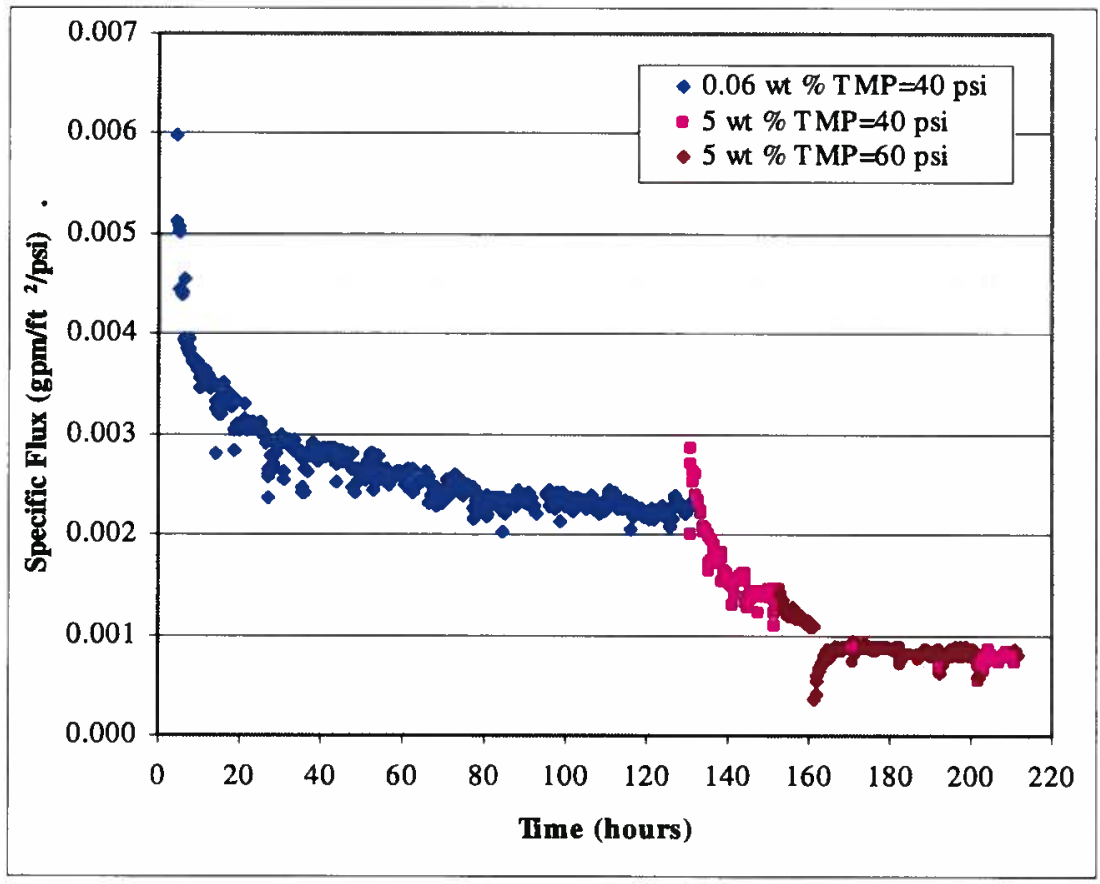

Figure 17. Specific Flux with Simulated Tank 8F Sludge + MST 


\subsection{PARTICLE SIZE ANALYSIS OF TEST FEED}

The SRNL Analytical Development organization measured particle size for feed samples from the start and end of both solids loadings with a Microtrac S3000 using a carrier fluid containing $1.91 \mathrm{M} \mathrm{NaOH}, 2.14 \mathrm{M} \mathrm{NaNO}_{3}$ and $0.52 \mathrm{M} \mathrm{NaNO}_{2}$. Results for the $0.06 \mathrm{wt} \%$ and $5 \mathrm{wt} \%$ testing as well as the Tank 8F sludge-only and the SB2 sludge-only simulant testing ${ }^{1}$ are shown in Figure 18. All tests used the 25-disk rotary filter.

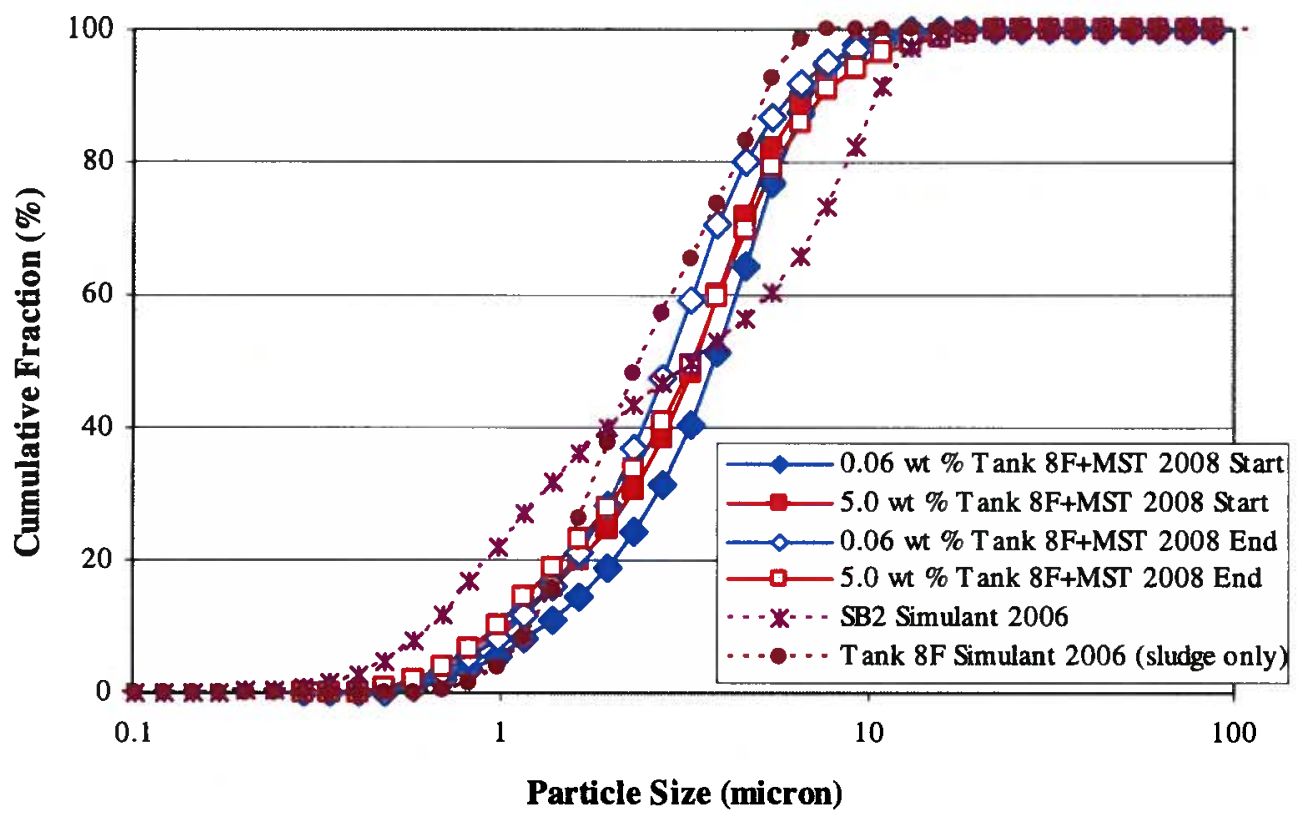

Figure 18. Comparison of Rotary Filter Feed Particle Size Analysis

The results displayed for the current testing are for samples at the start and end of testing. Results show that the particle size decreased from the start to the end of testing as expected. No trend is observed between particle size and flux from the current full scale rotary filter testing compared to previous slurry testing ${ }^{1}$. A slightly higher concentration of fines was measured in the Tank 8 Sludge with MST than the Tank 8 sludge-only testing from 2006 but, a significantly higher amount of fines were measured in the SB2 testing also from 2006. The SB2 and the Tank 8 sludge-only testing from 2006 both had significantly higher flux (approximately $3 \mathrm{X}$ ) than the Tank 8 Sludge + MST. It is concluded that particle size did not have a significant influence of flux and that the addition of MST affected the rheological properties of the feed and that had the greatest influence on the filtration rates.

\subsection{EFFECT OF FEED PRESSURE AND FEED FLOW ON FILTER FLUX}

Feed pressure and flow rate was varied to determine the effect on filtration rate. Figure 19 shows feed pressure and filtration rate throughout testing. Though not varied significantly $(\sim 25 \%)$, no noticeable trend is observed between the feed pressure and the filtration rate. 
This is consistent with results from previous testing at similar solids loadings. ${ }^{1}$ Filtration rate is dominated by the pressure drop across the membrane.

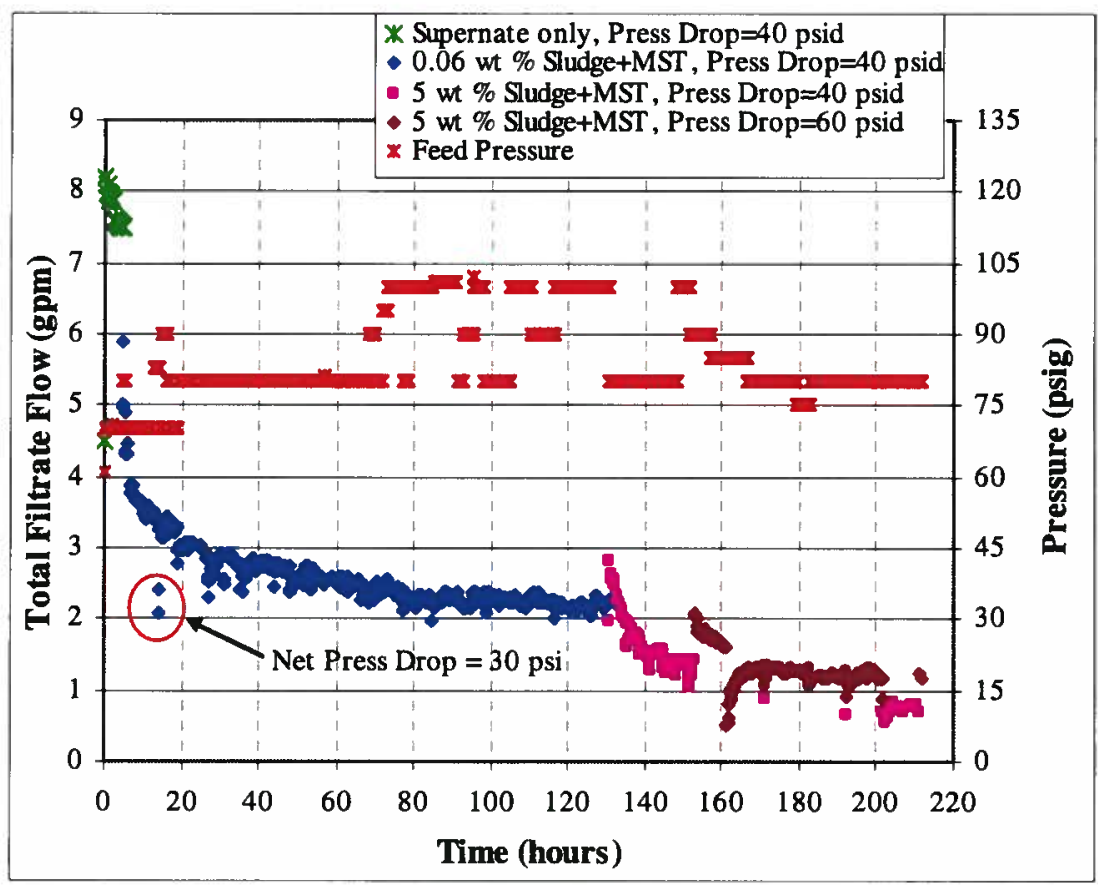

Figure 19. Filtrate Flow Relative to Feed Pressure at all Insoluble Solids Loadings with Tank 8F Simulant + MST

A previous study by the vendor ${ }^{11}$ has shown that an increase in feed flow can result in a slight increase in filtration rate at high solids loadings. As permeate passes through the membrane, the concentration of insoluble solids increases significantly at the membrane surface. Sufficient flow must be available to wash out the concentrated feed and permit fresh feed access to the membrane. Figure 20 shows the feed pressure and filtration rate during testing. Variations of feed rate by $25 \%$ showed no noticeable trend. It is expected that feed rate would have more effect as solids loadings are increased. 


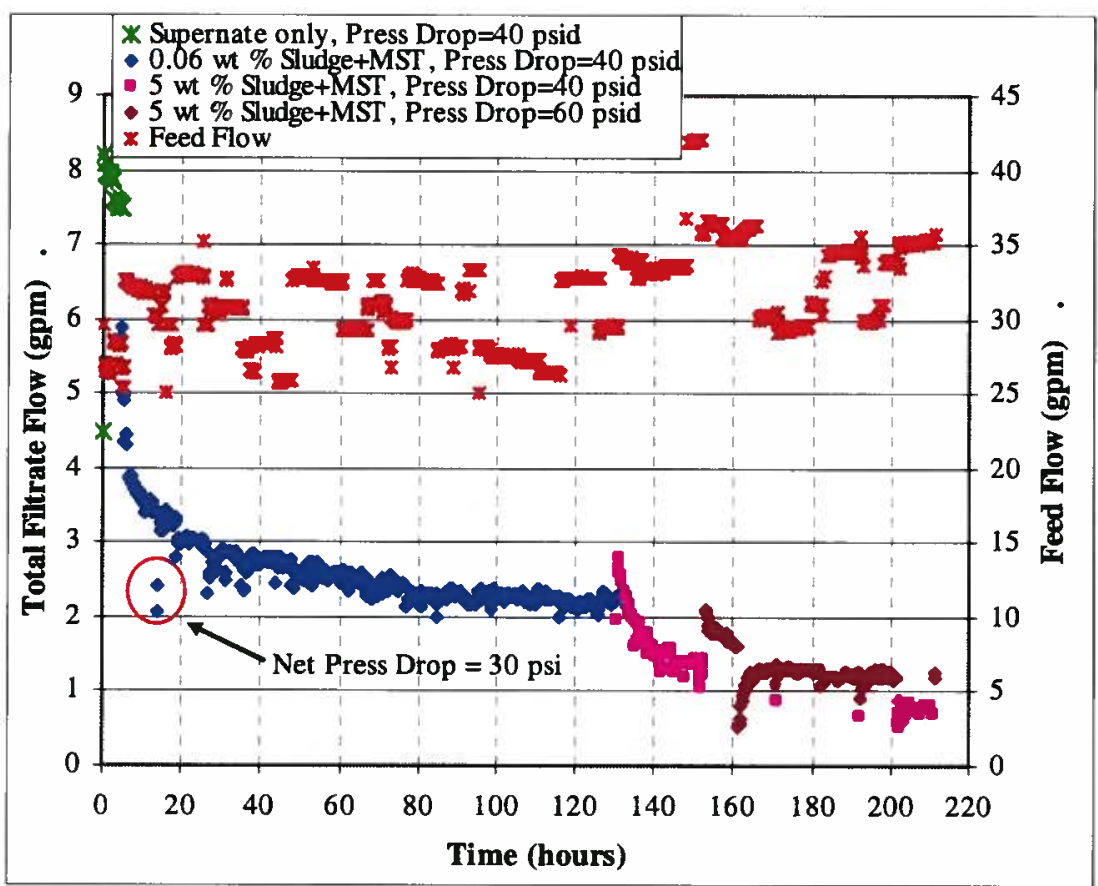

Figure 20. Filtrate Flow Relative to Feed Flow at all Insoluble Solids Loadings with Tank 8F Simulant + MST

\subsection{ROTARY FILTER POWER REQUIREMENTS}

The power and current drawn by the filter drive motor are shown in Figure 21. The vertical line marks the change in solids loading from $0.6 \mathrm{wt} \%$ to $5 \mathrm{wt} \%$ insoluble solids.

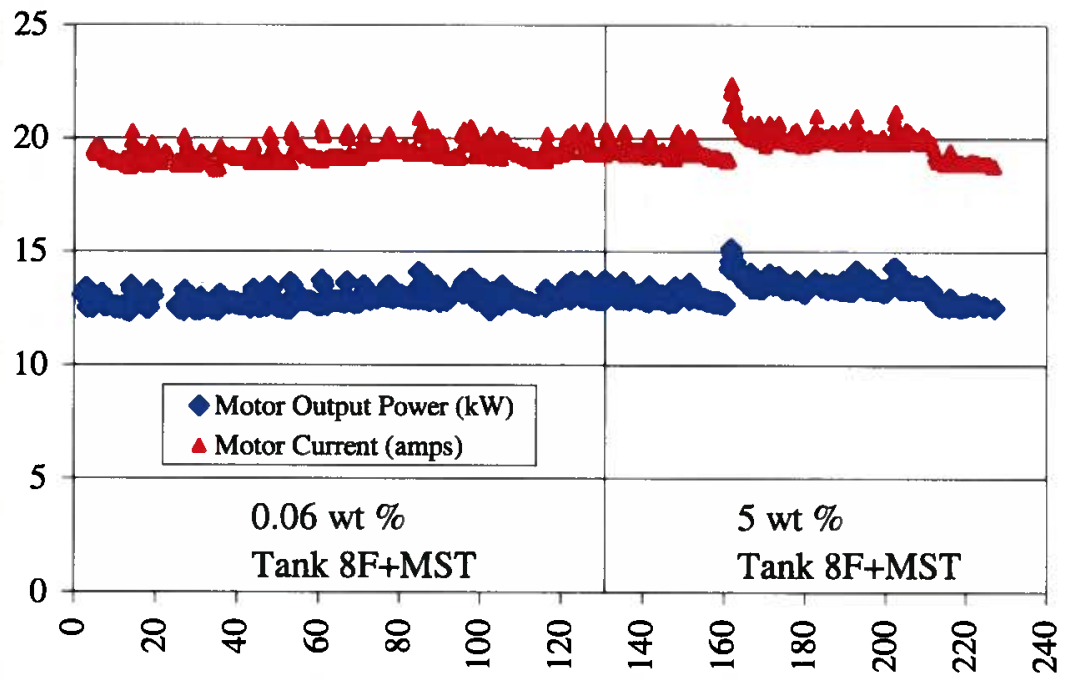

Time (hours)

Figure 21. Filter Motor Power and Current Draw 
Typically, power/current requirements were greatest at the start of daily testing with a gradual drop throughout the day. The sudden increase in power and current at approximately 162 hours into testing coincides with the sudden drop in flux noted in Figure 12. This occurred at startup after an overnight shutdown. All other parameters including solids loading, feed flow, feed pressure and net pressure drop were essentially the same compared to the previous day's testing. It is expected that the rotor speed was also constant though it was not directly measured at the time.

The data sheets from testing are provided as Attachment 3.

\subsection{TURBIDITY}

Daily samples of the filtrate were pulled for clarity analysis. Samples were pulled through a sample port in the filtrate line of the filter system. Samples were measured using a Hach Midel 2100P Turbidimeter. Each sample was measured twice. The results of the turbidity analyses are shown in Figure 22.

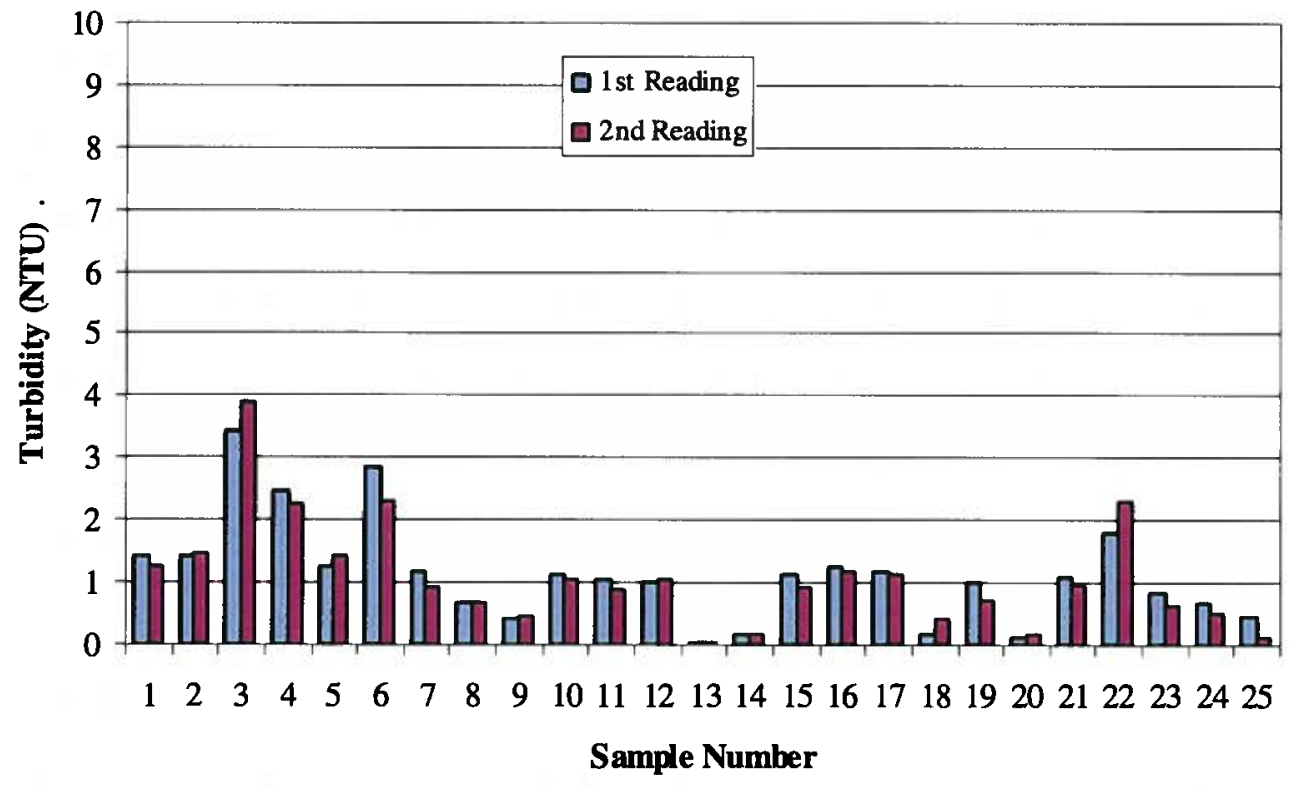

Figure 22. Turbidity Analysis of Filtrate Samples

All samples had turbidity measurements less than 4 NTU and were free of coloration.

\subsection{VIBRATION ANALYSIS}

Figure 23 shows the rotary microfilter used by researchers to conduct filter performance tests, and is labeled with monitoring points where baseline vibration data was collected. Vibration measurements contain information about a machine's health and operating characteristics, and will be useful as a full-scale rotary microfilter is developed. During early testing of the rotary filter, very little emphasis was placed on minimizing vibration. This 
included the mounting of the filter, which was accomplished using straps which are susceptible to vibration. Due to the relatively short expected test durations, it was believed that excessive vibrations would give a better indication of the effects on filter components that would be expected with extended operation in field applications.

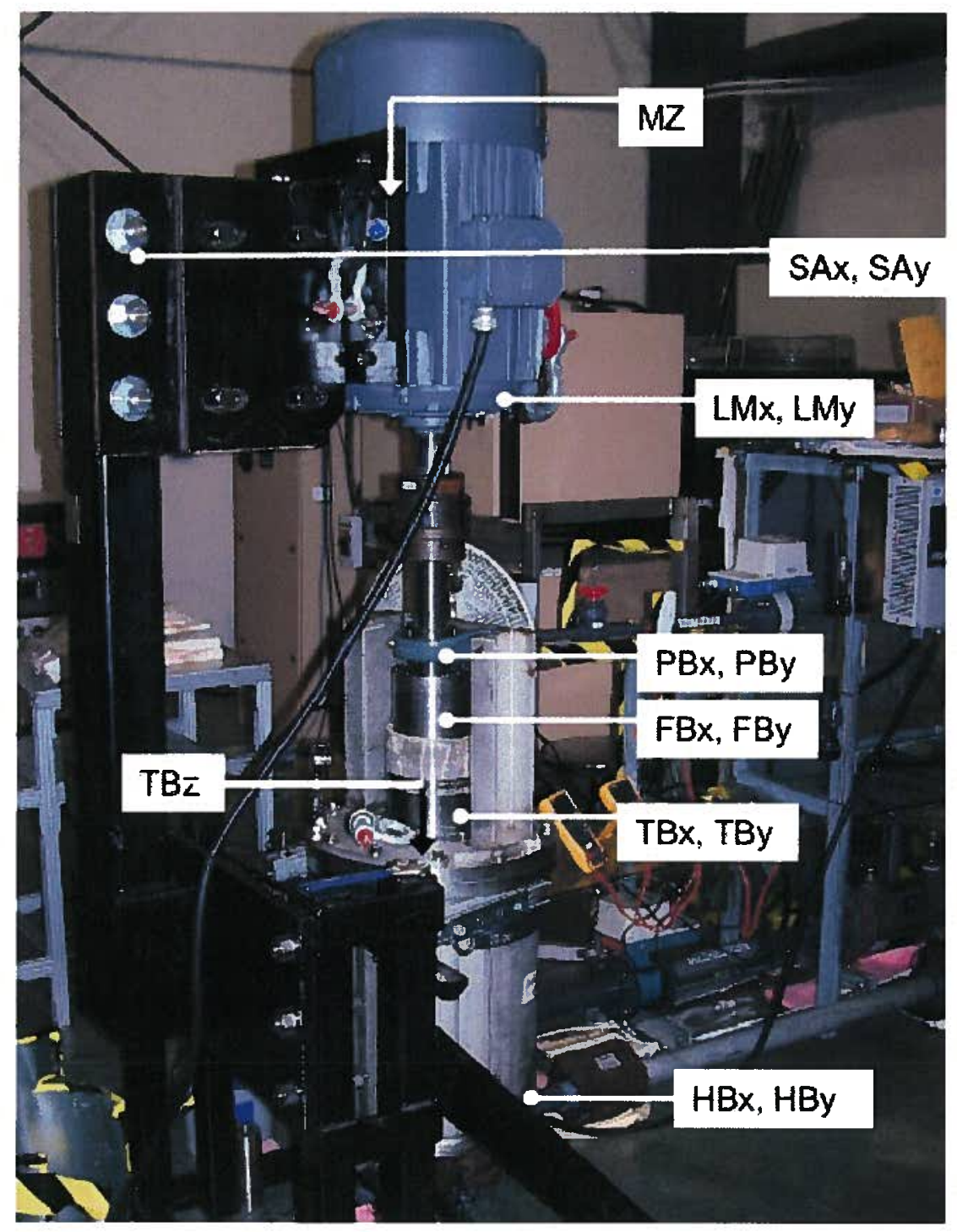

Figure 23. Locations of Accelerometers for Vibration Measurements

\section{Data Collection}

General purpose accelerometers were used for sensing vibration on the Rotary Microfilter. The transducers were screwed to adhesive mounted sensing pads during data collection. Pads for radial vibration measurements, " $x$ " and " $y$ ", were arranged orthogonal and grouped. Grouping was done to examine the phase relationship between the two, one-dimensional timebase plots and provide the option to display the two-dimensional dynamic motion for the component being monitored. A dual-channel Model 2120A-2 analyzer by Computational Systems, Incorporated collected the data. Data stored within the analyzer was transferred to the SRS computing network for analysis. 
$\underline{\text { Results }}$

Figure 24 shows a summary velocity plot from several locations on the filter and motor. The location of the readings is shown in Figure 23. The highest velocities were measured at the rotary joint (FBx, FBy).

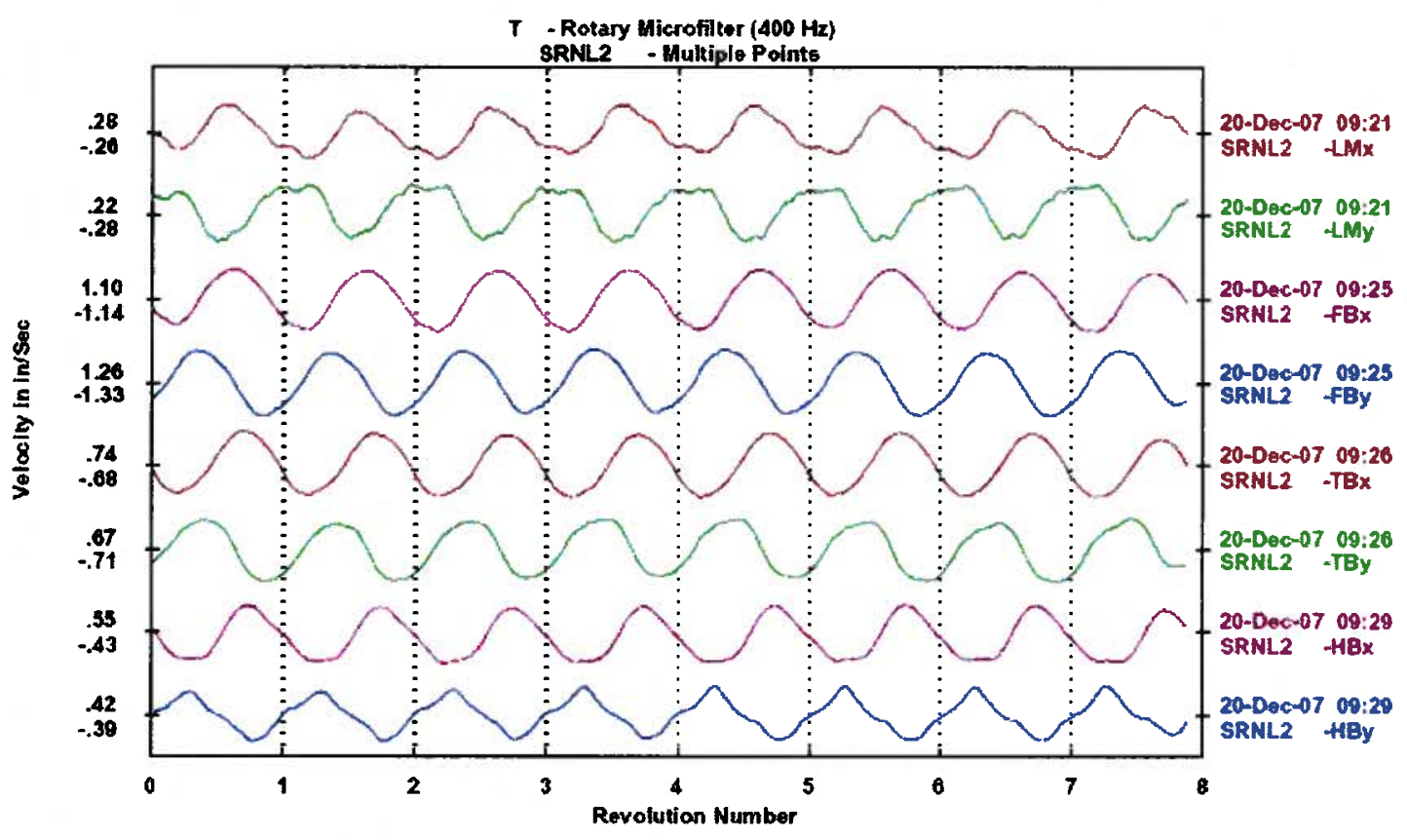

Figure 24. Baseline Vibration Measurements of the Rotary Filter

Attachment 4 shows the initial time domain and frequency domain plots for the rotary microfilter. The final plots in Attachment 4 show orbits. The velocity amplitudes in the plots are 5 to 10 times greater than normally observed by the analyst. The rotor frequency of 1xRPM dominates the vibration in both the radial and axial planes. The first order peak in the radial plane suggests imbalance, or a bent shaft. The high $1 \mathrm{xRPM}$ peak in the axial plane is suggestive of an alignment problem. The 2nd order peak from the support arm data narrows the problem to angular.

The clearance between the filter disks and shaft is over 0.040 ". The first attempt to improve the balance of the disks was to place 0.018 " shims on each flat of the shaft. A support arm was added to the motor mount, a support strap was added to the lower part of the filter tank and shims were also added to the bottom of the filter stack to decrease the gap between the bottom of the filter stack and the mating point in the filter tank. The incorporation of the shims showed an improvement in the vibration signature, though the amplitudes are still high. Figure 25 shows the same summary plot after the incorporation of the support arm, tank strap and shims. 


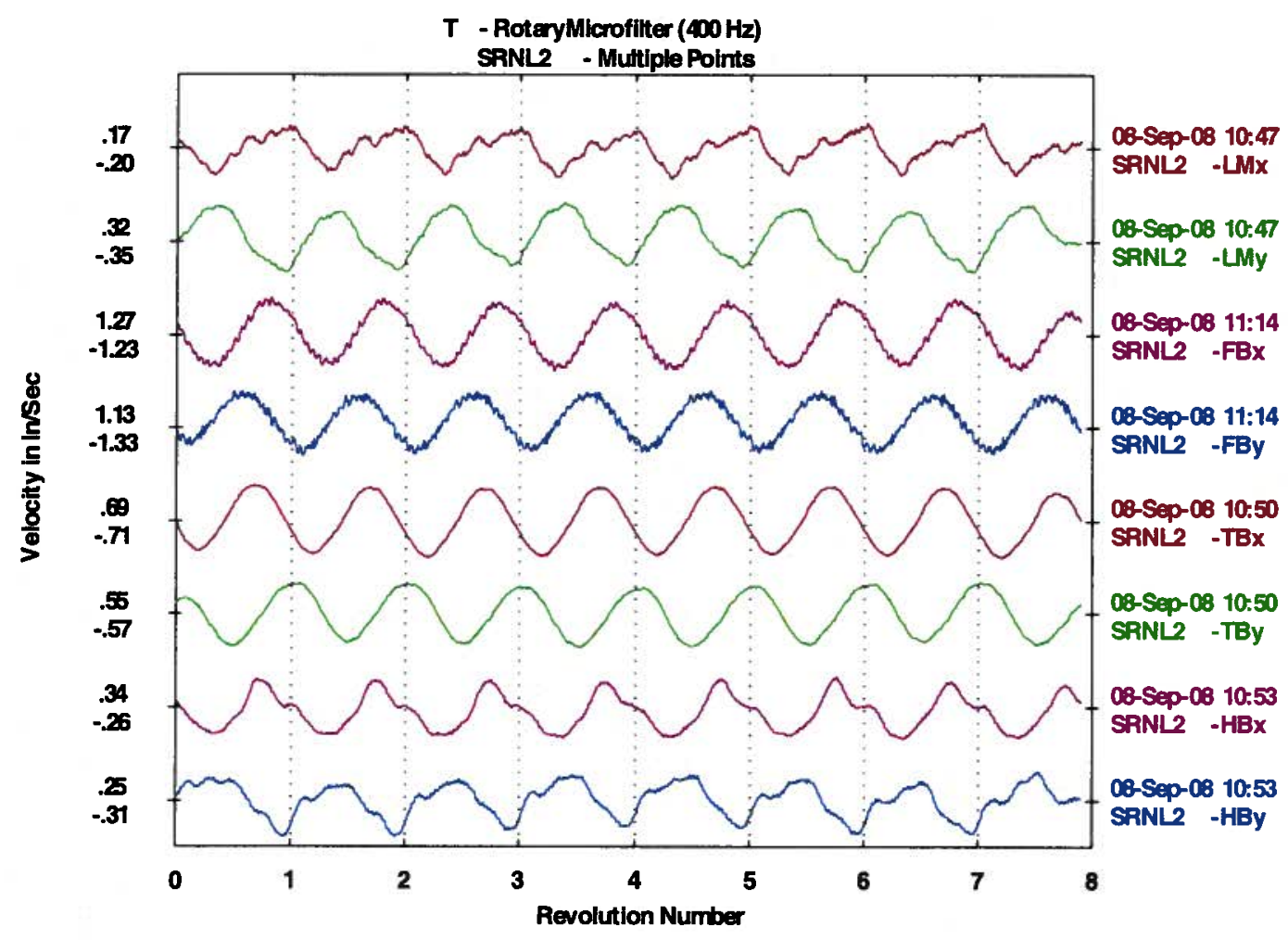

Figure 25. Summary Velocity Plot after the Incorporation of Shims and Support Arm

Improvements were seen in the vibration signature at the lower bushing ( $\mathrm{HBx}, \mathrm{HBy})$ and slight improvements at the main filter shaft and bearing (TBy). Improvements were also recorded at the drive motor (LMx, LMy) Also of note is a higher frequency overlay at the rotary joint as well as repeated impacts in acceleration indicating wear on the rolling element bearings. Attachment 5 shows the second set of time domain and frequency domain plots for the rotary microfilter.

\section{Suggestions for Lowering Vibration Severity}

- Tie the motor to the rotary microfilter. The two components are moving in and out of phase. This situation makes it impossible to maintain alignment. At the same time, features to aid with coupling alignment should be added.

- Reduce clearance between filter disk and shaft to $<0.002$ in. and tighten manufacturing tolerance on future orders.

- Perform single-plane balance on the filter disks, reassemble equipment and measure effectiveness. If the filtered vibration exceeds 0.2 ips peak, perform additional balancing to correct. Given the filter assembly length, the possibility that balancing in 2 planes may be required. The effectiveness of balancing the individual disks may be limited due to the expected buildup of filter cake on the disks during operation. 


\subsection{CLEANING}

After completion of the filter operation, the system was emptied of slurry and rinsed with 60 gallons of inhibited water (IW) (approximately 6 filter volumes). The rinsing was accomplished by loading the IW into the feed tank and operating the filter while circulating the filtrate into the feed tank. After draining the system, the filter stack was removed and inspected. Figure 26 shows the filter stack as it was removed from the system.

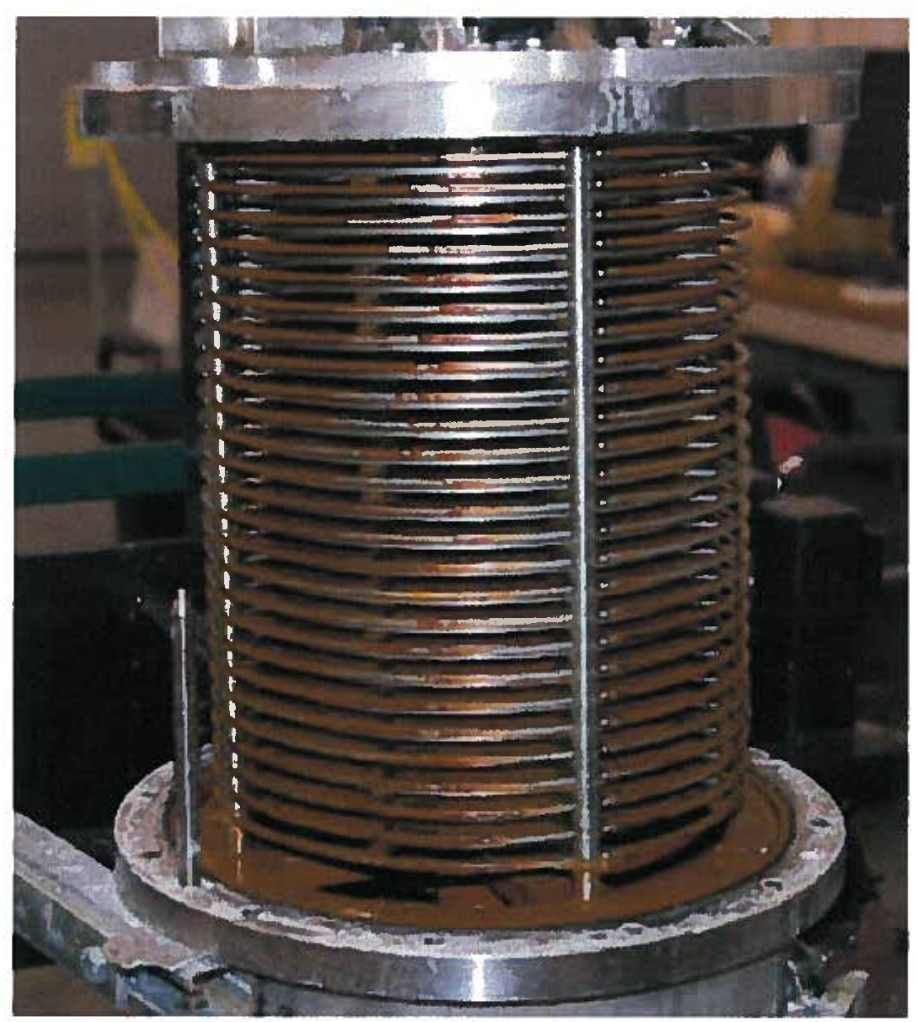

Figure 26. Filter Stack after Rinsing with Inhibited Water

The researcher noted that, based on visual observation, the stack had a greater amount of residual sludge material than in past testing. Several of the bottom filter disks were removed and Figure 27 shows the top and bottom of disk \#24 (second from the bottom). This disk was typical of those inspected. 

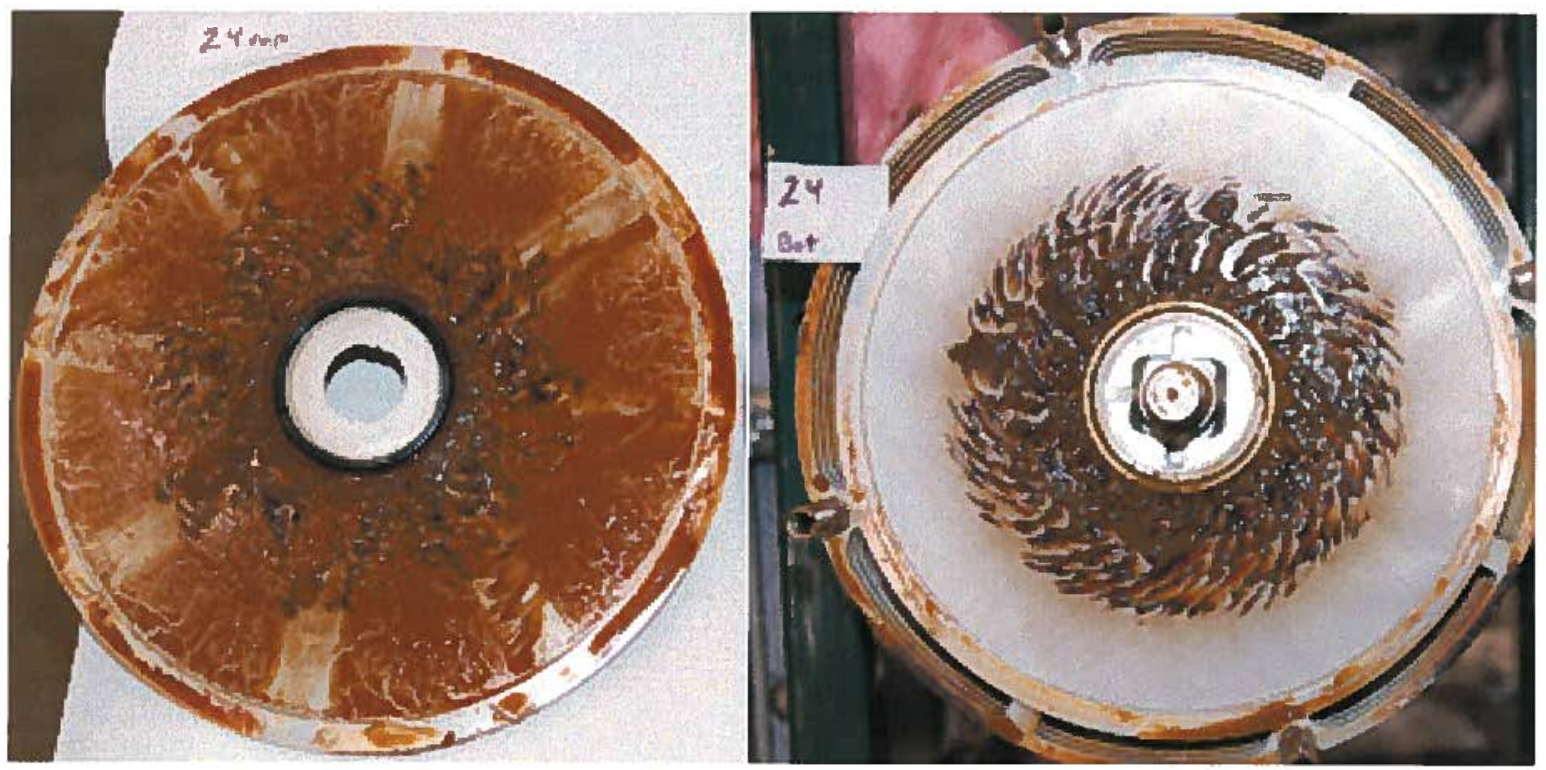

Figure 27. Disk 24 after Rinsing with Inhibited Water (top face, left, and bottom face, right).

Note the additional solids on the top of the disk. This pattern is consistent with previous testing ${ }^{1,2}$ and is believed to be due to gravity settling of the slurry solids when the filter in not in operation.

The filter system was then reassembled in preparation for cleaning with acid. Four-molar nitric acid was used in cleaning. Nitric acid was selected as an alternative to oxalic acid which had been used in previous tests ${ }^{12}$ due to the concerns of oxalate in down stream processing of the cleaning solutions. The filter was isolated from the rest of the system by closing the outlet choke valve. Since the feed-line flowmeter and the heat exchanger are made of carbon steel components, the inlet to the filter was removed and replaced with a PVC standpipe. This standpipe later included fittings to allow pressurizing the system.

Acid was added to the system through the standpipe. Once the filter inlet was completely submerged, a Randolf model 610 pump was attached to the filtrate line to draw filtrate and attempt to draw the remaining air from the filter tank. The acid was then allowed to soak for approximately 16 hours (overnight). A total of $26 \mathrm{~L}$ of acid were added to the filter system.

The acid was then drained from the system and the filter was rinsed using $26 \mathrm{~L}$ of inhibited water. Water was added through the standpipe and drawn from the filtrate line using the Randolf pump. The water was then drained and the filter opened for inspection. During the inspection it was observed that air was not purged from the upper half of the filter housing. Disks 13 through 25 were submerged in acid while the remaining disks were not. Figure 28 shows a comparison of the filter stack after water rinsing with the first attempt at acid cleaning. 


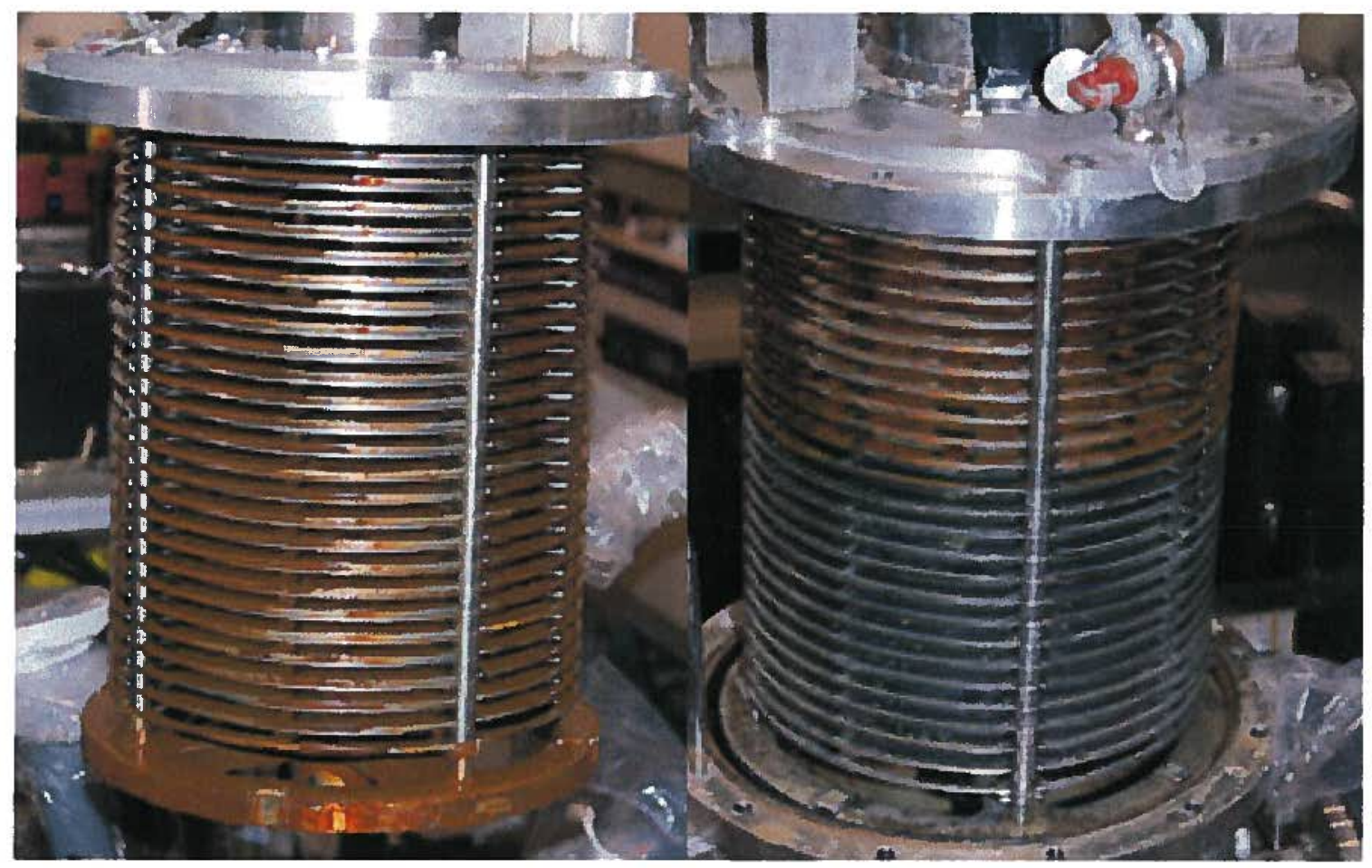

Figure 28. Filter Stack Comparison of IW Rinsed Filter (left photo) and Bottom Half Acid Washed (right photo)

Several of the bottom disks were removed and inspected, all of which had been submerged in acid. Figure 29 shows pictures of the top and bottom of disk \#24 (second from the bottom of the stack). Both sides of the disk showed significant cleaning. The top side of the disk still had solids residue especially in the inner radius. The bottom side of the disk had some discoloration due to solids residue. 


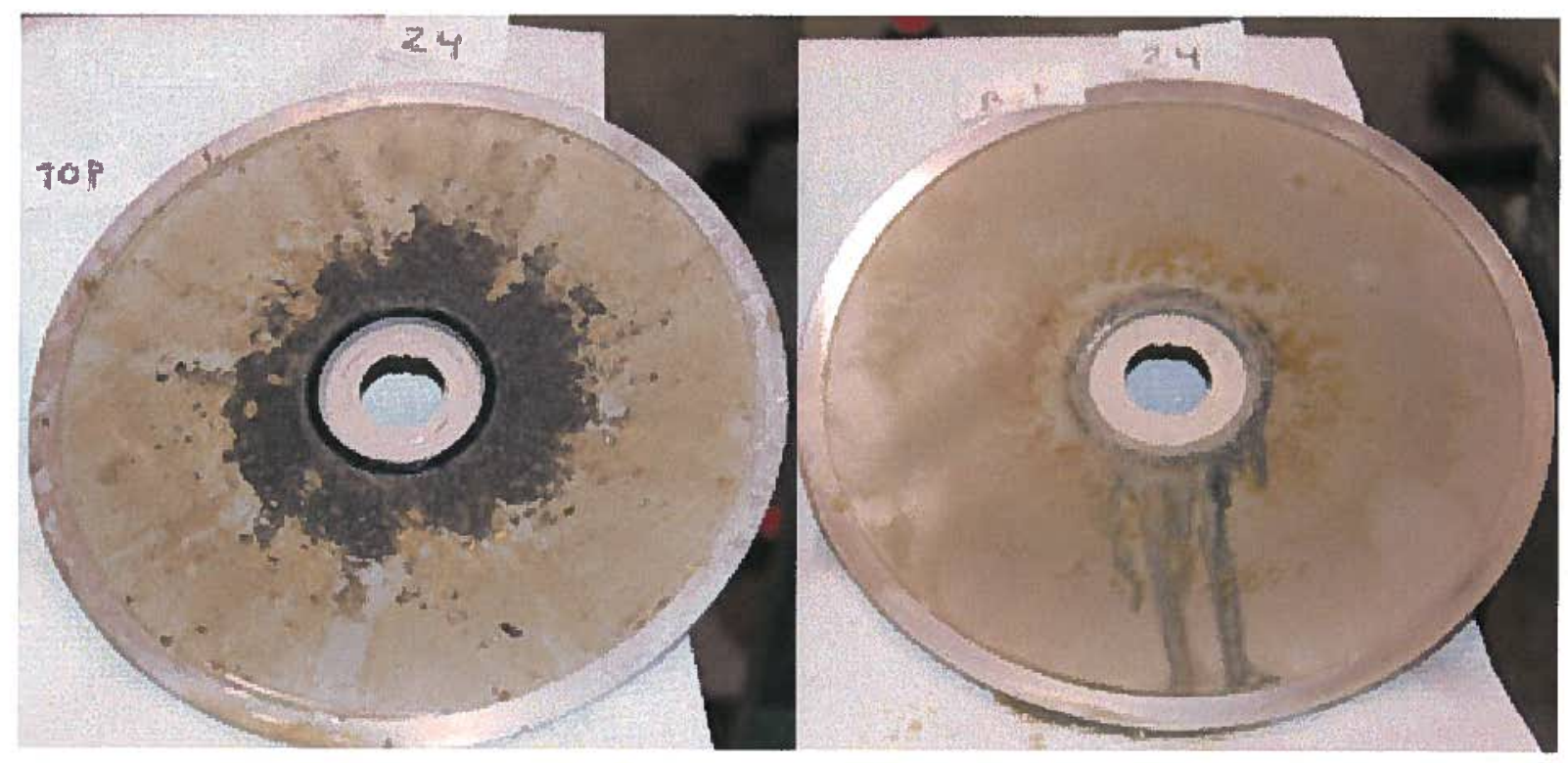

Figure 29. Disk \#24 Top (left photo) and Bottom (right photo) after First Acid Cleaning

The filter stack was again assembled and installed. An additional $11 \mathrm{~L}$ of fresh acid were added to the original $26 \mathrm{~L}$ to assure the entire disk stack was then covered. The filter stack was allowed to soak for an additional 14 hours. The filter tank was then drained of acid and rinsed with inhibited water. The inhibited water rinse was performed by connecting the Randolf pump discharge to the filter inlet and the pump suction to the carboy containing the inhibited water. The filtrate line was plumbed to the carboy containing the inhibited water. Once the volume of rinse water was delivered to the filter, the pump suction was connected to the filtrate line. This configuration allowed the pump to draw rinse through the disks.

After the water rinse was drained from the filter tank, the filter stack was removed and inspected. An additional reduction in the amount of solids was observed on the disks, primarily on the top side.

The filter stack was then re-assembled and installed. A small Jabsco pump (model 4720) was plumbed into the system to allow for the application of pressure to the filter tank. The $37 \mathrm{~L}$ of $4 \mathrm{M}$ acid was again added to the system. The acid was circulated for approximately 3 minutes and then the filter rotor was operated at approximately $1170 \mathrm{rpm}$. The system was pressurized to $15 \mathrm{psi}$ by choking the discharge valve resulting in a pump delivery of approximately $8 \mathrm{gpm}$ per the pump curve. The system was operated for approximately 4.5 minutes before being stopped due to the pump being starved for feed.

Ten liters of DI water were placed into the carboy serving as a feed tank to add volume and prevent pump cavitations. The acid was circulated and a pressure of approximately $20 \mathrm{psi}$ was applied to the feed tank resulting in a flow of approximately $5.5 \mathrm{gpm}$ per the pump curve. A back pressure of approximately 5 psid was applied to the filtrate line. The acid was circulated for approximately 4 minutes and then the rotor was activated. The rotor was operated for 10 minutes and the system was stopped. The filter was then drained of acid. 
The system was then rinsed with inhibited water. The rinse was performed by connecting the Jabsco pump discharge to the filter inlet; the pump suction was placed into a carboy containing the inhibited water. The filter discharge was choked by throttling the discharge valve. The filtrate line was plumbed to the inhibited water feed tank. During the circulation of the rinse, the rotor was engaged for 10 minutes at similar pressures and rotor speeds used in the acid cleaning. The filter tank was then drained and opened for inspection. Additional improvement was observed when the disks were removed and inspected. Figure 30 shows filter disk \#24 in each stage of the acid cleaning. Note that the most dramatic cleaning occurred in the initial soaking and after the rotor was operated during the cleaning cycle.

\section{Disk \#24 Top}
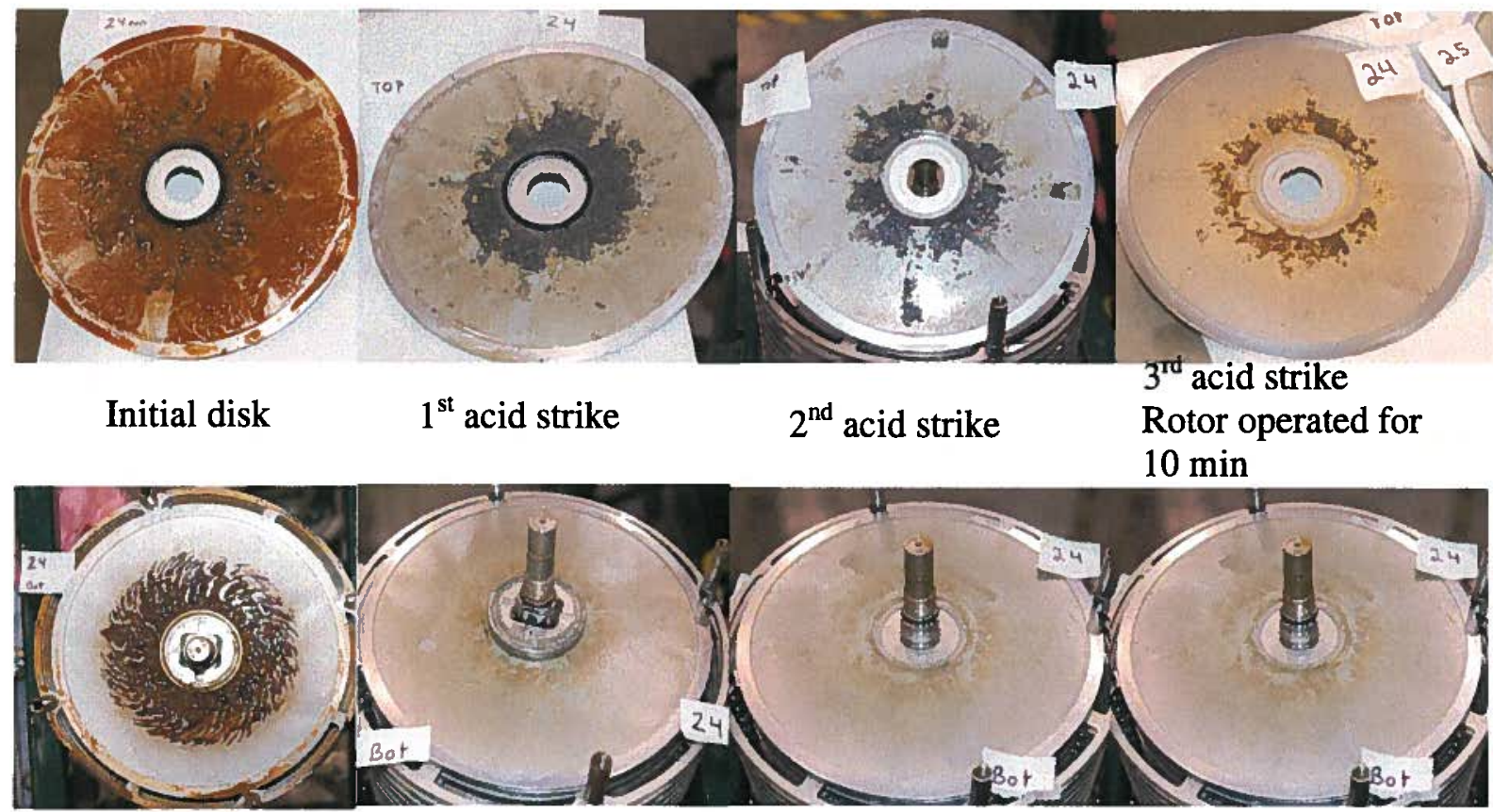

Disk \#24 Bottom

Figure 30. Comparison of Disk \#24 after Acid Cleaning Steps

After the inspection was completed, the filter stack was re-assembled and installed. The feed from the previous testing, $5 \mathrm{wt} \%$ insoluble solids, was filtered to determine the effectiveness of the cleaning. Figure 31 shows the resulting filter flux. The flux was restored to approximately $88 \%$ of the initial flux when the transition from $0.06 \mathrm{wt} \%$ to $5 \mathrm{wt} \%$ was made. In other words, the maximum flux at $5 \mathrm{wt} \%$ insoluble solids prior to the cleaning cycle was $2.80 \mathrm{gpm}$ at a net pressure drop of $40 \mathrm{psid}$. Cleaning restored the flux from 0.71 gpm at a net pressure drop of 40 psid prior to cleaning to $2.47 \mathrm{gpm}$ at a net pressure drop of $40 \mathrm{psid}$ after the cleaning. The flux decline as the filter continued to operate followed essentially the same curve as the previous testing. The net pressure drop was raised from 40 psid to 60 psid and the system responded with a flux that was initially greater that the 
previous transition from 40 to 60 psid. The decline in flux was similar, though slightly faster for the post-acid-cleaning testing.

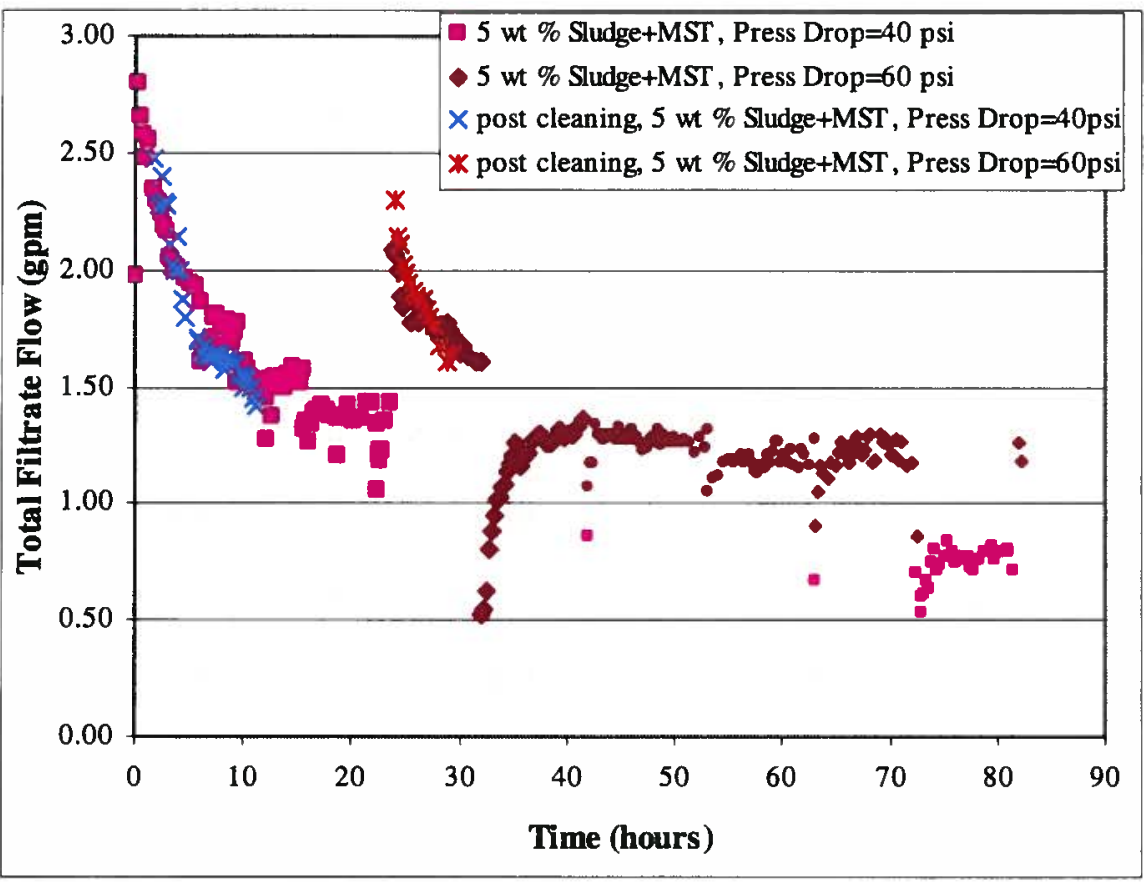

Figure 31. Comparison of Flux from Post Acid Cleaning to Original Data with 5 wt \% Insoluble Solids (Time scale aligned for "post acid cleaning" data for comparison)

Overall, the acid cleaning appeared to be very successful in restoring the filtration rate of the membranes while using a minimal amount of acid. Additional benefit can be obtained by extending the soak of the filter disks or increasing the circulation time of the acid during the cleaning cycle. The testing parameters were limited by the ability of the available pump to apply pressure to the system. It should be noted that SpinTek recommends a minimum of 20 psi be applied across the filter disk to overcome the centrifugal force due to rotating the disks at $1200 \mathrm{rpm}$ pushing permeate to the periphery of the disks.

For field applications, the cleaning would be carried out by draining the filter of the process fluid, rinsing with inhibited water, cleaning using acid, and rinsing again with inhibited water. Acid would be added to the system by restricting the outlet flow of the filter and allowing air to purge from the filtrate line. Purging of the filter has typically been accepted after the filtrate flowmeter shows a consistent signal. This is an indication that the filtrate line is liquid solid as gas in the line results in large variations in the reading of the flowmeter. The filter would be left to soak for several hours. After completing the soak, the filter would be operated. It is recommended that a feed (acid) pressure of at least $25 \mathrm{psi}$ and a filtrate back pressure of $5 \mathrm{psi}$ be applied to the system to prevent the possibility of delaminating of the filter disk. An outlet flow should be maintained to allow any loosened solids to be discharged from the filter. This flowrate can be low, on the order of $1 \mathrm{gpm}$ to minimize the amount of cleaning acid required. The filtrate flow should be monitored for improvement. 


\subsection{DISASSEMBLY.}

\subsubsection{Air Seal Inspection.}

After filter disassembly, the air seal assembly was removed, disassembled and inspected. Figure 32 shows the stationary silicon-carbide seal face after 230 hours of operation compared to a new seal face. Inspection of the seal face used in testing showed no unanticipated wear. The air grooves appear to be in good shape and do not appear excessively worn.

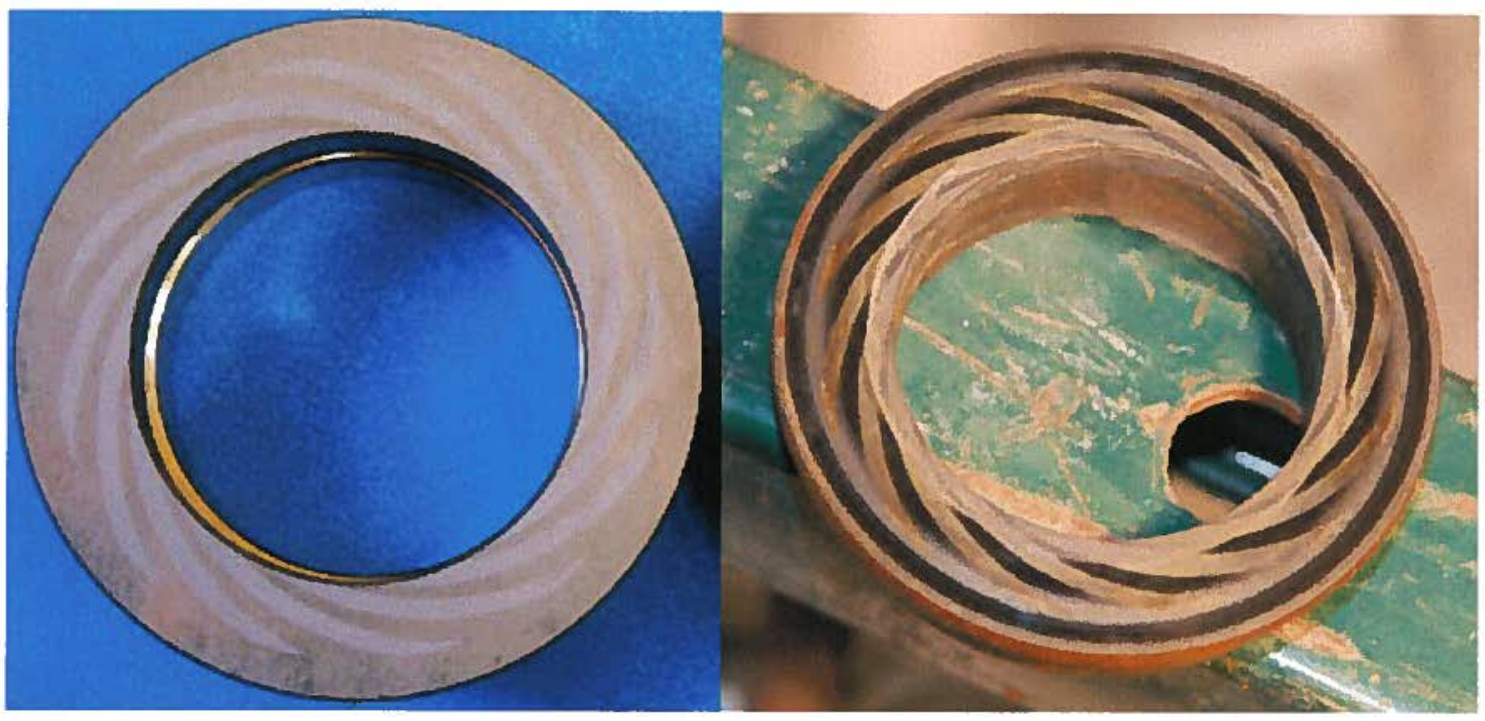

Figure 32. New Air Seal Silicon- Carbide Face Compared to Seal Face with 230 Hours of Operation

Figure 33 shows a picture of an interface between the air groove and the seal face. Note that the interface remains sharp and shows no excessive wear. 


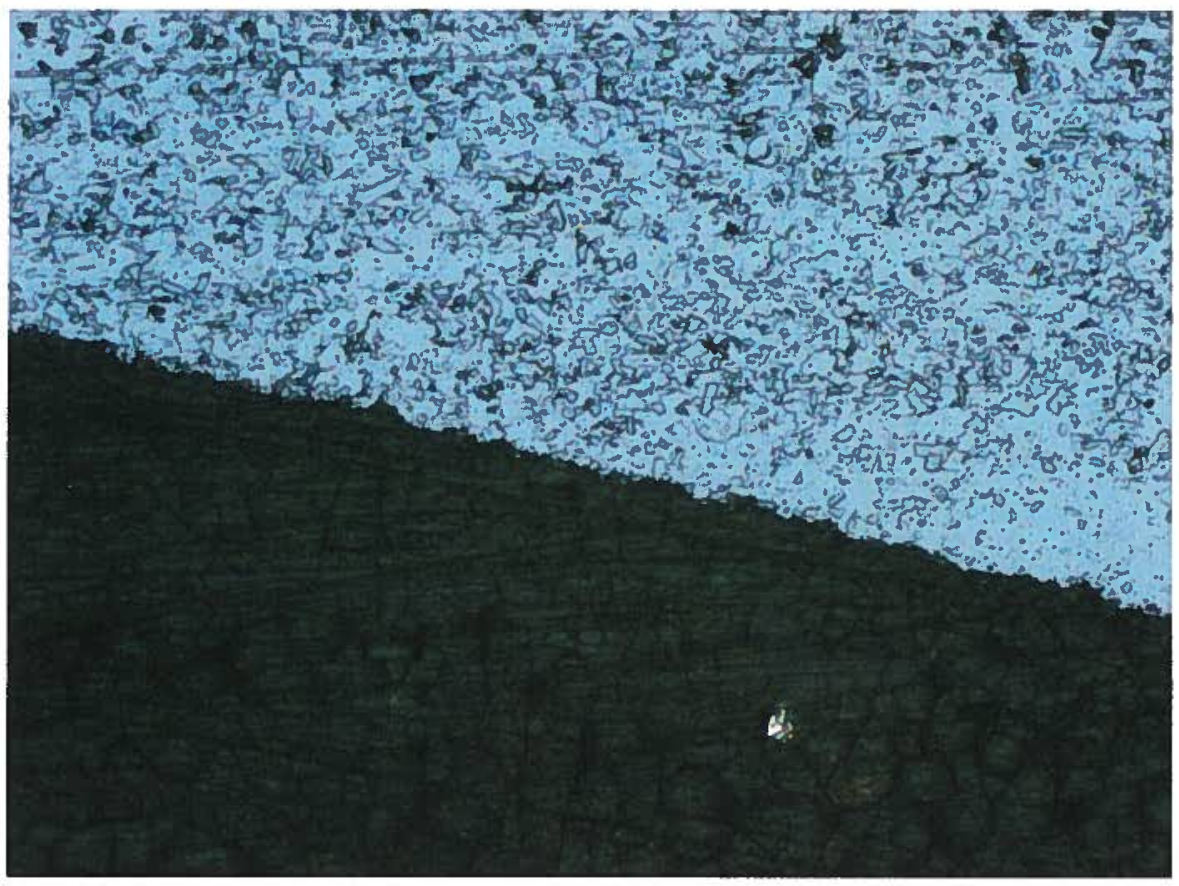

Figure 33. Air Seal Carbide Face at the Interface of an Air Groove at the Seal Dam - 10X Magnification

A photo of a new air seal carbon face compared to the carbon face after 230 hours of operation is shown in Figure 34.

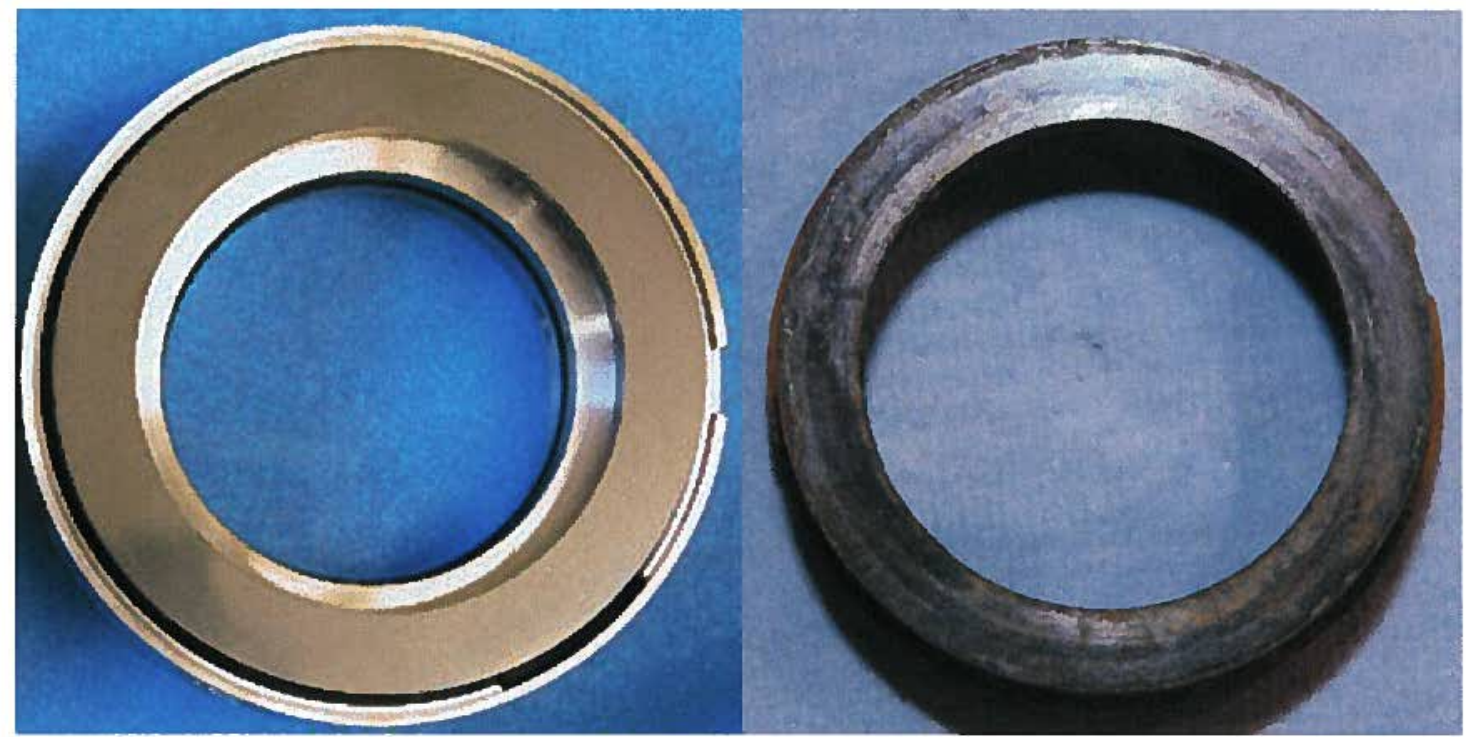

Figure 34. New Air Seal Carbon Face Compared to the Carbon Seal Face after 230 Hours of Operation

The wear on the carbon face is judged to be "normal" for a nominally abrasive environment. The wear is not excessive. Measurements of the thickness of the seal face were the same as measured with a hand micrometer prior to start of testing (0.704"). 
Figure 35 shows an area of the carbon seal face at the seal dam at $4 \mathrm{X}$ magnification. Some polishing of the seal face is observed in the photo. No evidence of significant scratching was observed when the seal face was examined under a microscope. Wear seen on the seal face occurs prior to liftoff, mostly occurring at startup and shutdown. The seal was subject to approximately 50 startup/shutdown cycles during testing.

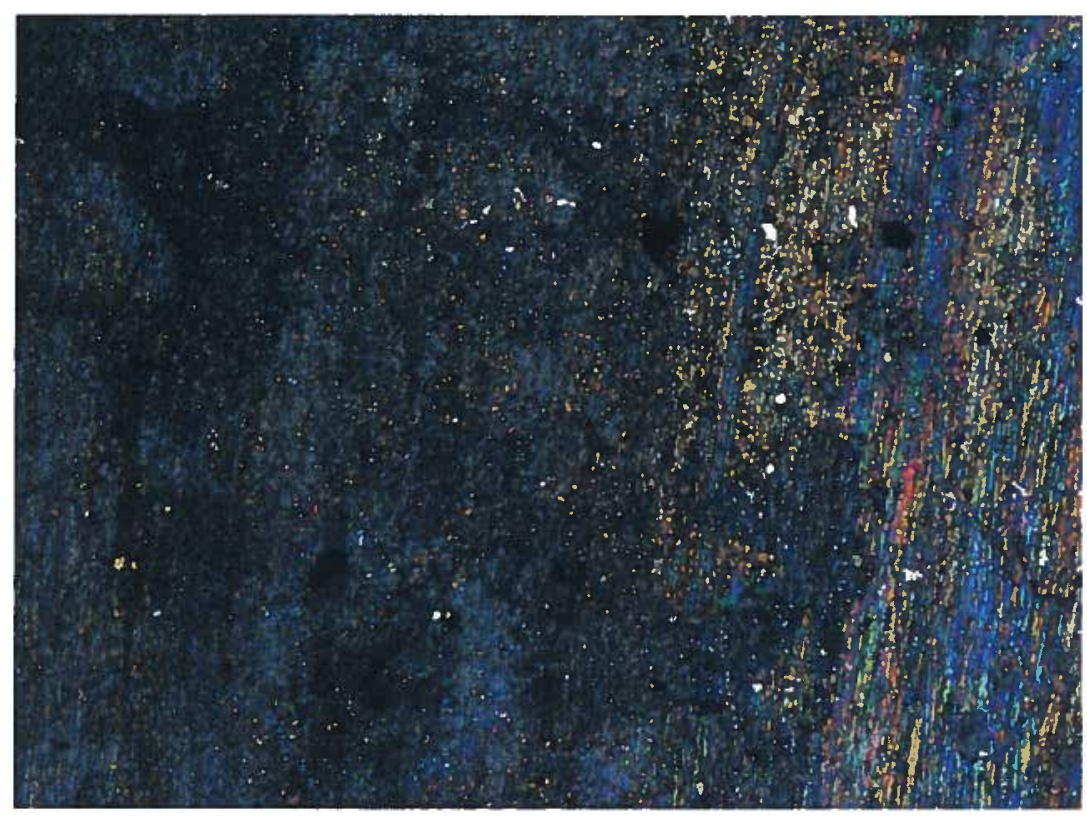

Figure 35. Air Seal Carbon Face at 4X Magnification

Figure 36 shows a photo of the drive tang from the seal after disassembly as compared to a new seal face. The two seal faces are photographed back-to-back with the drive tangs aligned. The new seal face is on the bottom and the seal used in testing is stacked on top. Note how there is significantly less wear on the drive tang than was observed on the initial air seal shown in Figure 6. 


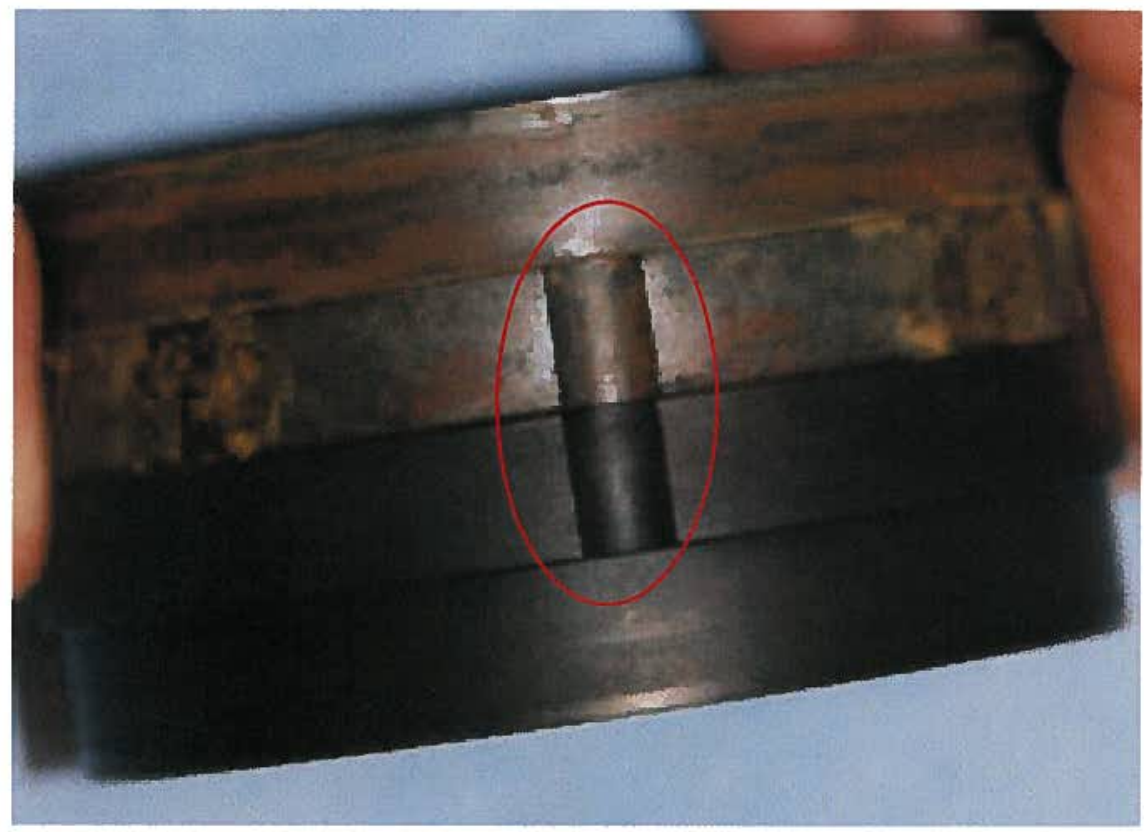

Figure 36. Photo of Seal Drive Tang after 230 Hours of Operation (top) Compared to a New Seal (bottom)

The decrease in the wear of the drive tangs indicates that improvements have been made to the amount of vibration seen by the seal, translating into less observable wear.

Based on the amount of wear observed and that no changes in thickness could be measured and the improvements in vibration made and planned, barring operational error or a significant number of starts and stops, there is no reason to expect that the air seal will not reach or exceed the commercial design life of 3 years. To reach the maximum lifetime of the seal, the seal should not be disassembled, vibration should be minimized, and the number of starts and stops should be minimized.

\subsubsection{Bushing Inspection}

Inspection of the shaft bottom bushing shows that the assembly continues to wear well. This is the second test campaign using this bushing configuration. Total operational time is approximately 380 hours. The primary area of contact on the shaft bushing is at the bottom of the bushing and continues to show the most polishing. A photo of the bushing removed from the shaft is shown in Figure 37. The polishing observed just above the chamfer is continuous around the circumference. 


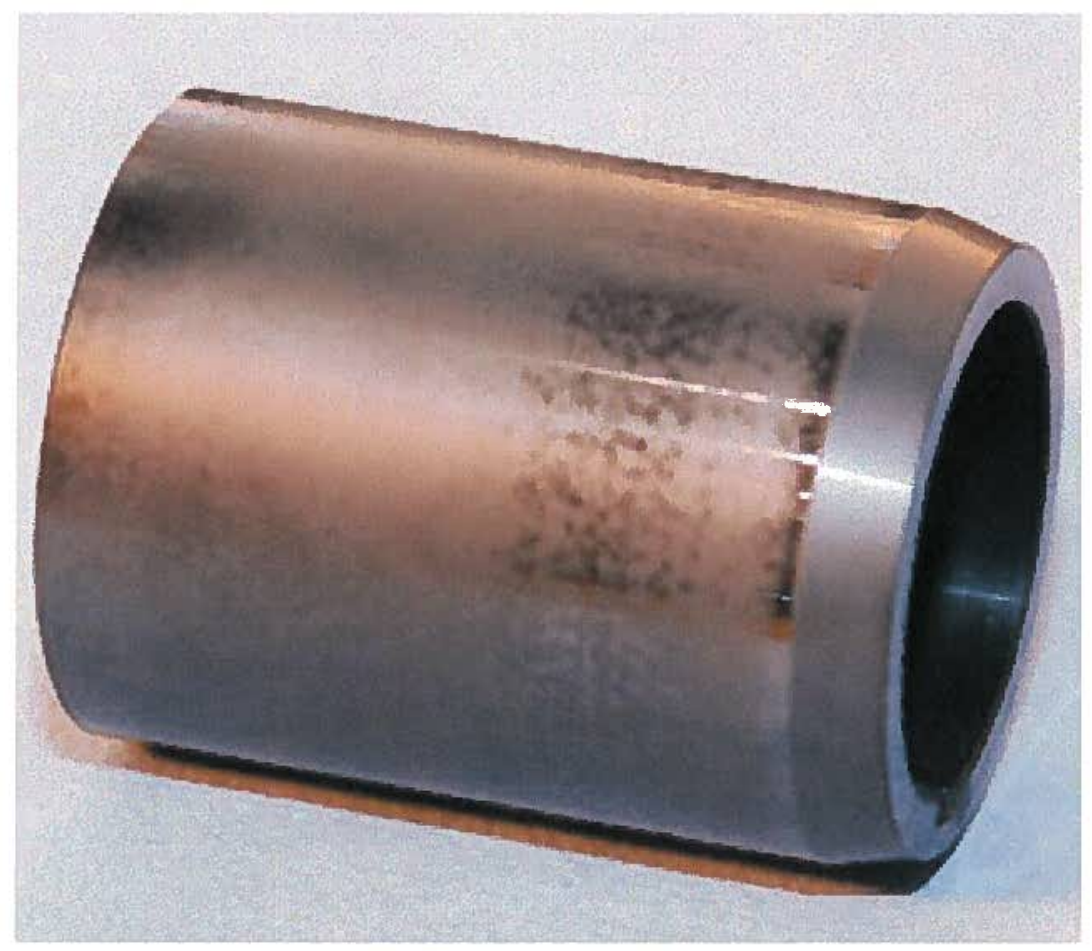

Figure 37. Photo of Lower Shaft Bushing Rotating Part

The end of the bushing also continues to show polishing. The sealant that prevented the bushing from sliding down on the shaft was completely dissolved by the process or cleaning fluids. Therefore, the bushing was able to contact the bottom cup and a wear pattern can be observed. Figure 38 is a photo of the stationary silicon-carbide cup. The circular trace from the rotating bushing is seen in the bottom of the cup and some minor polishing can be observed in the lower side walls. 


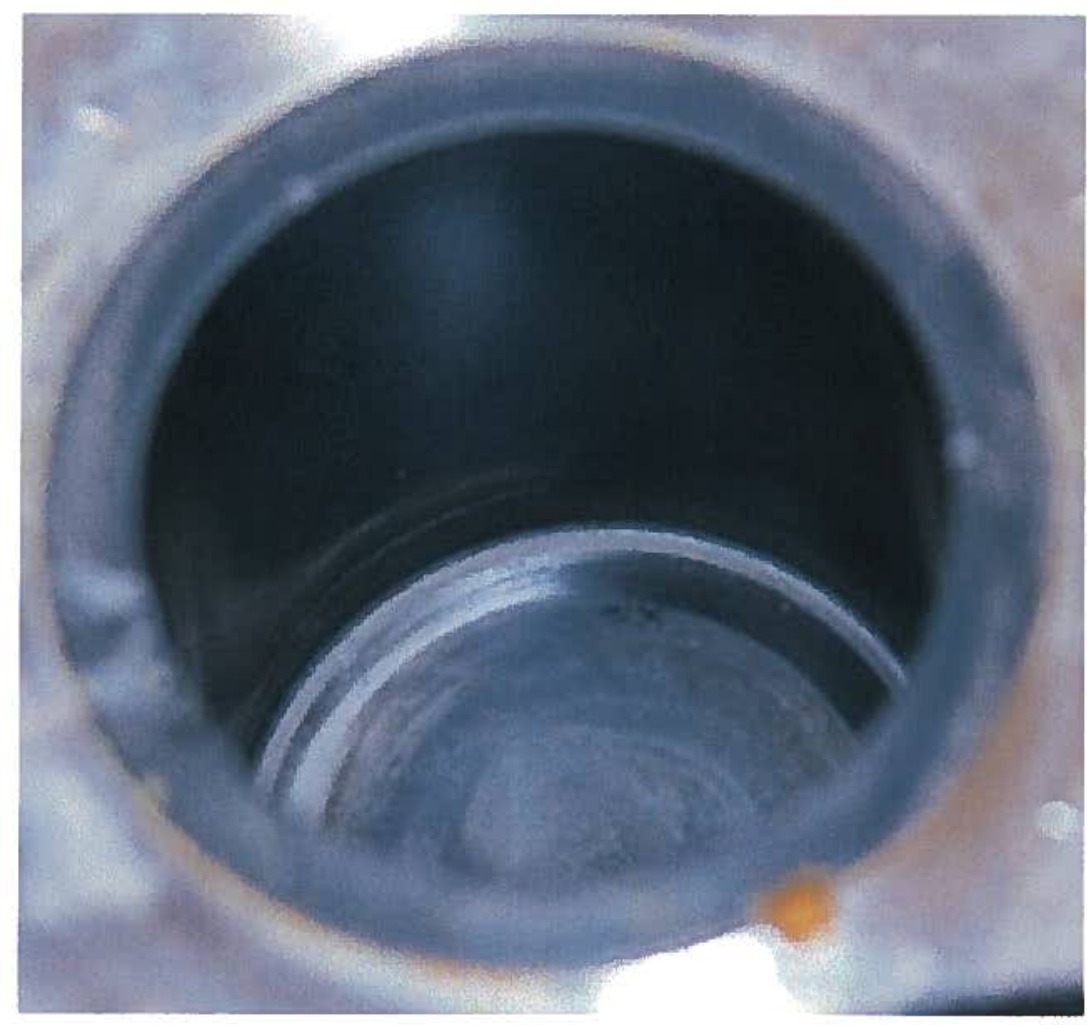

Figure 38. Photo of Lower Shaft Bushing Stationary Cup

In spite of the good performance by the current bushing design, the authors recommend updating the design to improve the expected lifetime. The update would include incorporating a locking ring to retain the rotational bushing in place, removing the bottom of the cup to allow fluid path through and including flow channels in the bushing to increase cooling flow.

\subsubsection{Rotary Joint Inspection}

The rotary joint used in this set of tests was the same used in the majority of rotary filter testing. The rotary joint in this inspection was used in approximately 509 hours of the 515.3 hours of total operation of the filter system.

Inspection of the rotary joint prior to disassembly showed a fair amount of what appeared to be dried salt deposits. These deposits were found on both the top and bottom side of the rotary joint. A picture of the top of the rotary joint is shown as Figure 39. Some of the deposits had a brownish color similar to corroded carbon steel. The deposits did not have the brown color until nitric acid was used in cleaning of the filter disks. 


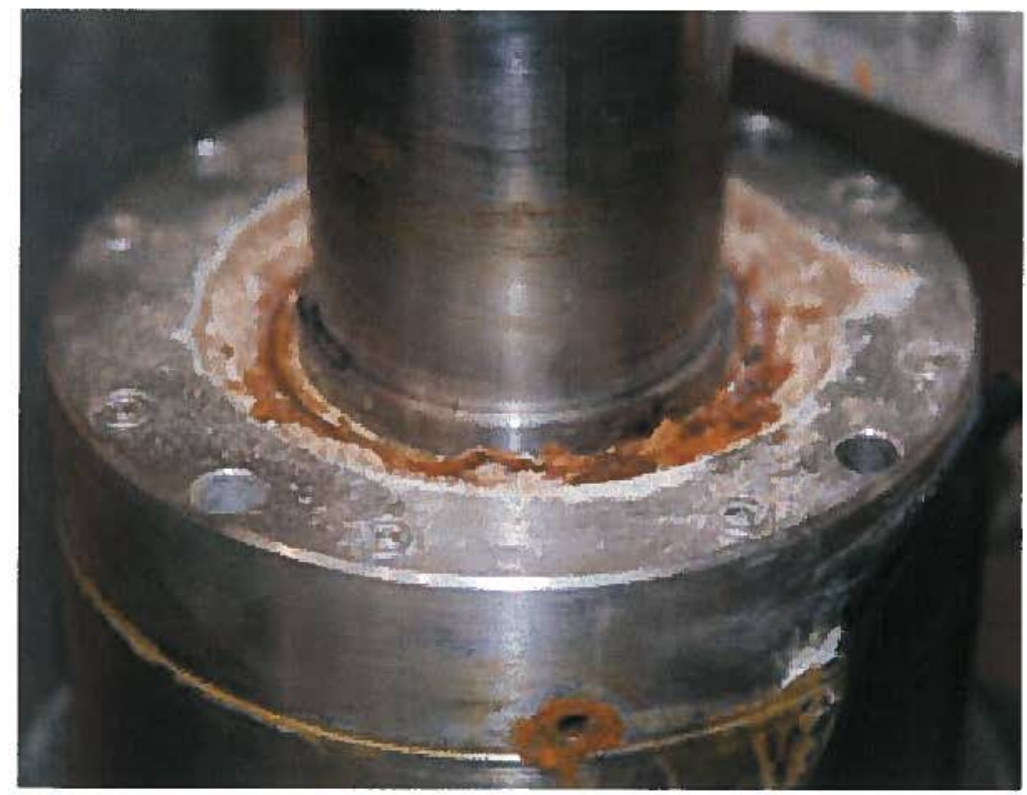

Figure 39. Rotary Joint at Test Completion

Disassembly revealed that salt solution had penetrated both the upper and lower bearings. Rust was evident on both bearings, and is the probable cause on the brown color on the material on the outside on the joint. The bearings were not manufactured from stainless steel. The upper bearing seal ring showed evidence of excessive torque as the seal ring had distended. A photo of the upper bearing is shown in Figure 40.

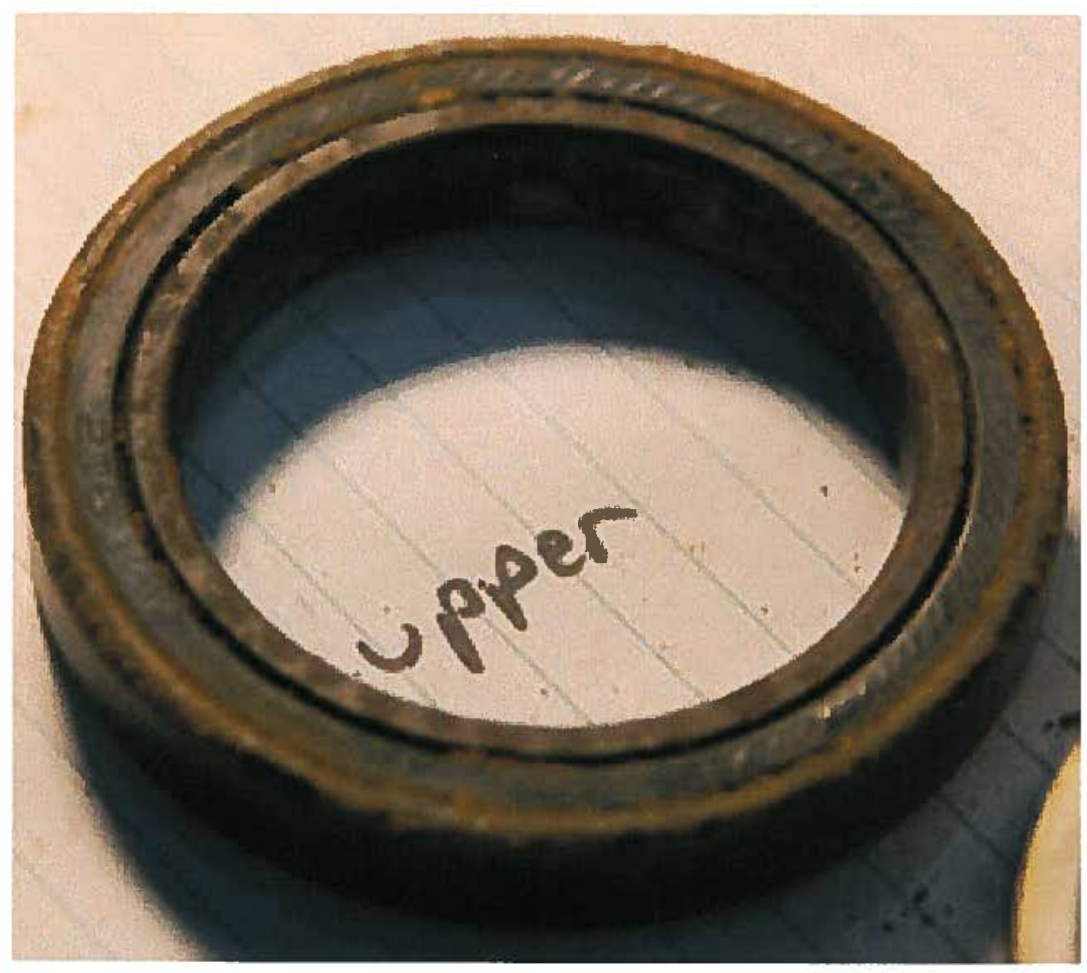

Figure 40. Photo of Upper Bearing from Rotary Joint 
Upon removal, the upper bearing initially did not operate smoothly when turned by hand. After several rotations, the action of the bearing smoothed out. The rough action of the bearing suggests penetration by the weeping salt solution used in testing and eventual drying of the fluid leaving salt deposits behind. The deposition of salt was expected, more-so on the lower bearing as any fluid passing the mechanical seal would rest on the bearing until exiting the rotary joint through the weep holes. Salt deposits in the bearing which is located above the mechanical seal indicate that fluid that passed the mechanical seal did not have ample spacing to exit the joint without coming in contact with the bearing.

Both the upper and lower seals were inspected in the rotary joint. Both seals passed fluid at various rates throughout the recent rotary filter testing. Salt traces were observed on the exterior of the rotary joint during operation.

A picture of the carbon seal face from the top seal of the rotary joint is shown in Figure 41 with a $4 \mathrm{X}$ magnification shown in Figure 42. The high polish on the center area is indicative of the seal operating at least partially dry. This operating mode was expected as the discharge from the rotary joint is currently located in the middle of the two seals thus allowing air to be trapped at the top seal. It is recommended that the discharge from the rotary joint be raised to minimize the trapping of air during operation of the filter.

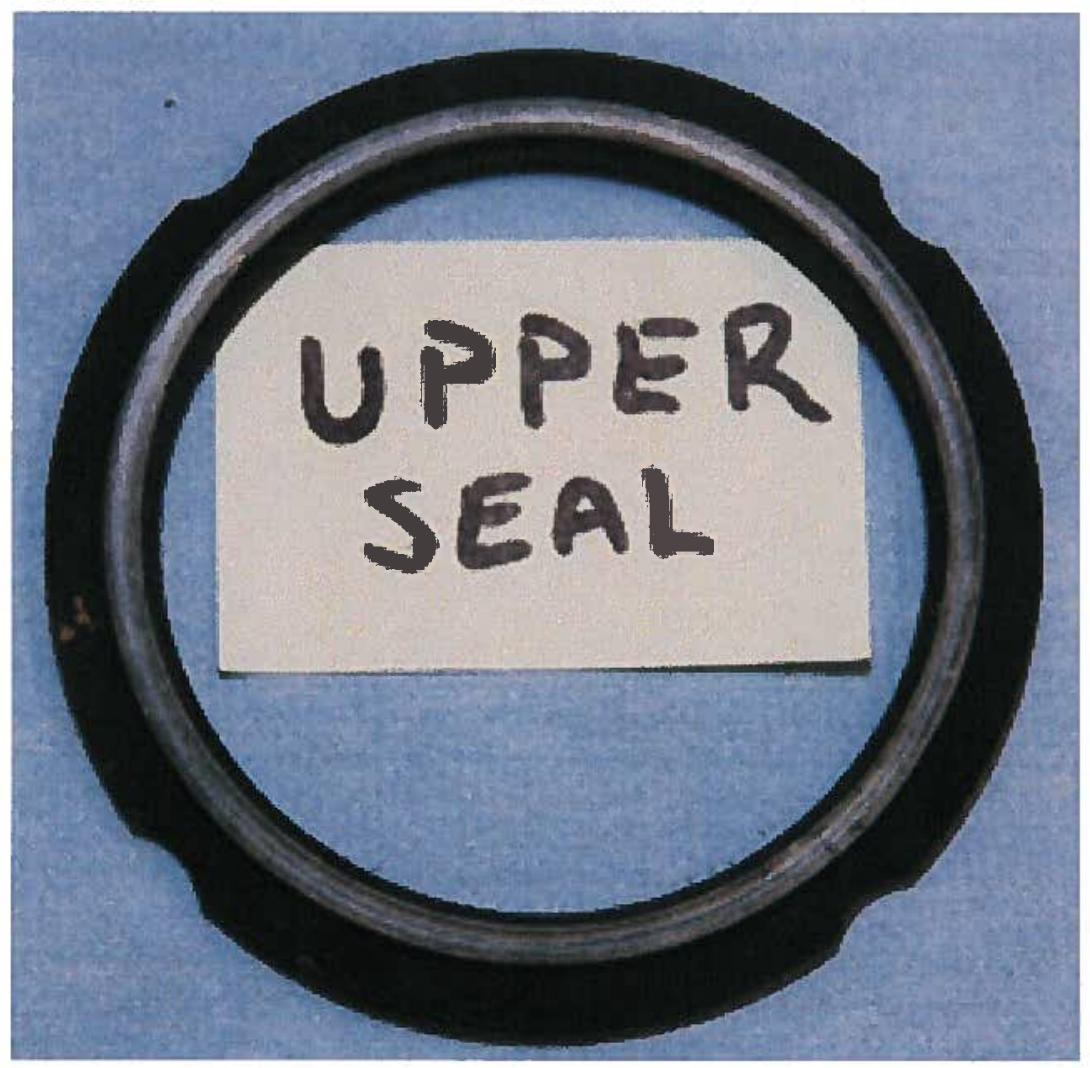

Figure 41. Rotary Joint Carbon Face of Upper Seal 


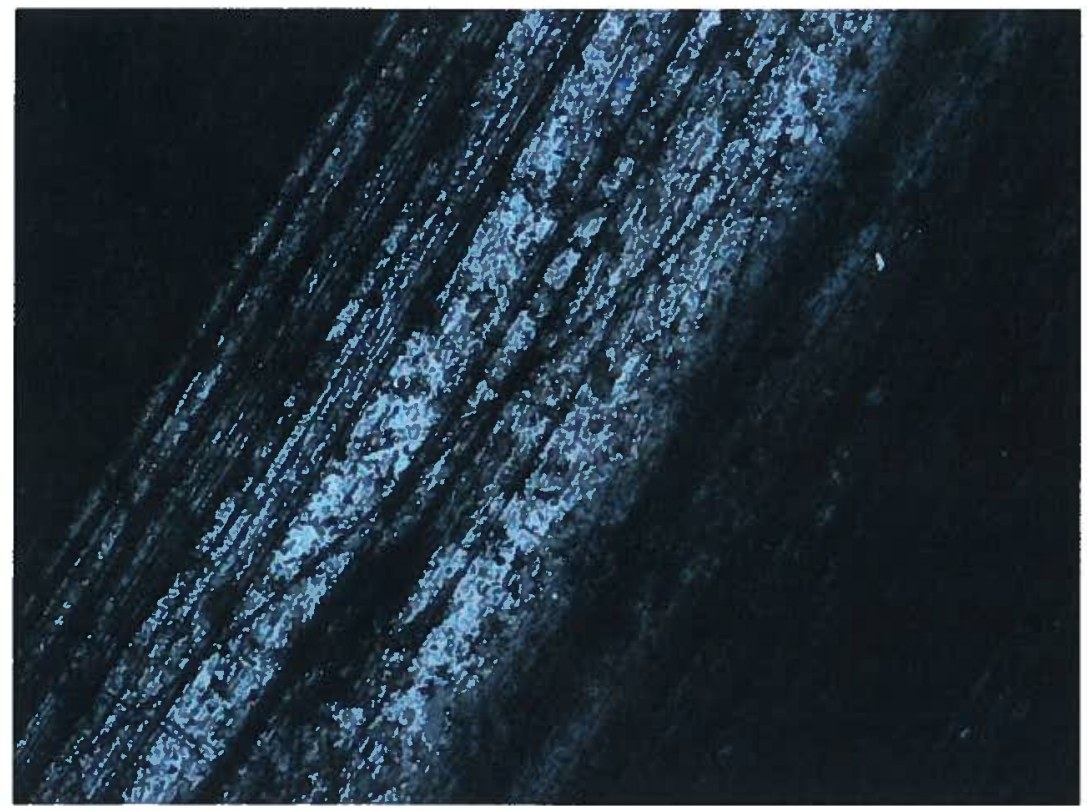

Figure 42. Carbon Seal Face from Top Seal of Rotary Joint at 4X Magnification

The lower seal face, shown in Figure 43 and at $4 \mathrm{X}$ magnification in Figure 44, shows more even radial wear. In contrast to the upper seal, the lower seal was submerged in filtrate and therefore consistently received proper cooling and lubrication.

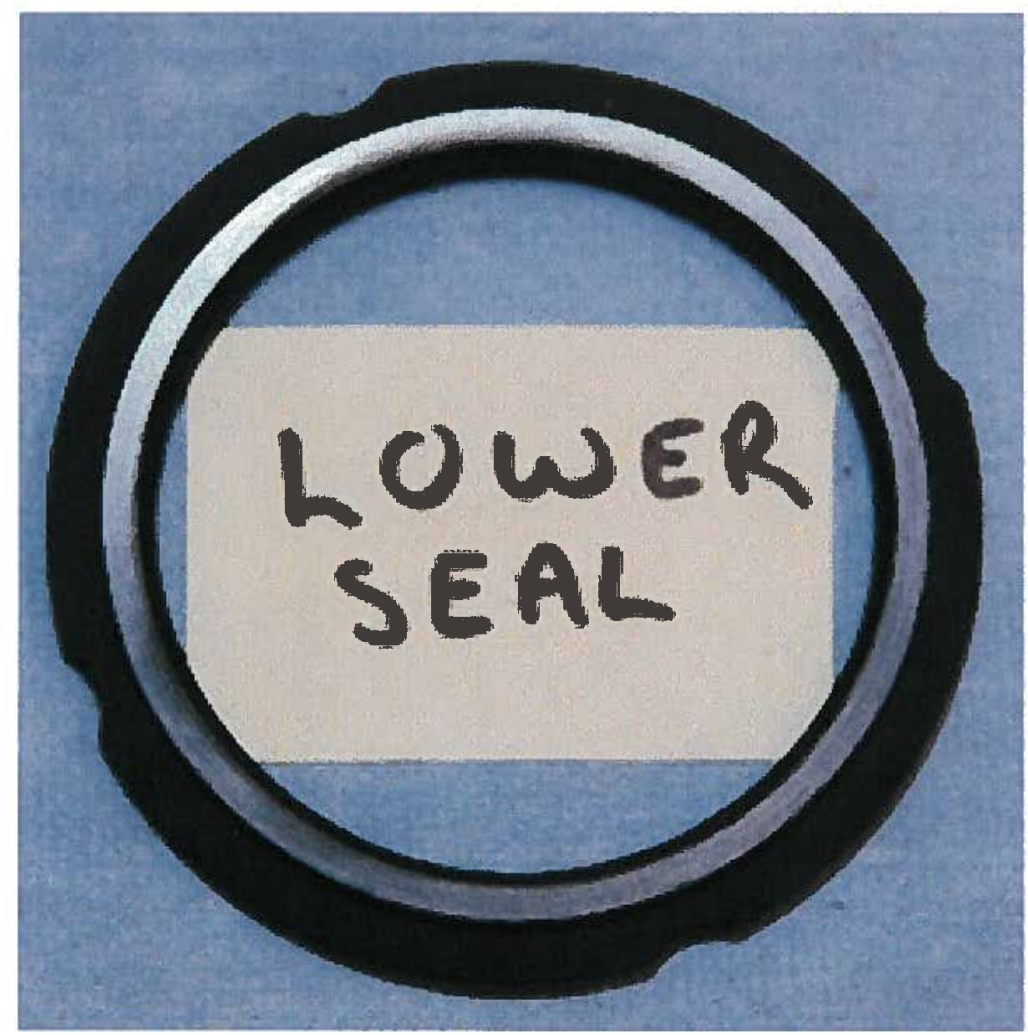

Figure 43. Rotary Joint Carbon Face of Lower Seal 


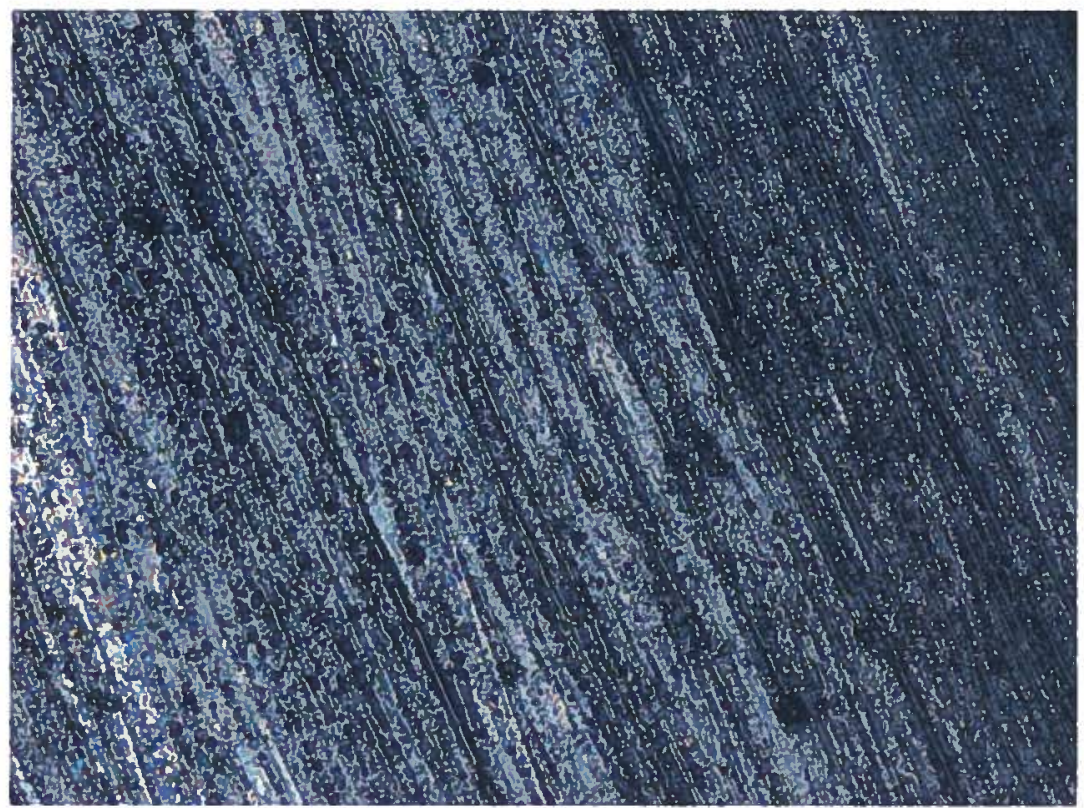

Figure 44. Carbon Face from Bottom Seal of Rotary Joint at 4X Magnification

Thickness measurements showed that both seals wore at relatively the same rate. Hand micrometer measurements ranged between 0.2572 and 0.2576 inches for the upper seal and between 0.2569 and 0.2574 inches for the lower seal. The range in thickness around the circumference of the seal indicates that the weeping of both seals was primarily due to the lack of flatness across the seal faces. This wear pattern is consistent with wear due to excessive vibration. The reduction in the vibration would greatly extend the life of both seals.

Figure 45 is a photo of the ceramic (alumina) face from the lower seal of the rotary joint outside of the seal area. The photo shows fluid that has passed between the seal faces and dried. 


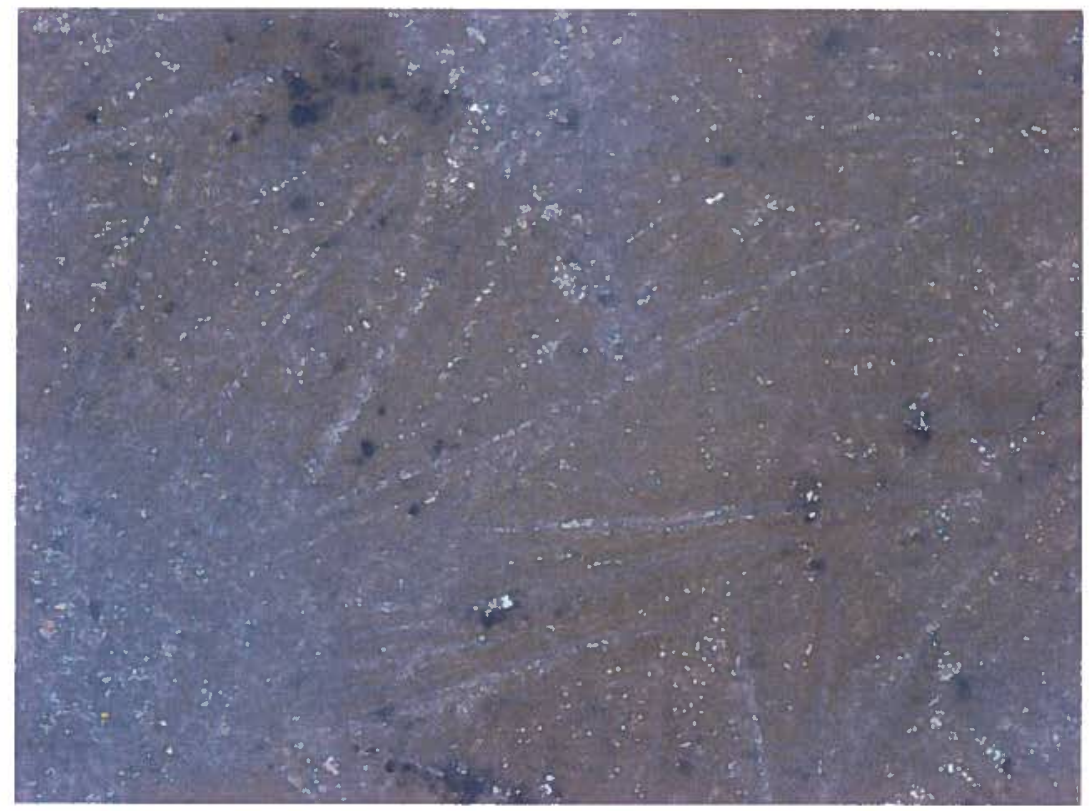

Figure 45. Alumina Seal Face from Bottom Seal of Rotary Joint Showing Dried Salt Outside of Sealing Area

Several upgrades are recommended for the rotary joint to increase expected lifetime. These recommendations include raising the location of the discharge port to minimize trapped gas; providing drip protection to the bearings through the use of forsheda rings or similar design; increasing the size of the weep area to allow any weeping filtrate to discharge more readily; and using stainless steel components in all bearings to prevent corrosion.

\subsubsection{Wear Part Summary}

Table 3 shows a summary of the main wear parts and for which rotary filter test campaigns they were installed. The variable frequency drive that controls the filter rotor reads 515.3 hours. Total documented test time is approximately 506 hours. The remaining 9.3 hours include unrecorded operation such as tours and startup testing. 
Table 3. Summary of Wear Part Use in Each Rotary Filter Test Campaign

\begin{tabular}{|l|l|c|c|c|c|c|}
\cline { 4 - 6 } \multicolumn{2}{c|}{} & \multicolumn{4}{c}{ Test Program } \\
\cline { 3 - 7 } \multicolumn{2}{c|}{} & $\begin{array}{c}\text { 2006 SRS } \\
\text { SB2 and } \\
\text { Tank 8F } \\
\text { Sludge Only }\end{array}$ & $\begin{array}{c}\text { Preparation } \\
\text { for } \\
\text { Hanford } \\
\text { Testing }\end{array}$ & $\begin{array}{c}2007 \\
\text { Hanford } \\
\text { Simulant }\end{array}$ & $\begin{array}{c}2008 \\
\text { SRS } \\
\text { Tank 8F } \\
+ \text { MST }\end{array}$ & $\begin{array}{c}\text { Total } \\
\text { Hours }\end{array}$ \\
\hline $\begin{array}{l}\text { Test Duration } \\
\text { (hours) }\end{array}$ & 129 & 26 & 124 & $227^{*}$ & 506 \\
\hline Main Shaft Seal & $\begin{array}{l}\text { Type 1 } \\
\text { Si-C/Si-C }\end{array}$ & 123 & NA & NA & NA & 123 \\
\cline { 2 - 7 } & $\begin{array}{l}\text { 28LD } \\
\text { Gas Seal }\end{array}$ & NA & 26 & 124 & NA & 150 \\
\cline { 2 - 7 } & $\begin{array}{l}\text { 28LD } \\
\text { Gas Seal }\end{array}$ & NA & NA & NA & 230 & 230 \\
\hline Rotary Joint & & 129 & 26 & 124 & 230 & 509 \\
\hline $\begin{array}{l}\text { Bushing/Journal } \\
\text { Bearing }\end{array}$ & Graphite & 129 & NA & NA & NA & 129 \\
\cline { 2 - 7 } & Si-C/Si-C & NA & 26 & 124 & 230 & 380 \\
\hline
\end{tabular}

Three hours of testing preparation not included in test time NA=Not Applicable 


\subsection{CONCLUSIONS}

The conclusions from this testing follow.

Operating Performance:

- During restart of the filter, the main air seal developed a leak. Evaluation of the seal led to the conclusion that the leak was caused by several small blisters that formed on the carbon seal face. The cause of the blisters is believed to be a contaminant being drawn between the seal faces and not an inherent flaw in the application of the air seal technology with the rotary filter. The change in wear pattern due to the disassembly of the seal allowed the contaminant to enter between the seal faces.

- The filter flux at $0.06 \mathrm{wt} \%$ solids reached a near constant value at an average of $0.090 \mathrm{gpm} / \mathrm{ft}^{2}(2.2 \mathrm{gpm}$ total $)$ at a net pressure drop of $40 \mathrm{psi}$.

- The filter flux at $5 \mathrm{wt} \%$ solids reached a near constant value at an average of $0.049 \mathrm{gpm} / \mathrm{ft}^{2}$ (1.2 gpm total) with a net pressure drop of $60 \mathrm{psi}$.

- Filtration rate has a linear relationship to the net pressure drop between 20 and 60 psid. The most productive net pressure for the tested slurry at low weight percent insoluble solids ( $\leq 5 \mathrm{wt} \%)$ is 60 psi.

- Filtration rates are consistent with similar tests run previously using a pilot scale 3disk rotary filter using sludge + MST. ${ }^{10}$ The addition of MST results in a loss of flux versus filtering sludge only.

- Filtrate turbidity measured < 4 NTU for all samples collected.

Chemical Cleaning

- The rotary filter was successfully cleaned using approximately 50 liters of $4 \mathrm{M}$ nitric acid. Flux was restored to approximately $88 \%$ the initial flux at $5 \mathrm{wt} \%$ insoluble solids.

Mechanical Wear

- Inspection of the faces of the main shaft seal after approximately 230 hours of operation showed an expected amount of initial wear, no passing of process fluid through the seal faces, and very little change in the air channeling grooves on the stationary face.

- The rotary joint was disassembled and inspected after approximately 509 hours of service. Both upper and lower seals showed signed of leakage. Wear on the seals was primarily from vibration. The upper seal showed signs of running dry due to trapped air restricting liquid (coolant/lubricant) access to the seal for at least a portion of operational time.

- Evaluations of all mechanical seals show that vibration is a primary cause of component wear. Reduction of vibration in deployment of the rotary filter will greatly extend the lifetime of all seals and bearings. 
- Measurements show that the mount of the filter in the test stand is a primary source of vibration to the rotary filter and requires improvement to allow for the accurate measurement of the vibration signature of the filter.

- Some polishing was observed at the bottom surface of the shaft bushing after a total operational time of approximately 380 hours.

Recommended Improvements

- Add a locking ring to restrain the bushing and incorporate grooves to provide additional cooling.

- Prevent trapped air in the rotary joint by raising the location of the discharge port thereby allowing the filtrate to lubricate and cool the seal.

- Install a forsheda ring (or similar) in the rotary joint to shield the lower bearing from filtrate that crosses the mechanical seal faces. Additionally, assure all bearings are stainless steel to prevent corrosion.

- Incorporate a motor stand to simplify alignment between the drive motor and the filter to reduce unit vibration.

- Reduce the open volume near the air seal to limit splashing of process fluid and maintain the gas pocket and the top of the filter.

- Reduce the tolerances of the filter disks and disk hubs to improve load balance on the shaft.

- Improve the alignment guides between the filter stack and the filter tank to reduce vibration. 


\subsection{FUTURE WORK}

The primary areas of improvement needed on the rotary filter are scheduled to be addressed. A second generation unit will be fabricated with all of the enhancements recommended in this report. These enhancements include the use of a motor stand to link the filter and drive motor to reduce vibration. Tighter tolerances will be required in the fabrication of the filter disks in reference to their fit to the shaft to improve overall rotor balance. The open area around the air seal in the filter chamber will be restricted to minimize exposure of the seal to the process fluid and solids. The lower bushing will be restrained to the shaft and modified to include flow channels to improve cooling. The filter stack alignment at the bottom of the filter tank will be improved to minimize vibration. The rotary joint will include design improvements to shield the bearings from any fluid that passes the seal faces. The discharge port from the rotary joint will be raised to minimize the potential of trapped air. The bearings in the joint will be made from stainless steel components to minimize corrosion.

Once fabricated, the filter will be operated at the vendor shop for an extended endurance test to demonstrate the enhancements. 


\subsection{REFERENCES}

${ }^{1}$ D.T. Herman, M.R. Poirier, S.D. Fink, "Testing and Evaluation of the Modified Design of the 25-Disk Rotary Microfilter", WSRC-STI-2006-00073, August 2006.

${ }^{2}$ D.T. Herman, M.R. Poirier, D.B. Stefanko, S.D. Fink, "Testing of a Rotary Microfilter to Support Hanford Applications", WSRC-STI-2008-00339, June 26, 2008.

${ }^{3}$ M.R. Poirier, D.T. Herman, and S.D. Fink, "Task Technical and Quality Assurance Plan for the Testing of a Rotary Microfilter to Support Enhanced Processes for Radionuclide Removal (EPRR)", WSRC-RP-200700471 , May 1, 2008

${ }^{4}$ T.M. Punch, "Scope of Work, Modular Salt Processing, Project Y491", P-SOW-H-00008, rev. 0, April 2007

${ }^{5}$ T. Chee, "Development of Rotary Microfilter for SRS/Hanford Deployment (08.1.4.1.2.1)", Project number SR071101, January 29, 2008.

${ }_{7}^{7}$ Patent Application D.T. Herman and D.N. Maxwell, S/N 11/245,843 "Rotary Filtration System," October 7 , 2005

${ }^{8}$ M.R. Poirier, "Recipe for Tank 8 Simulated Sludge Containing No RCRA Metals or Halides", WSRC-TR2005-00045, January 14, 2005.

${ }^{9}$ B.J. Adkins, "Modular Salt Processing System Head Scoping Calculation," M-CLC-F-01152, December 20, 2007.

${ }^{10}$ M. R. Poirier, D. T. Herman, S. D. Fink, R. Haggard, T. Deal, C. Stork, and V. Van Brunt, "Pilot-Scale Testing of a SpinTek Rotary Microfilter with SRS Simulated High Level Waste", WSRC-TR-2003-00071, February 3, 2003.

${ }^{11}$ W.A. Greene, P.A. Kirk, R. Hayes, J. Riley, "Centrifugal Membrane Filtration Final Report”, Prepared for FETC Contract No. DE-AC21-96MC33136, August 4, 1999.

${ }^{12}$ M.R. Poirier, S.D. Fink, "Investigation of Alternative Approaches for Cleaning MOTT Porous Metal Filters", WSRC-TR-2002-00526, November 12, 2002. 


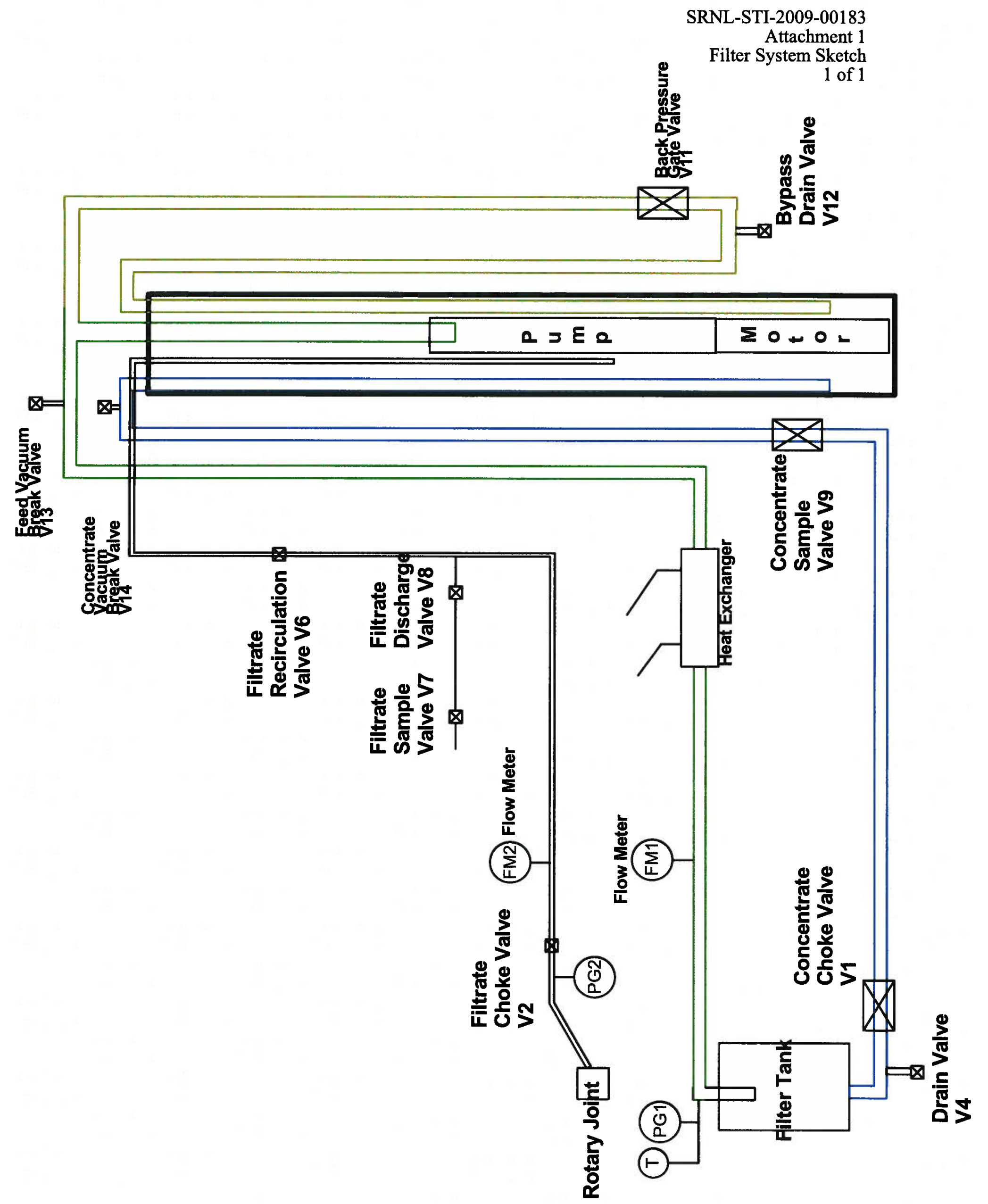


SRNL-STI-2009-00183 REVISION 0

Attachment 2

John Crane Seal Analysis Report

1 of 8

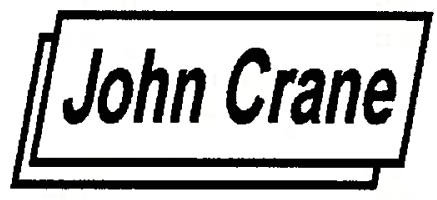

John Crane, Inc.

\author{
Doug Morgan \\ 406 King Charles Circle \\ Summerville, SC 29485 \\ Mobile/Pager: (843) 729-7216 \\ Office: (843) 821-3663 \\ Fax: (843) 832-5715
}

Failure Analysis 28LD at SRS HSP-1029734-1

Operation: This seal has been designed to operate in an abrasive atmosphere where a clean source of vapor (air) is available and is drawn in at the $\mathrm{ID}$ of the seal with grove technology generating a pressure as the shaft turns causing the opposing faces to "Lift Off" and run in a noncontacting manner after initial start up. A minuet amount of the sealing vapor (air) is pumped into the seal chamber creating a "Bubble" which the seal runs in. There are thus two distinct forms of sealing; a dynamic vapor seal generated during run and a static contact seal formed at rest. The failure of the seal in question primarily occurred in the "At rest" state but both aspects will be discussed.

The picture taken below by Mr. Herman illustrates the damage observed upon disassembly.

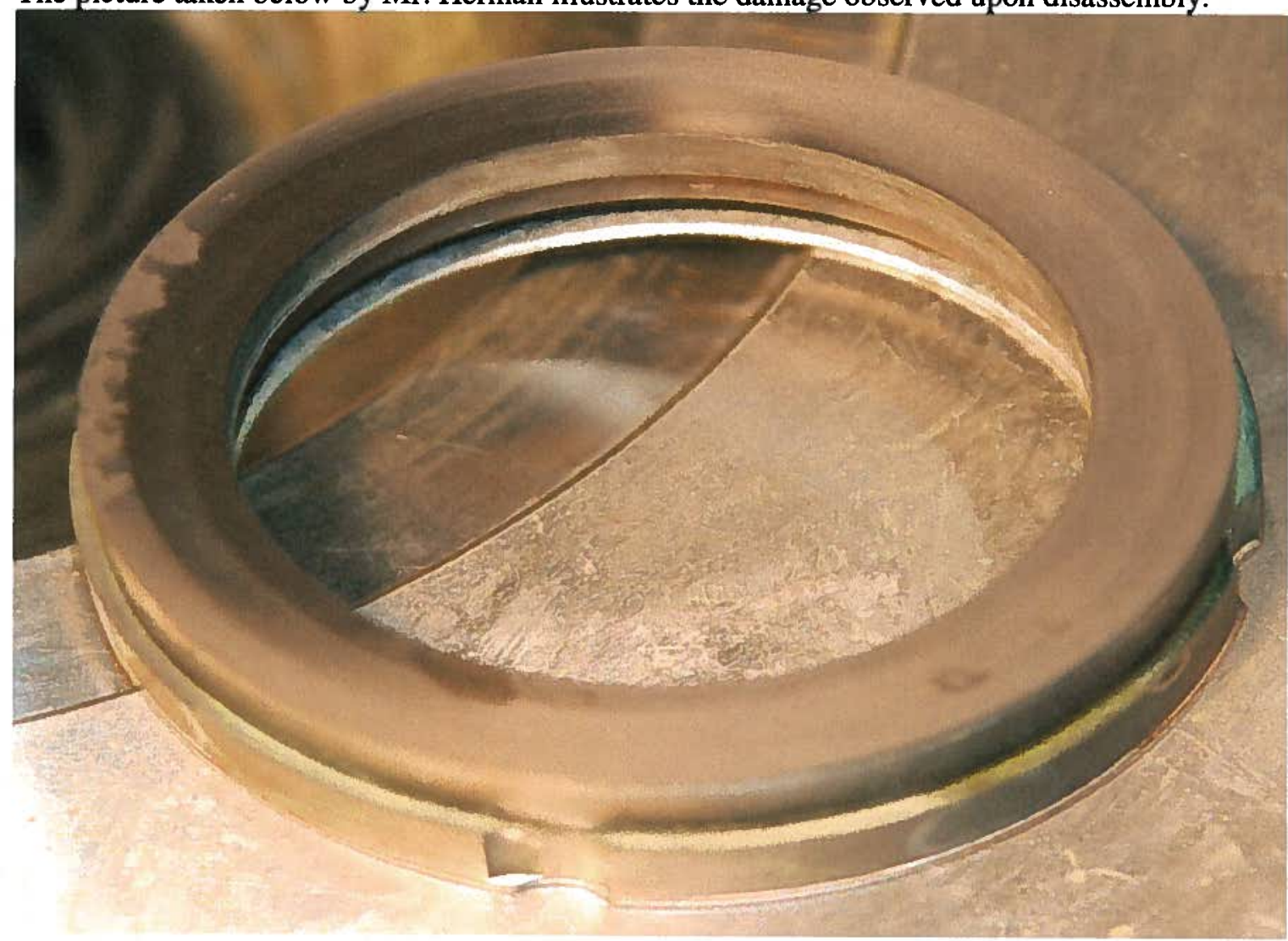


The chipping that is observable at the 9:00 position is the root cause of leakage. These are what are referred to as "Blisters" and occur in much the same manner as "Gaulling" of metal.

Normally something of a viscous nature gets between the faces and causes an adhesion that leads to pullout of surface particles. This is not uncommon in certain services where the nature of the product is viscous in nature but to occur in one single confined segment of the carbon ring as this is, is not easily explained. None of those who have observed this type of damage have seen this effect before. For lack of another explanation we believe this is an anomaly that has occurred and is due to some foreign substance being drawn between the faces. If the general process fluid had caused this we would expect the damage to be random in multiple quadrants not confined and excessive at just one point. The substructure of the carbon appears consistent and if this was a defect in the material itself it would be extremely odd that it would occur strictly in one extensive wear area showing as multiple blisters.

There were wear factors that also must be addressed at this point that have probably contributed to this. Below is a Radial profilometer reading of the Carbon face. The wear is not excessive when viewed in this manner. 


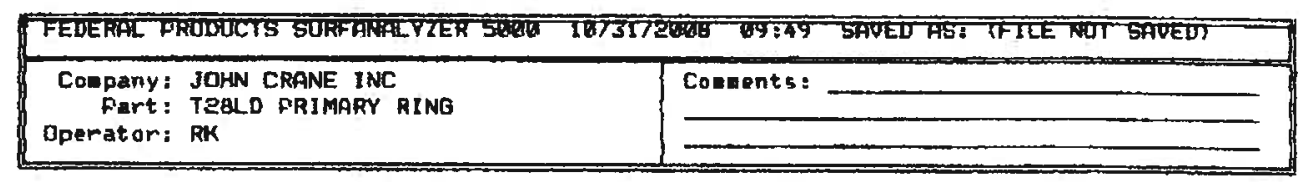

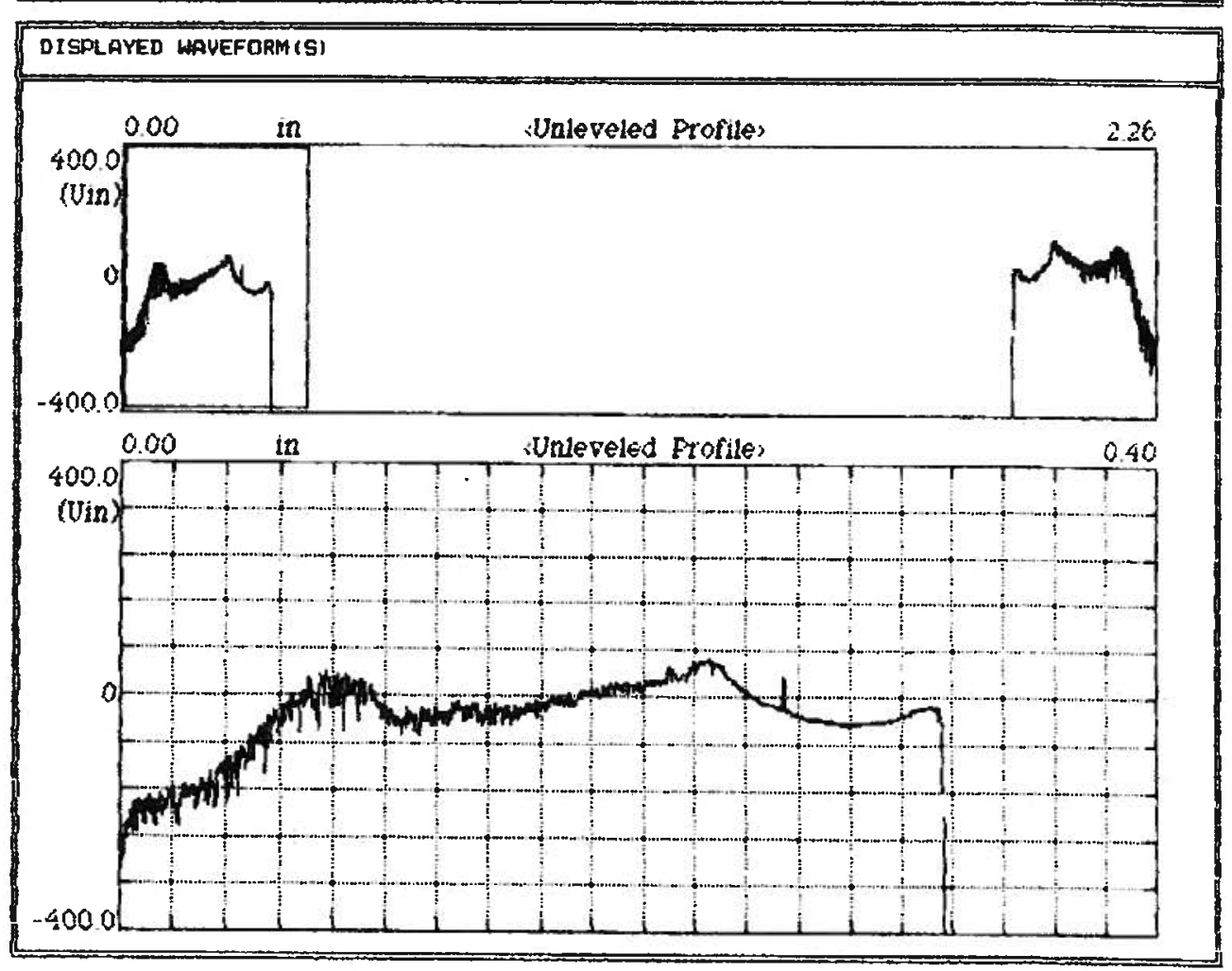

\begin{tabular}{|c|c|c|c|}
\hline $\begin{array}{l}\text { CUTOFF (r) } \\
\text { FILTER } \\
\text { PROBE RANGE } \\
\text { EUALUATION }\end{array}$ & $\begin{array}{l}0.939 \text { in } \\
\text { ANSI 2-RC } \\
+1-500 \mathrm{Uin} \text { (H) } \\
2.26 \text { in }\end{array}$ & $\begin{array}{l}\text { CUTOFF (W) } \\
\text { DRIVE SPEED } \\
\text { PROBE RATIO } \\
\text { TRAUERSE }\end{array}$ & $\begin{array}{l}0.030 \mathrm{in} \\
0.01 \mathrm{in} / \mathrm{sec} \\
1: 1 \\
\text { uin }\end{array}$ \\
\hline
\end{tabular}

PE08-1929.max

The following view is a radial trace of the carbon: 

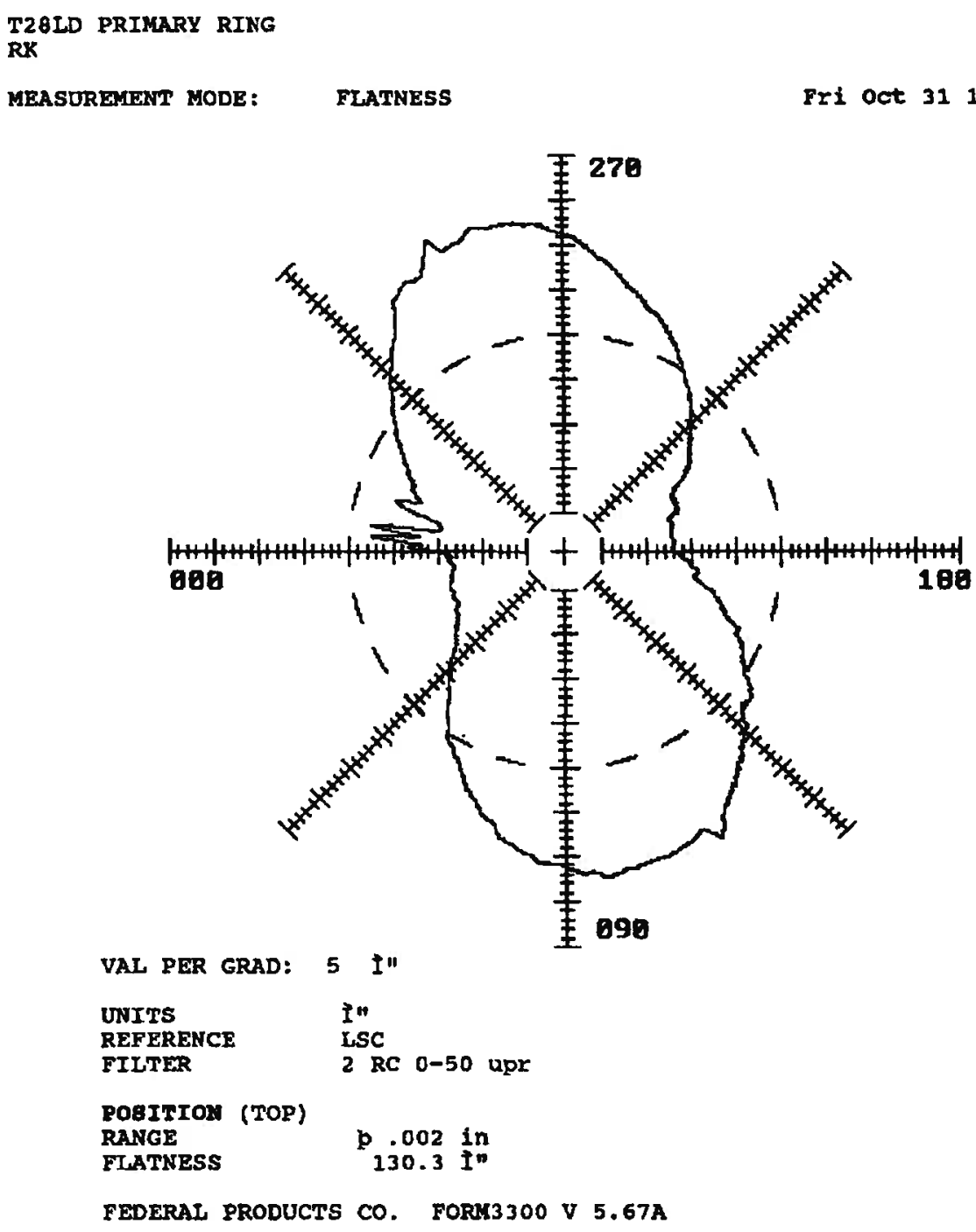

From this view we see an excessive amount of wear with a variation of 130 micro inches in a saddle pattern. On the left side 9:00 o'clock position the spikes are where the needle grazed the blisters. I had anticipated that we would perhaps see a flat area indicating a slight "hang up" of the carbon caused by process grit around the dynamic o-ring. This would cause wear in one spot, but the symmetric quality of this pattern is more in line with a more severe than anticipated harmonic vibration causing wear at 12:00 and 6:00. We are aware of some vibration in the unit and saw indications in the dent wear of the carbon. 
The following picture indicates the dent wear. Notice that the single scallop dent has elongated into two scallops. (Top of Carbon)

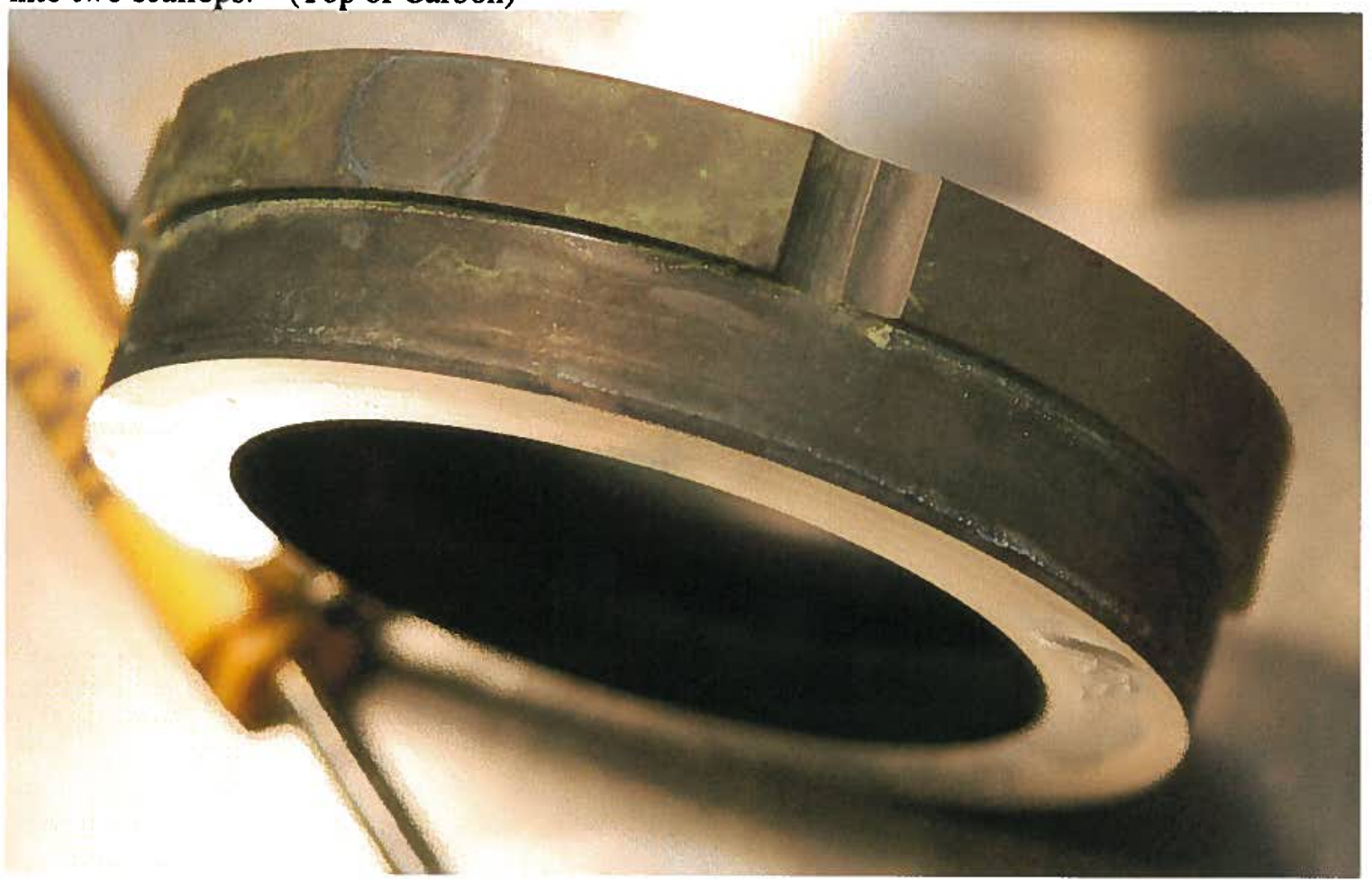

The additional traces of the Silicon Carbon faces have indicated no problems. We had feared that abrasive wear might have affected them but as you can see that is not the case: 
SRNL-STI-2009-00183 REVISION 0

Attachment 2

John Crane Seal Analysis Report

6 of 8

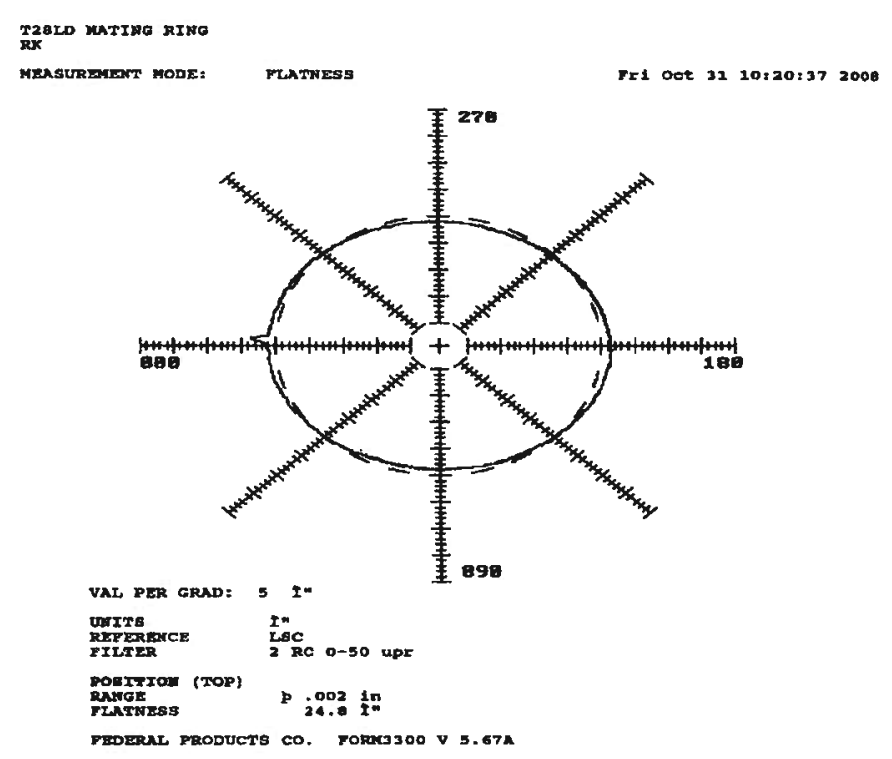

PEOQ.1929.max

There is little or no axial distortion. The radial trace shows the grooves are still within specification depth: 

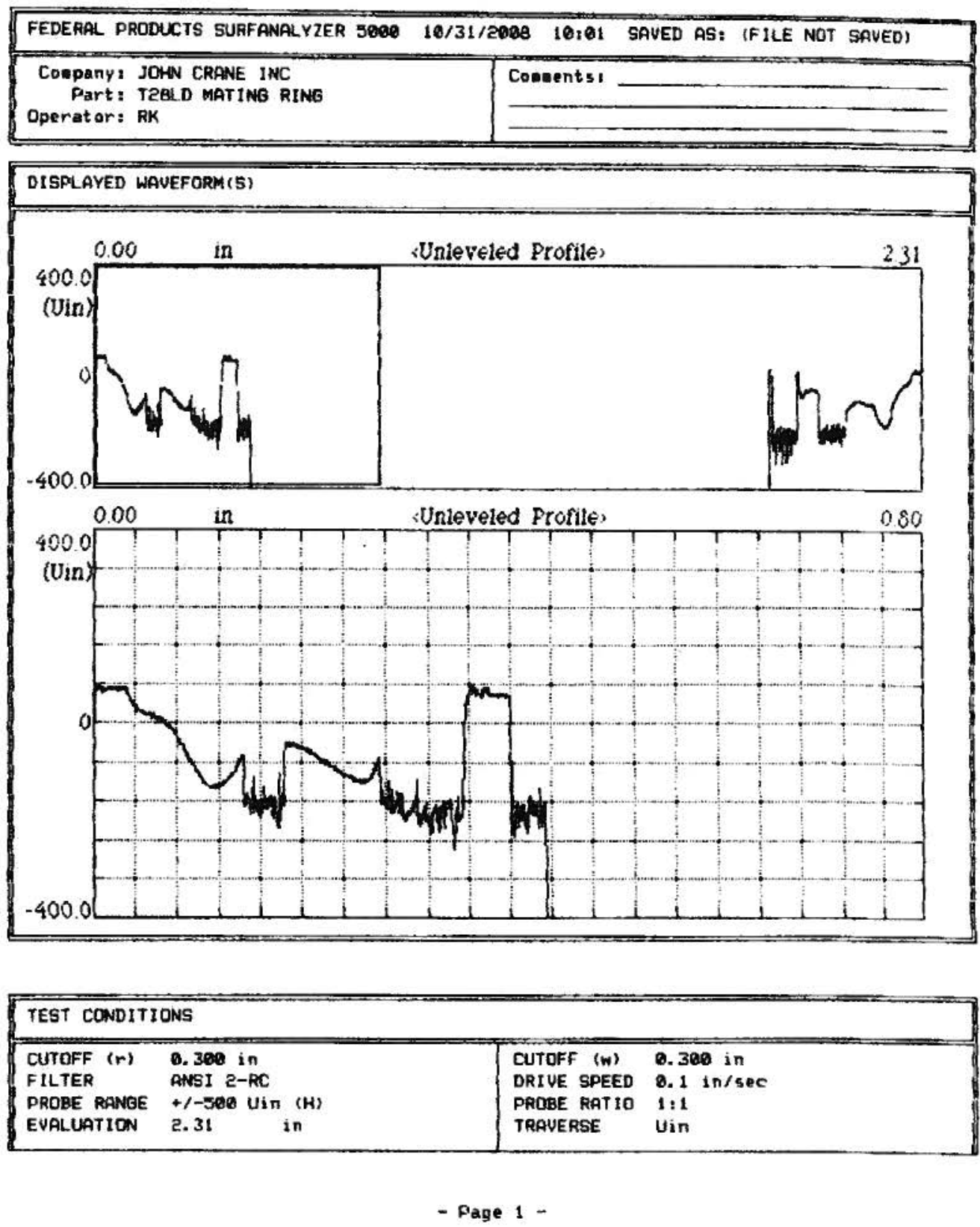

PE08-1929.max

Conclusions: It must be considered that during the normal run of the seal it will not be subject to disassembly in the same manner as testing. Each time a seal is disassembled the wear pattern 
is altered which has an enormous effect on the seals life. The in-service acid wash has had little or no effect on the seal and in fact probably helps. It is the conclusion of all that have viewed this seal that the blistering is most probably an anomaly that may be from an unknown contaminant possibly "Pipe Dope". Capillary action would tend to drawn this in and the exaggerated high spot could have contributed to the amount of blister.

The vibration is more of a concern at this point and it is highly recommended that we continue to monitor the wear to observe if that has decreased. We have observed that many improvements in the bracing have been done since the start of this test and the next seal we hope will reveal an improvement in wear. Since we have a format by which to judge, any further tracings that are needed will be done in a much speedier manner. 


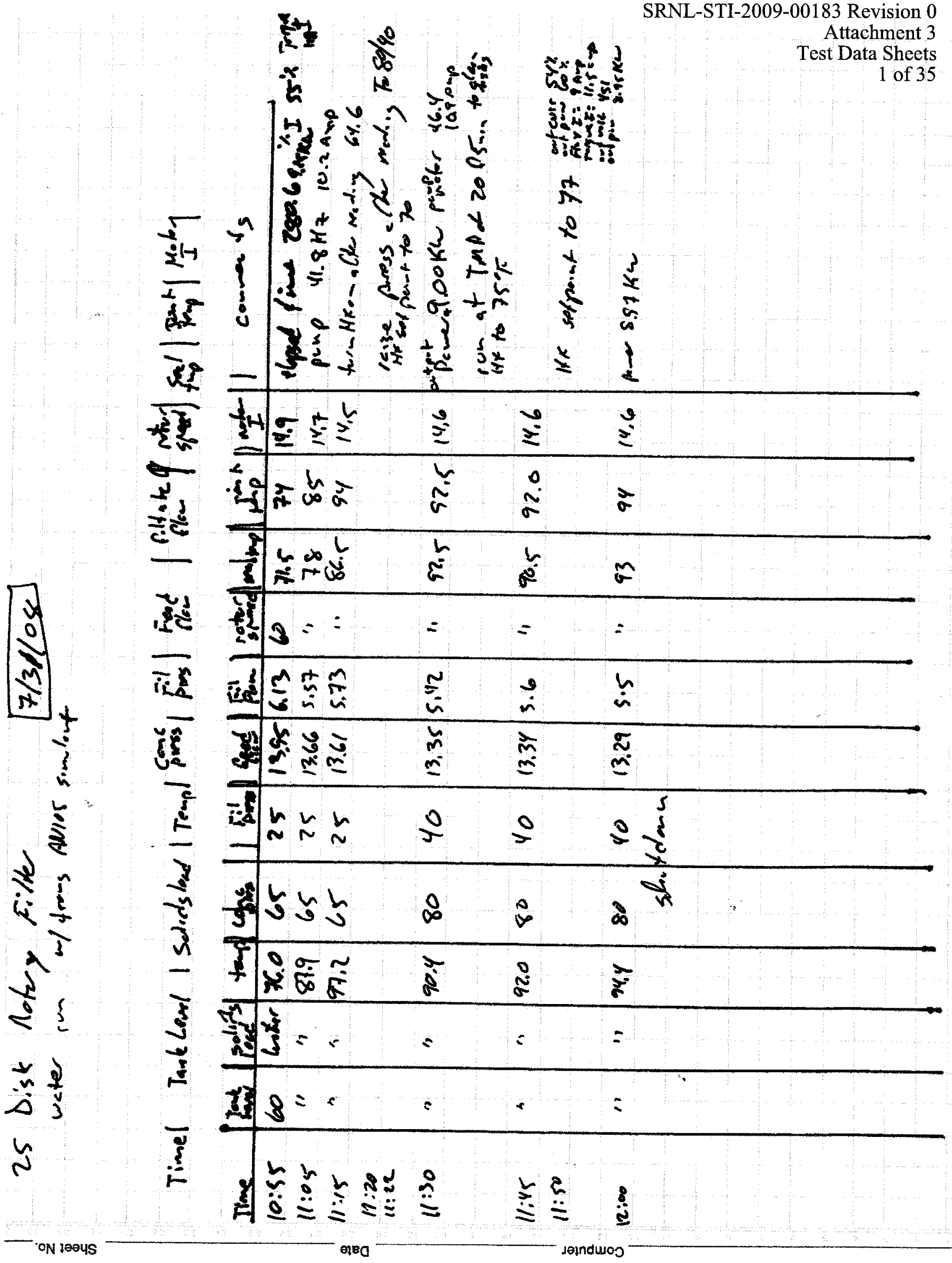

Attachment 3

Test Data Sheets

1 of 35

sys 

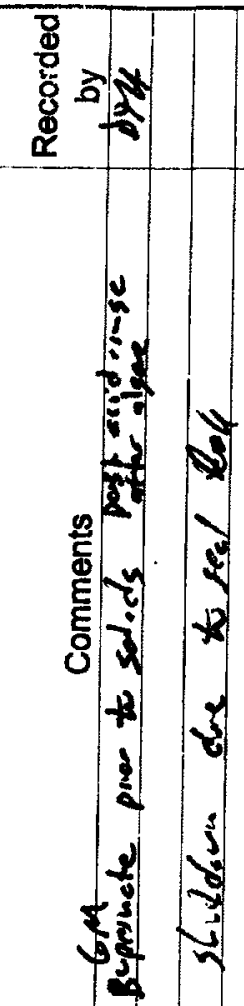

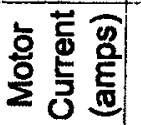

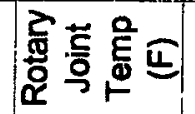

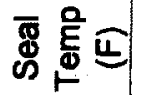

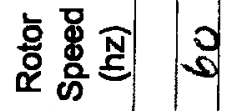

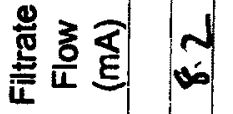

退亭 $\overline{\mathrm{E}}$

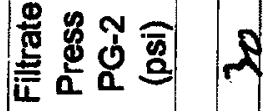

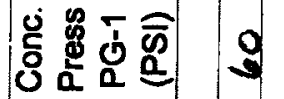

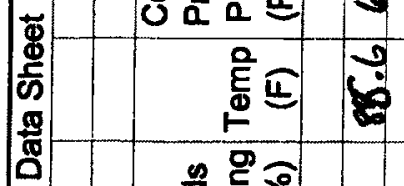

혀 응 응

政

.

- 8900

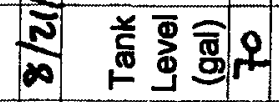

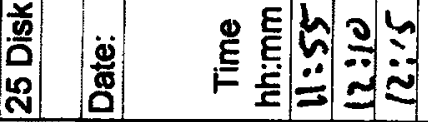




\section{Ho \\ SRNL-STI-2009-00183 Revision 0 \\ Aftachment 3 \\ Test Data Sheets}

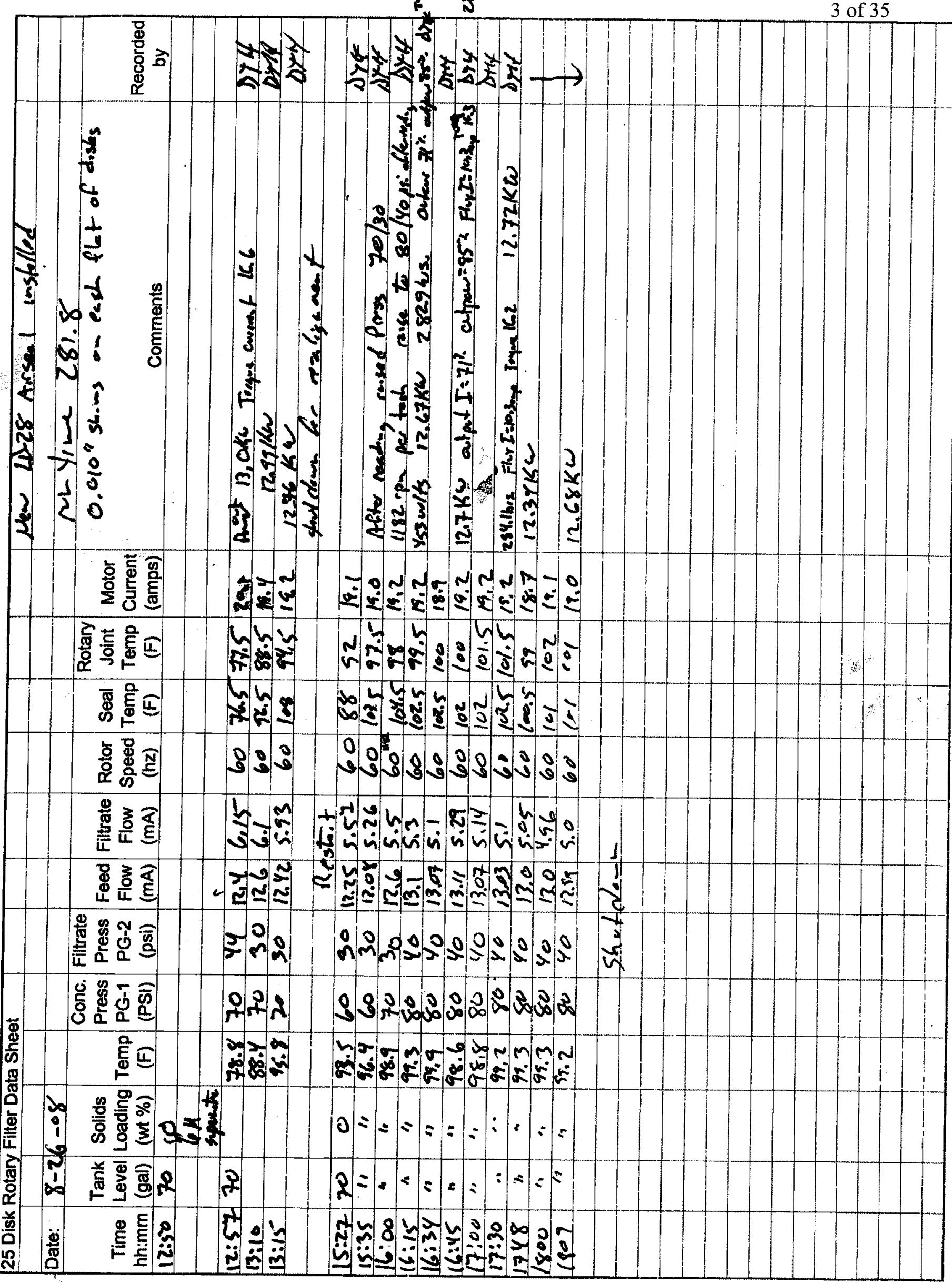




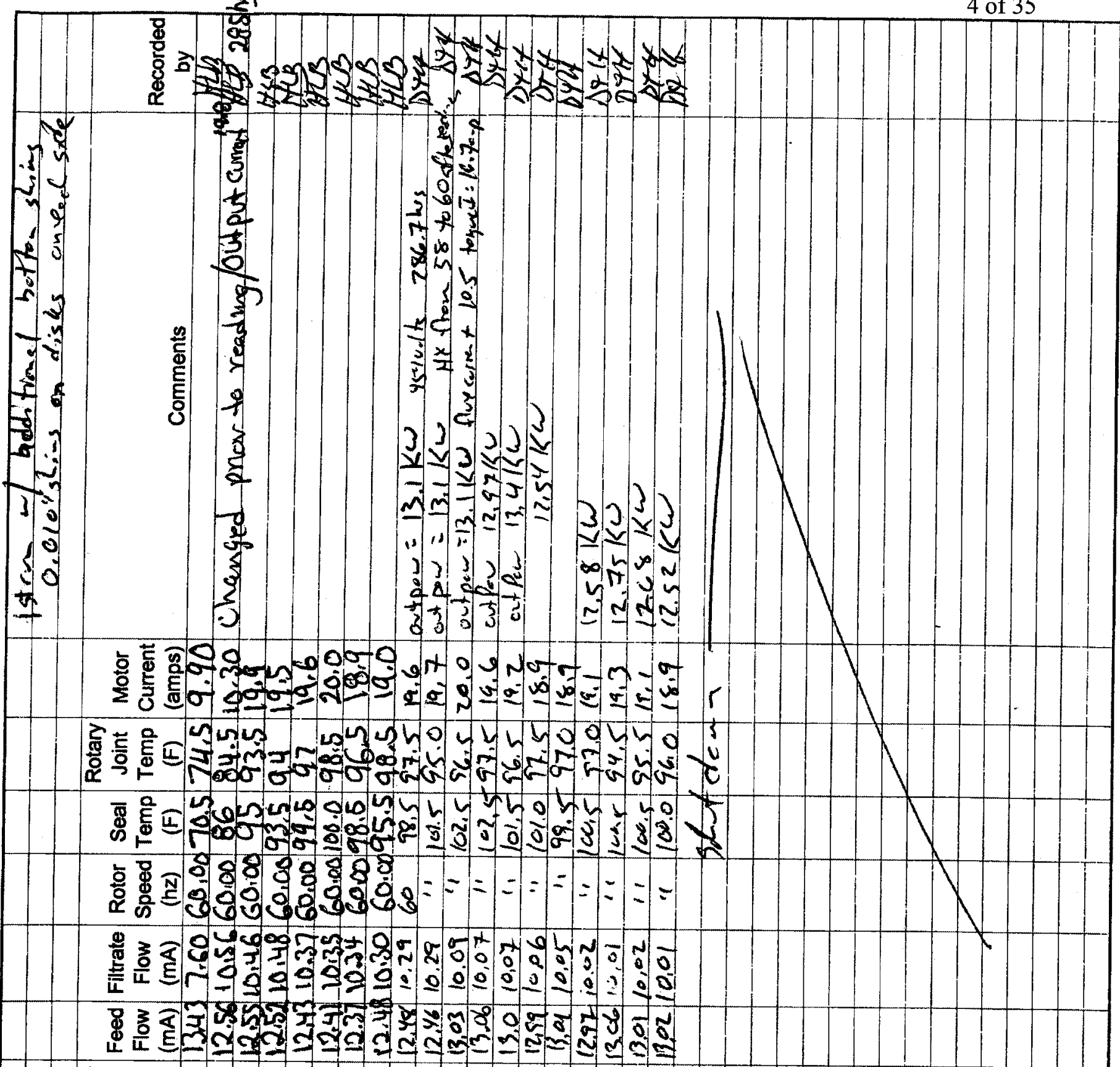

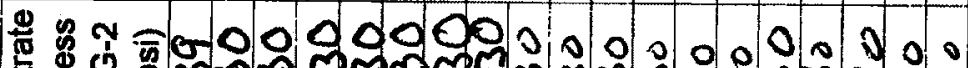

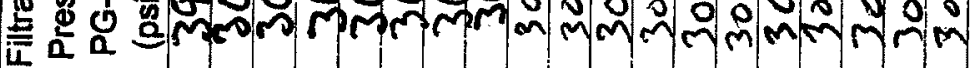

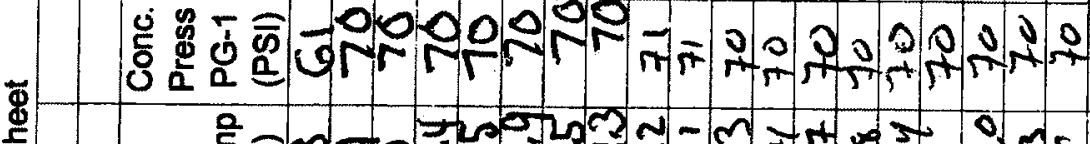

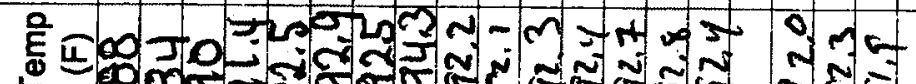

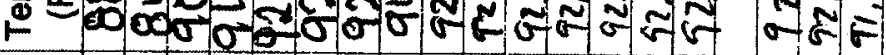

음응. $0<-x$

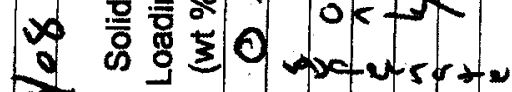

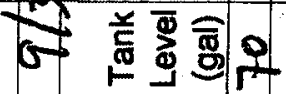

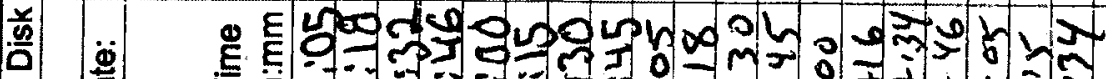

造 F 


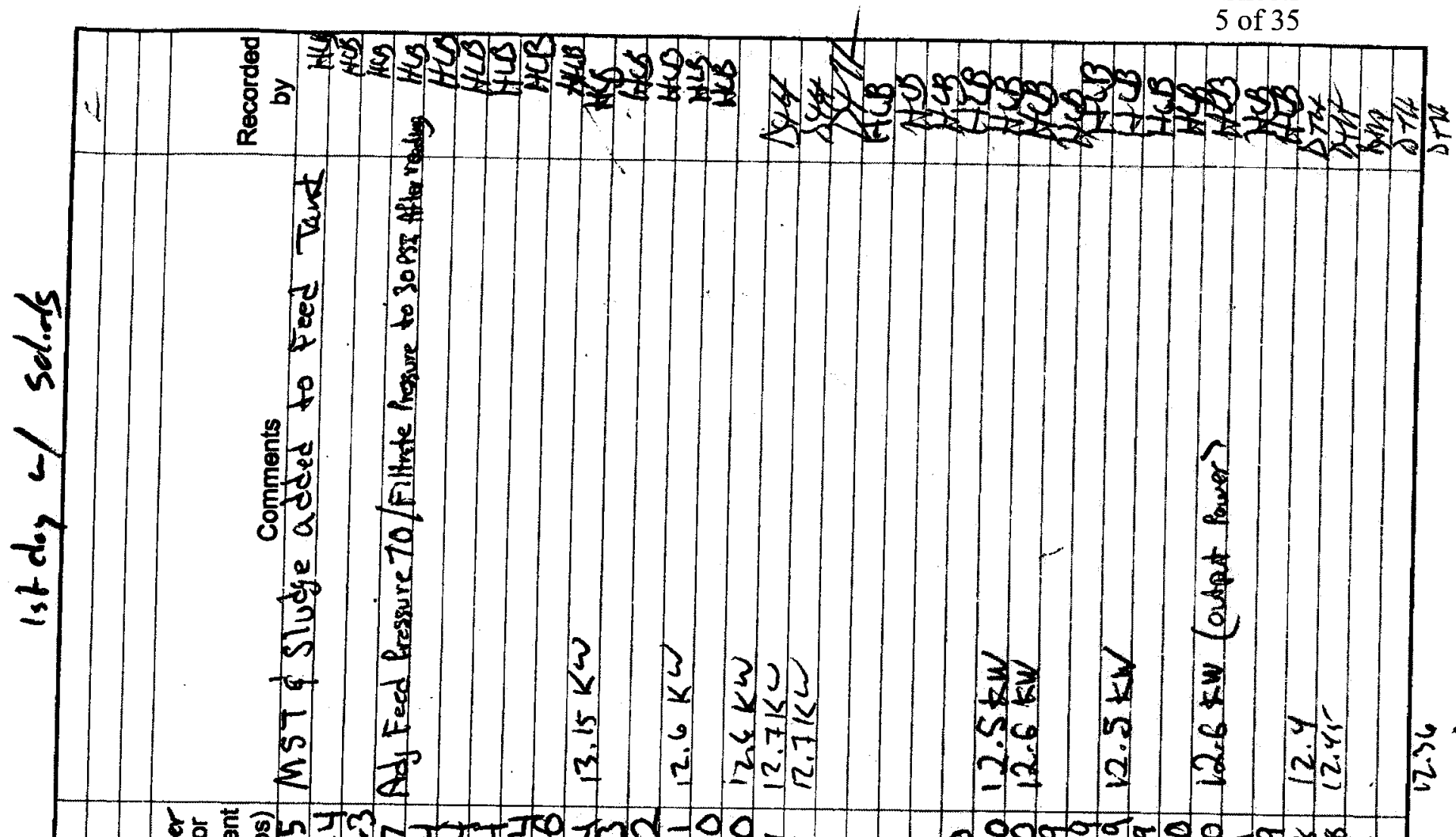

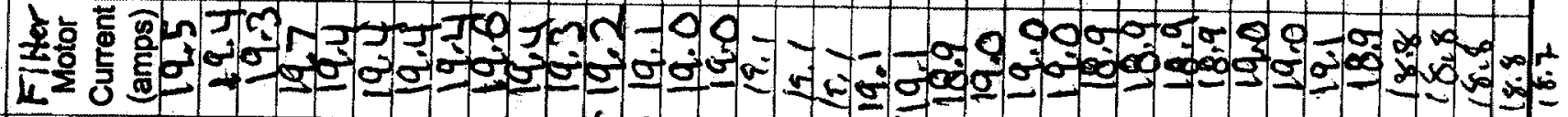
贾 है

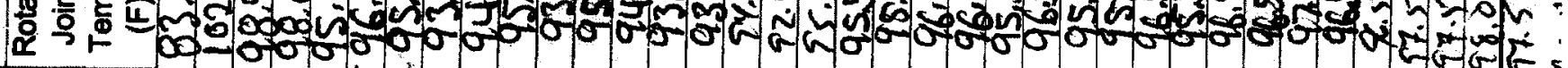

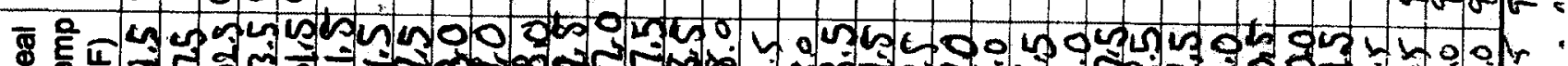

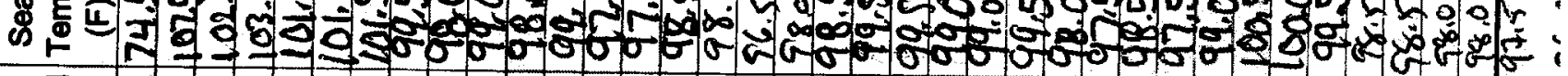

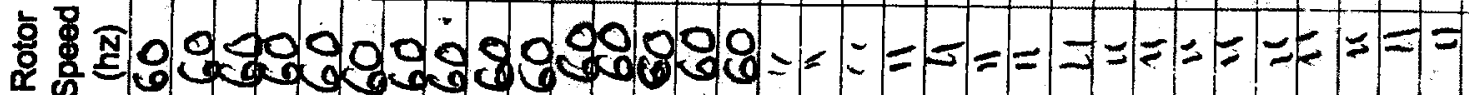
"

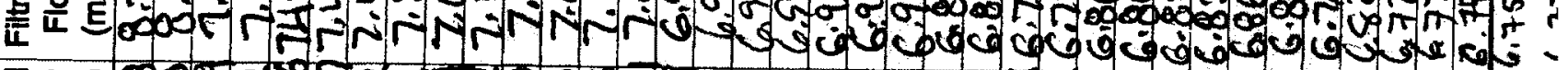
४ 3 री

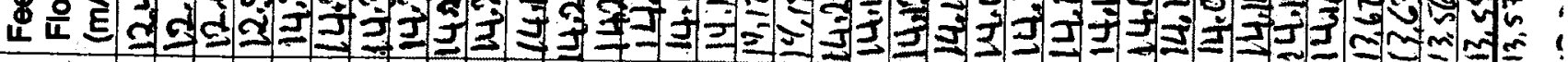

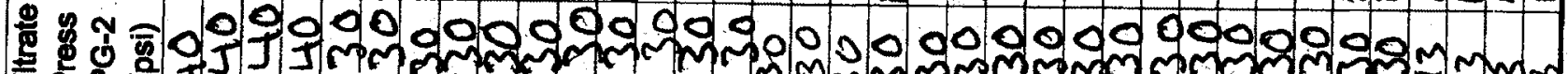

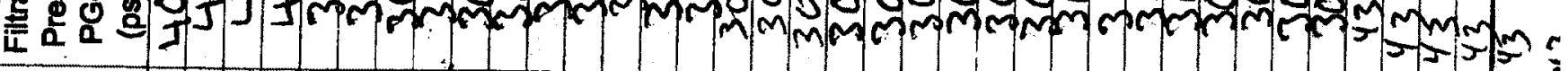

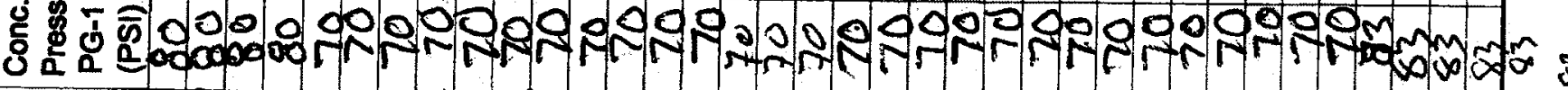

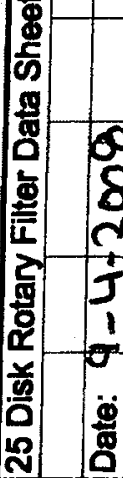

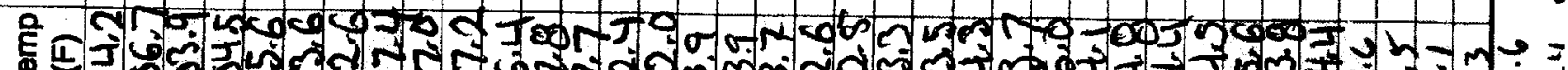

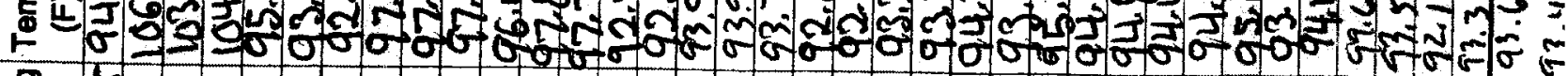
옹

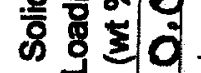

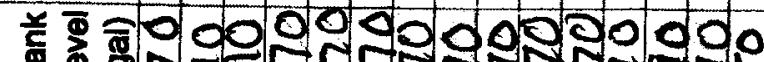

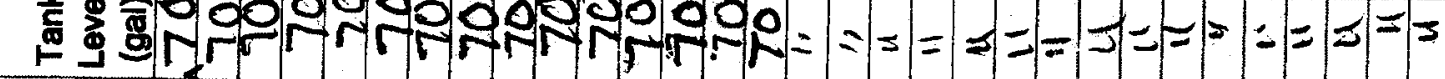

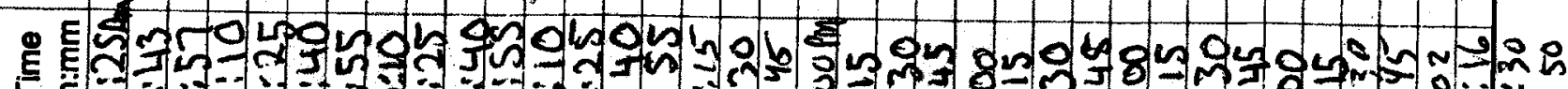
$\checkmark$ cod is. 


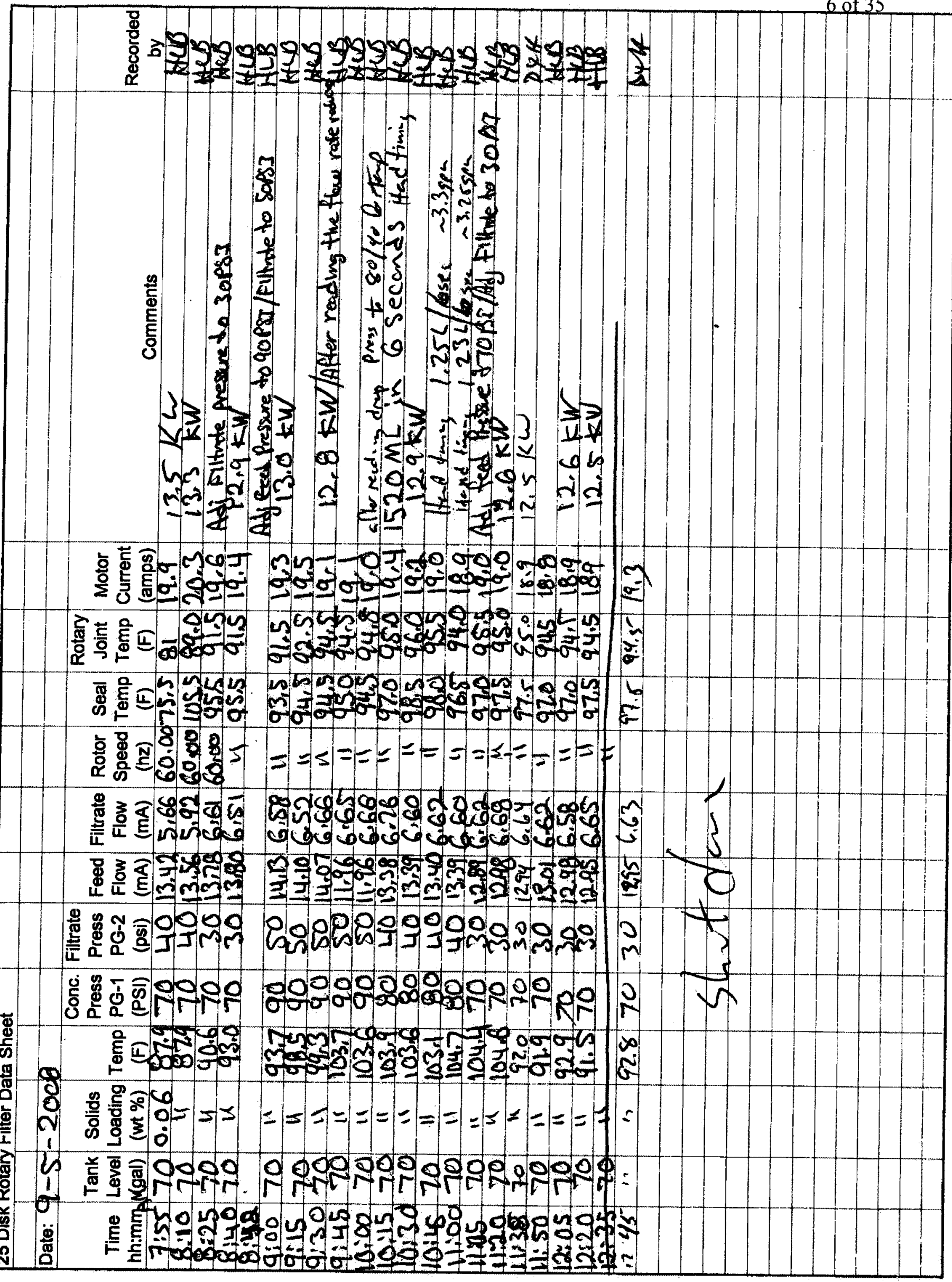



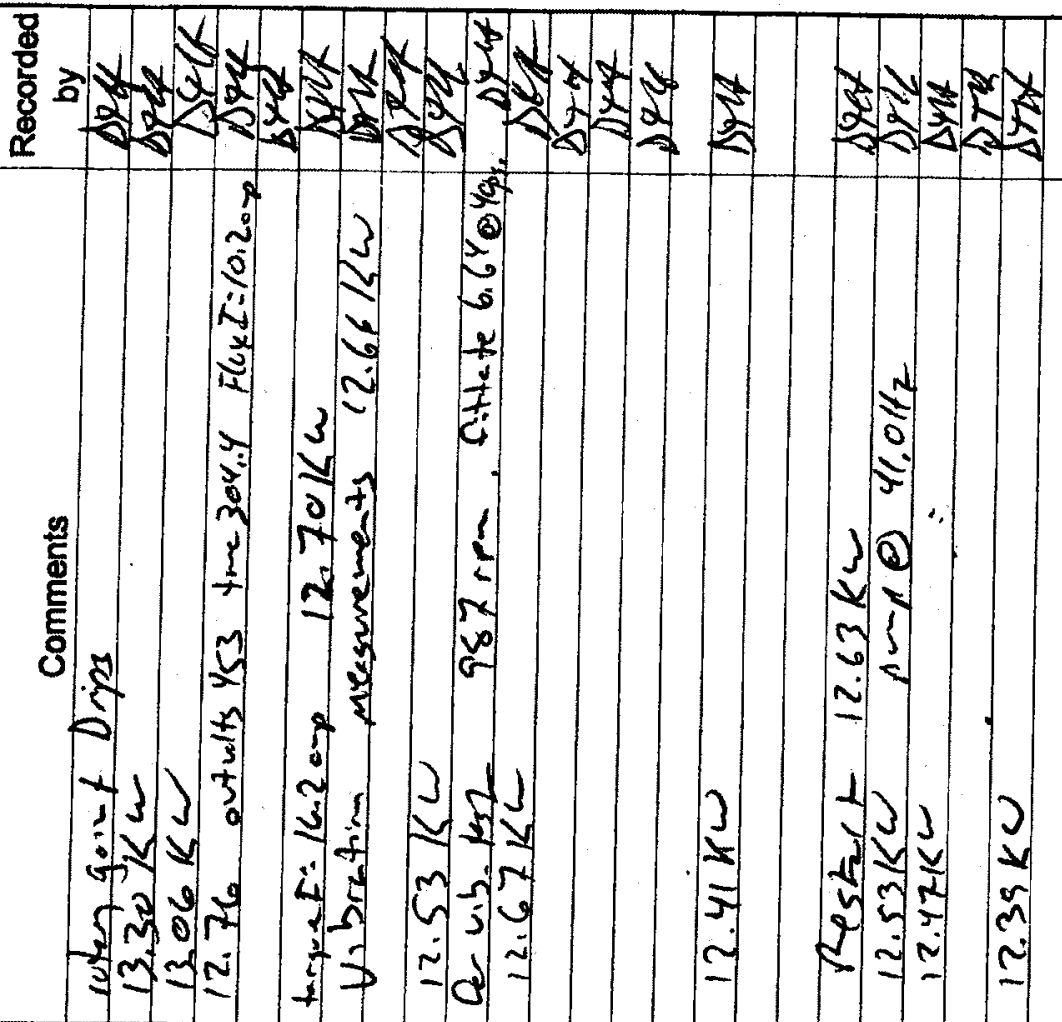

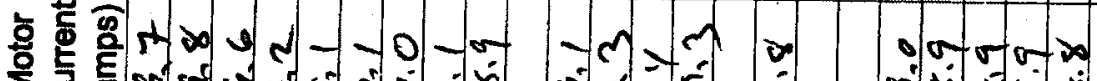

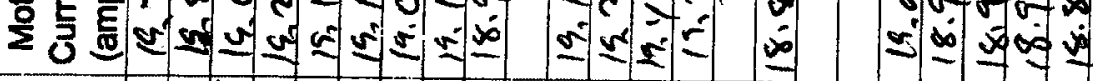

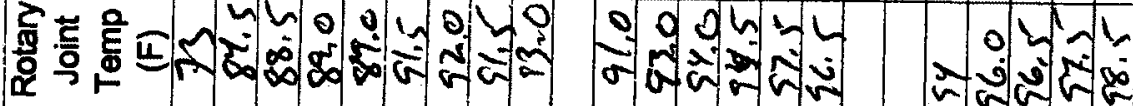

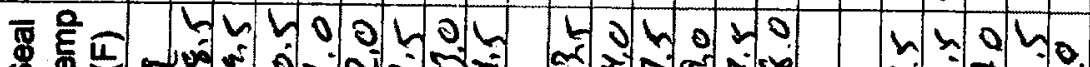

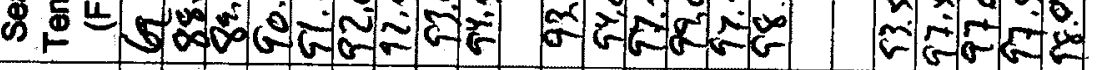

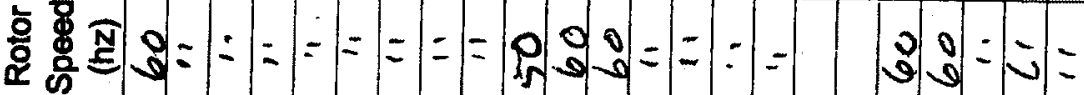

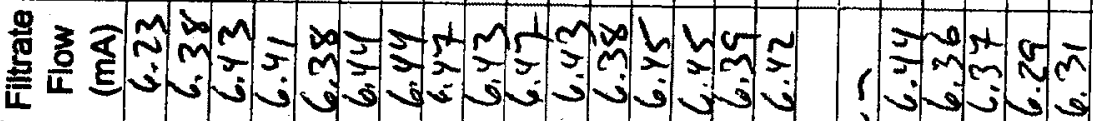

\$

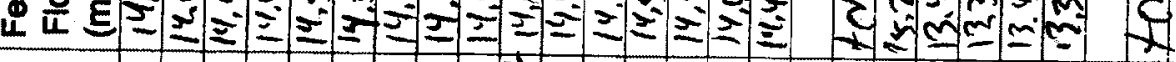

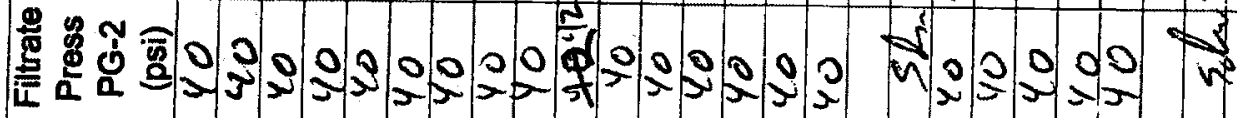

造安

\$̆

है-

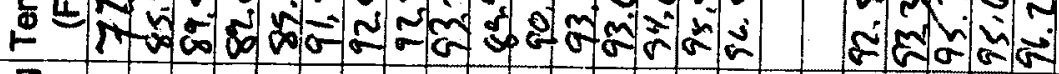

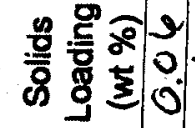

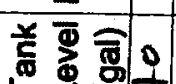

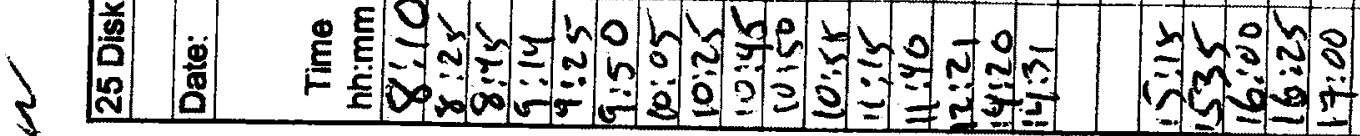




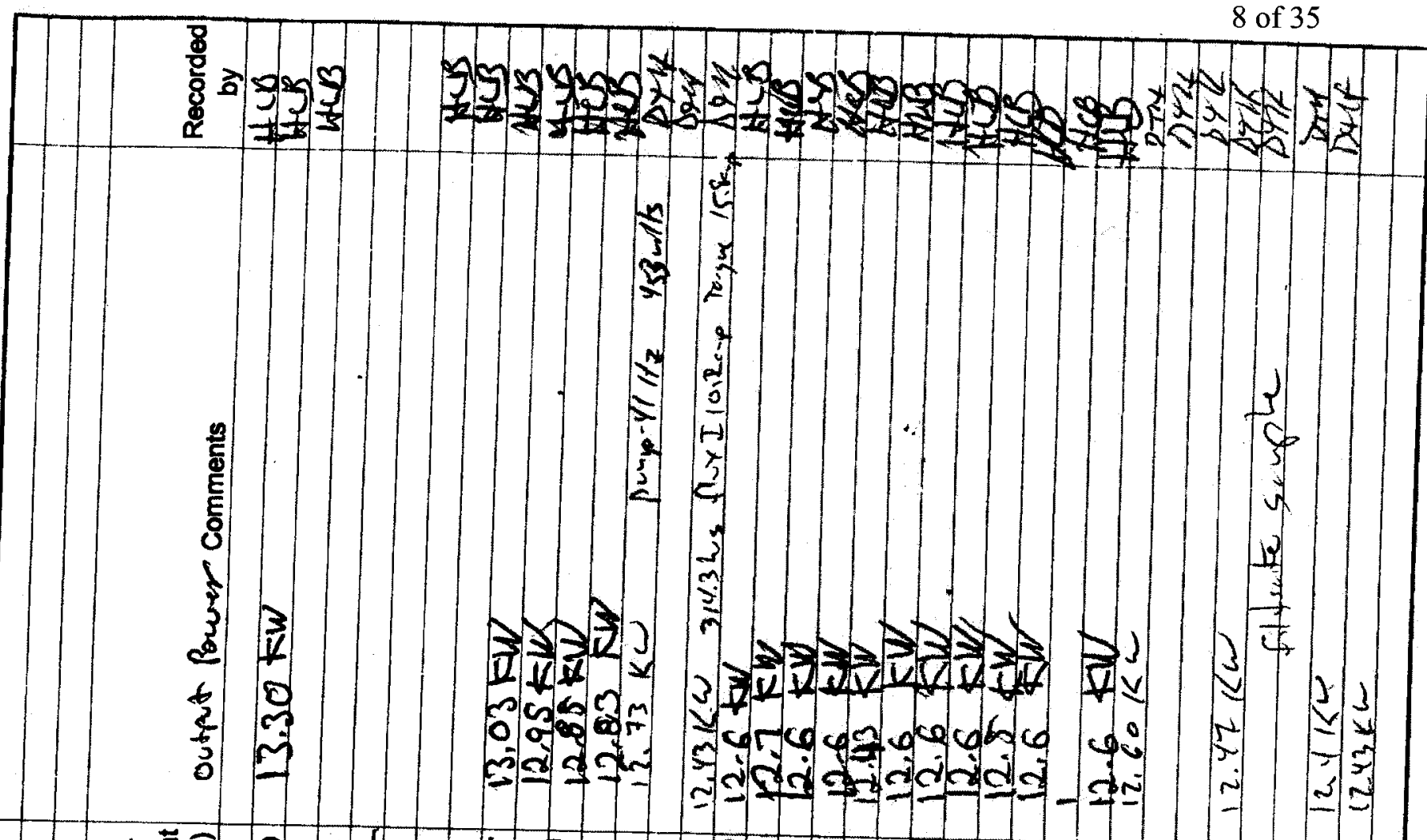

흘

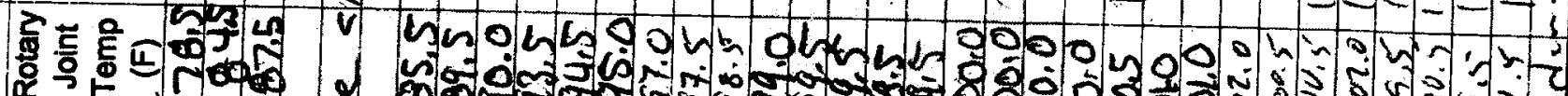

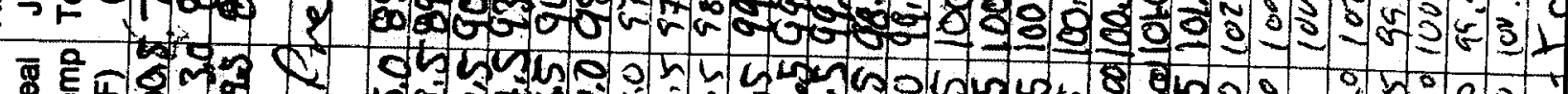

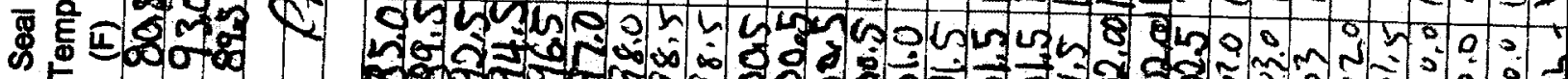

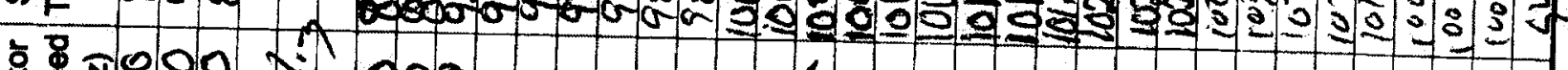

\&

产

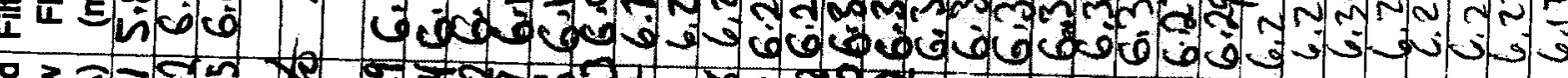
क्ष

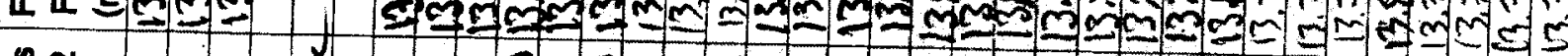

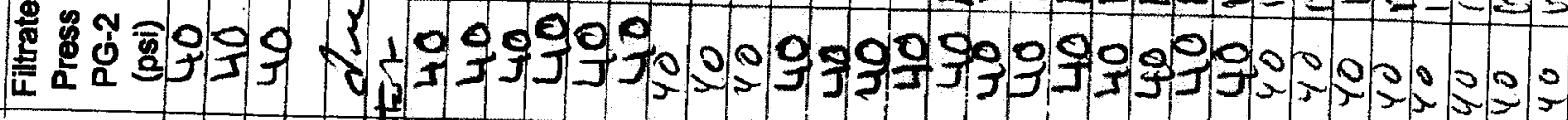

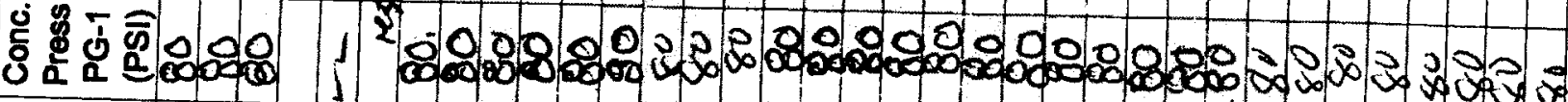

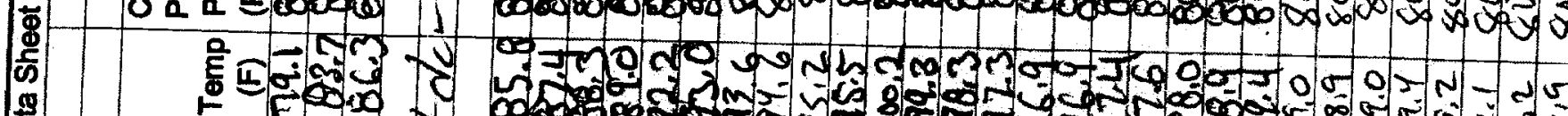

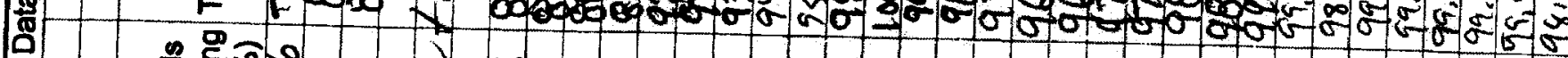
竞 : ज

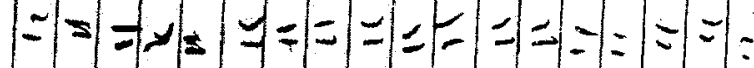
is 5000000 of 


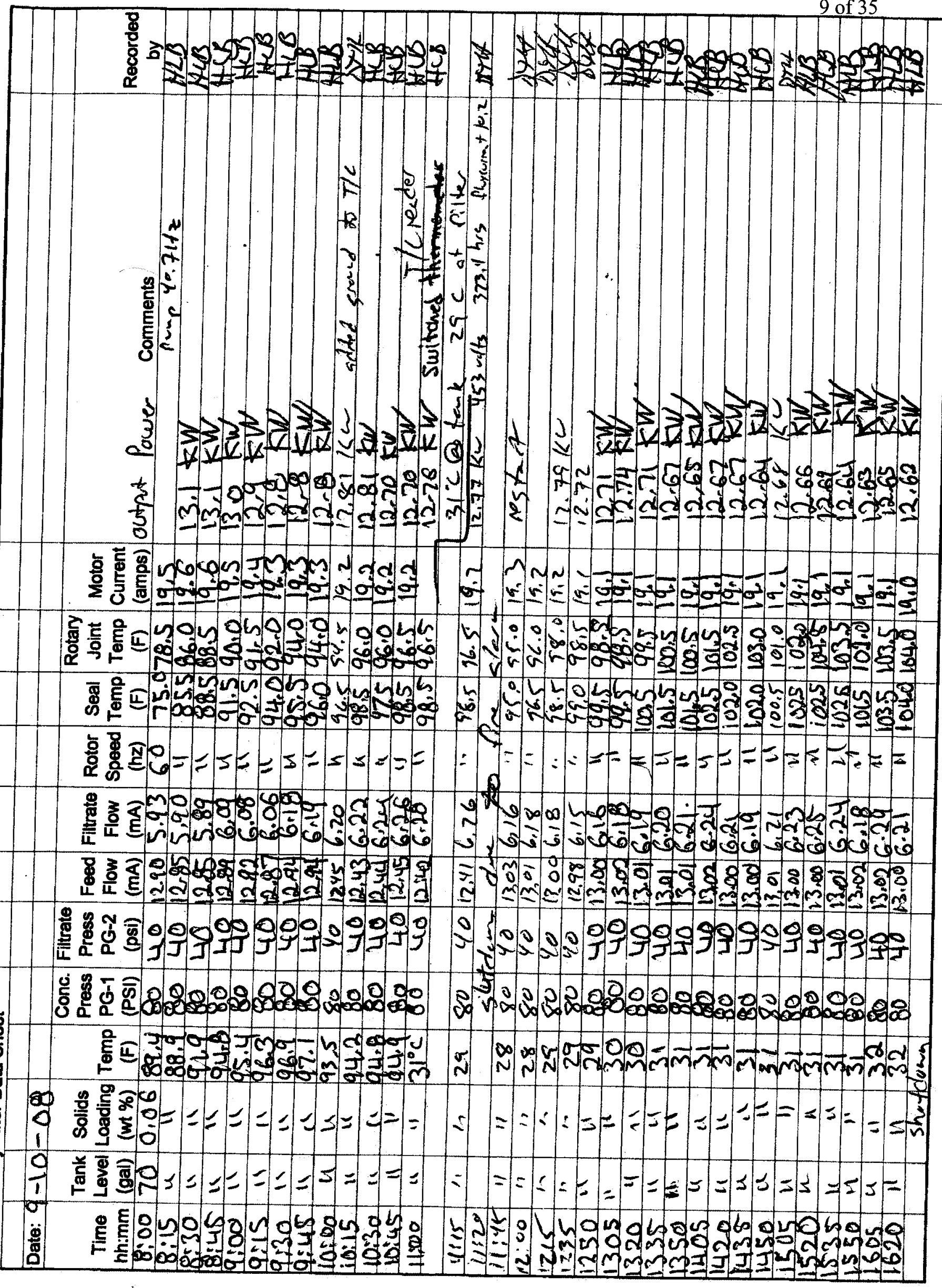




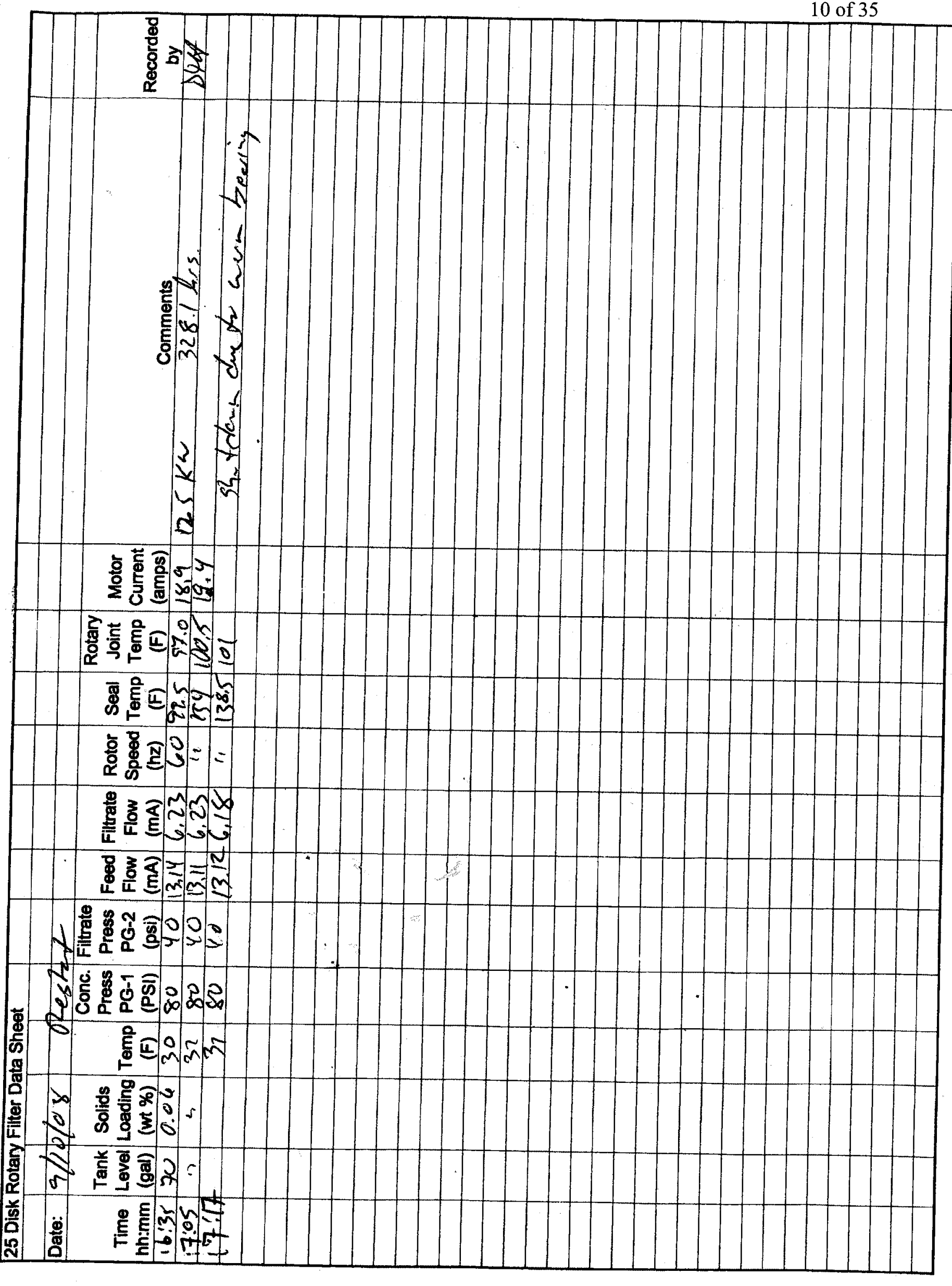




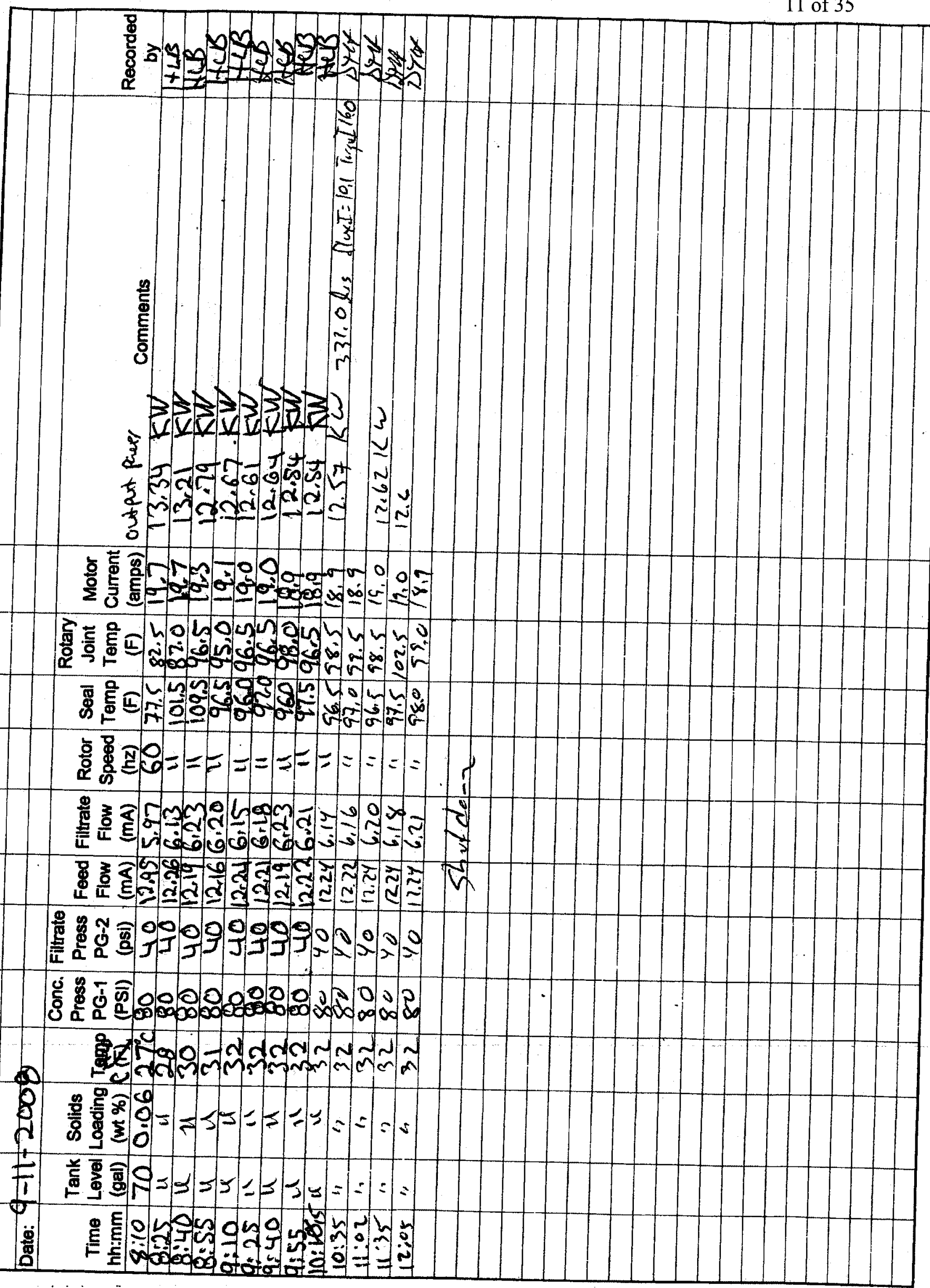




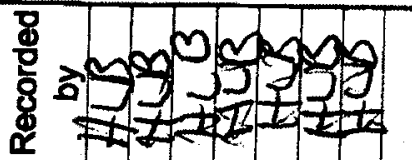

\section{0}

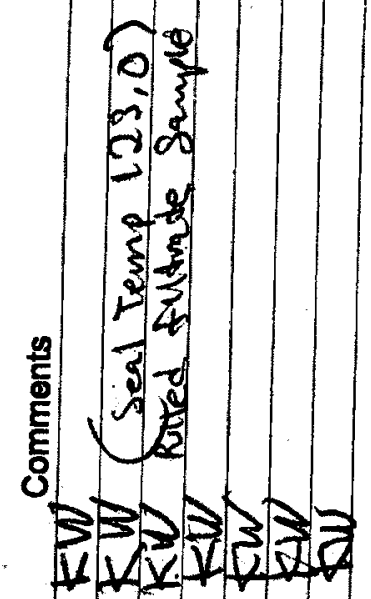

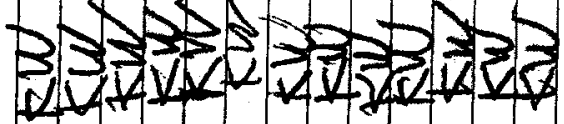

5 tsot dobe S. I r क o o 9

zon $\sin ^{2} d$

mascos

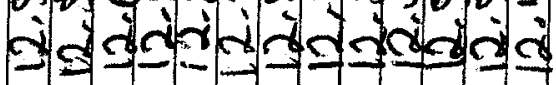

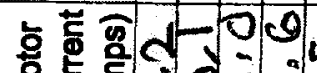

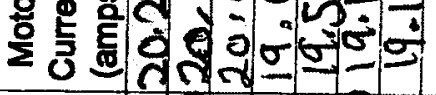

츨 을

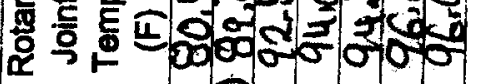

oj goto o o jo ojo

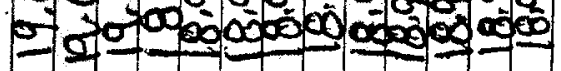

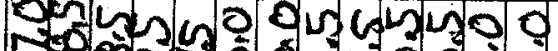

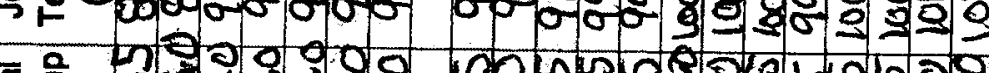

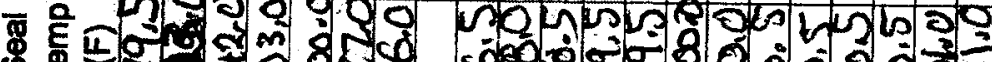

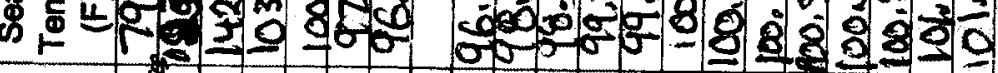

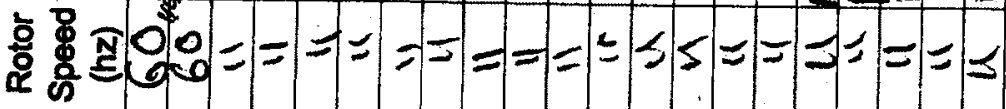

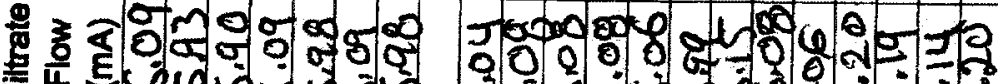

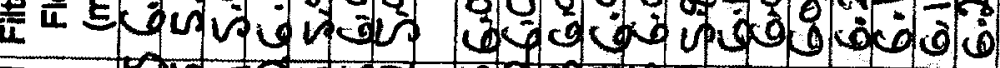

\&

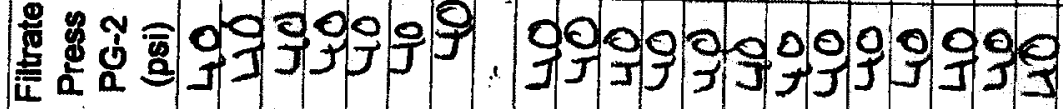

$\$$

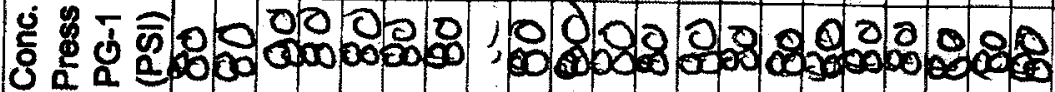

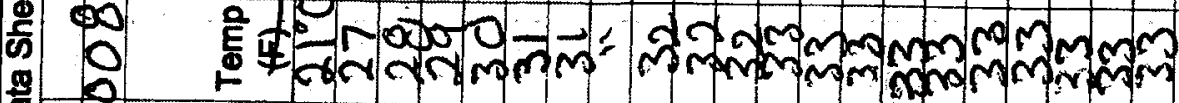

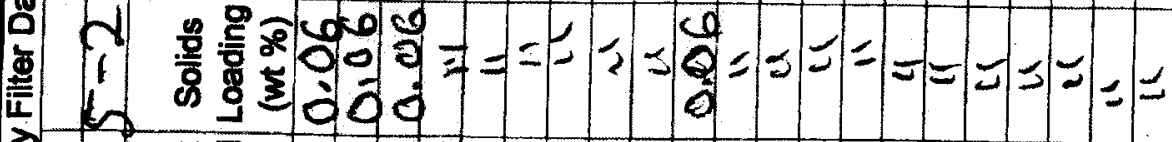

解

.

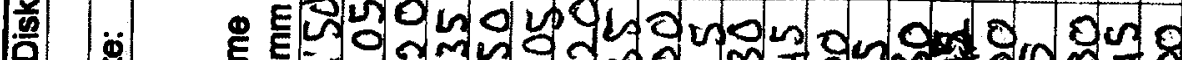




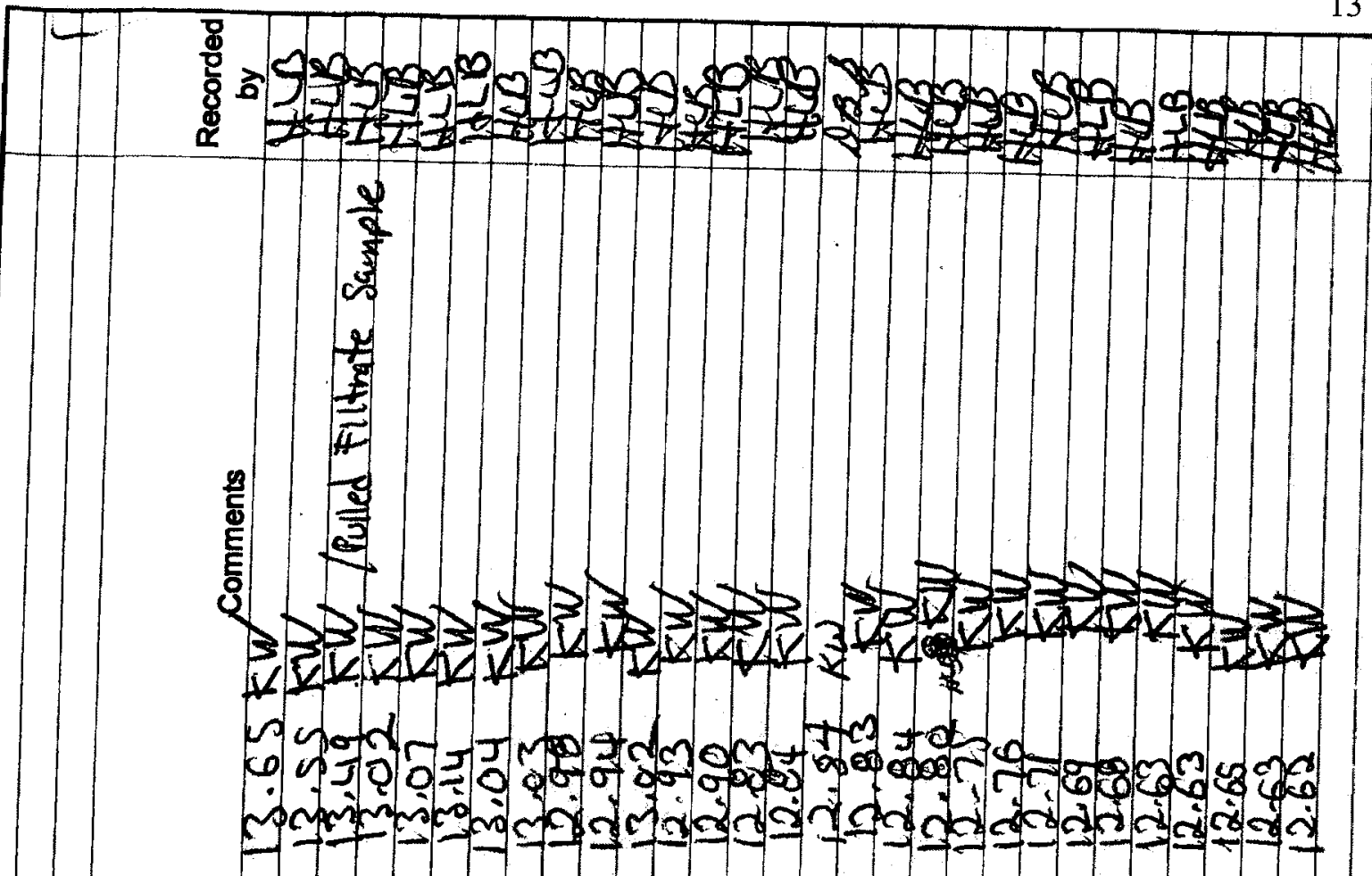

之े ¿्ञ ¿

I E 4.

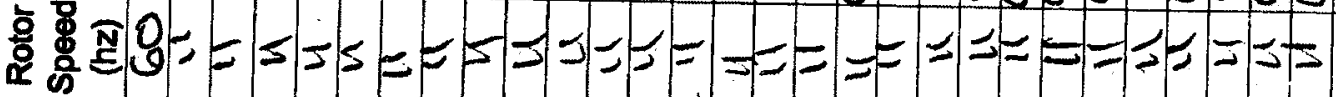

E

\& ₹

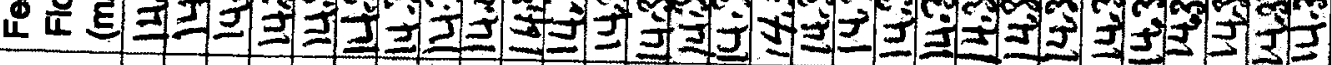

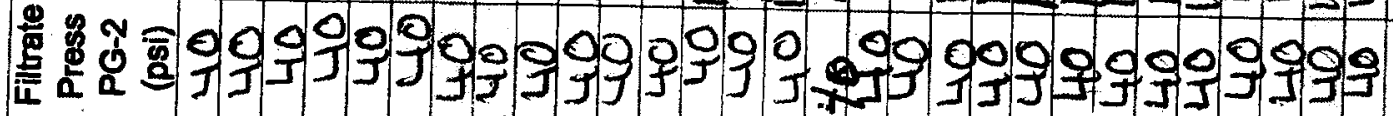

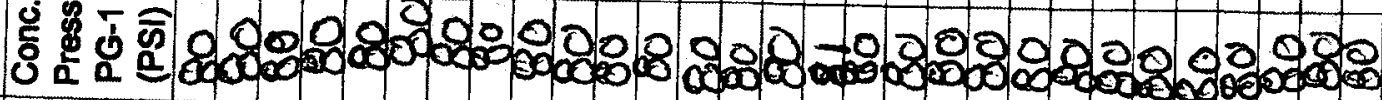

$\bar{\Phi}$

क) E

8

옹

o

$\frac{1}{1}$

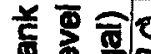

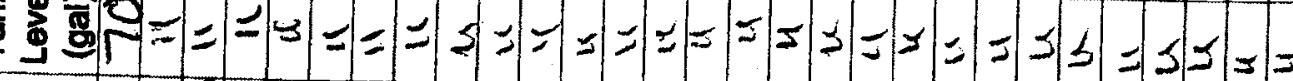




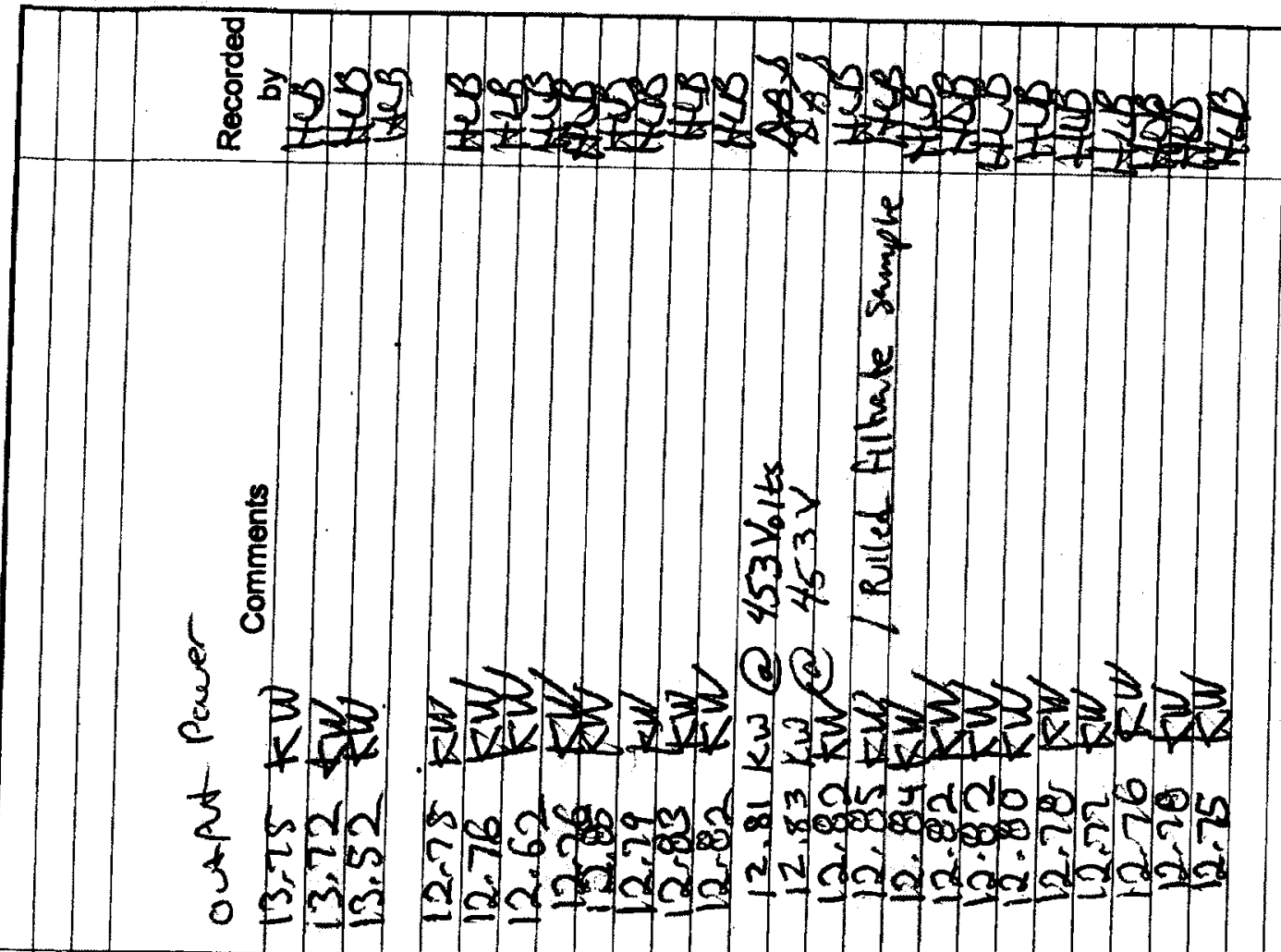

है

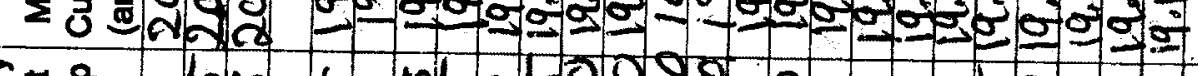

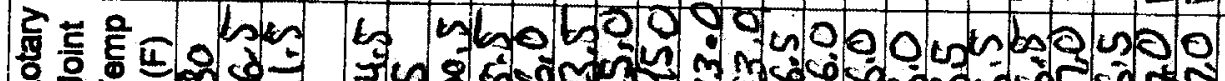
Q

区 है 1 in \& E

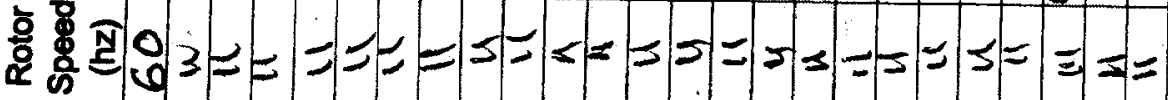

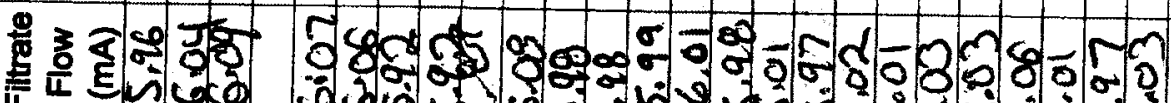

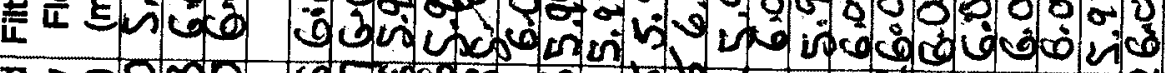

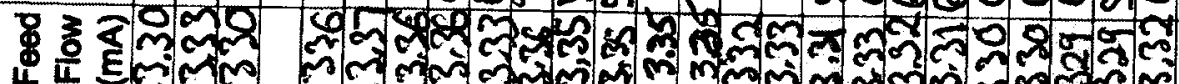

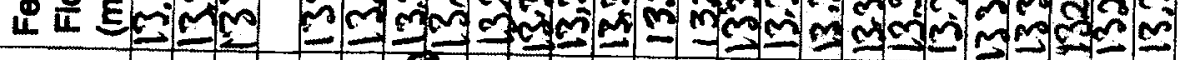

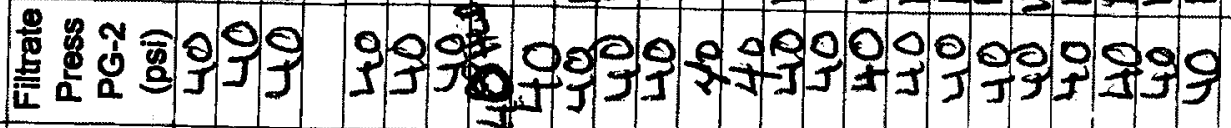

$\check{\Phi}$

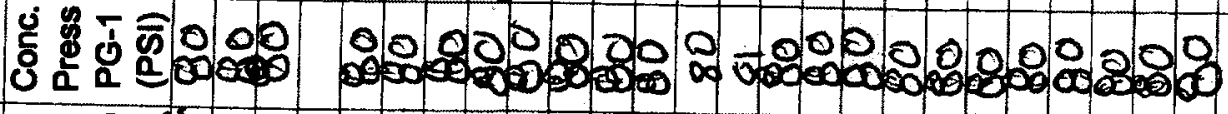

वUं

8

옹응

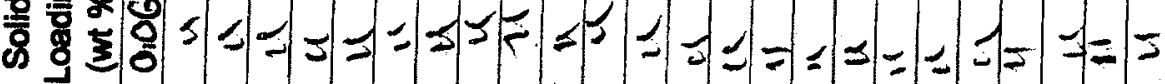

2

更

-

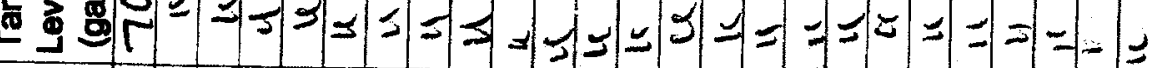




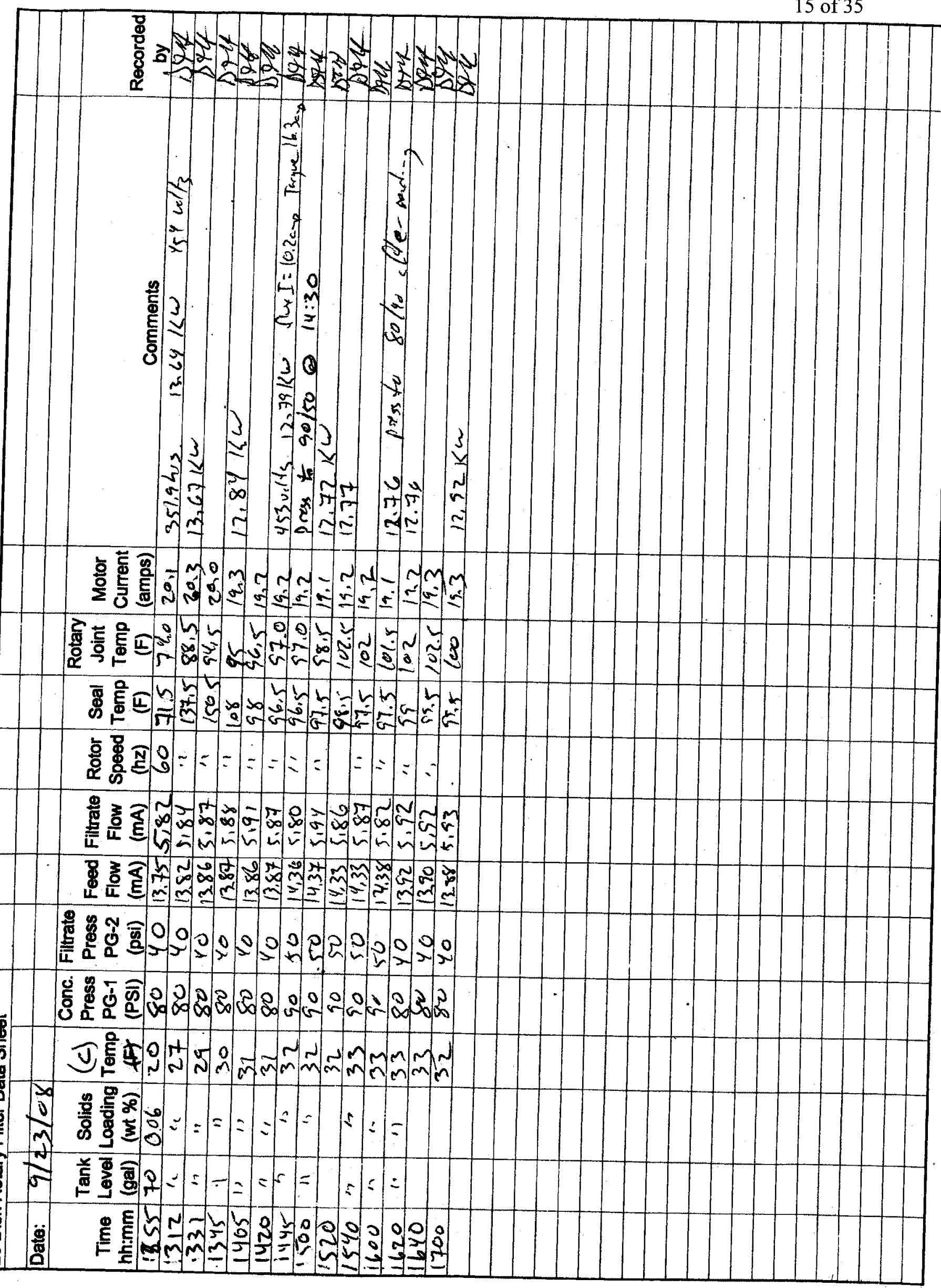




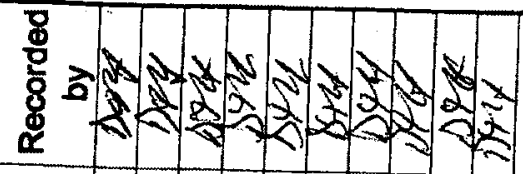

Fo 20 *
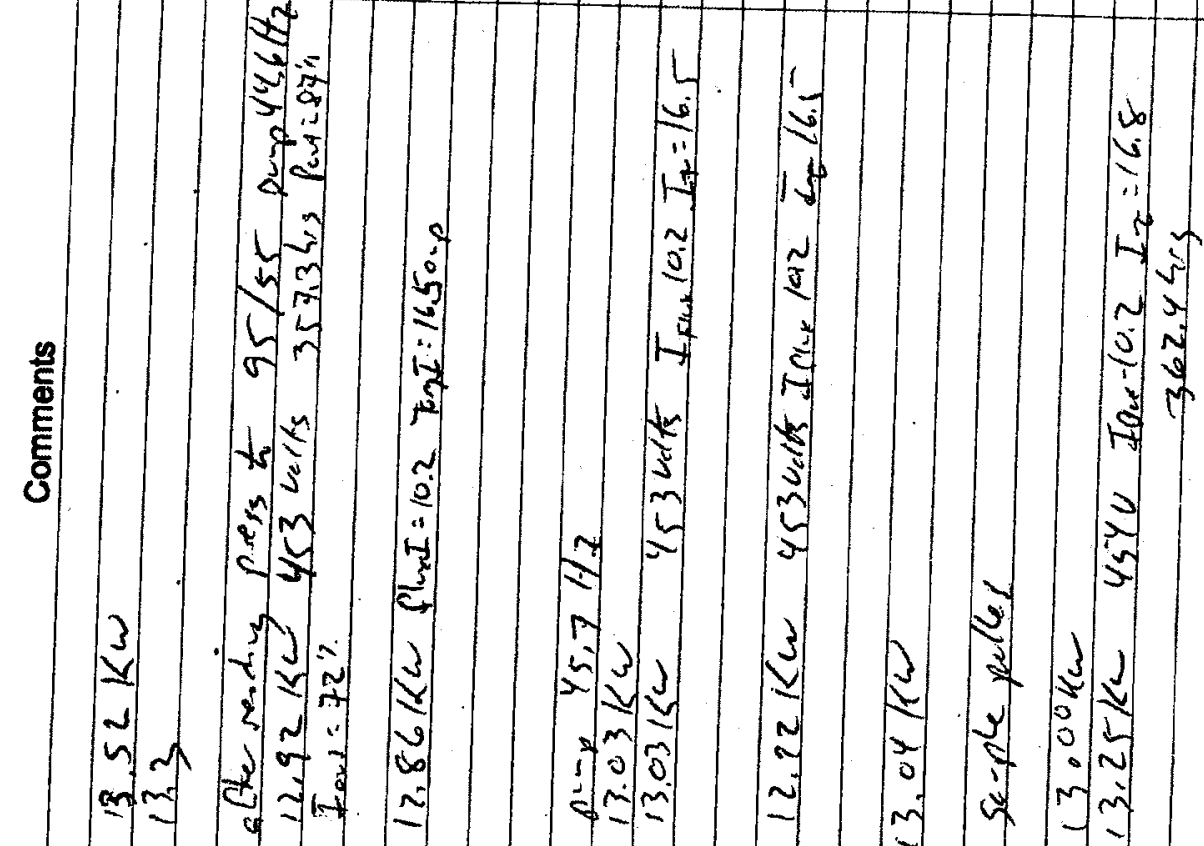

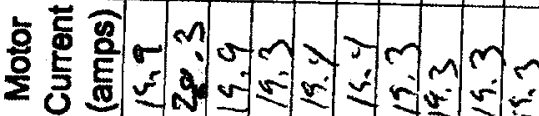

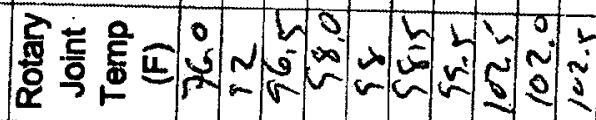

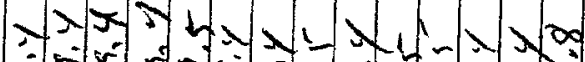

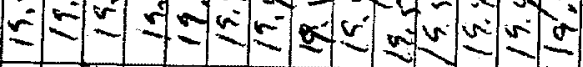

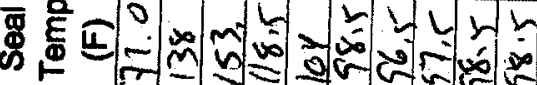

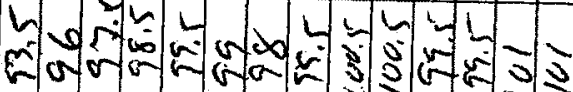

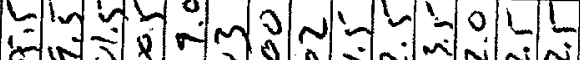

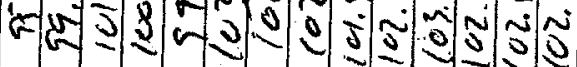

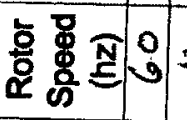

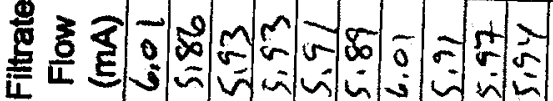

要言

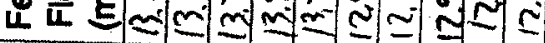

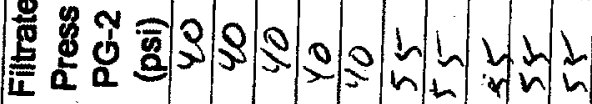

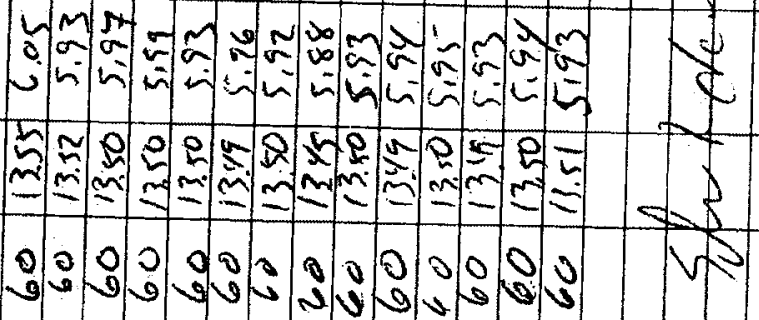

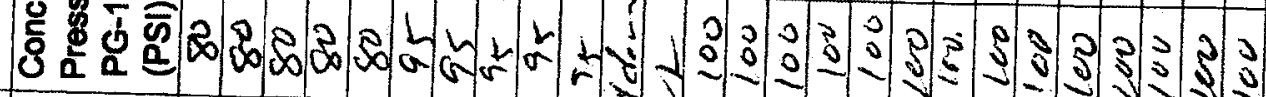

E्ञ

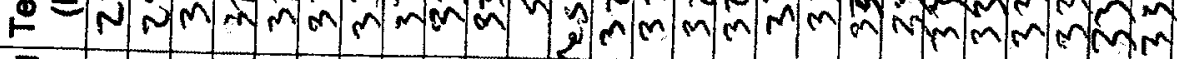

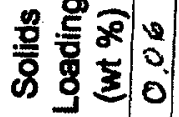




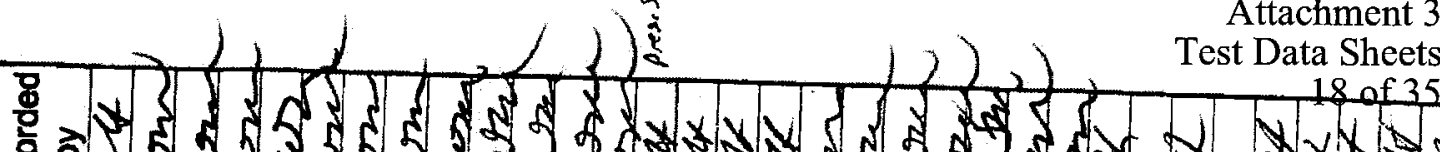

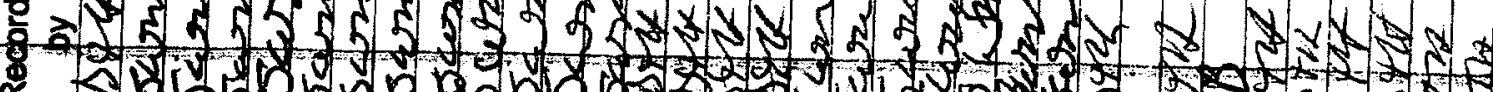

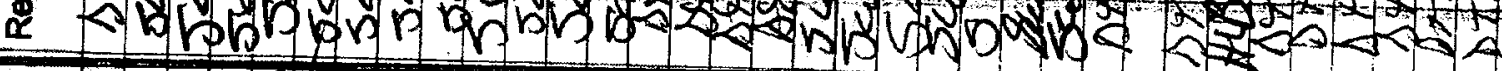

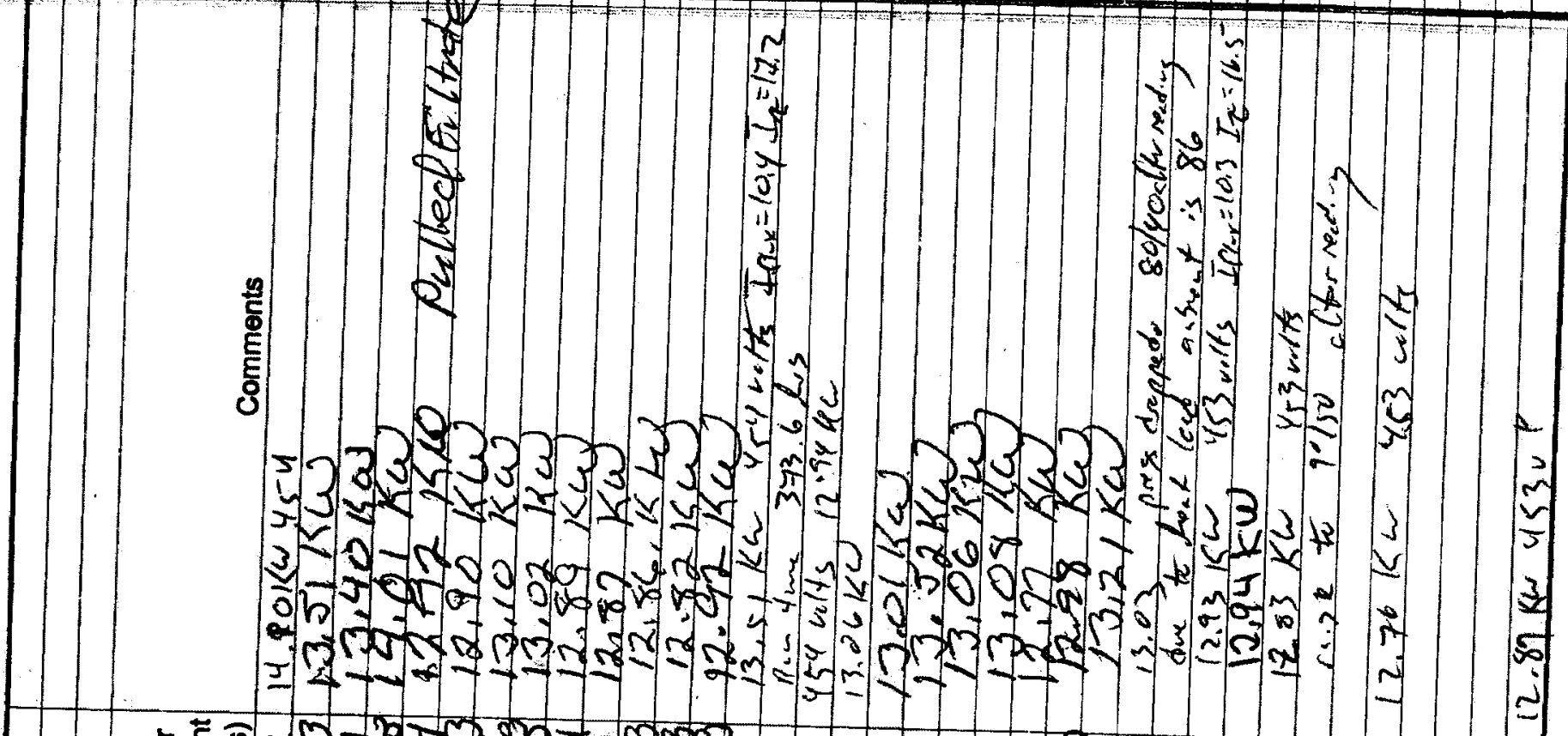

5.

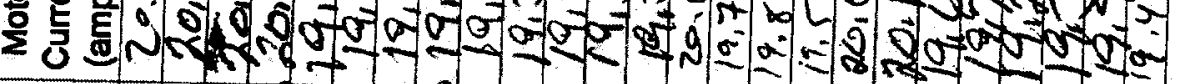

Ẽ

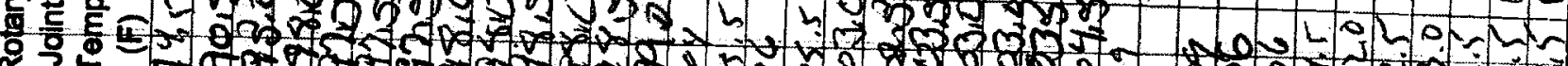
¿

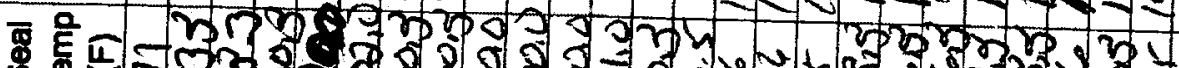

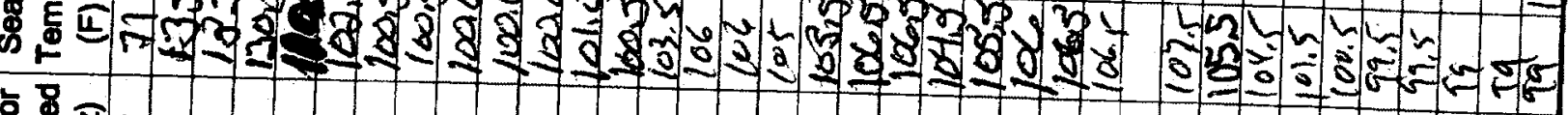

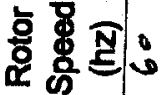

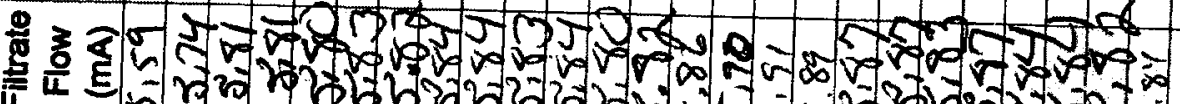

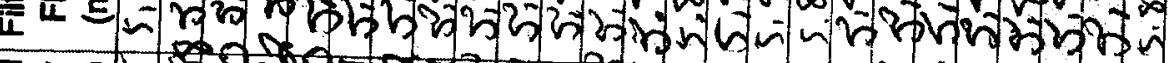

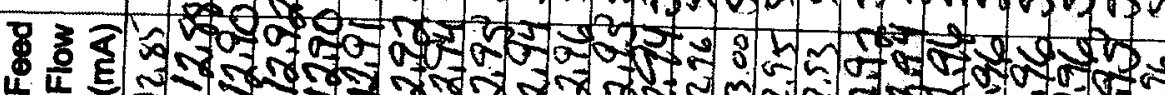

$\rightarrow=00 \rightarrow$ in $N$ F

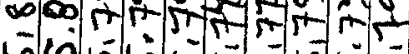

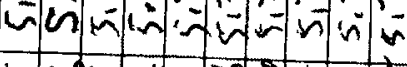
L

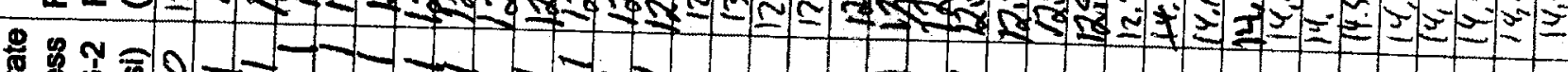

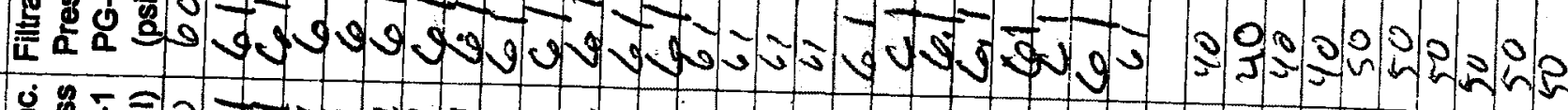

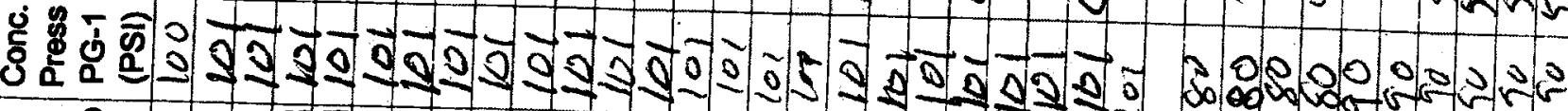
EE

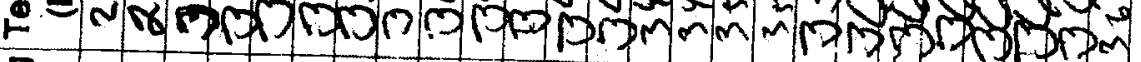

要

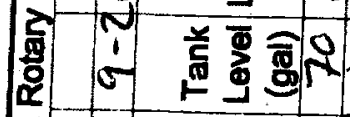

: E En 


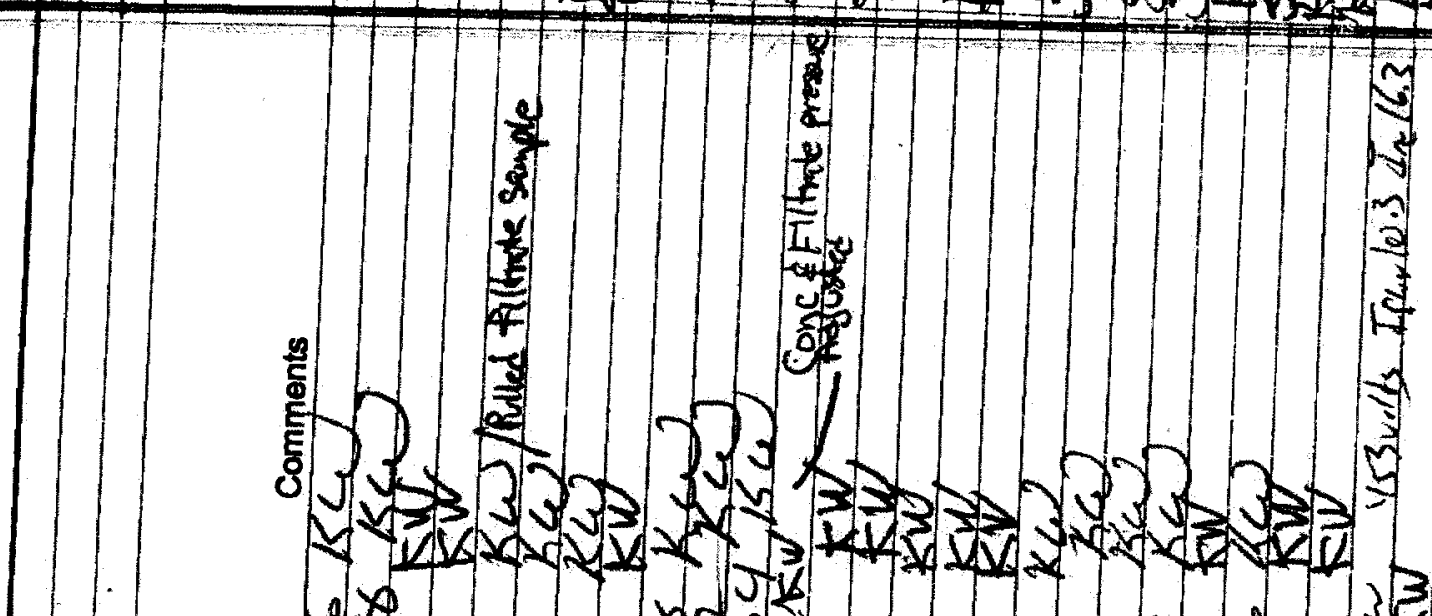

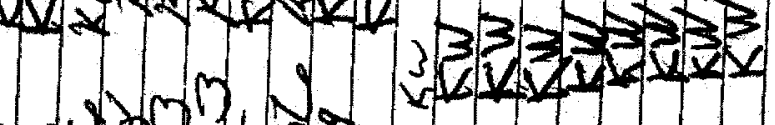
MJ 2 - w

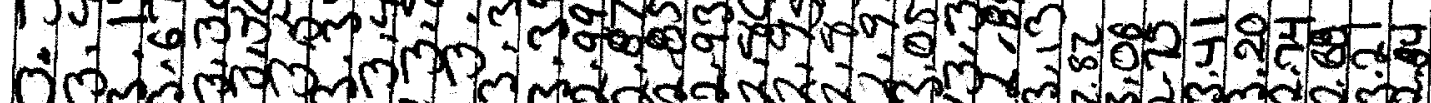

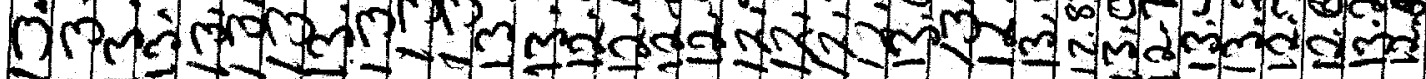

능

¿

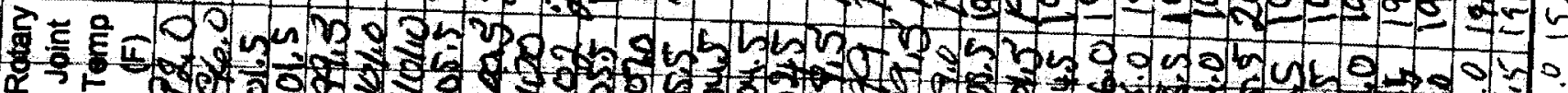

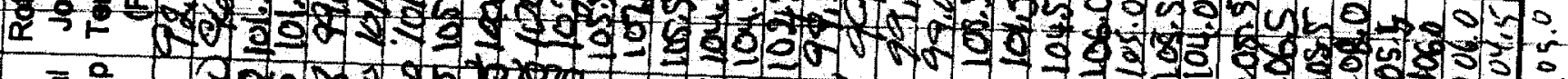
\% है I

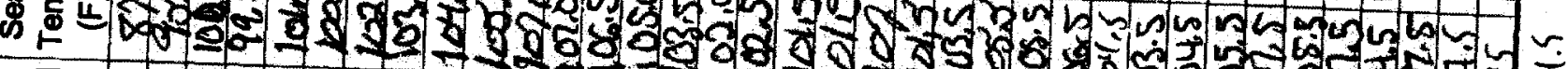
总要

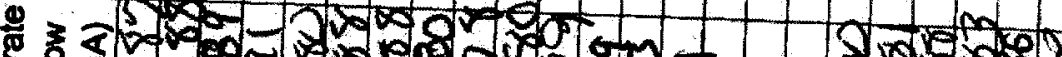
E

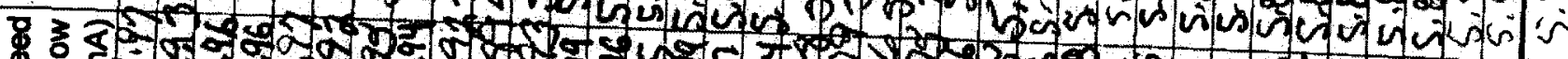
फ 는

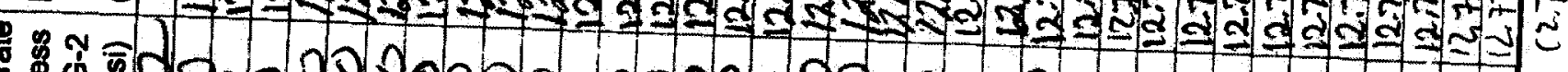
吾

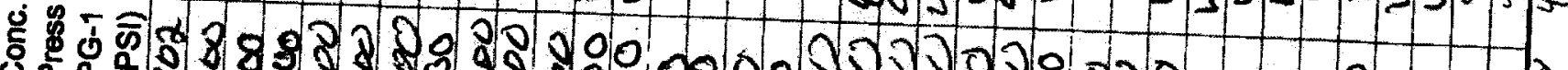

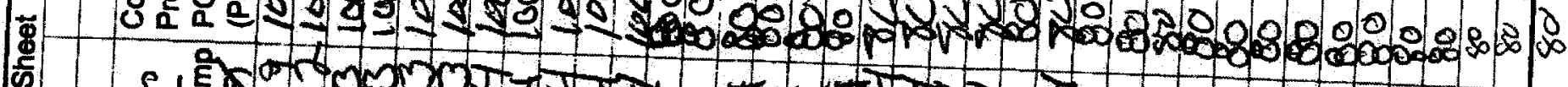

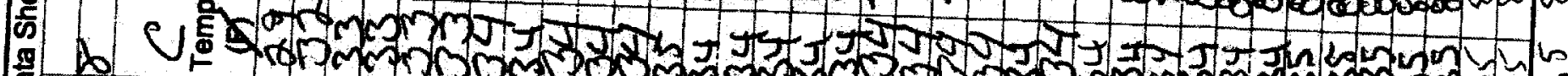

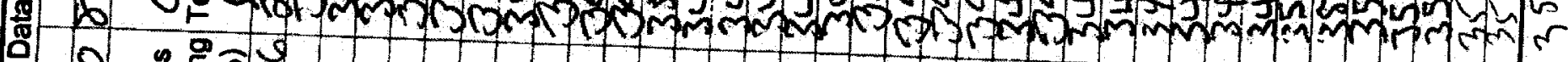
인

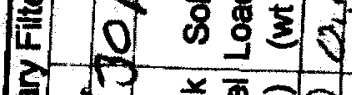

期

\% (2) 


\section{क्षे

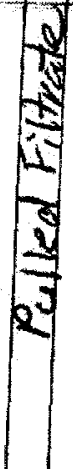

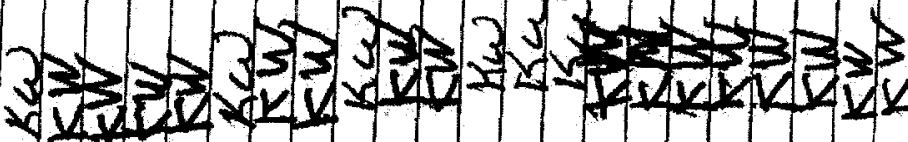

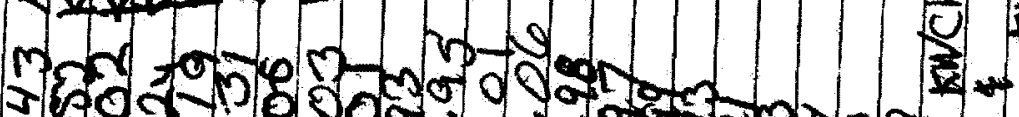
ming

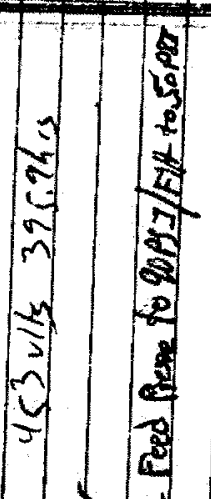

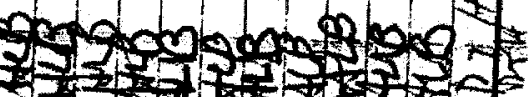

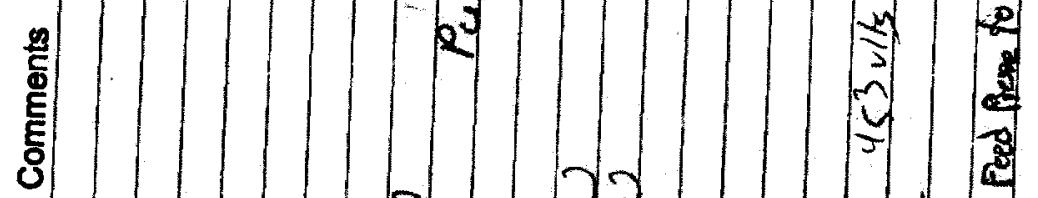

1

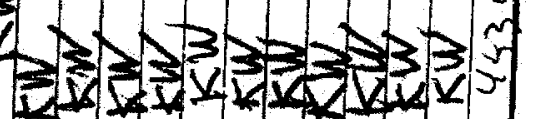

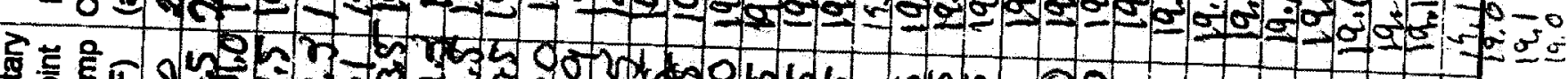
o.

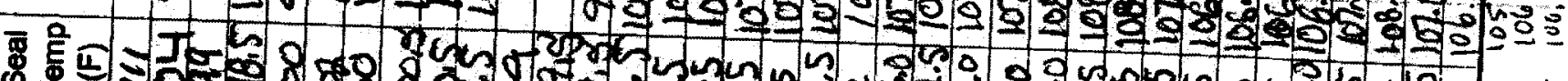

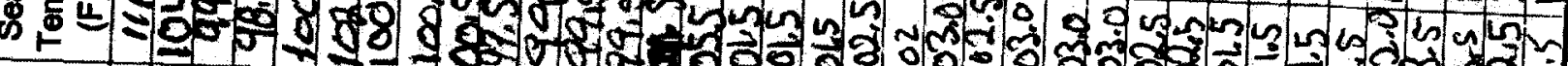

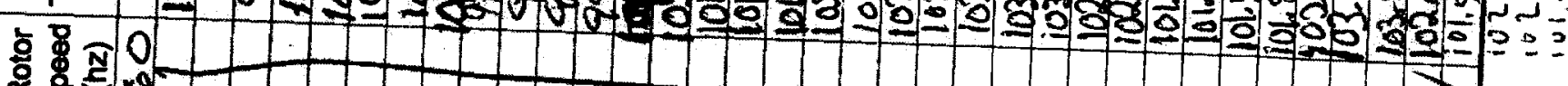
\&

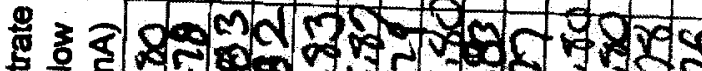

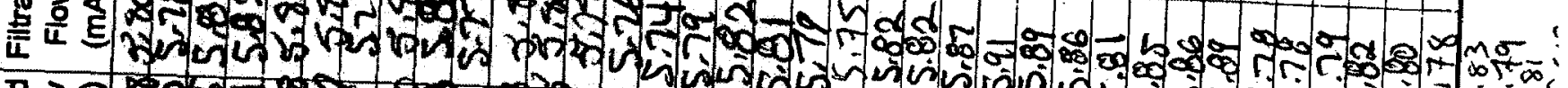

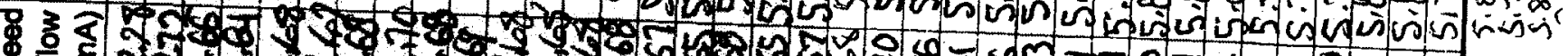

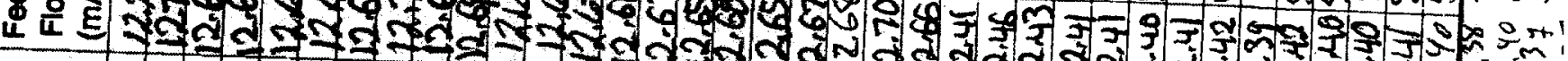

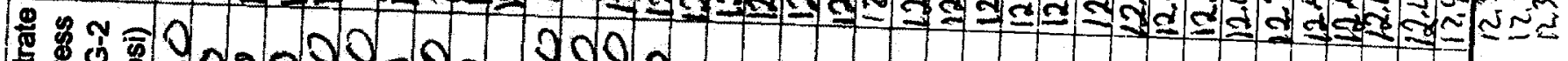

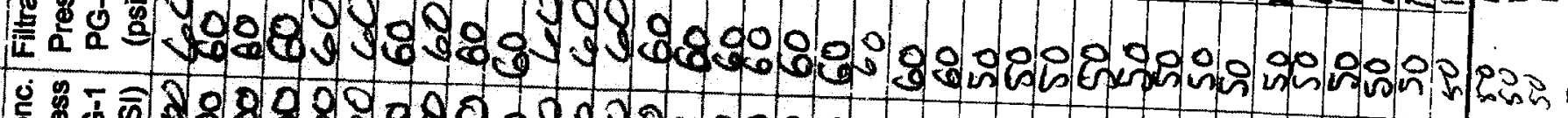

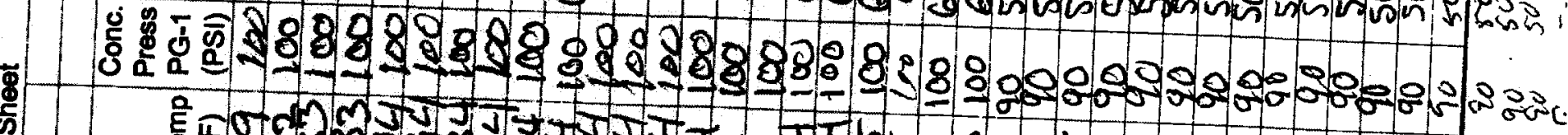

$\$$ E.

(20

妾 을 응

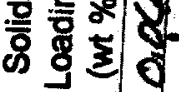

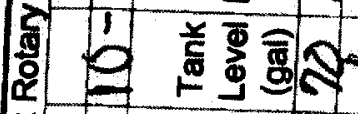

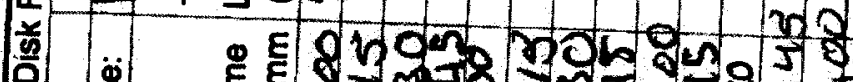

ล 


\section{党

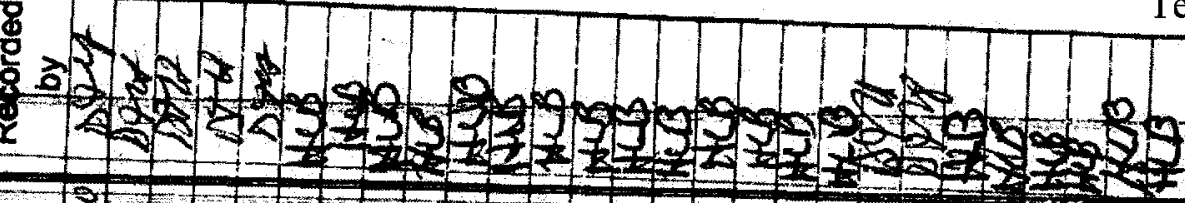
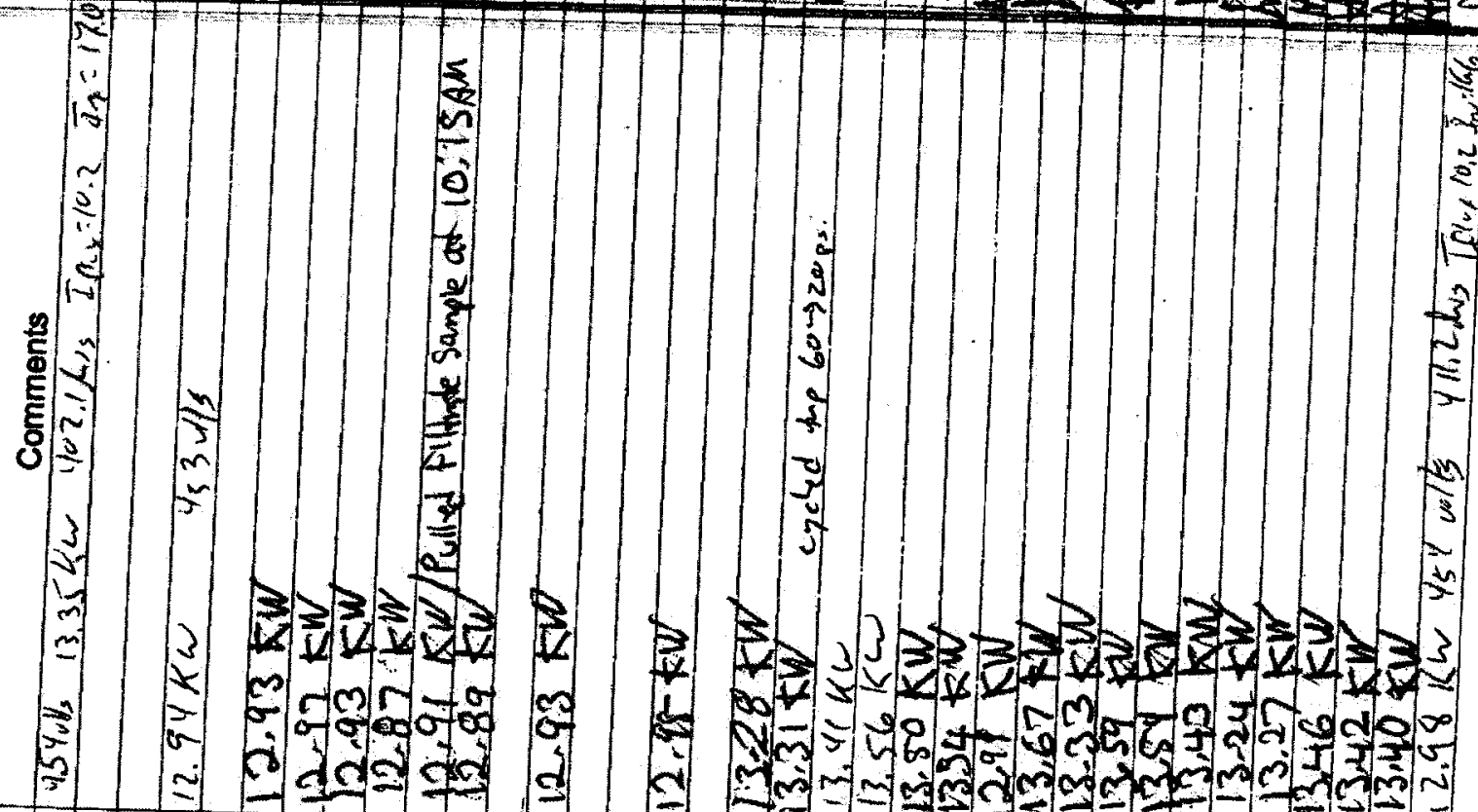

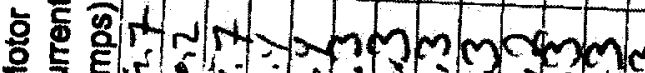

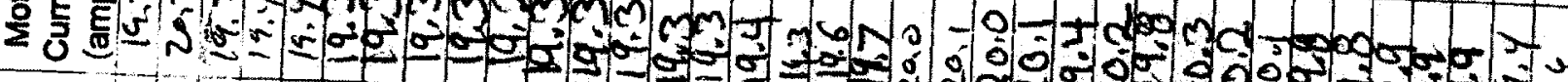

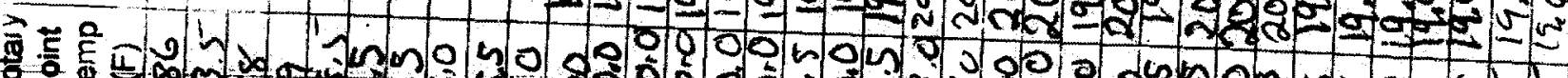

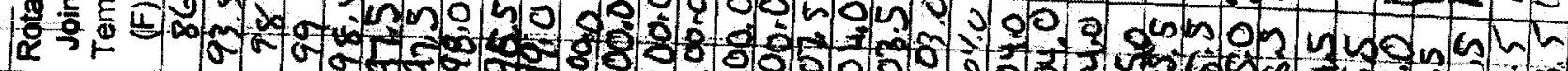

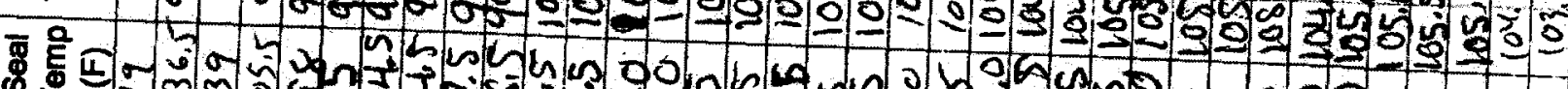
\&

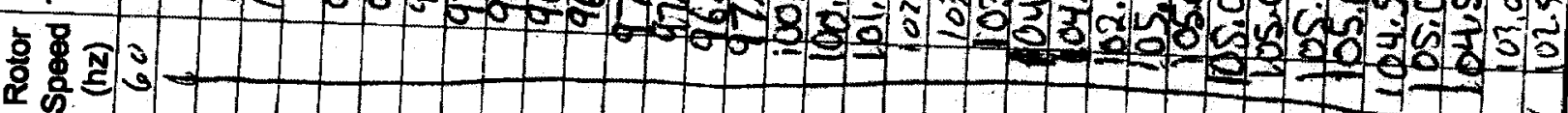

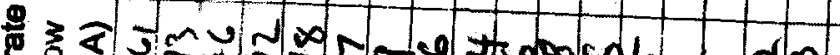

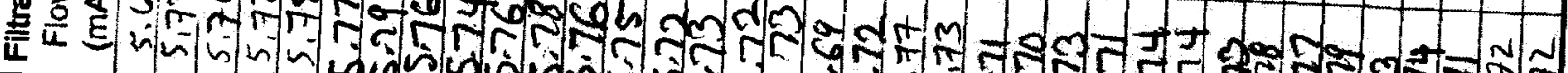

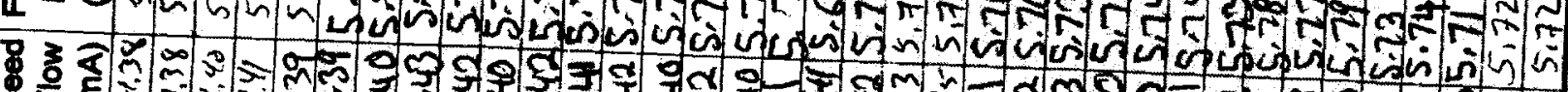

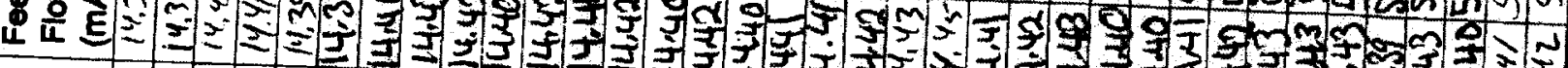

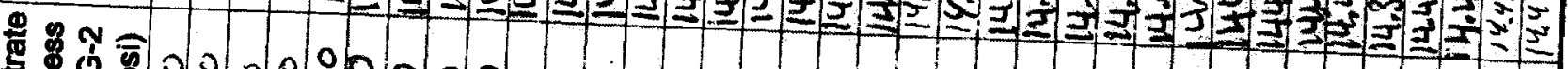

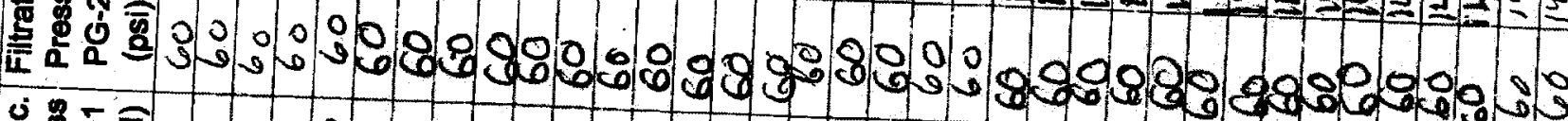
\% -

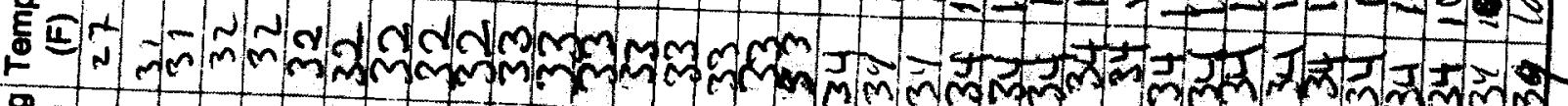

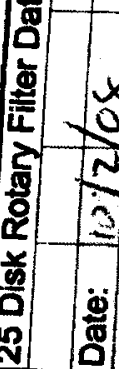

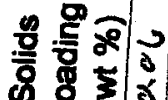
கृ

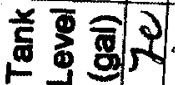

采 $m$ 


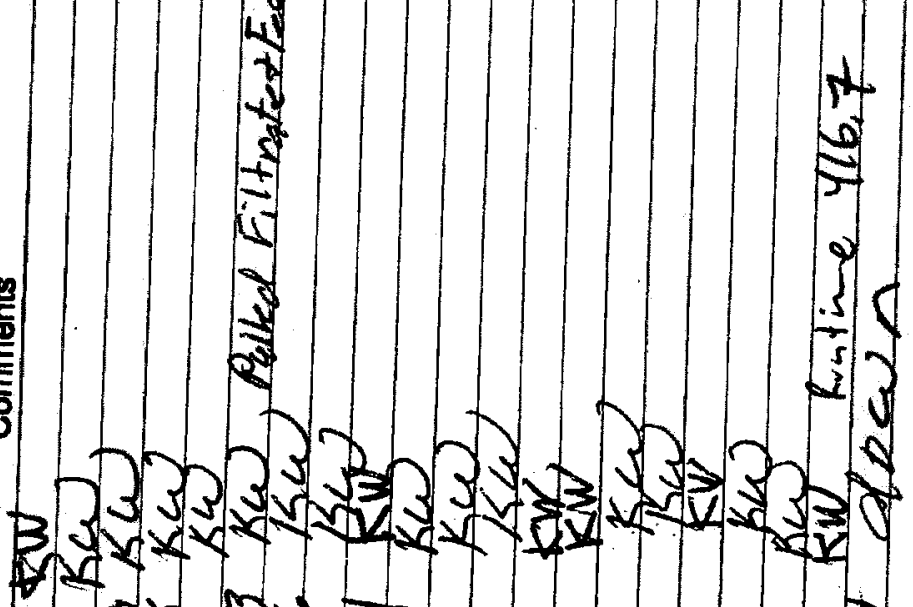

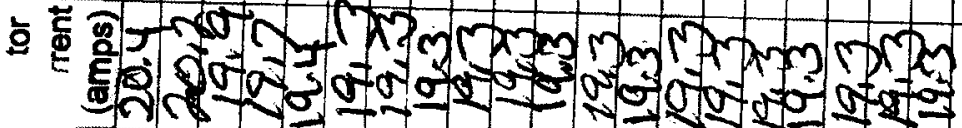

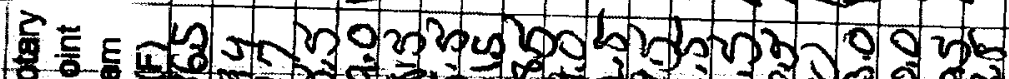

Q.

(

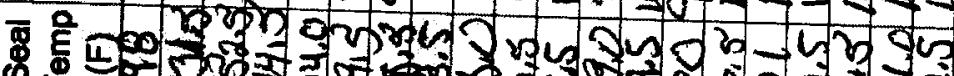

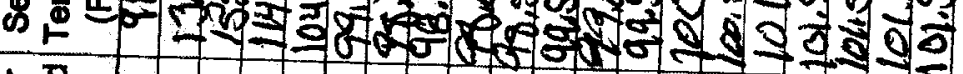

总兽

\%

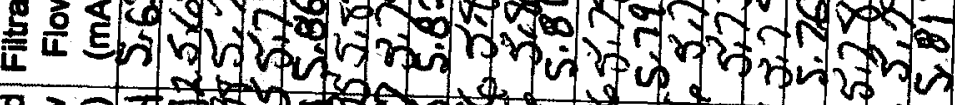

\&

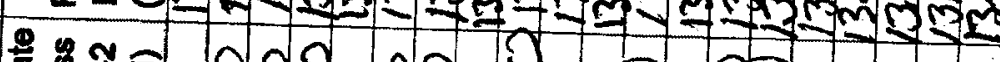

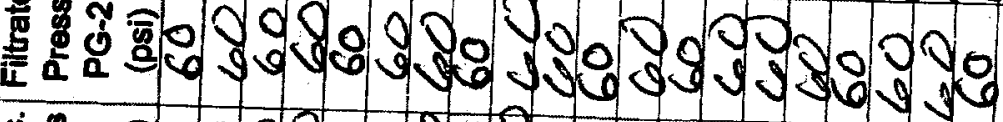

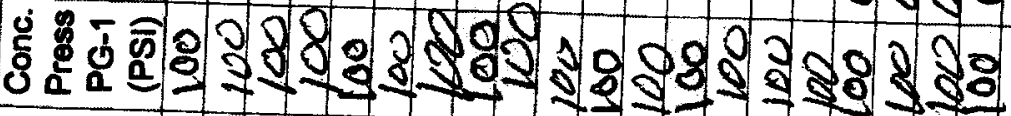

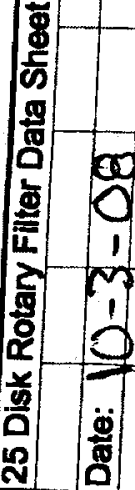

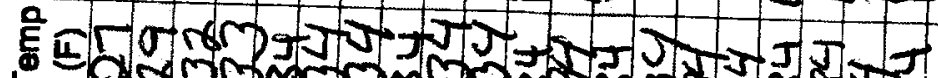

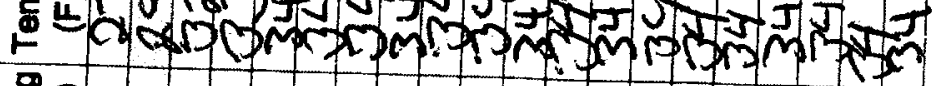

$0^{\infty}$

늠 음

\& 50

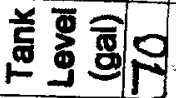

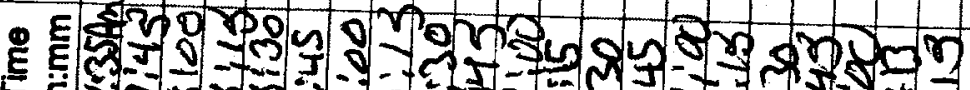

$F$ ह 


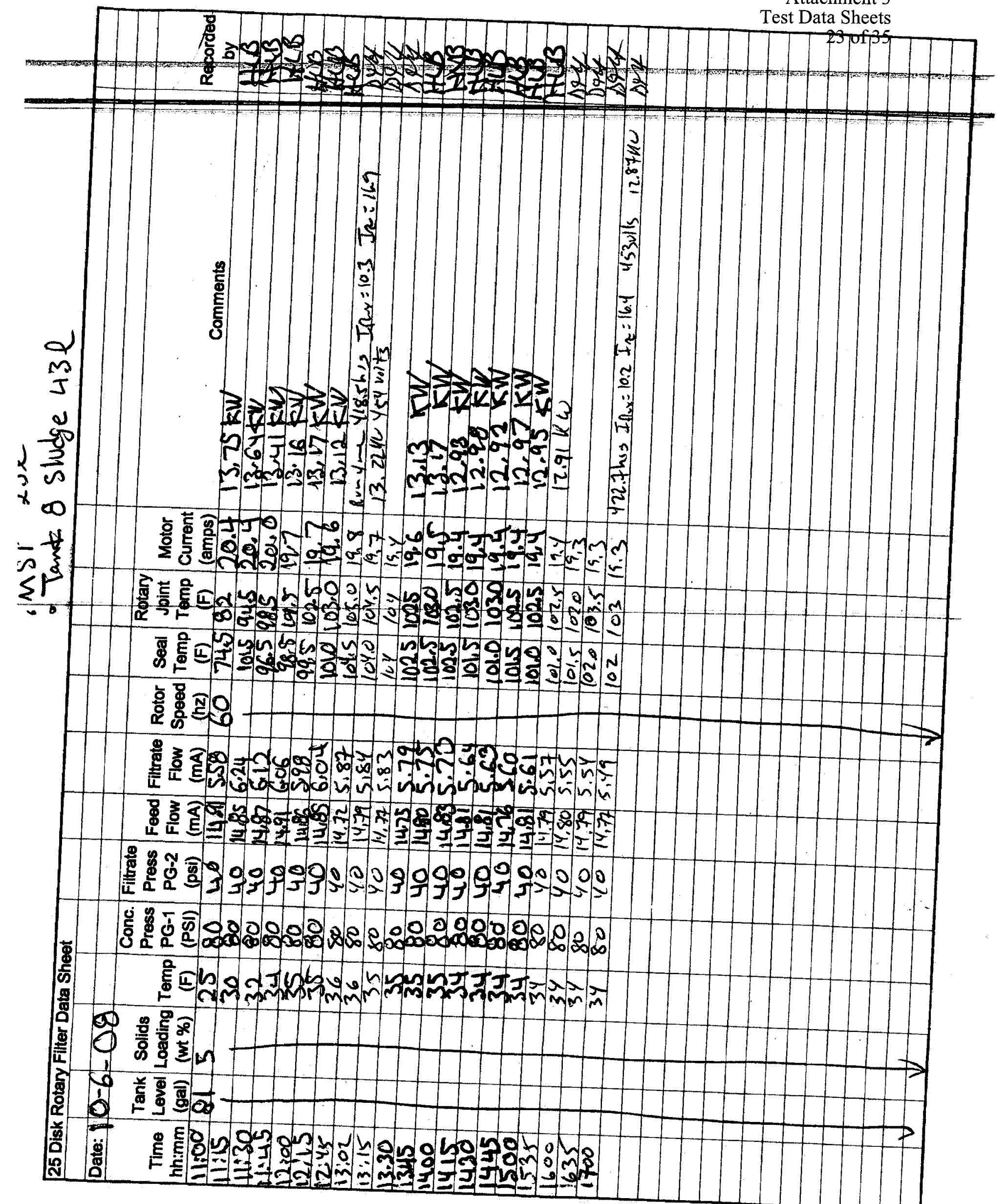




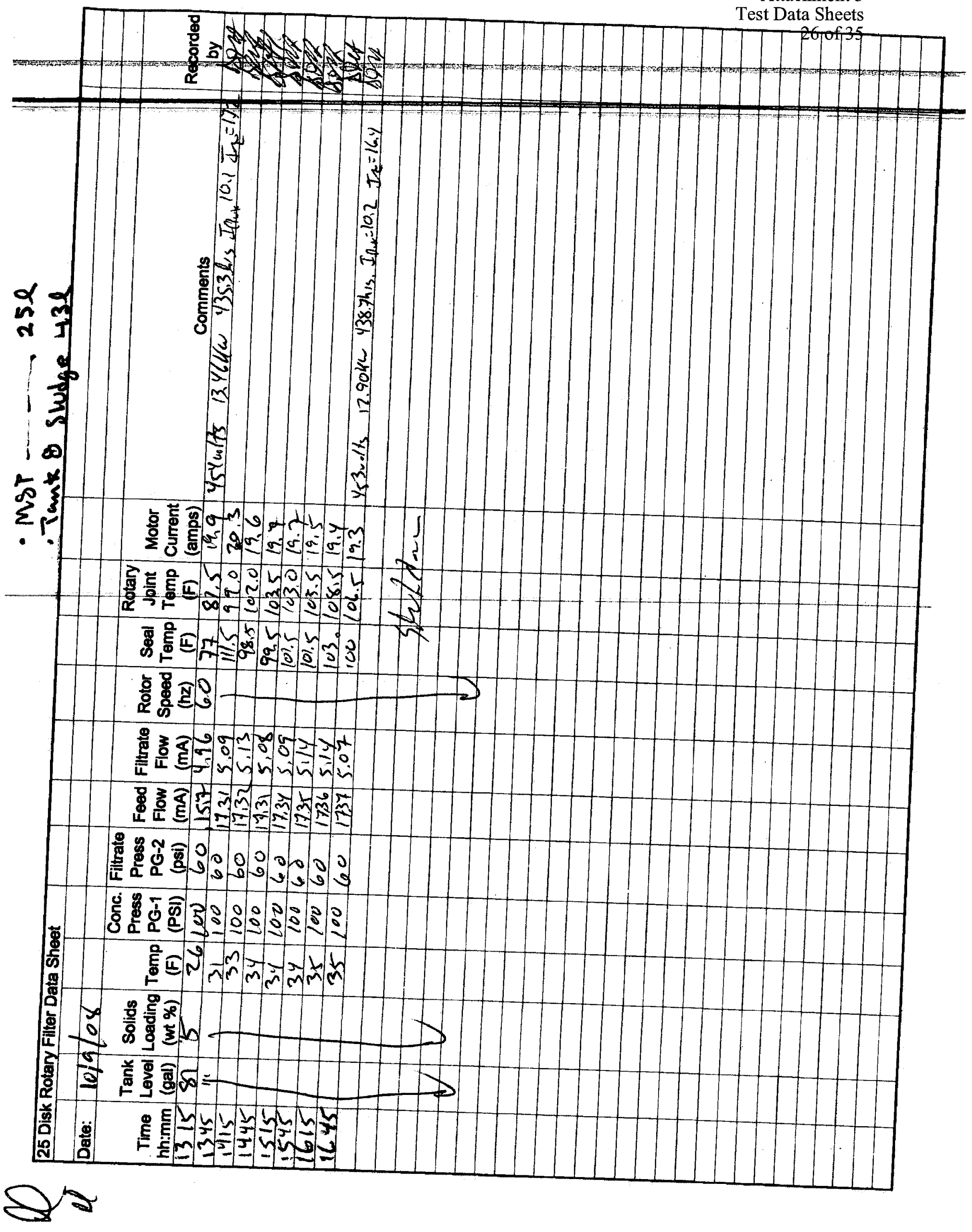




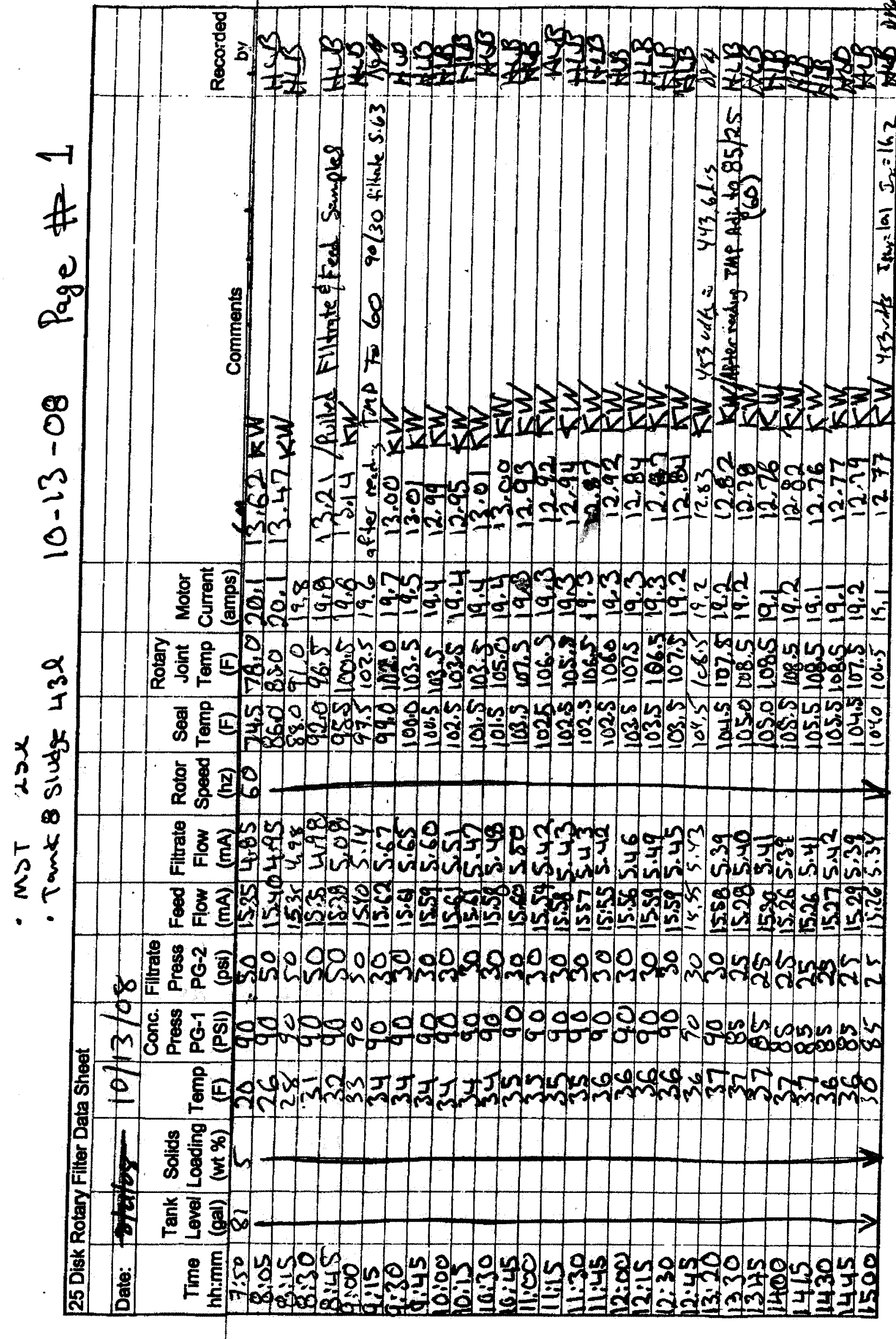




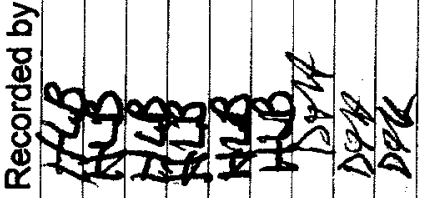

0
4
4
8
0
0
0
2
1
0

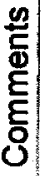

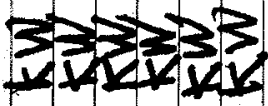

I J 00

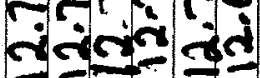

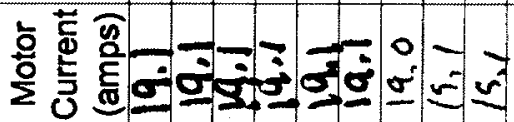

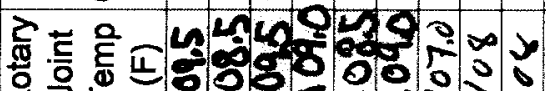

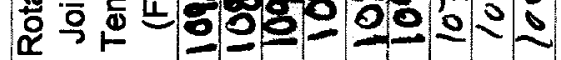

을

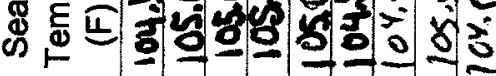

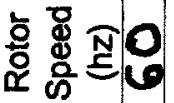

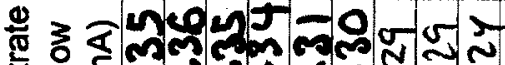

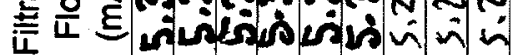

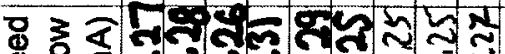

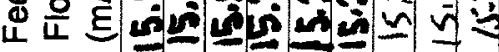

密

竞宫

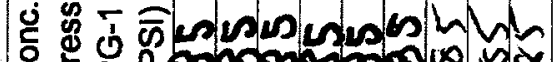

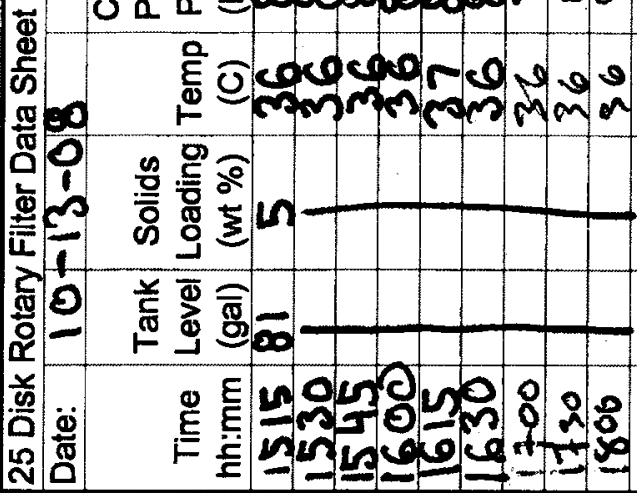




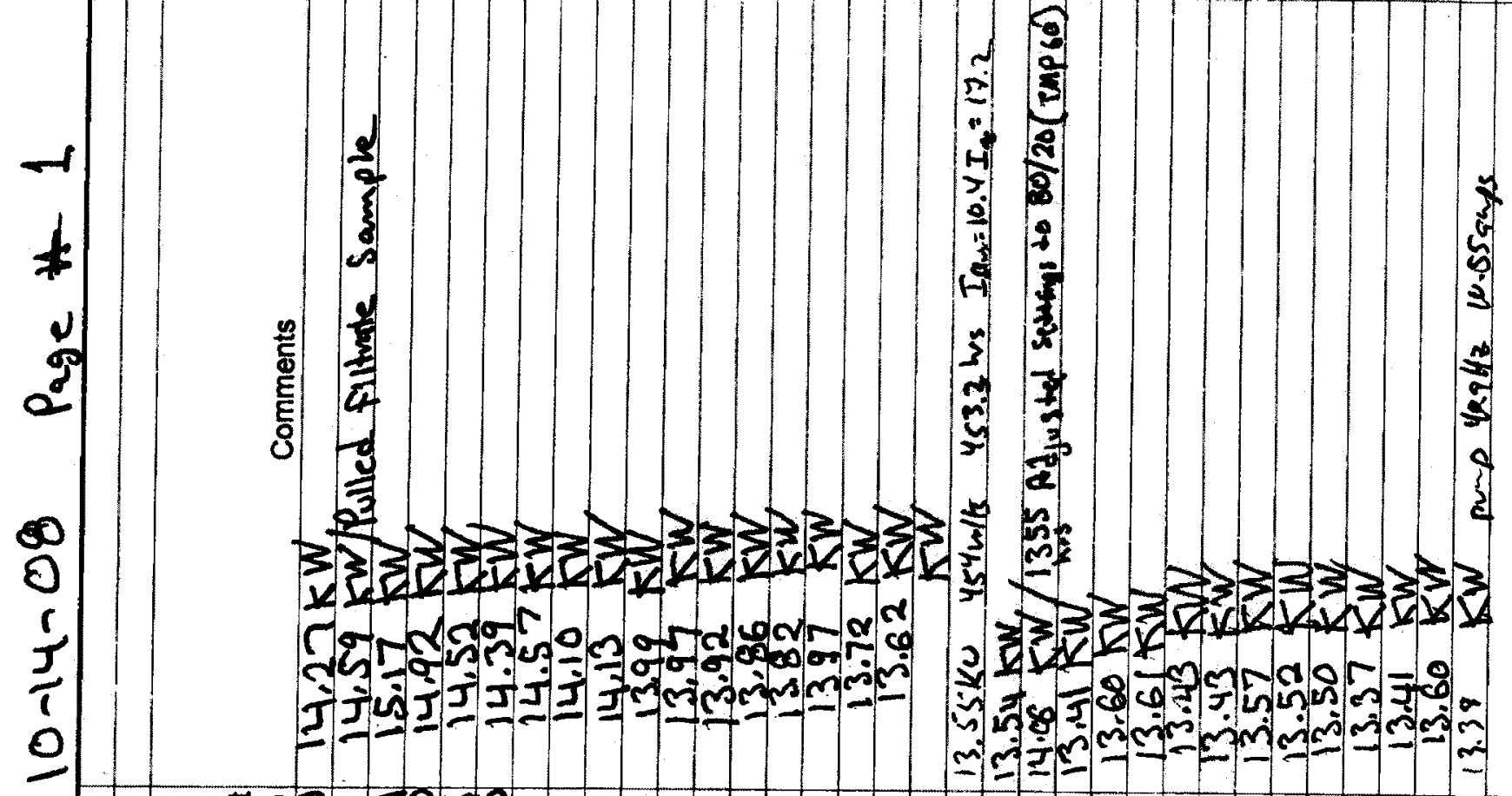

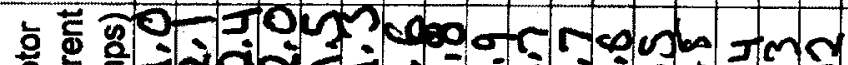

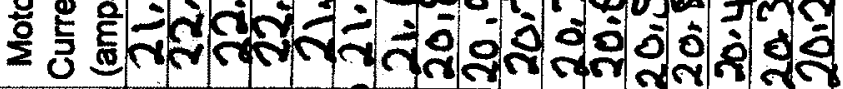

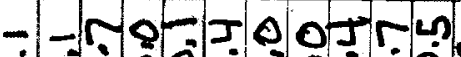

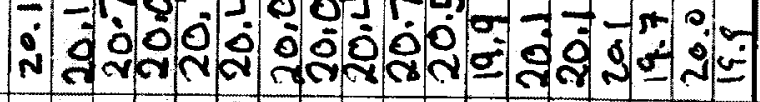

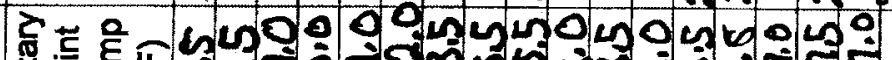

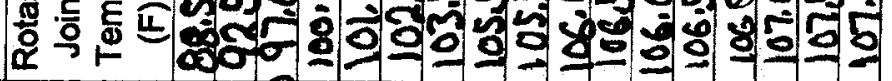

๑) क

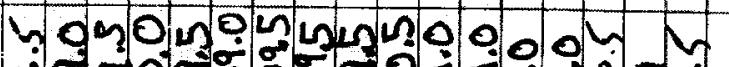

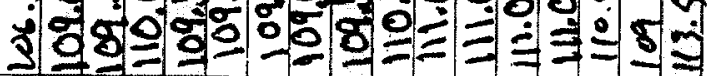

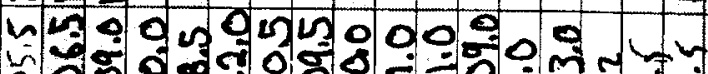

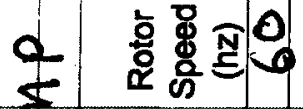

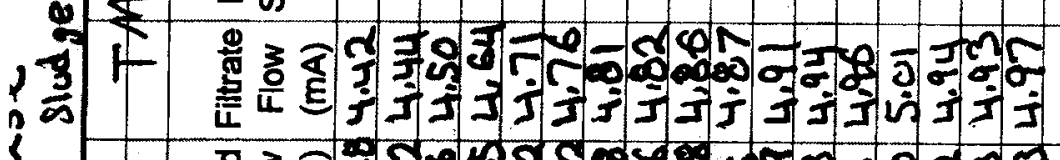

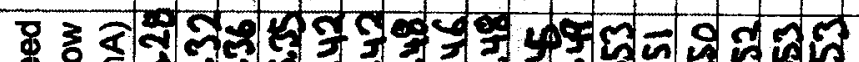

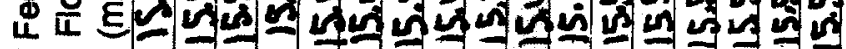

ॠँ \% 店 :

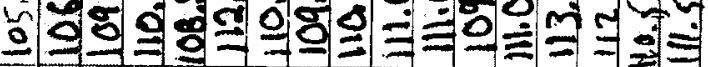

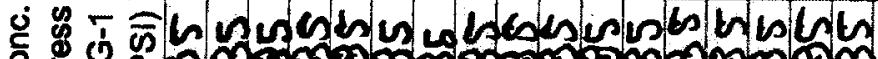

$\$$

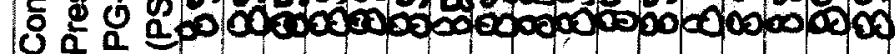

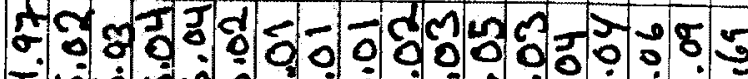

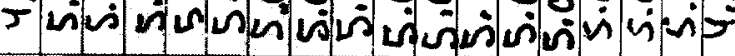
-

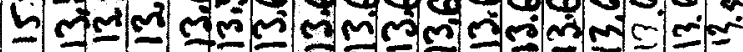
N

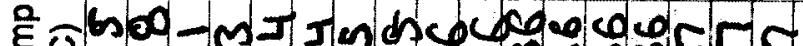




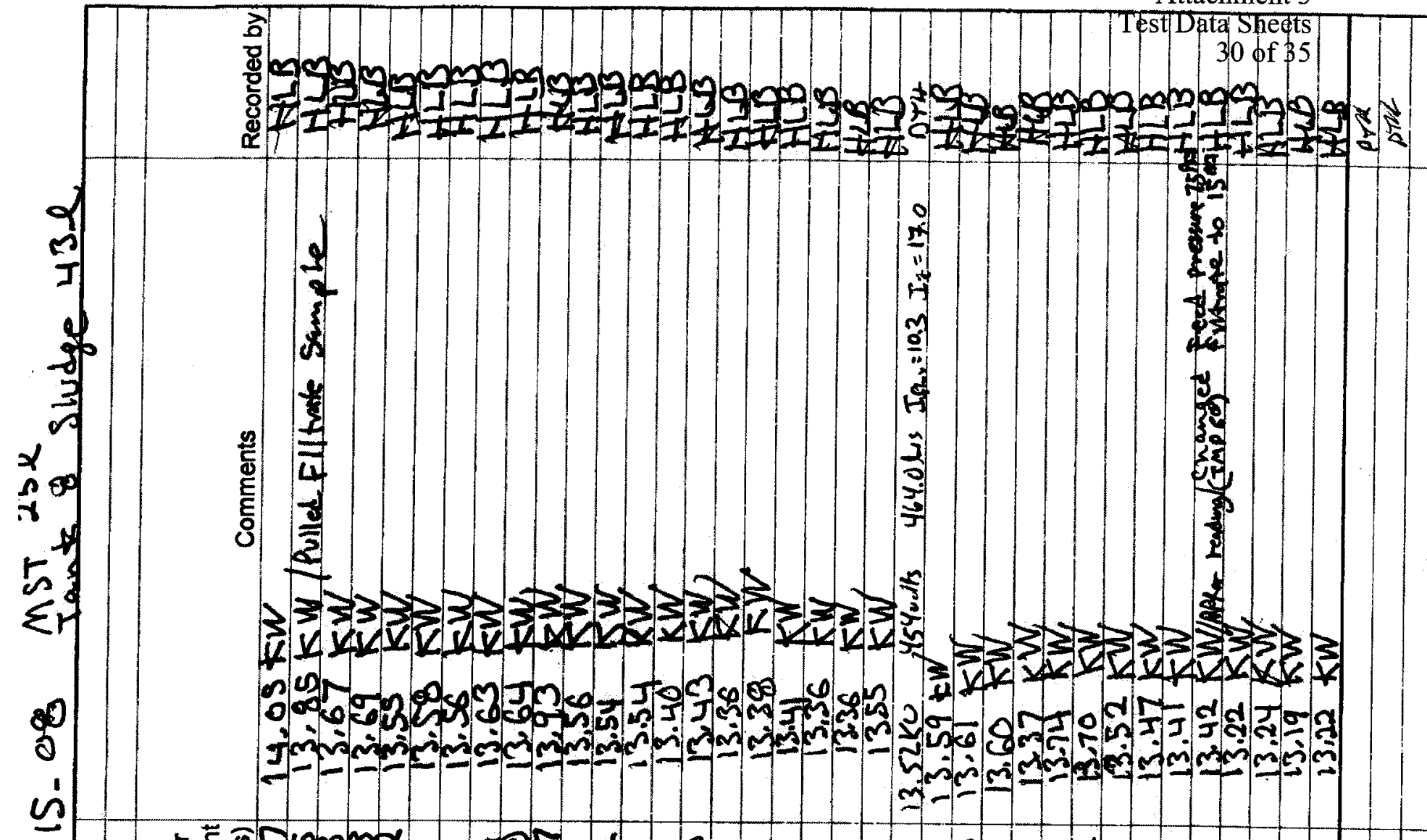

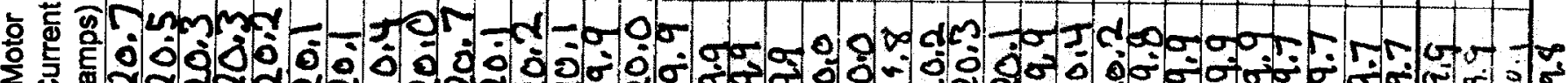
之

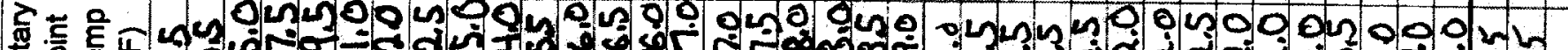

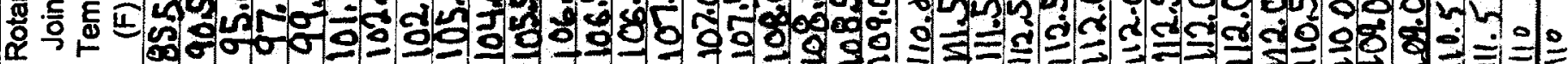
व ๙

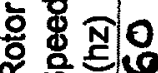

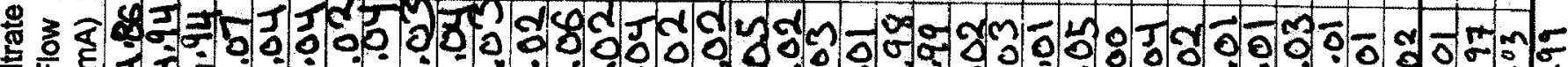

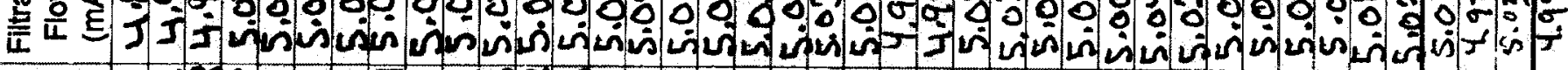

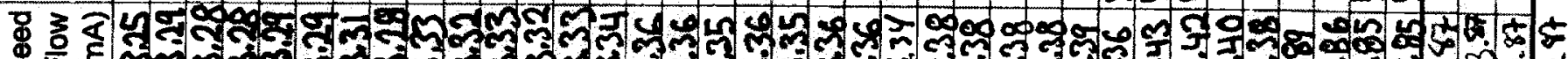
L

ฆั "

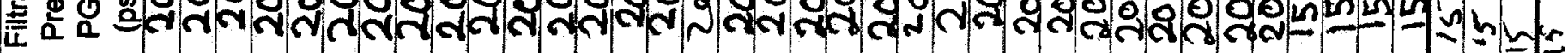

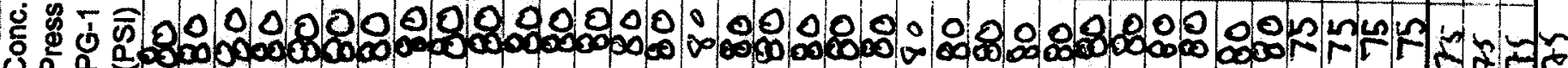
$\ddot{\$}$

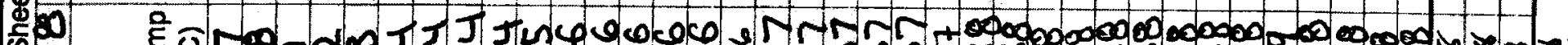
क0 $\quad$ E

की

1)

앵

เ

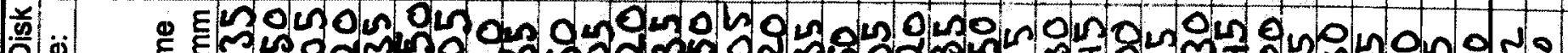

¿̈ E ผ 


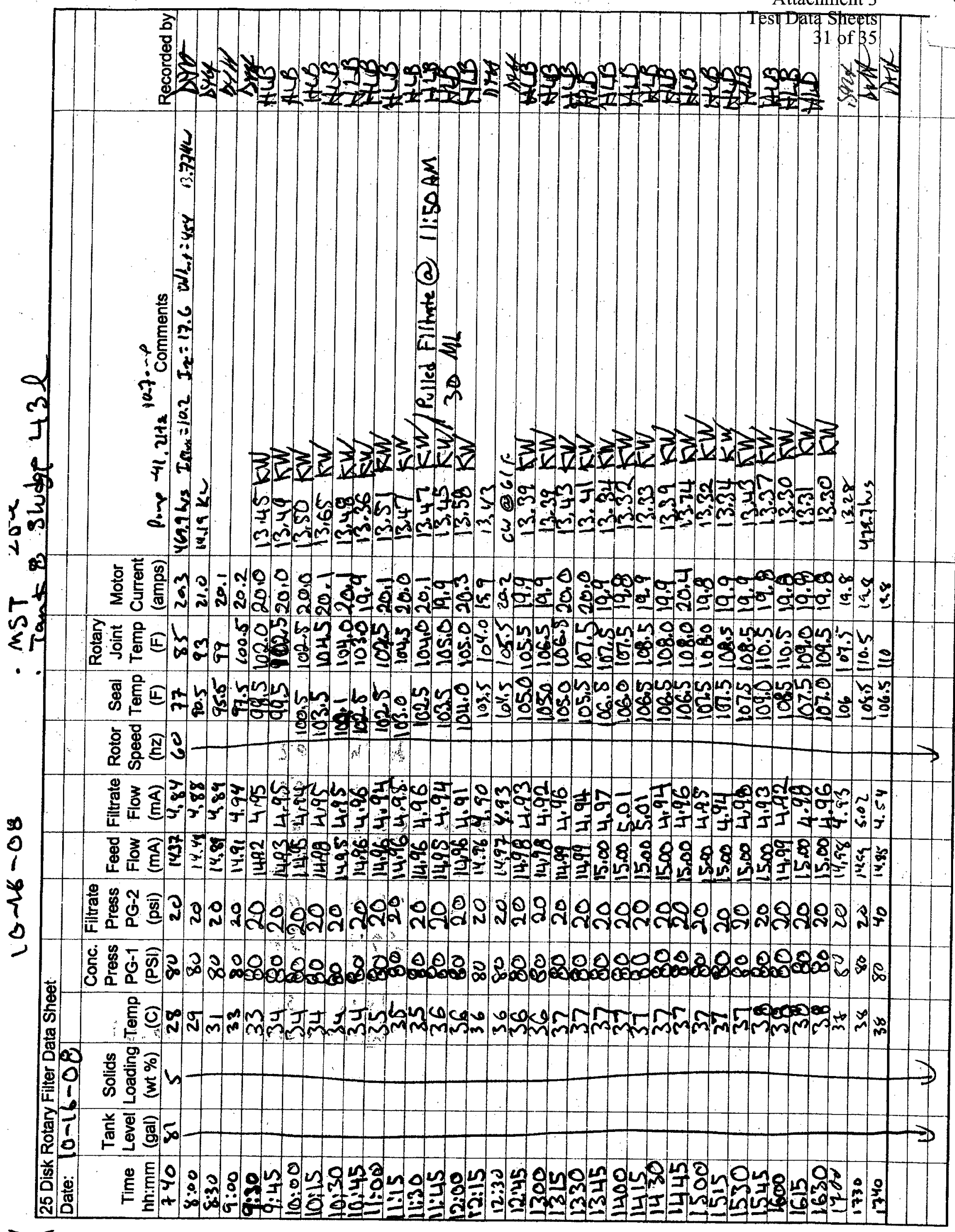




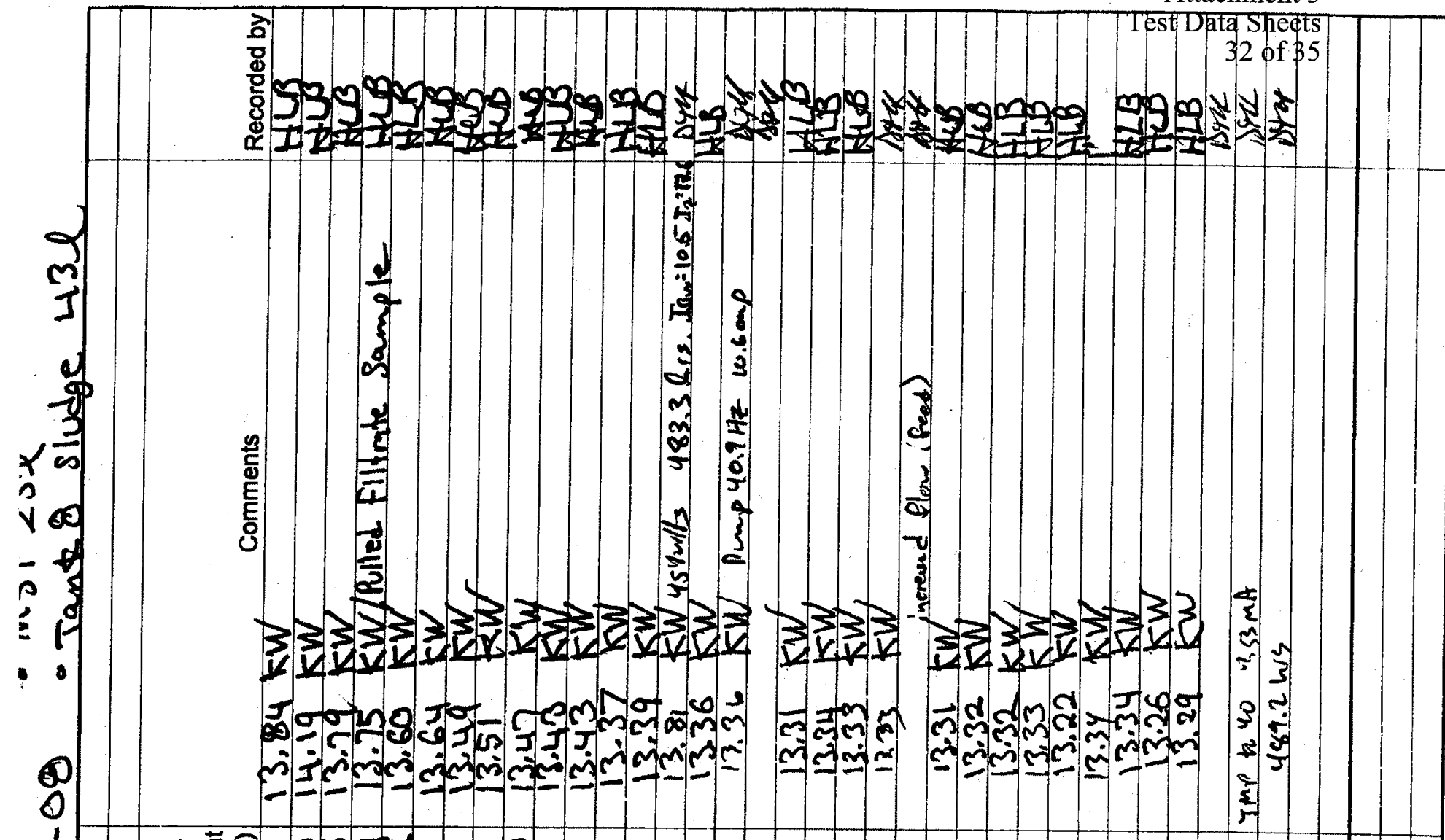

$\frac{1}{5}$

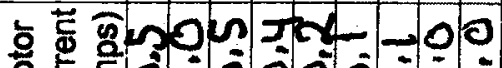

之े

Z̃

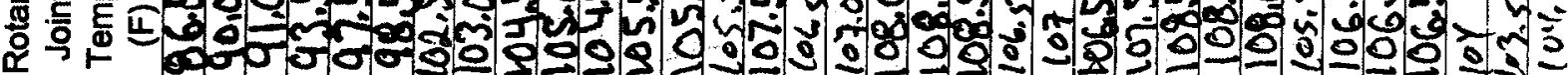
है हning ஸे

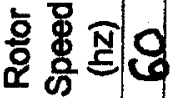

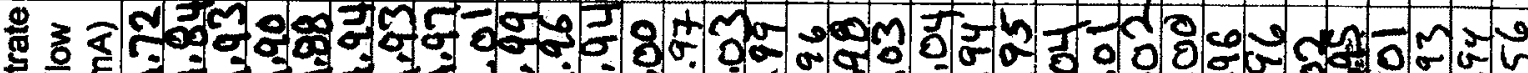
密

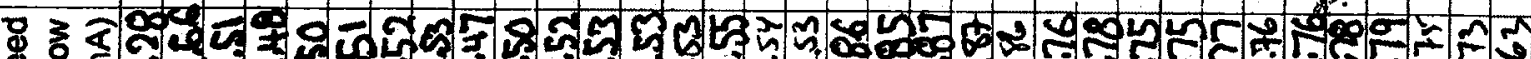
\&

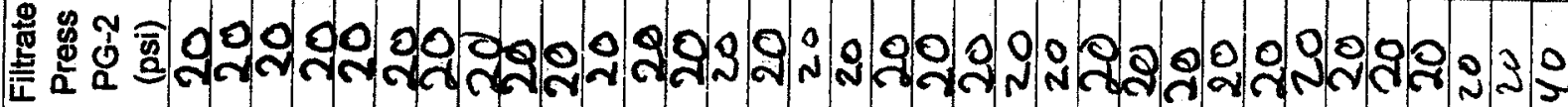

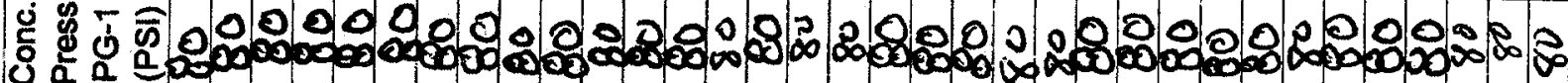

$\overline{\$}$

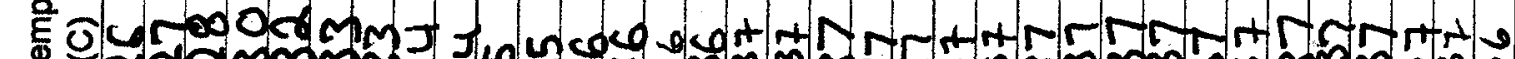

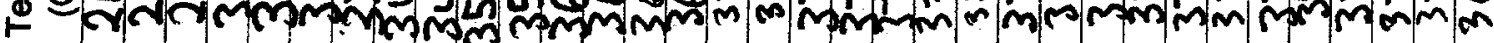

O 0 : 을

1 年

- 95

密

1 990

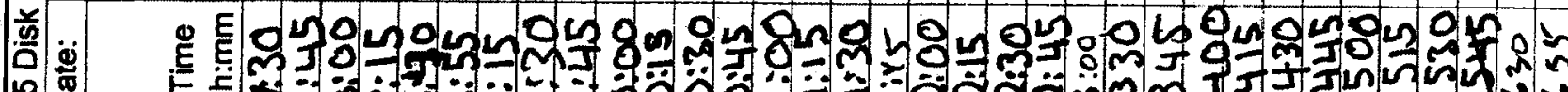




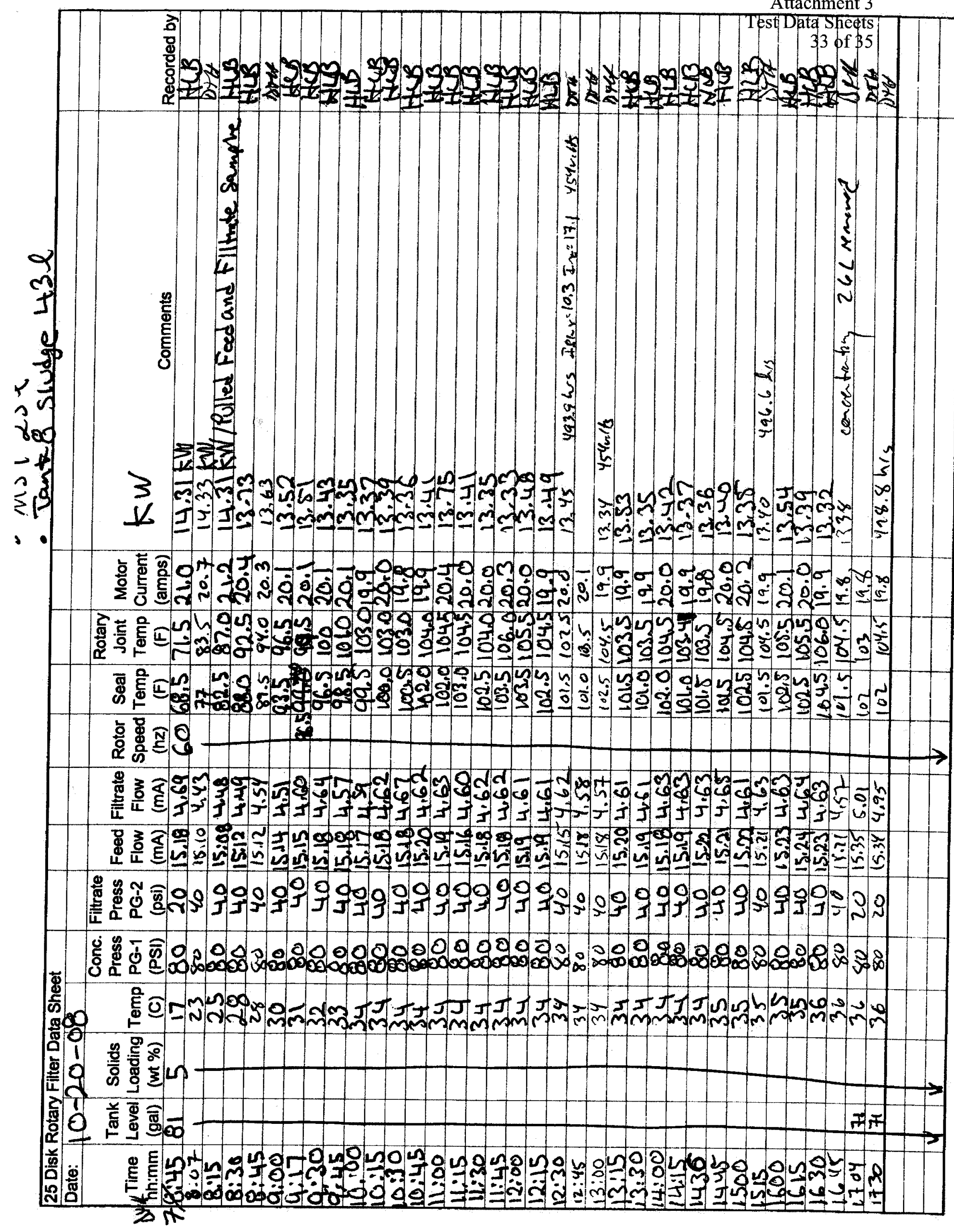




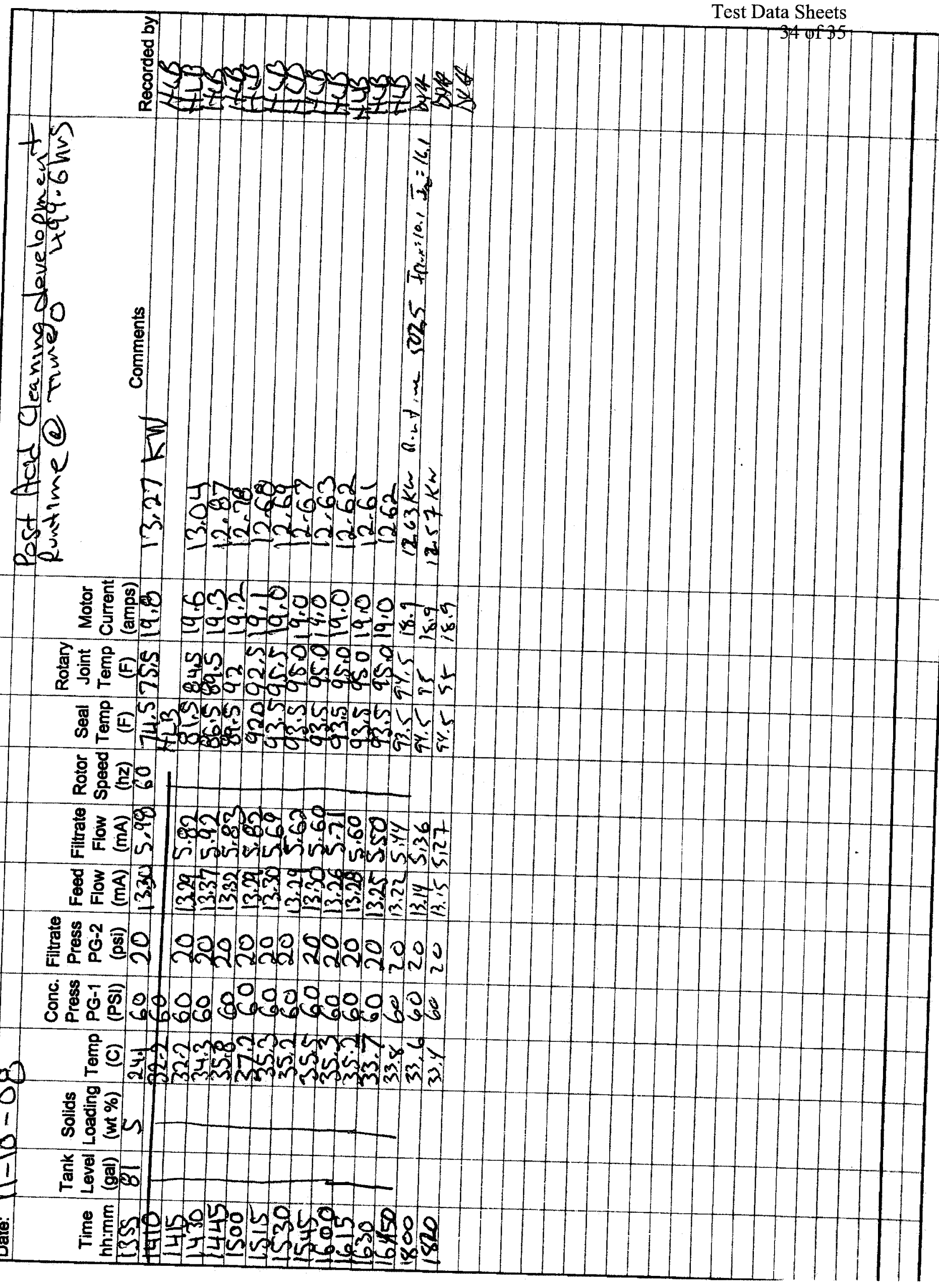




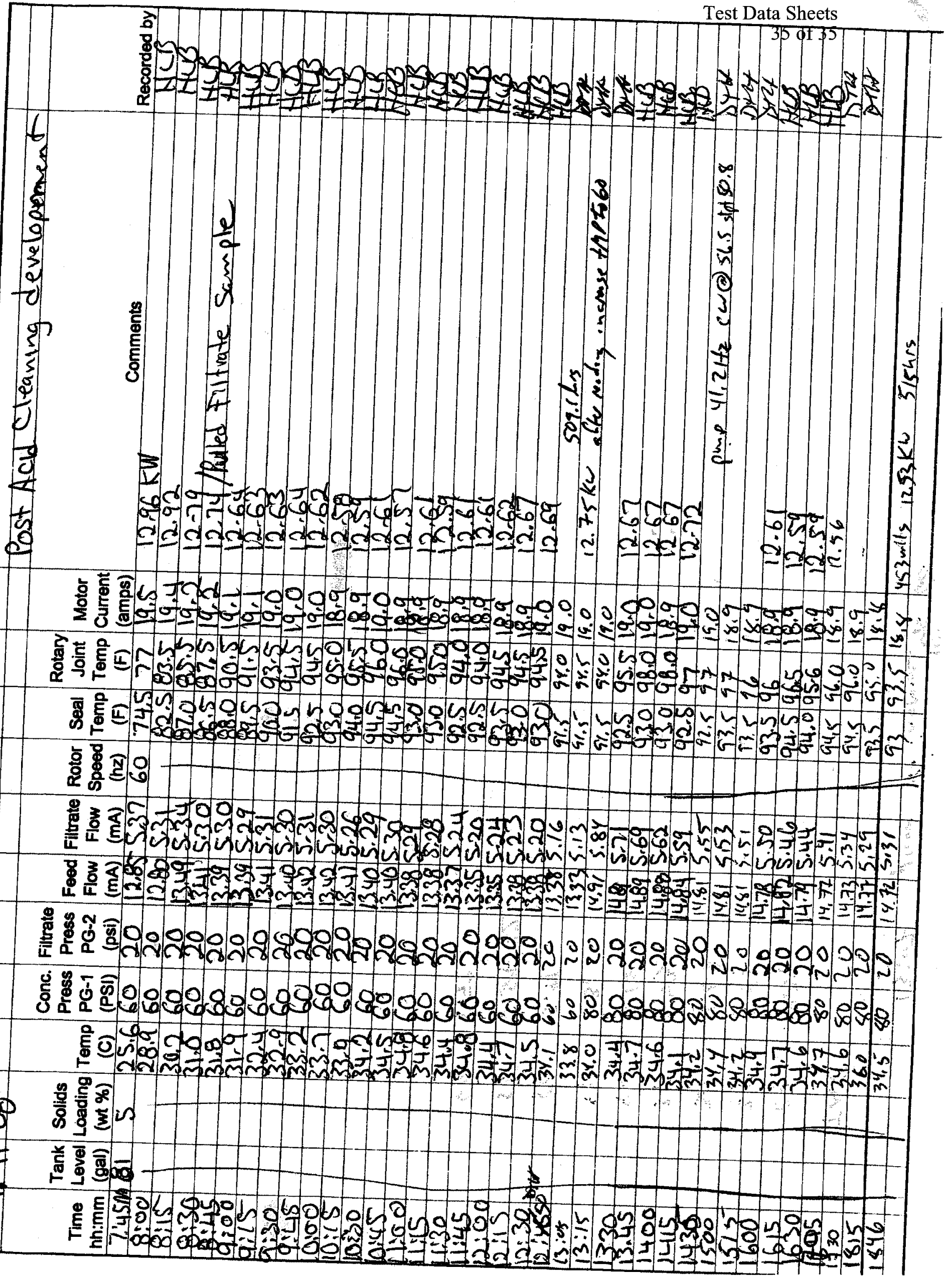


SRNL-STI-2009-00183

Attachment 4

ACTL Rotary Microfilter - Vibration Baseline

Initial Vibration Measurements

1 of 10

\section{ATTACHMENT 4}
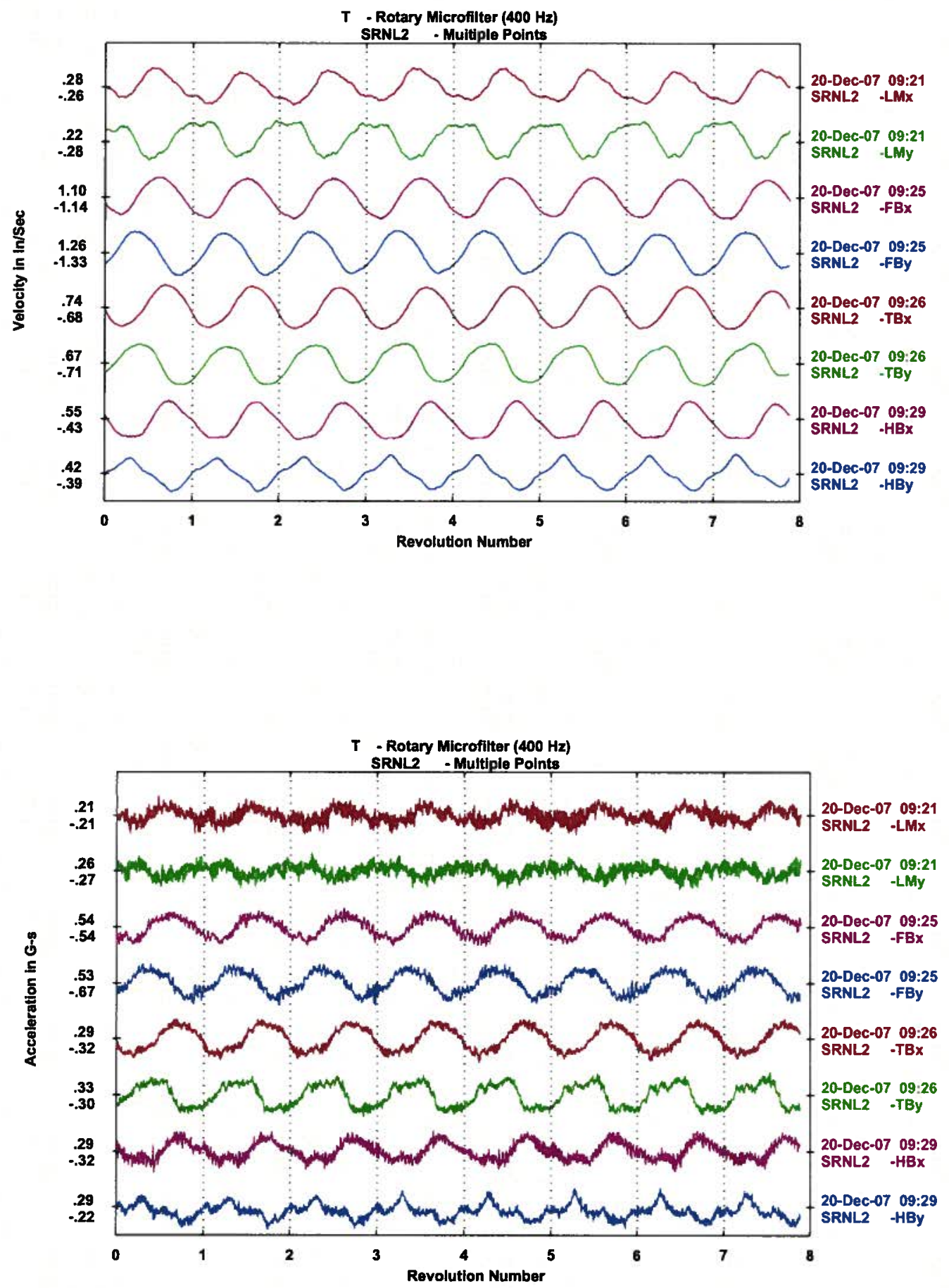

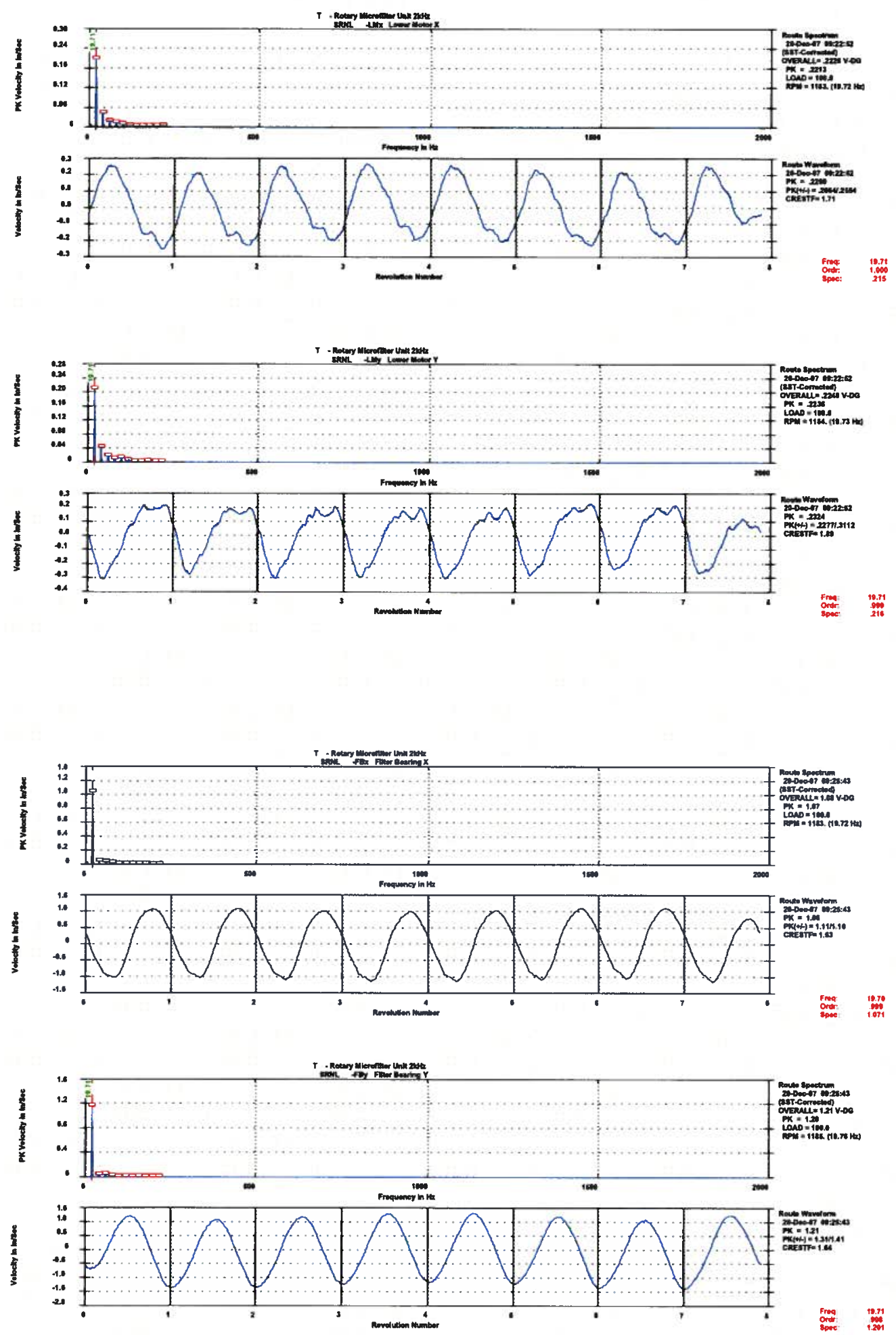

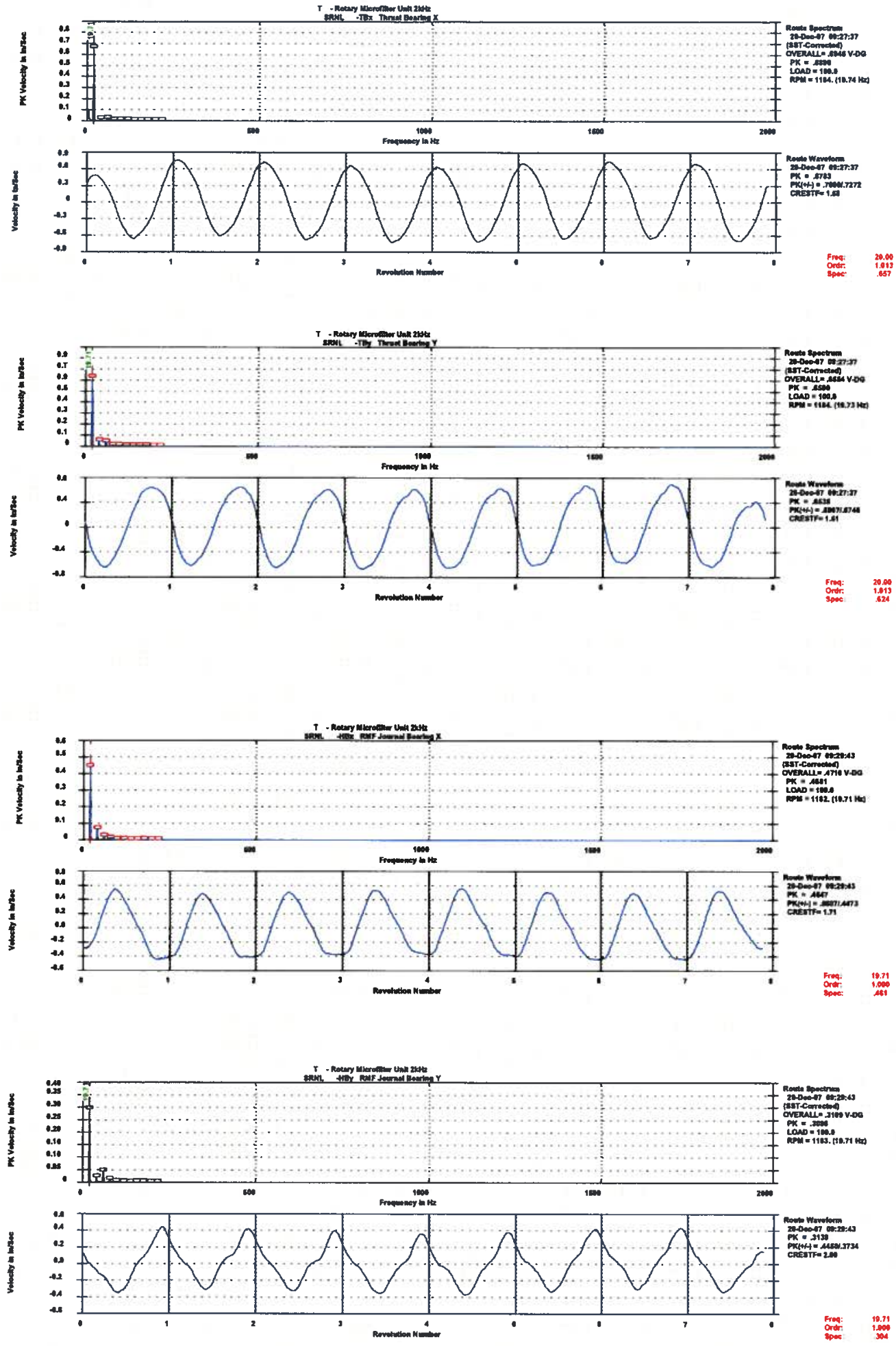

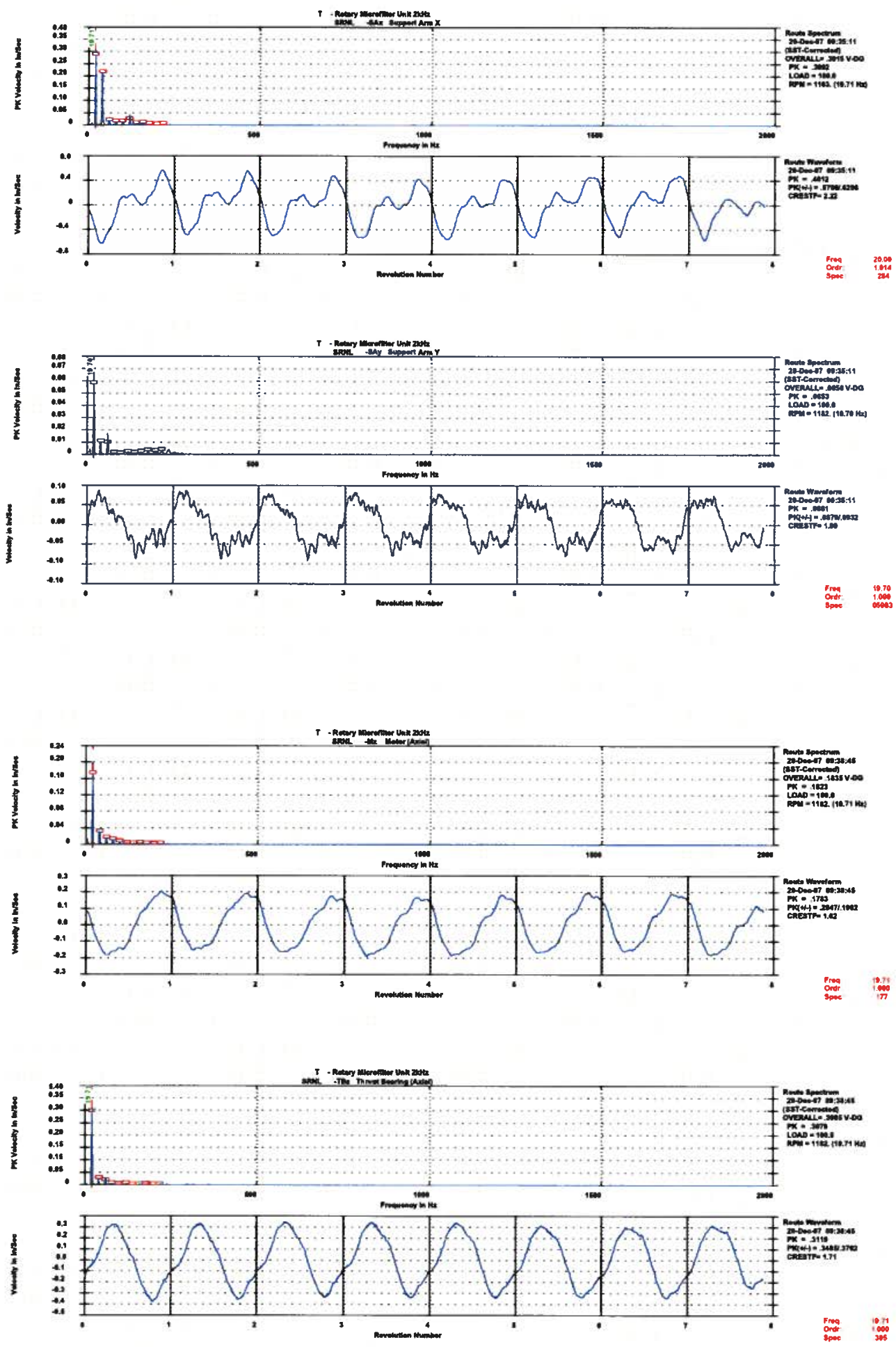

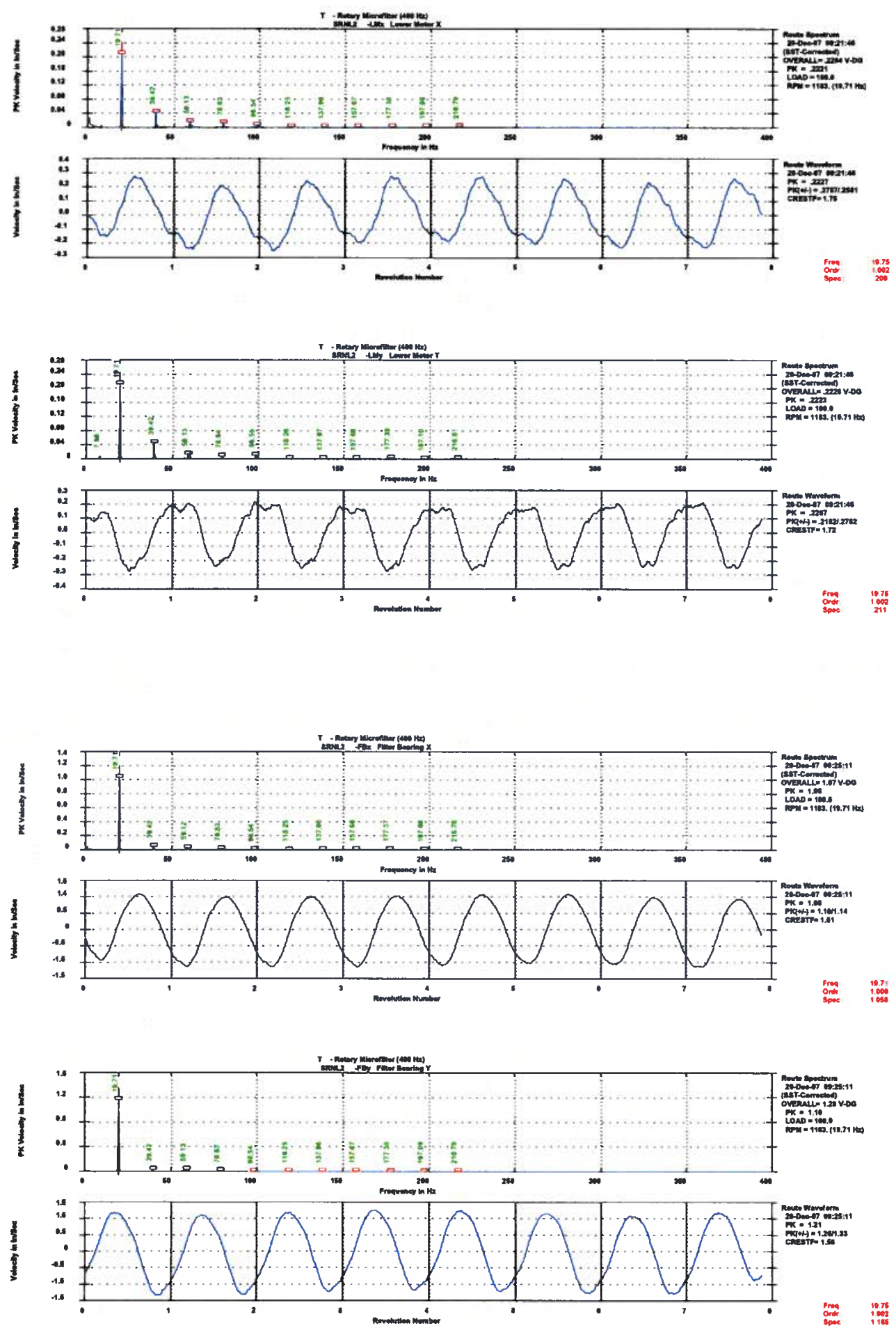

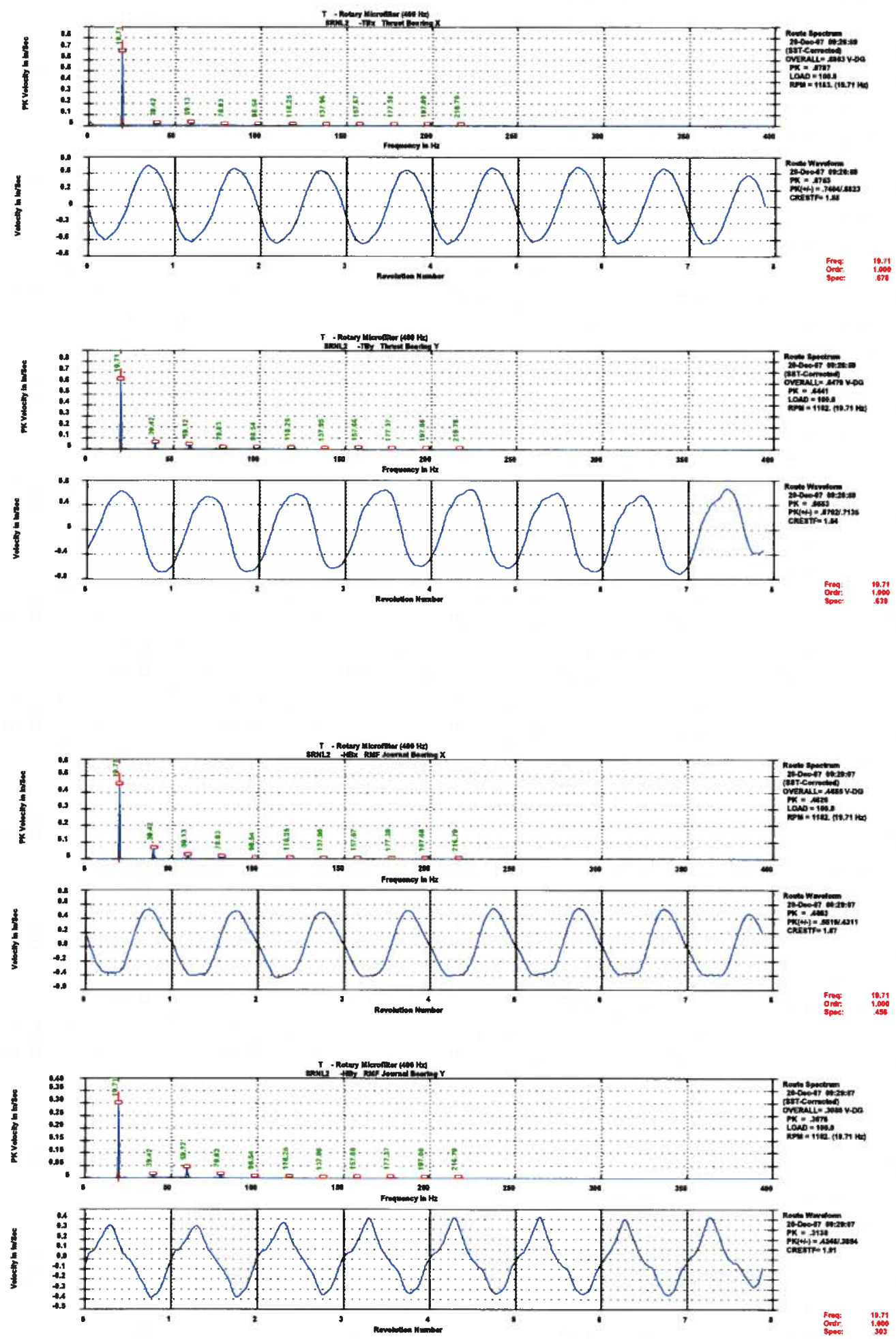

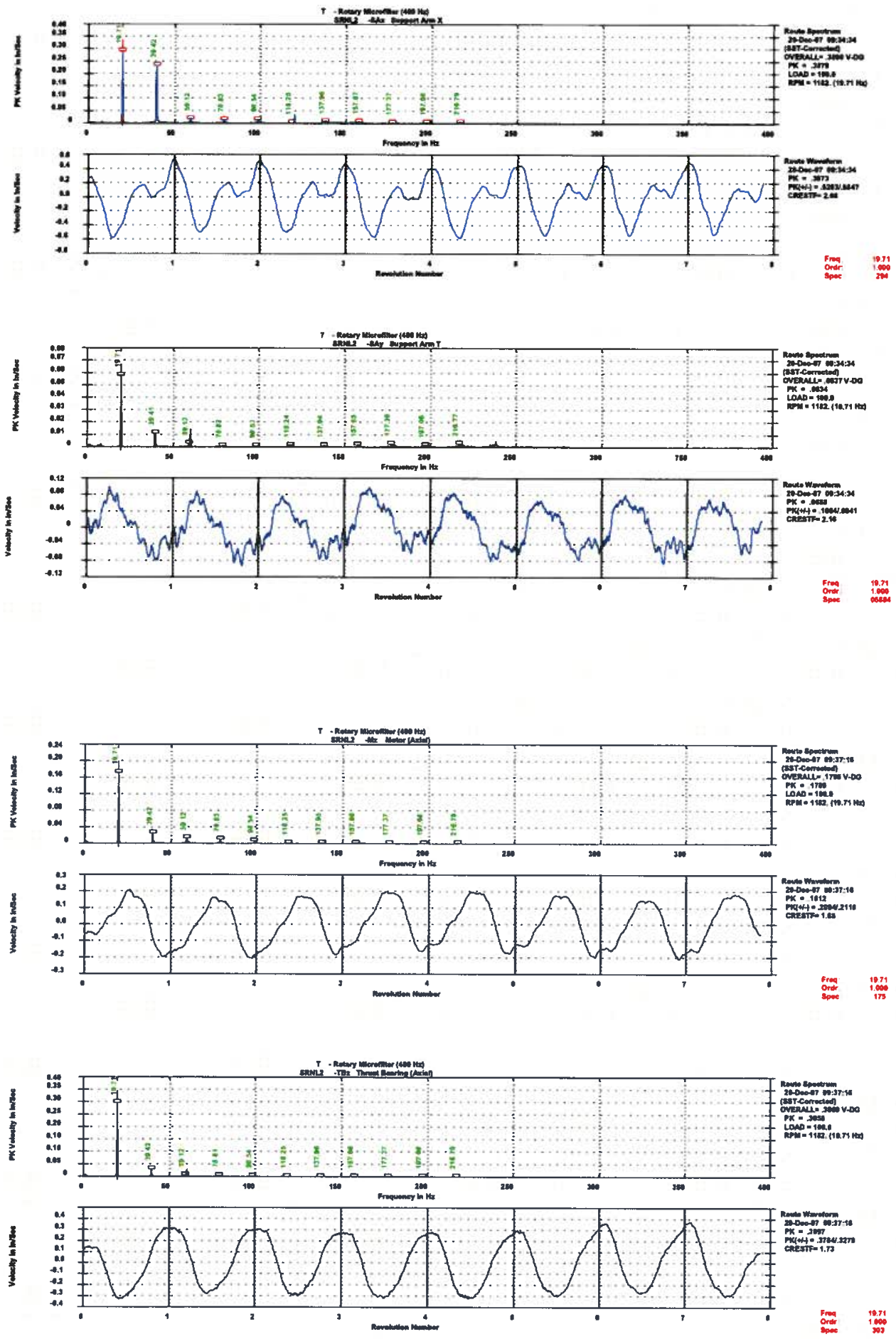
SRNL-STI-2009-00183

Attachment 4

ACTL Rotary Microfilter - Vibration Baseline

Initial Vibration Measurements

8 of 10
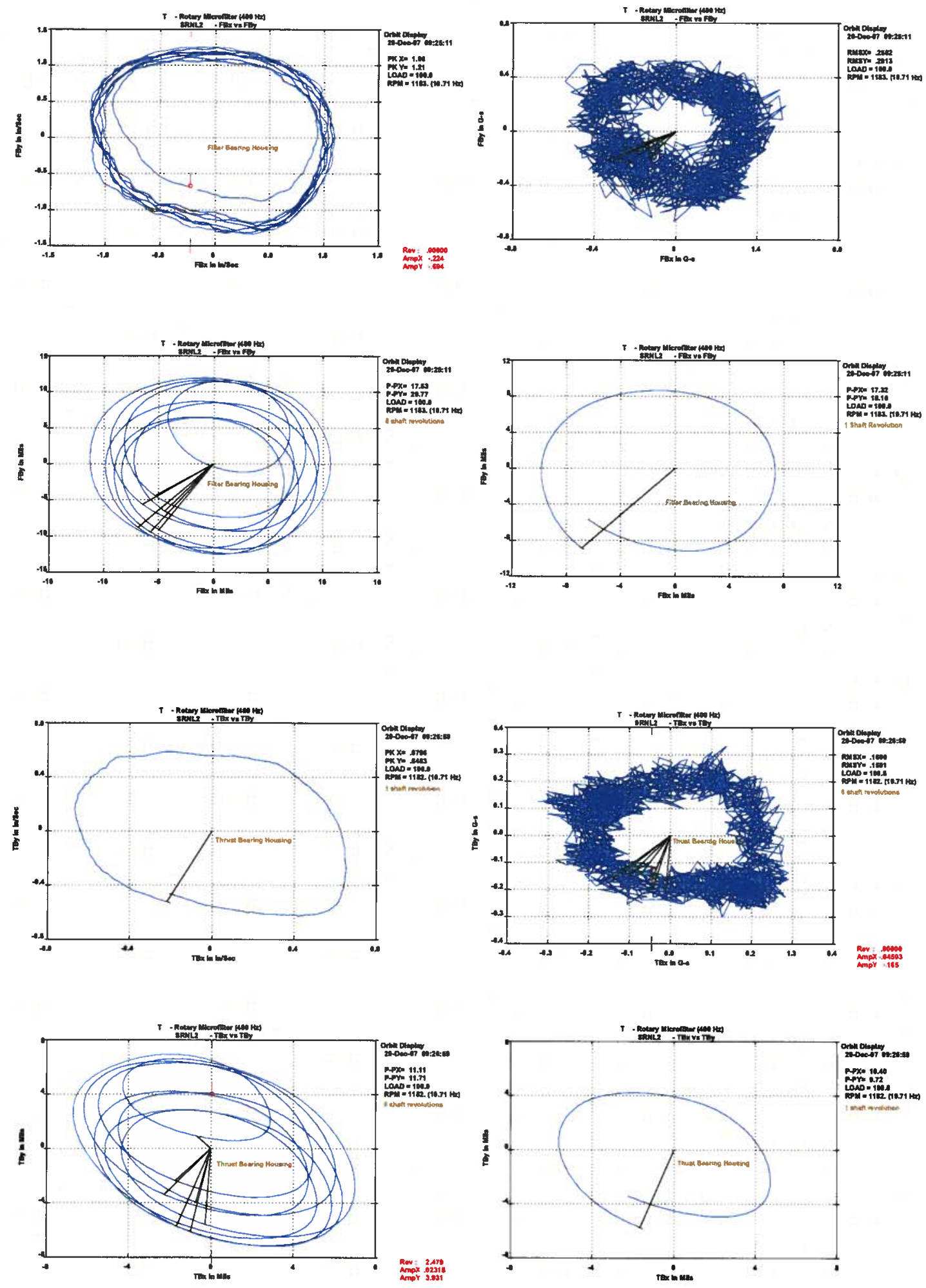
SRNL-STI-2009-00183

Attachment 4
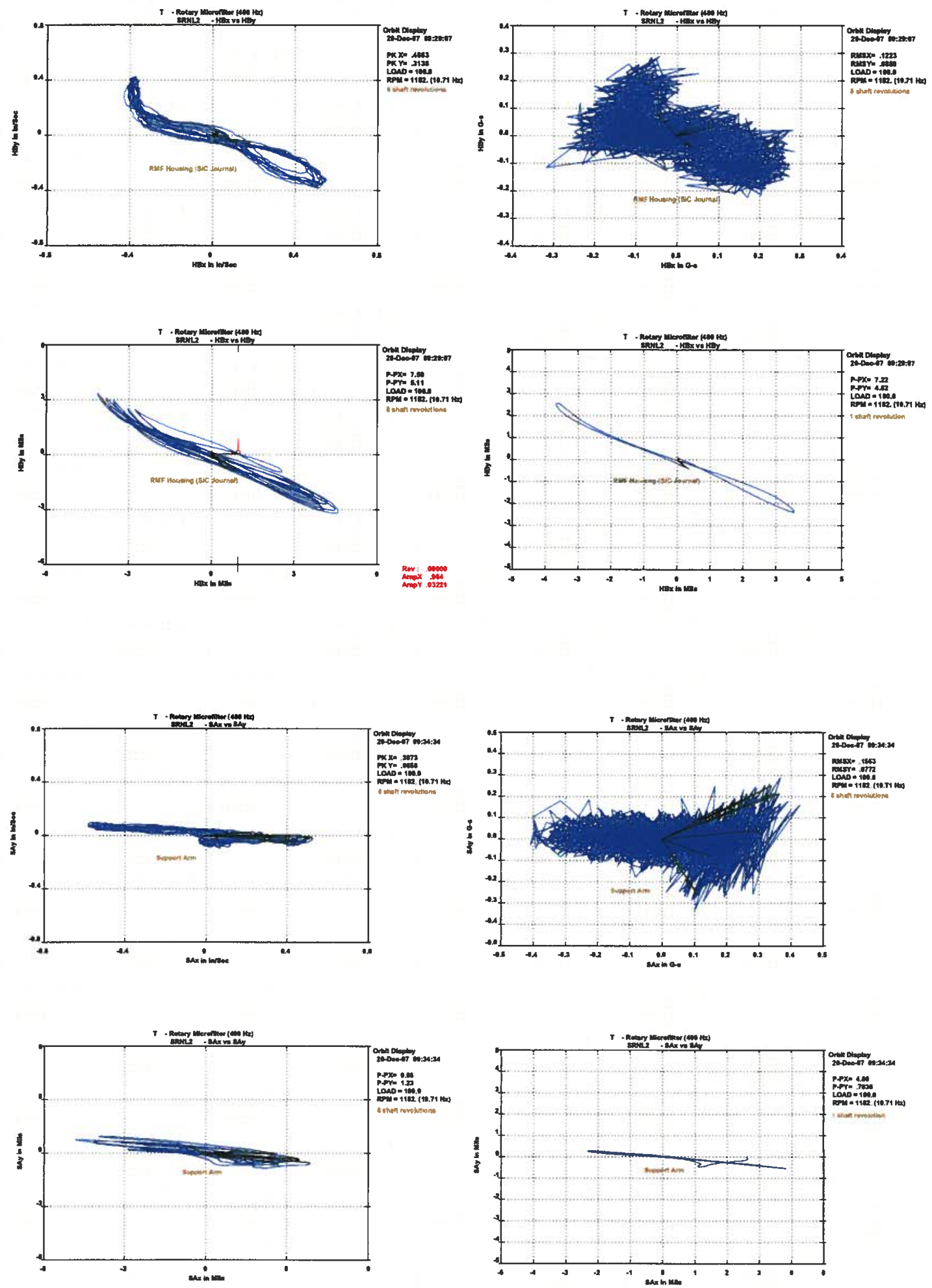

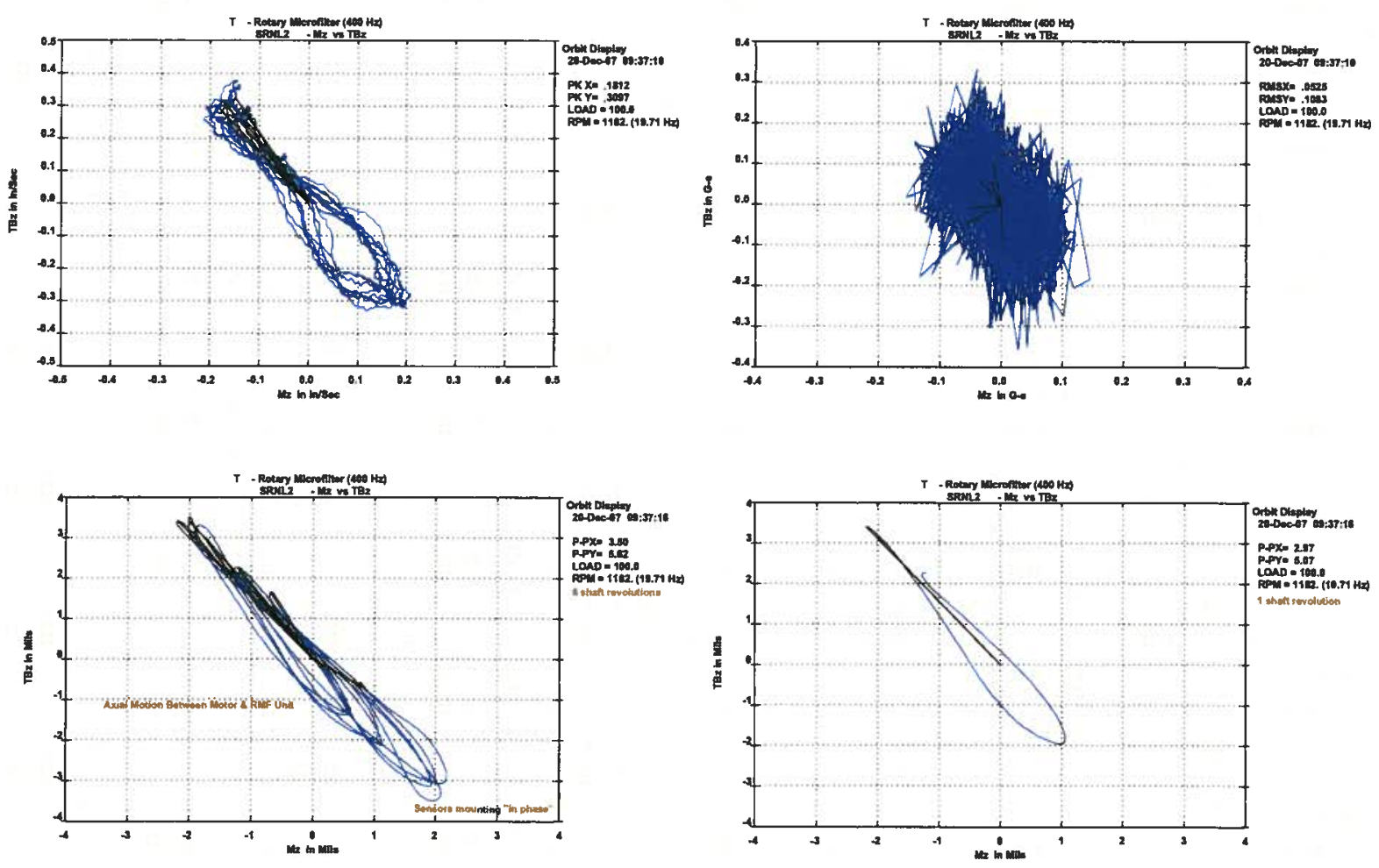
SRNL-STI-2009-00183 Revision 0

Attachment 5

Second Vibration Measurement

1 of 21

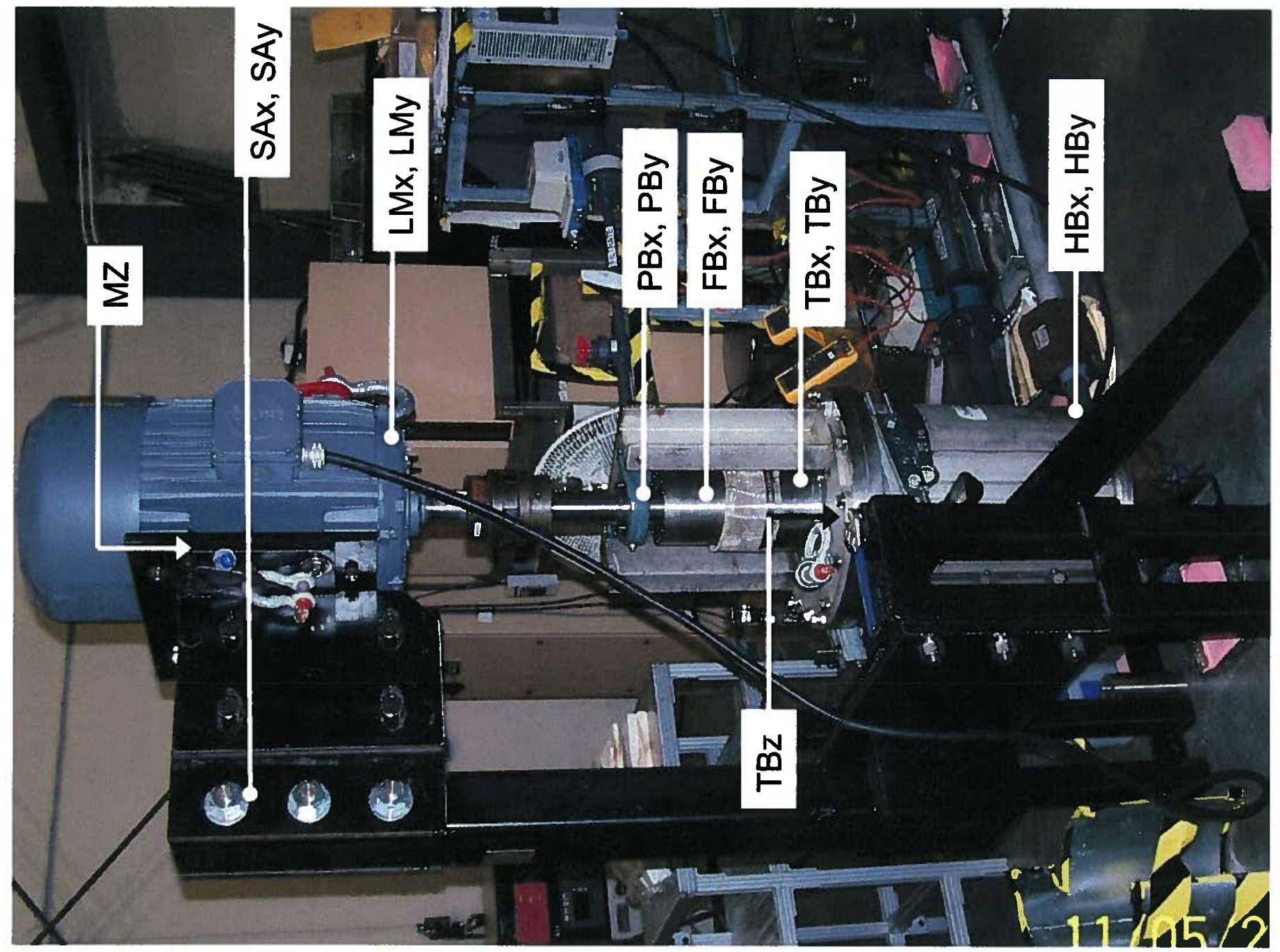


SRNL-STI-2009-00183 Revision 0

Attachment 5

Second Vibration Measurement
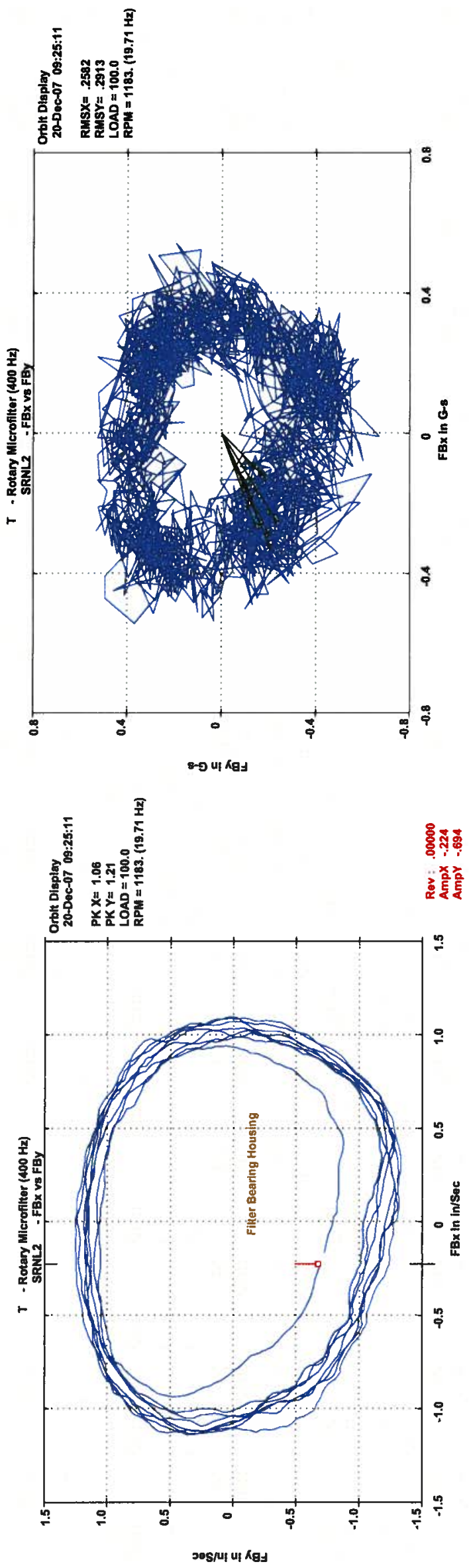

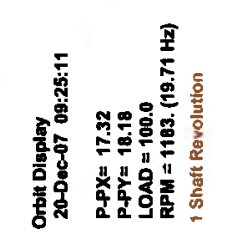

2 of 21
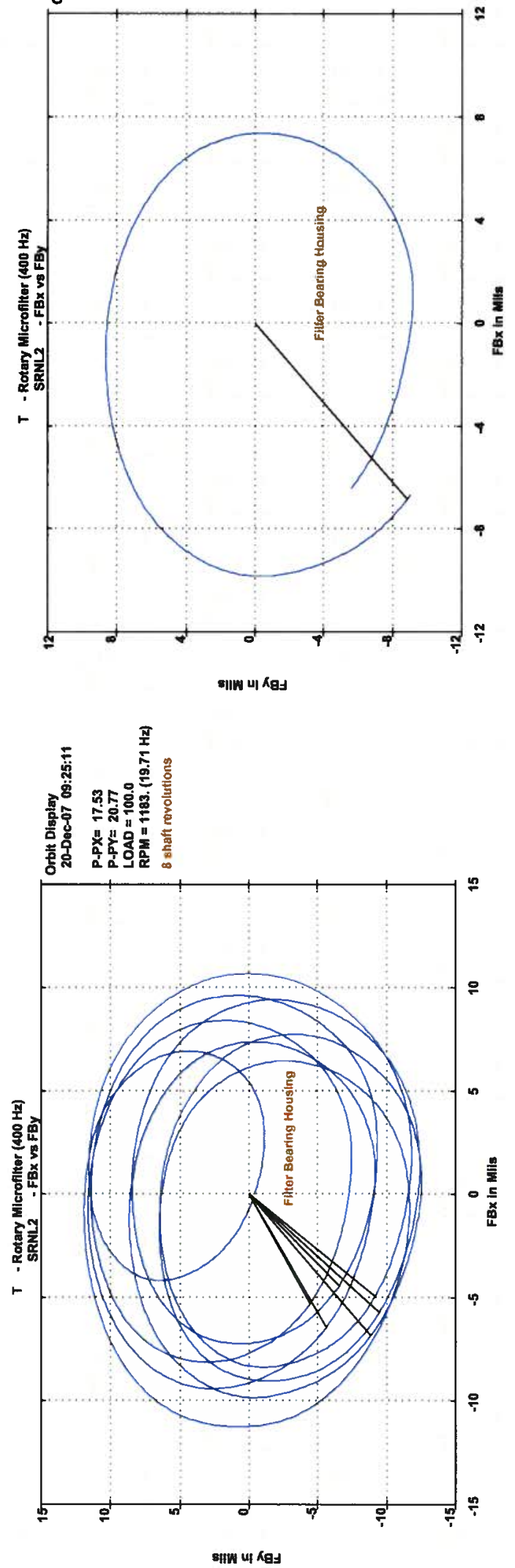
SRNL-STI-2009-00183 Revision 0

Attachment 5

Second Vibration Measurement

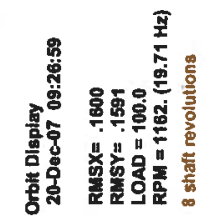
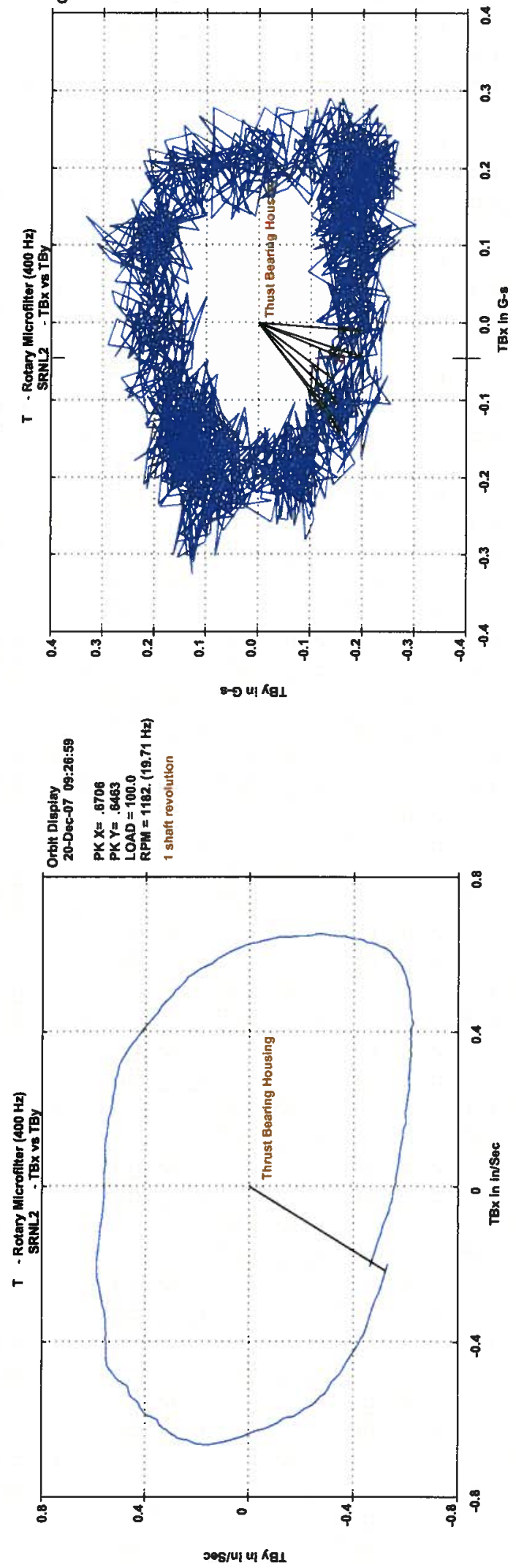

3 of 21
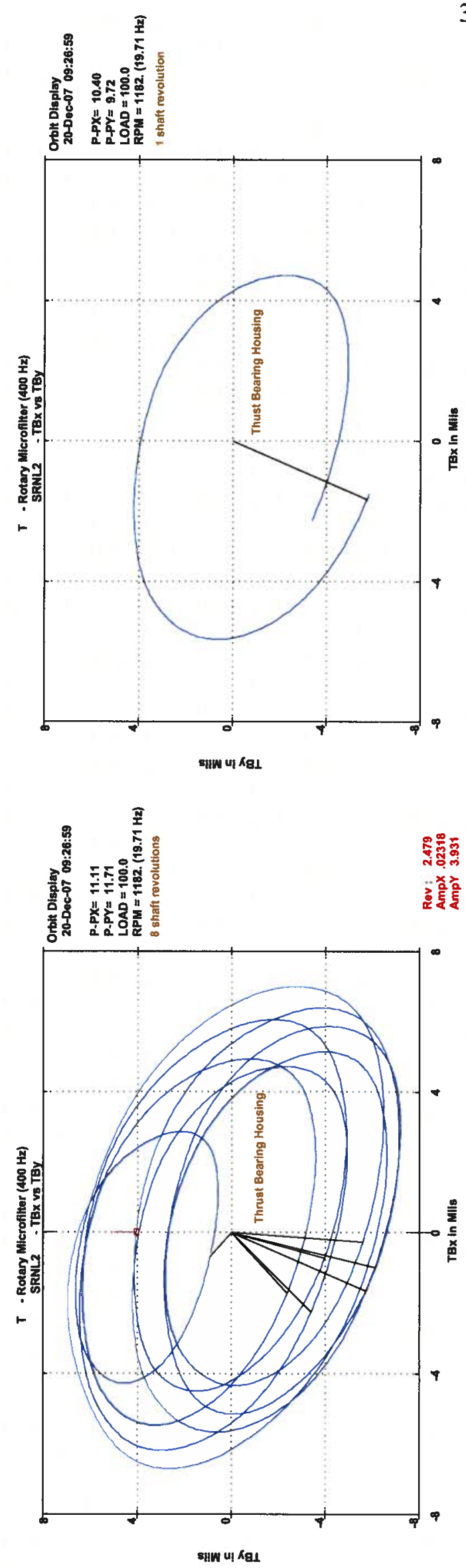
SRNL-STI-2009-00183 Revision 0 Attachment 5

Second Vibration Measurement

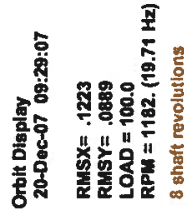
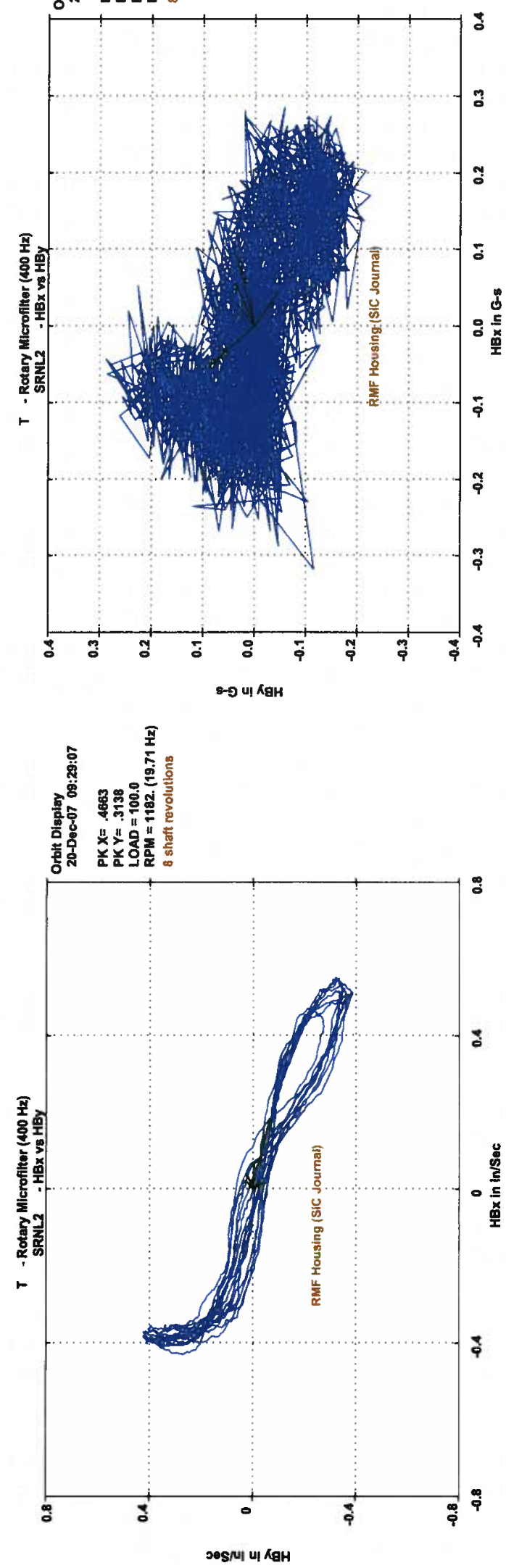

4 of 21
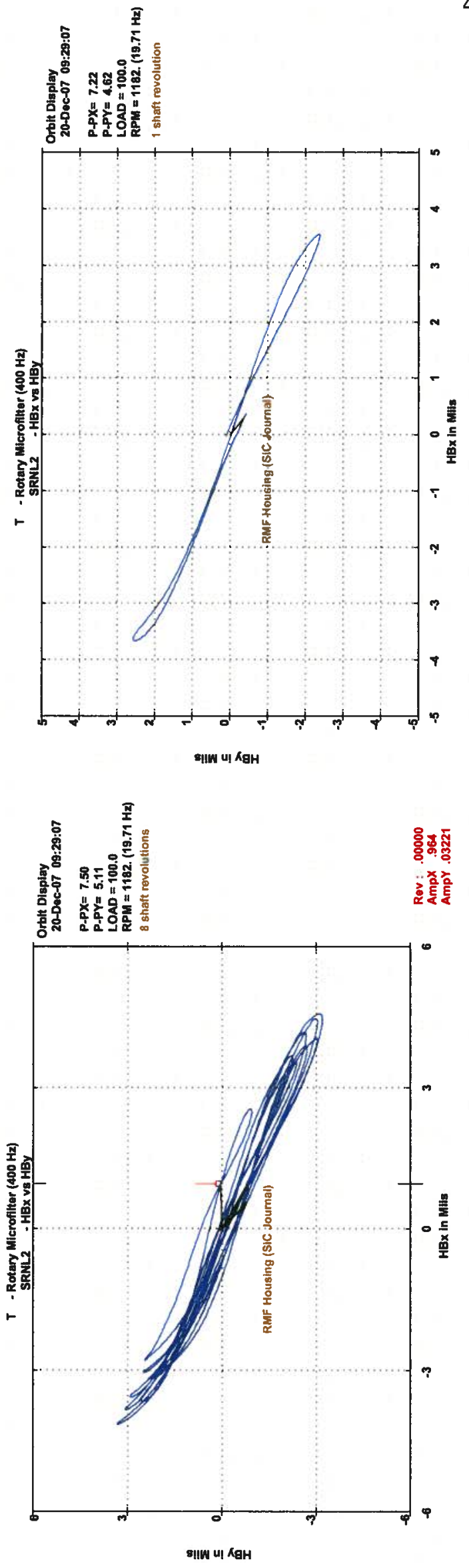

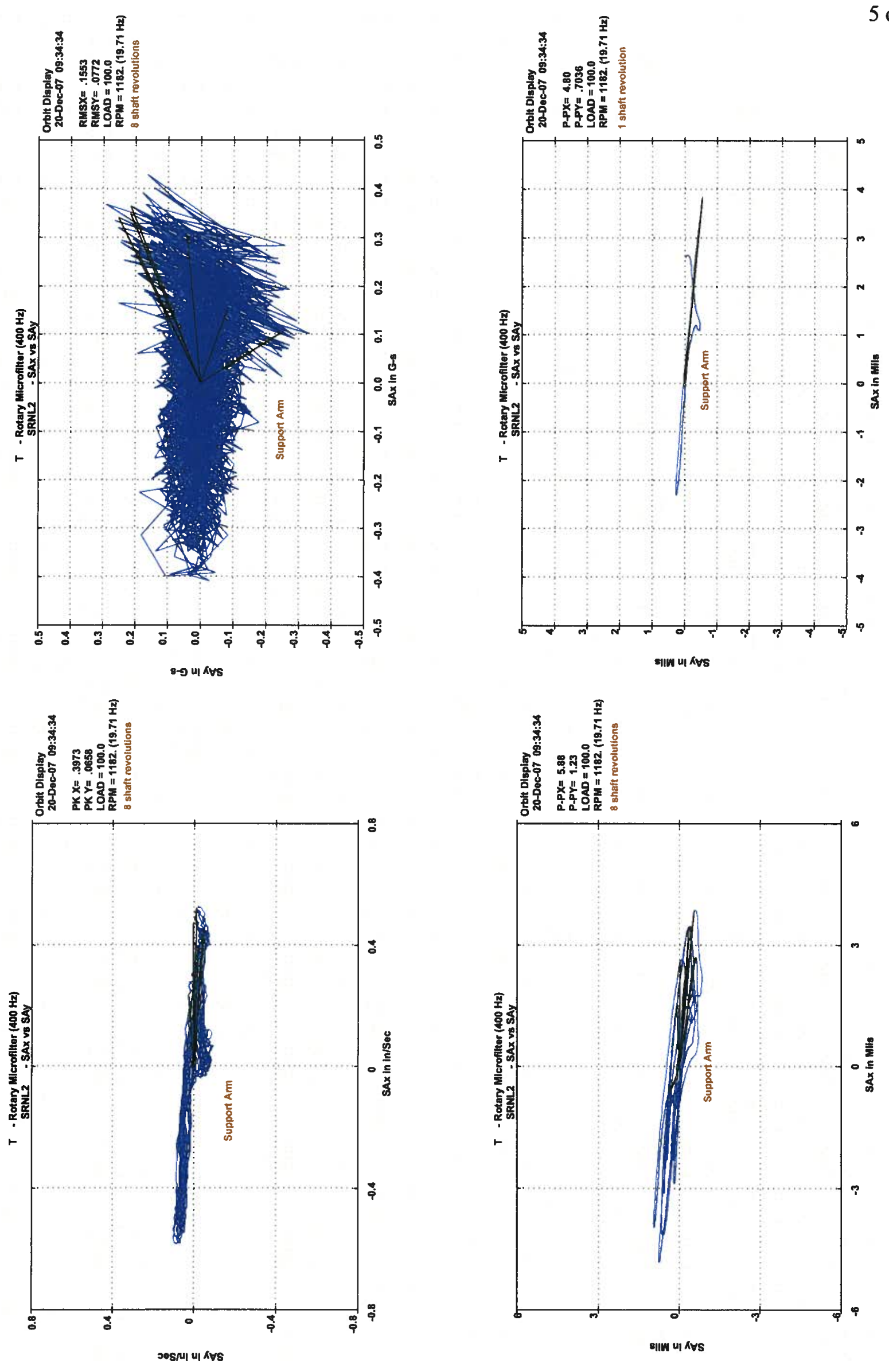
SRNL-STI-2009-00183 Revision 0

Attachment 5

Second Vibration Measurement

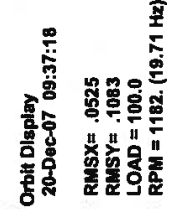
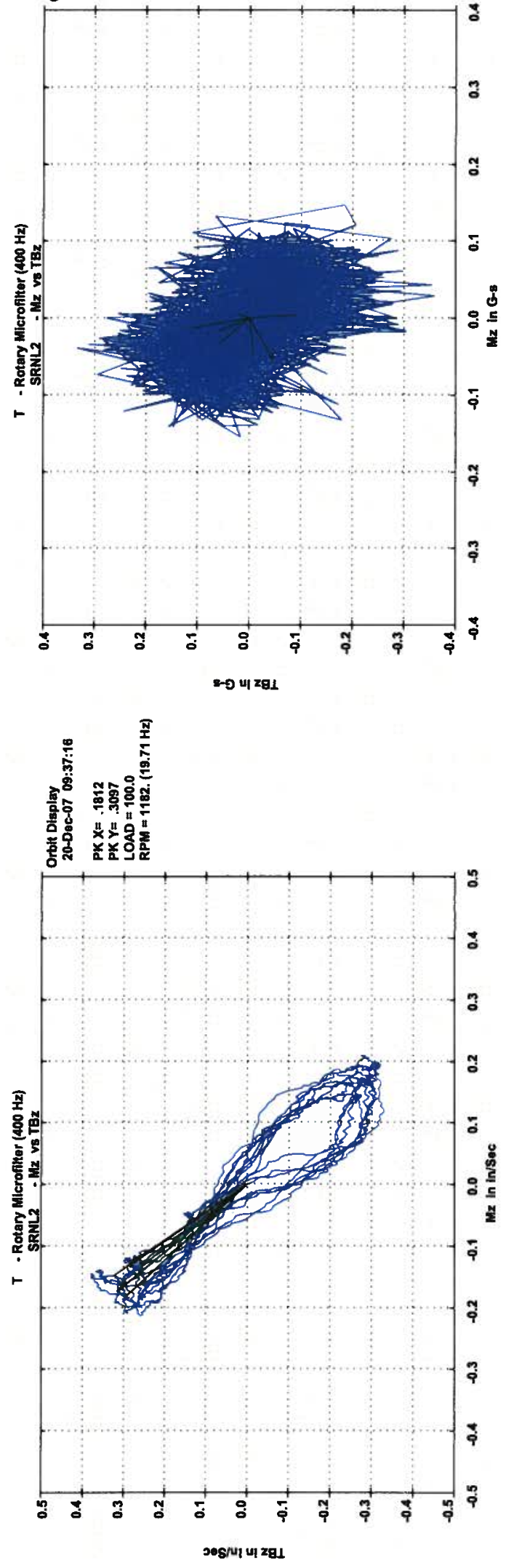

6 of 21
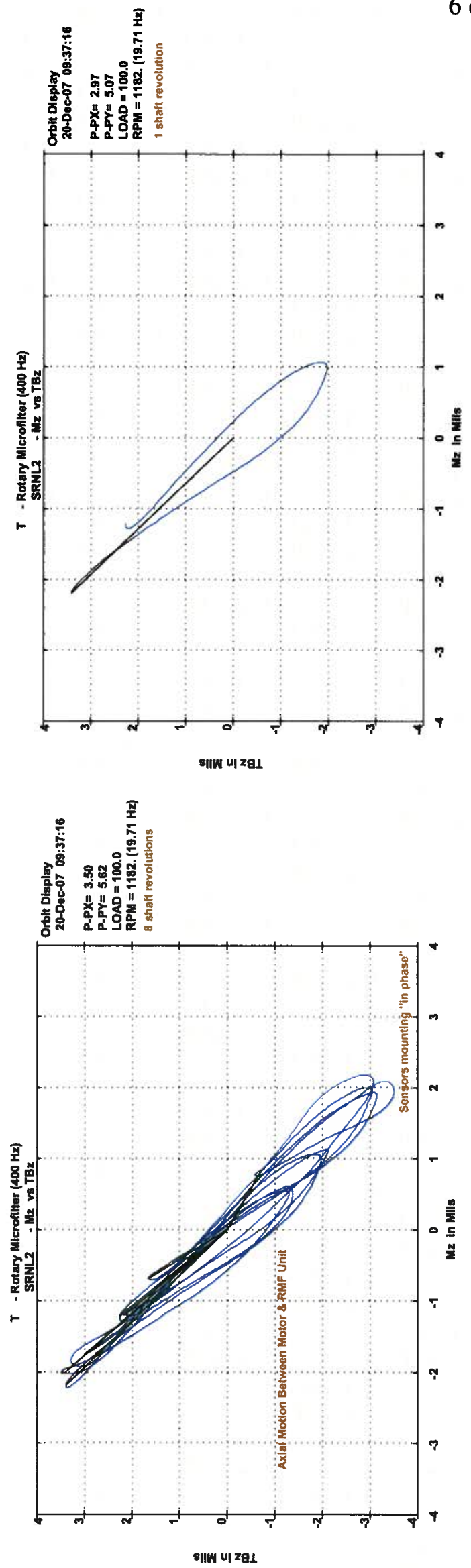


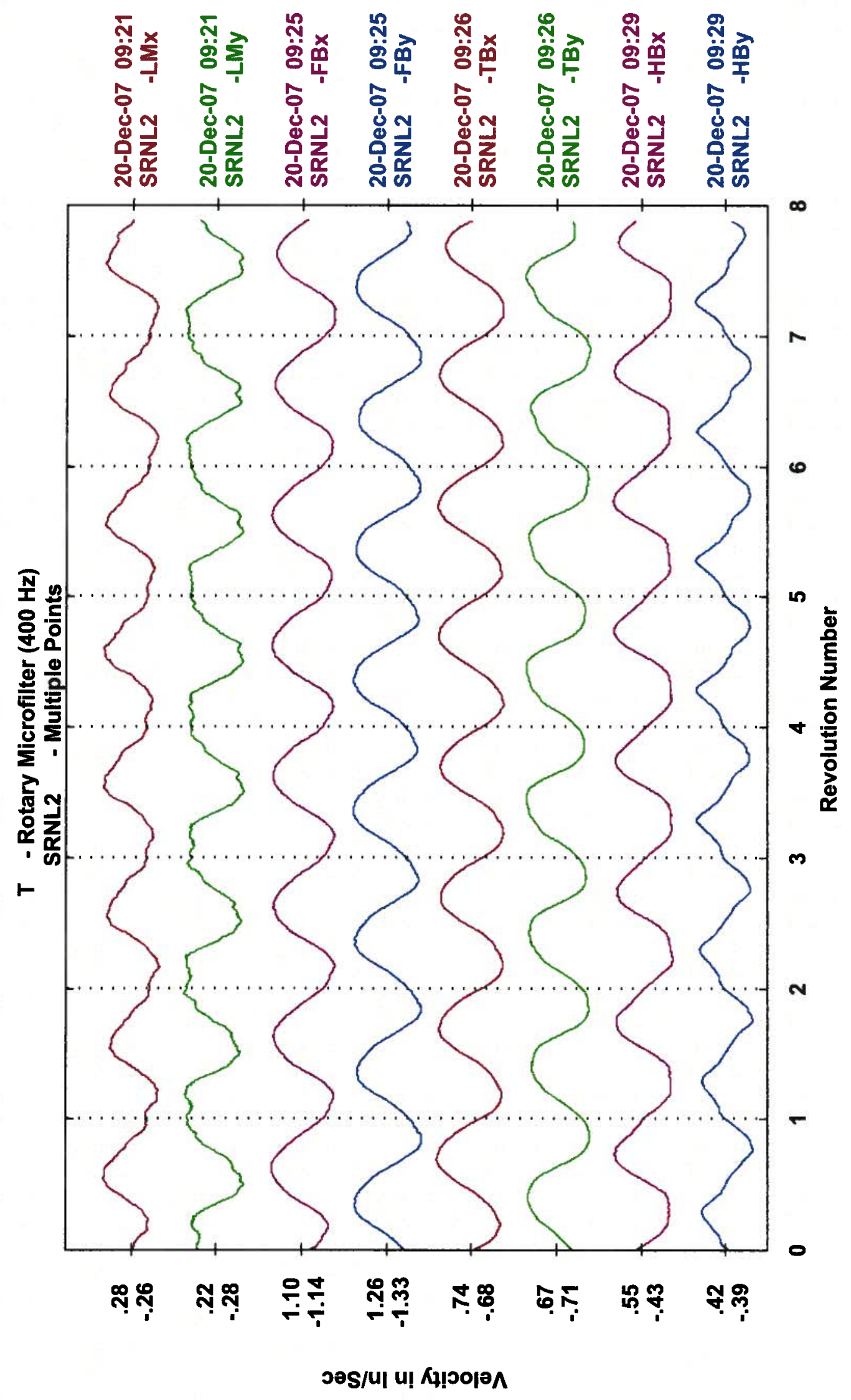




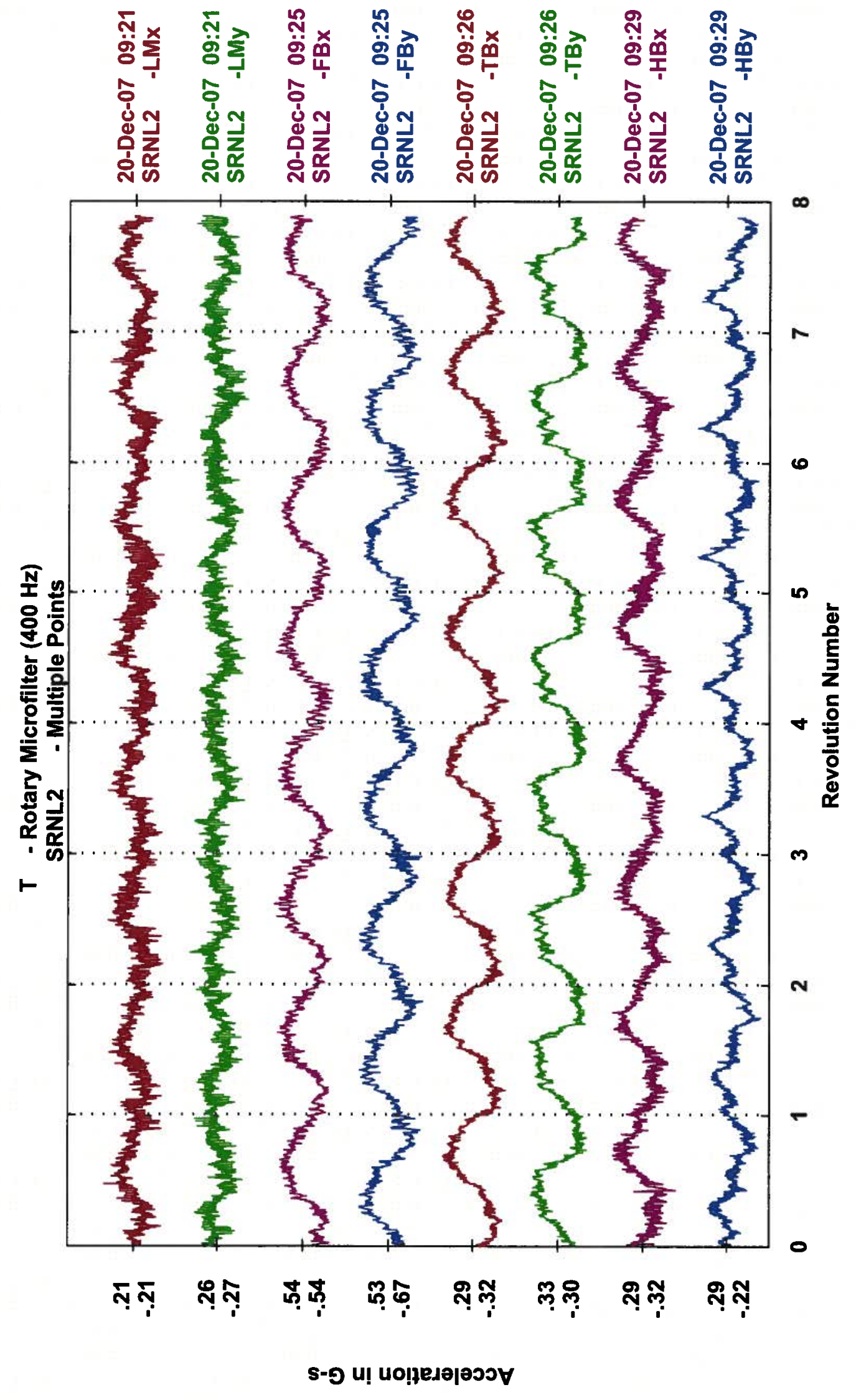




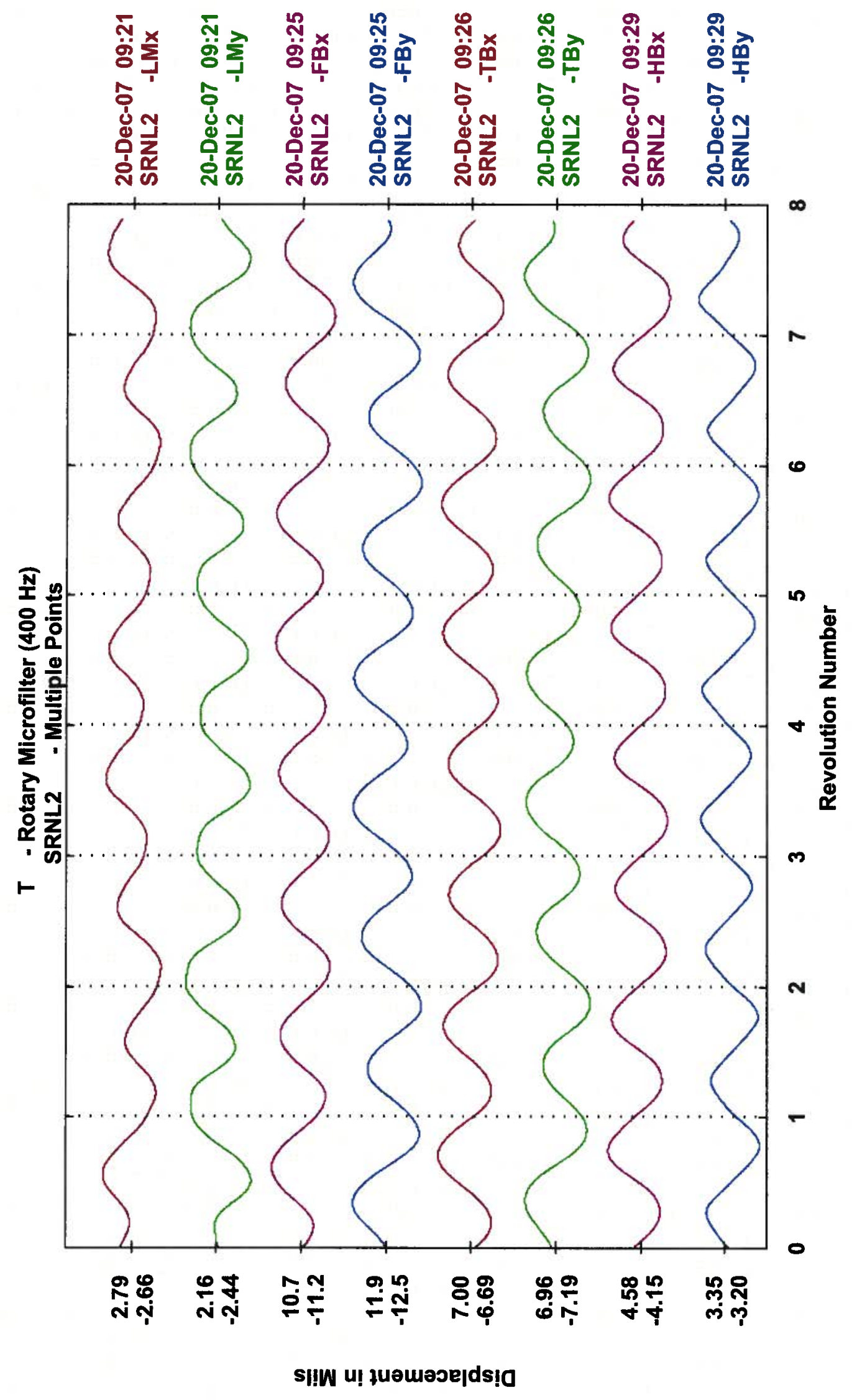




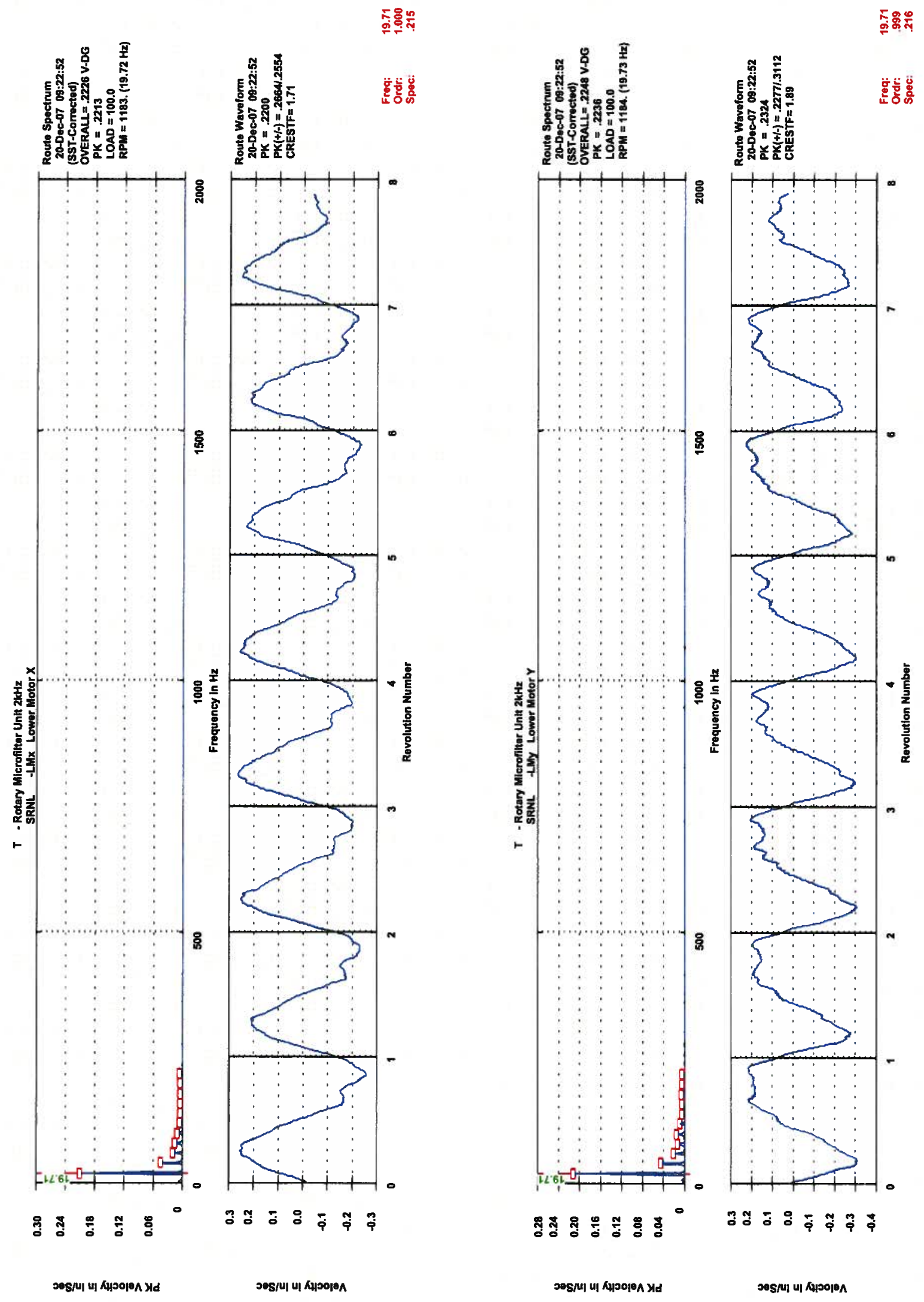


SRNL-STI-2009-00183 Revision 0

Attachment 5

Second Vibration Measurement

11 of 21

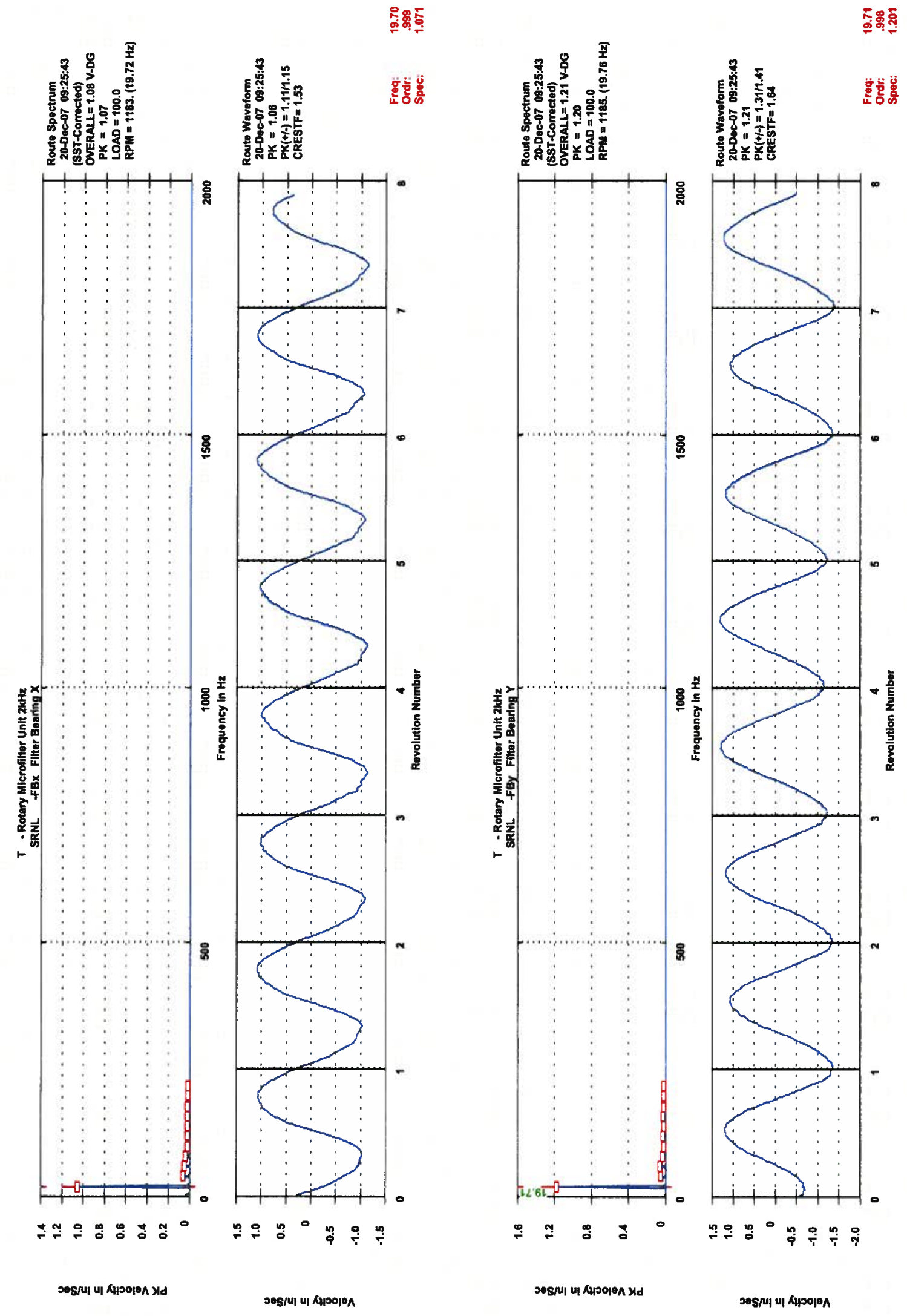


SRNL-STI-2009-00183 Revision 0

Attachment 5

Second Vibration Measurement

12 of 21

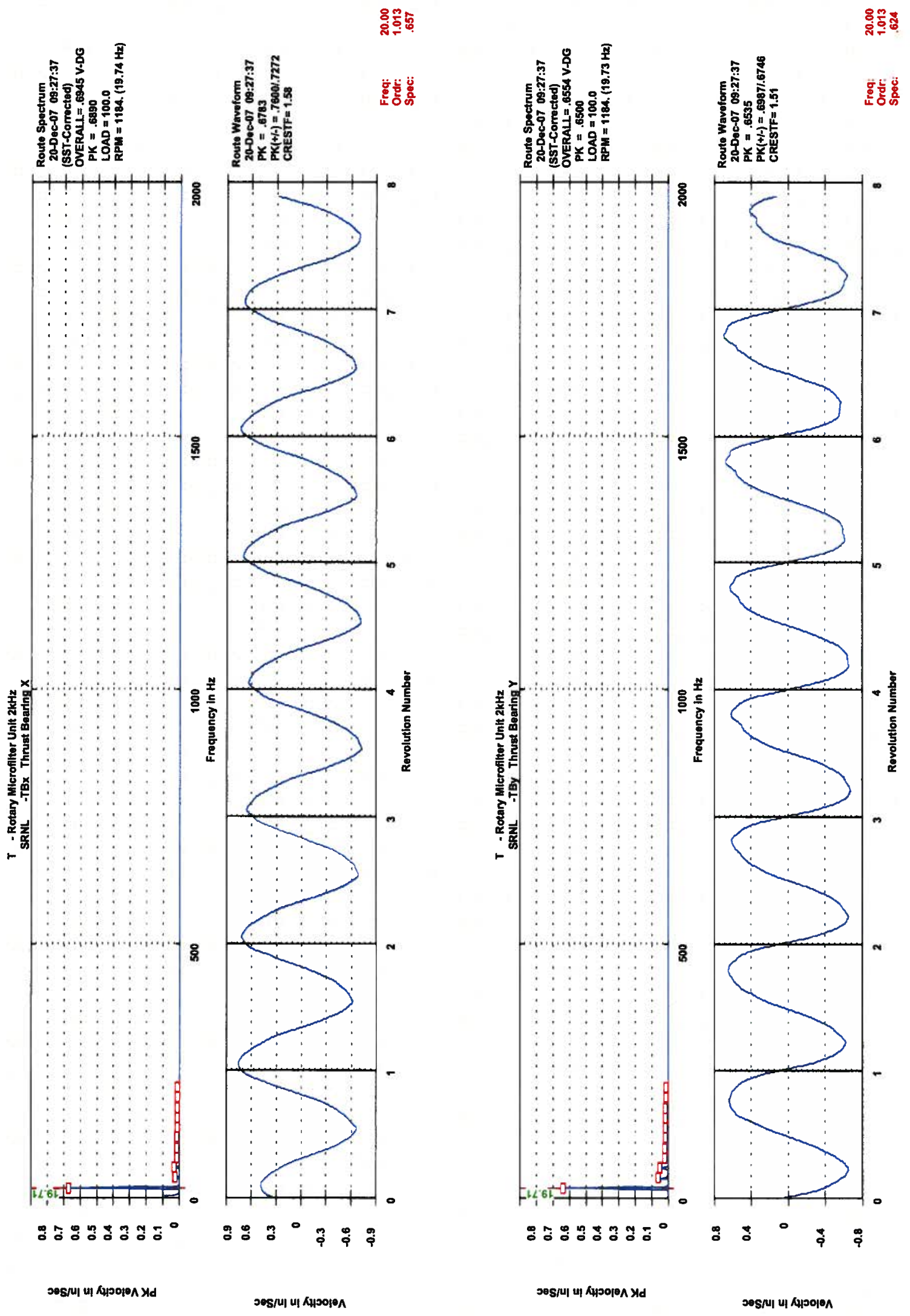


SRNL-STI-2009-00183 Revision 0

Attachment 5

Second Vibration Measurement

13 of 21

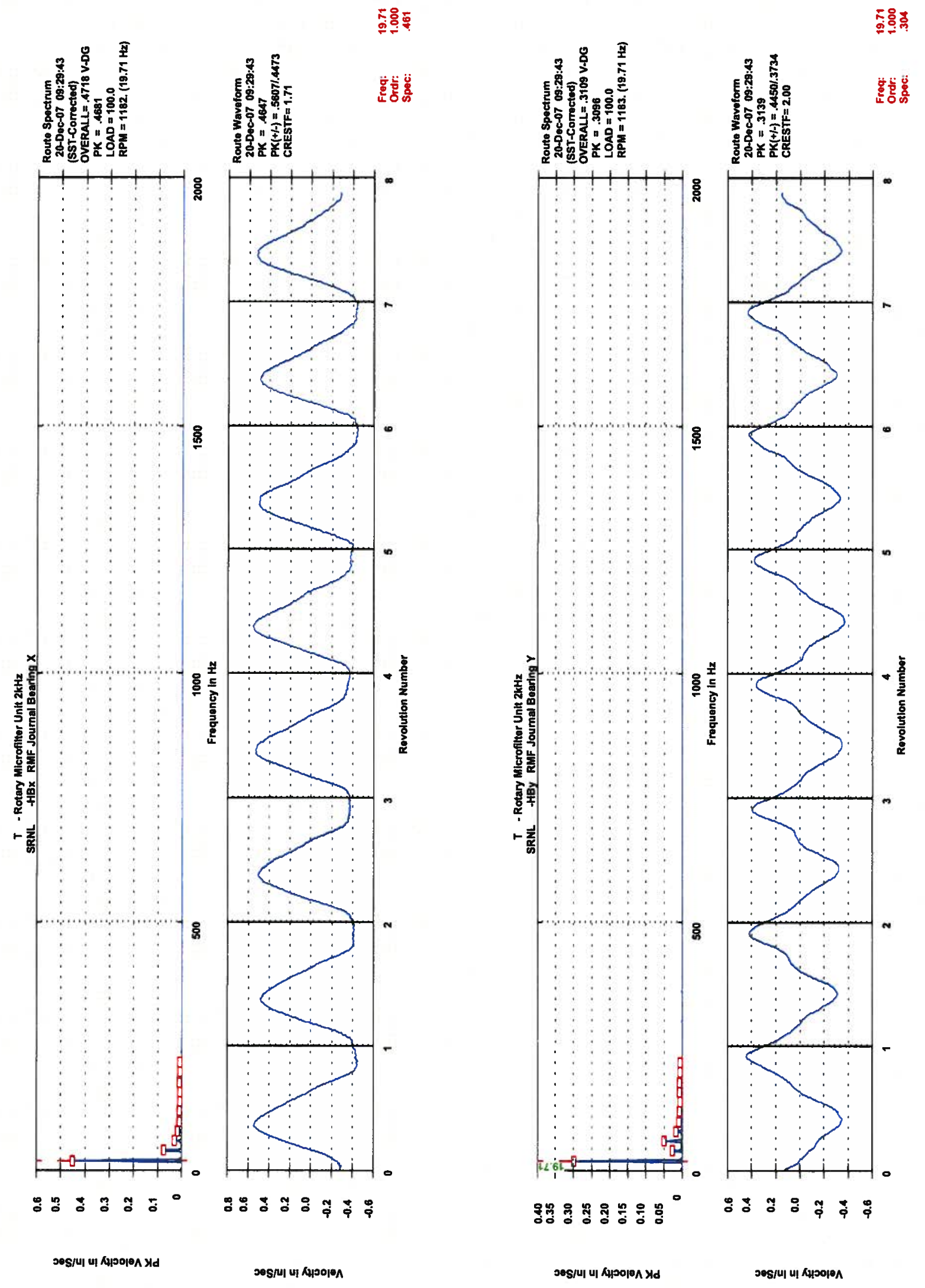




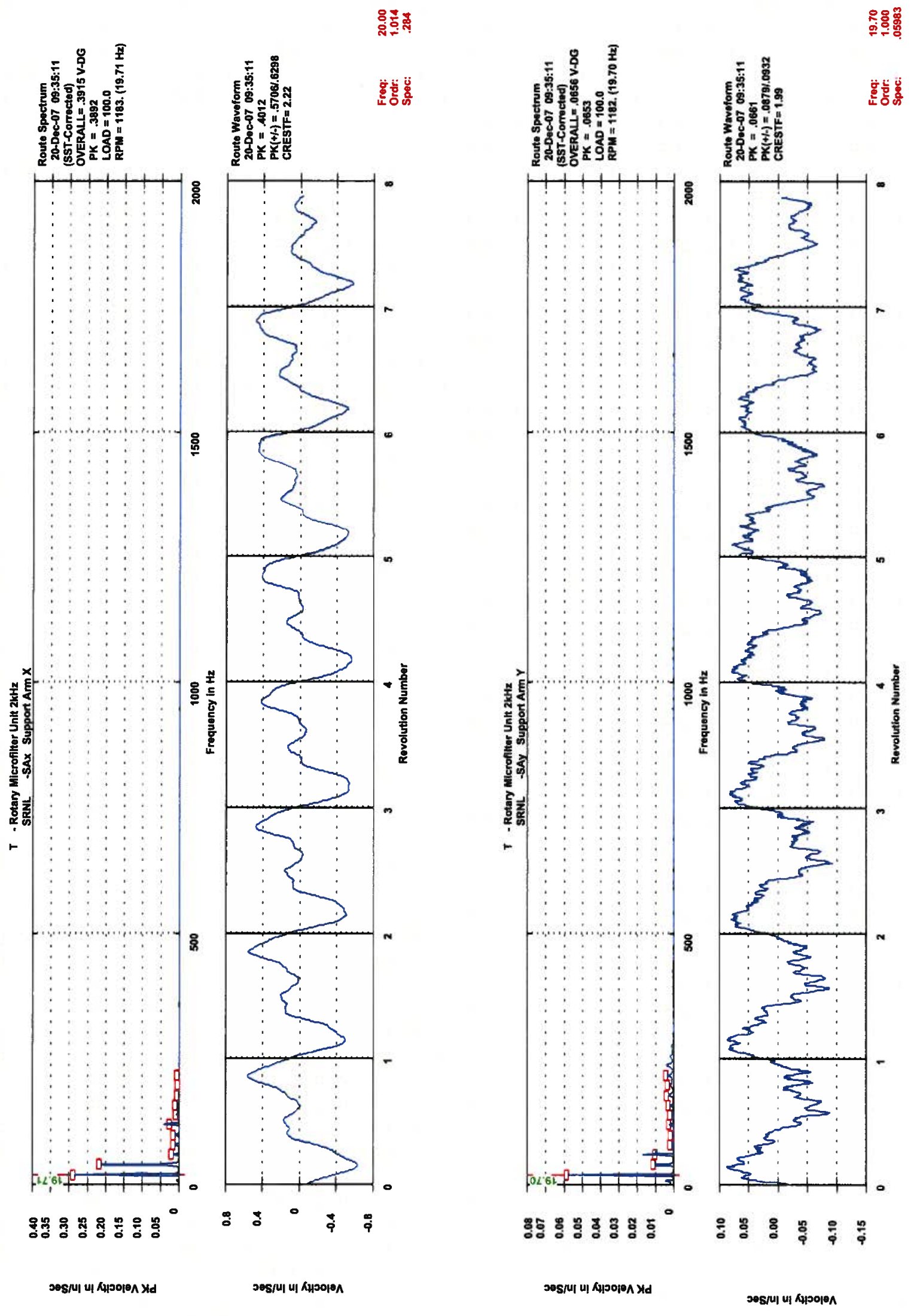




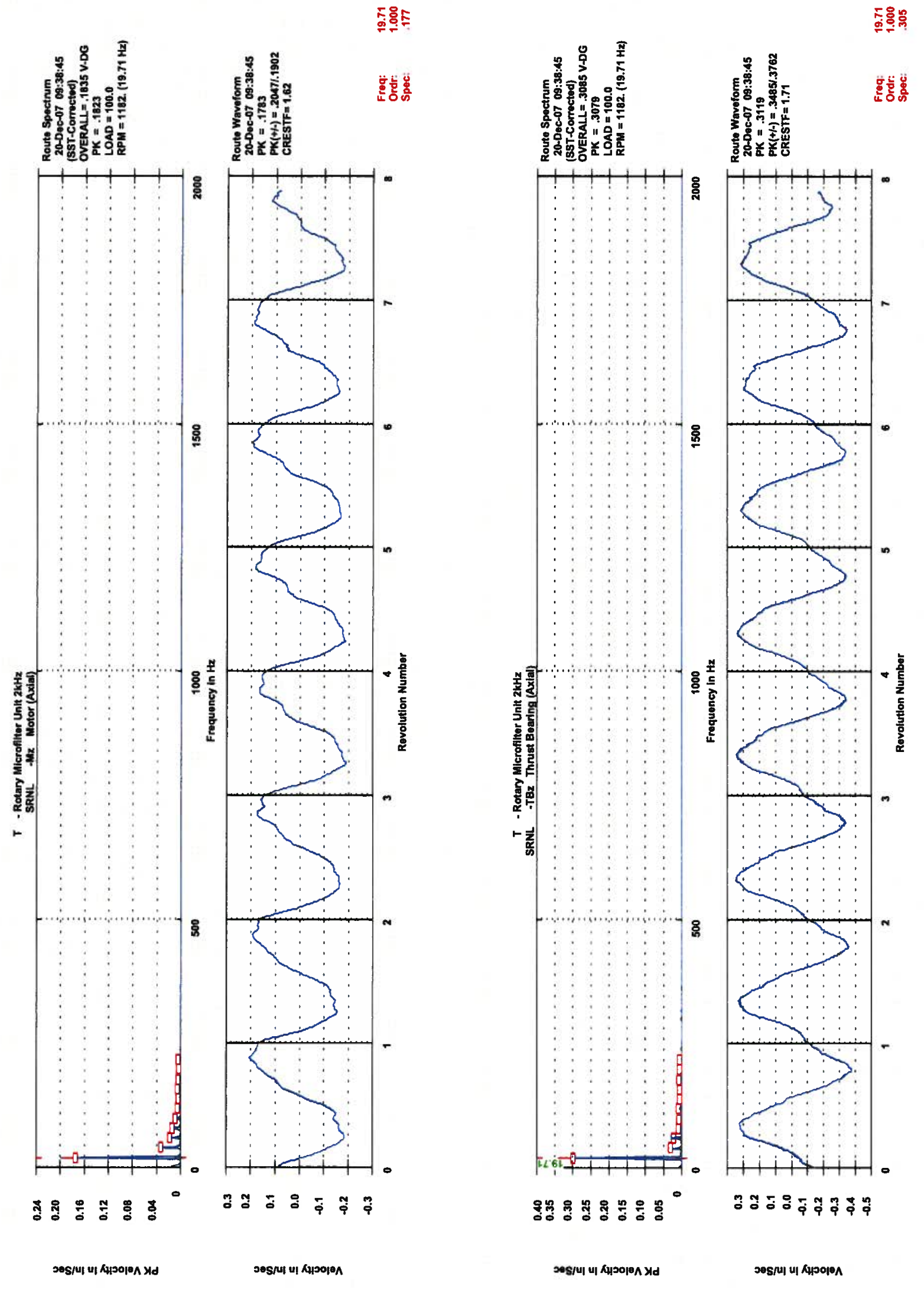




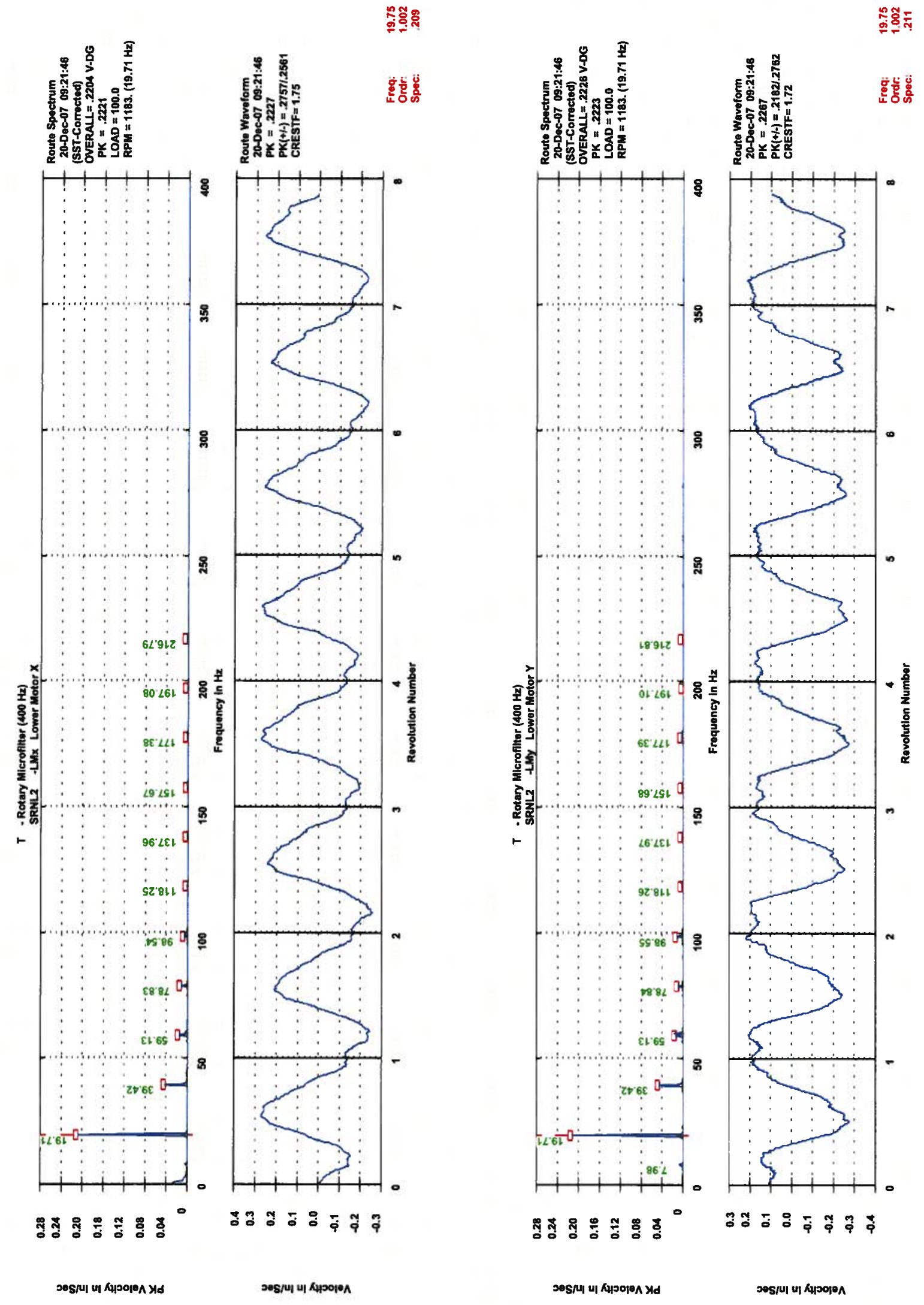


SRNL-STI-2009-00183 Revision 0

Attachment 5

Second Vibration Measurement

17 of 21

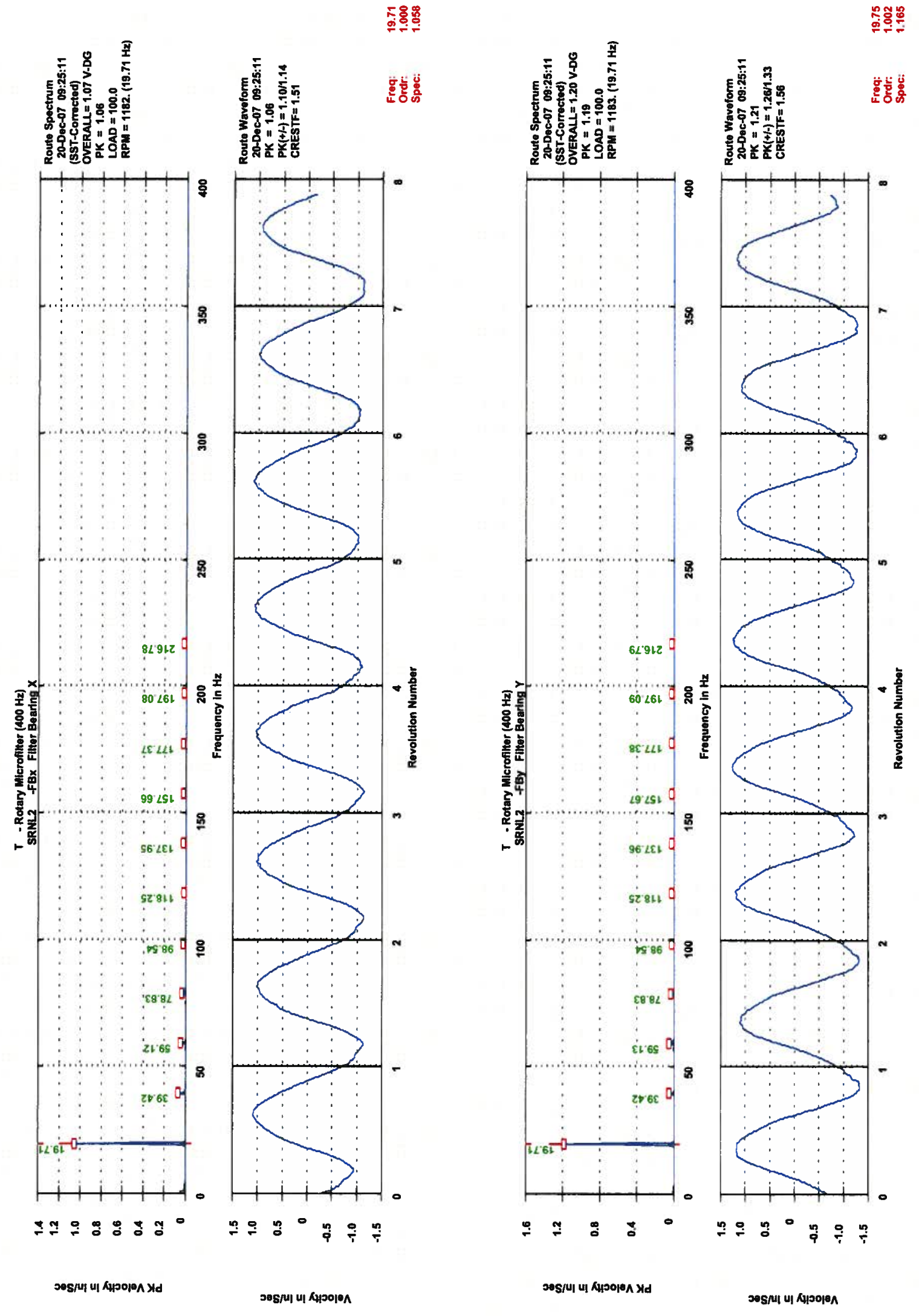


SRNL-STI-2009-00183 Revision 0

Attachment 5

Second Vibration Measurement

18 of 21

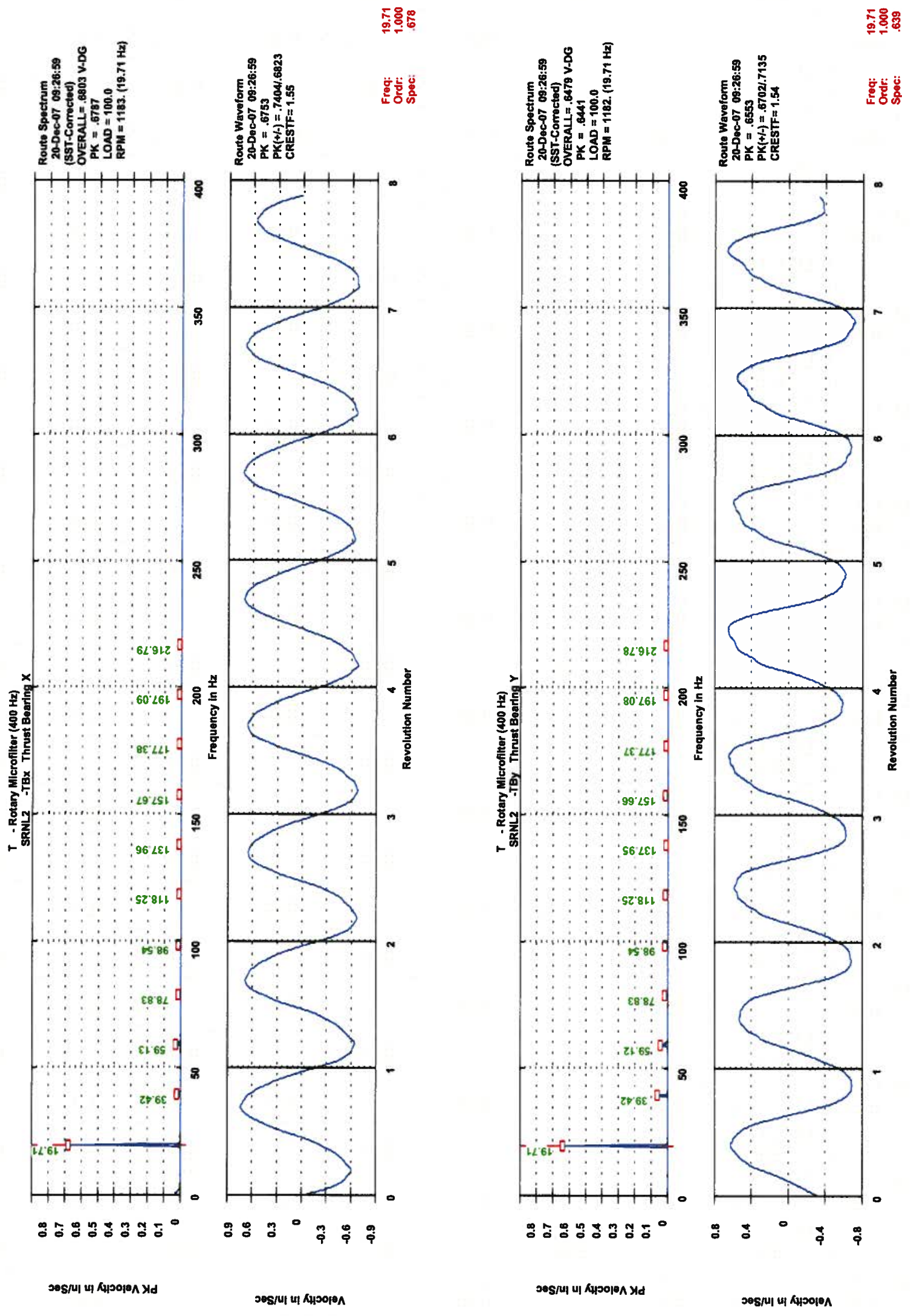


SRNL-STI-2009-00183 Revision 0

Attachment 5

Second Vibration Measurement

19 of 21

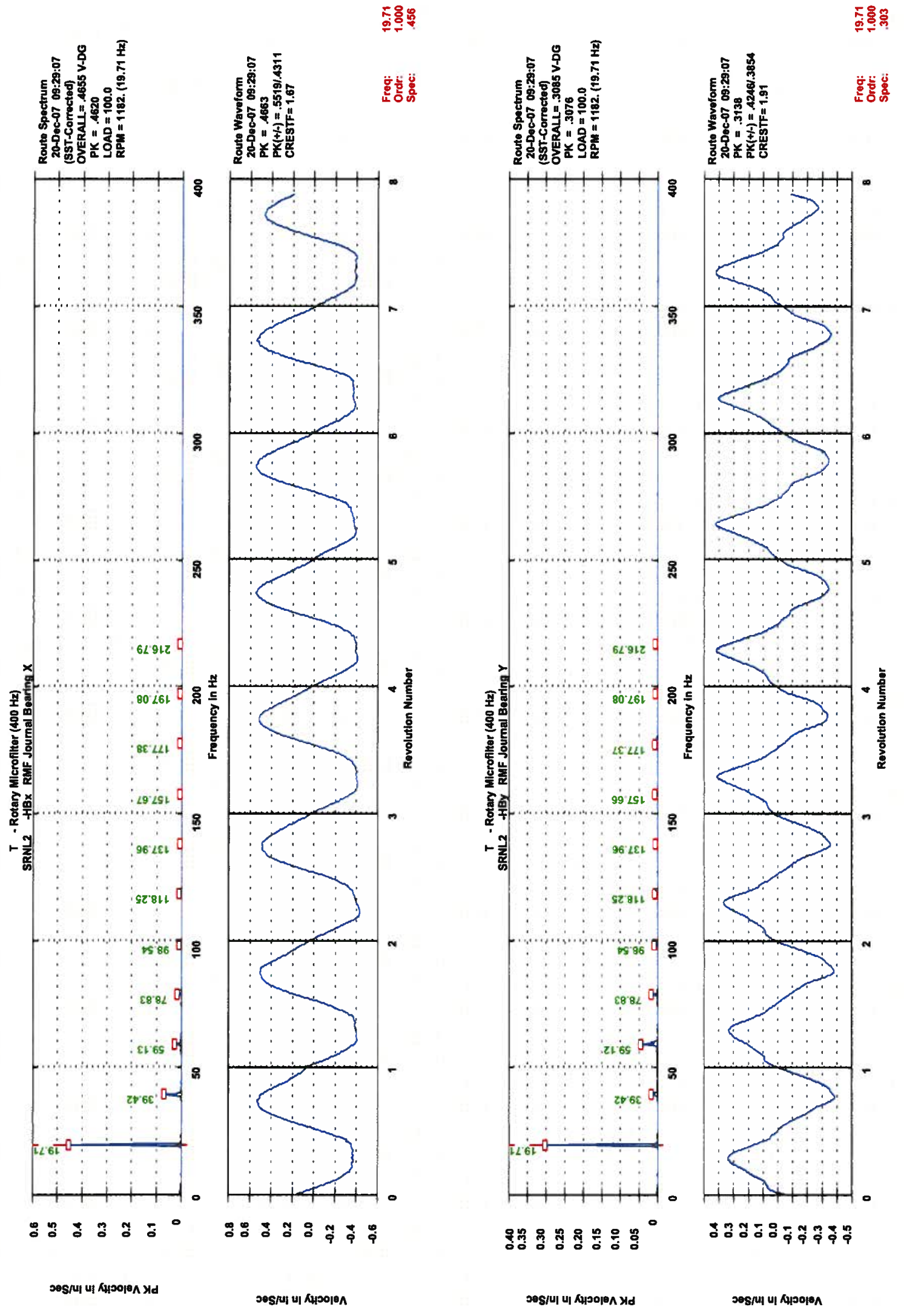


SRNL-STI-2009-00183 Revision 0

Attachment 5

Second Vibration Measurement

20 of 21

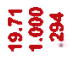
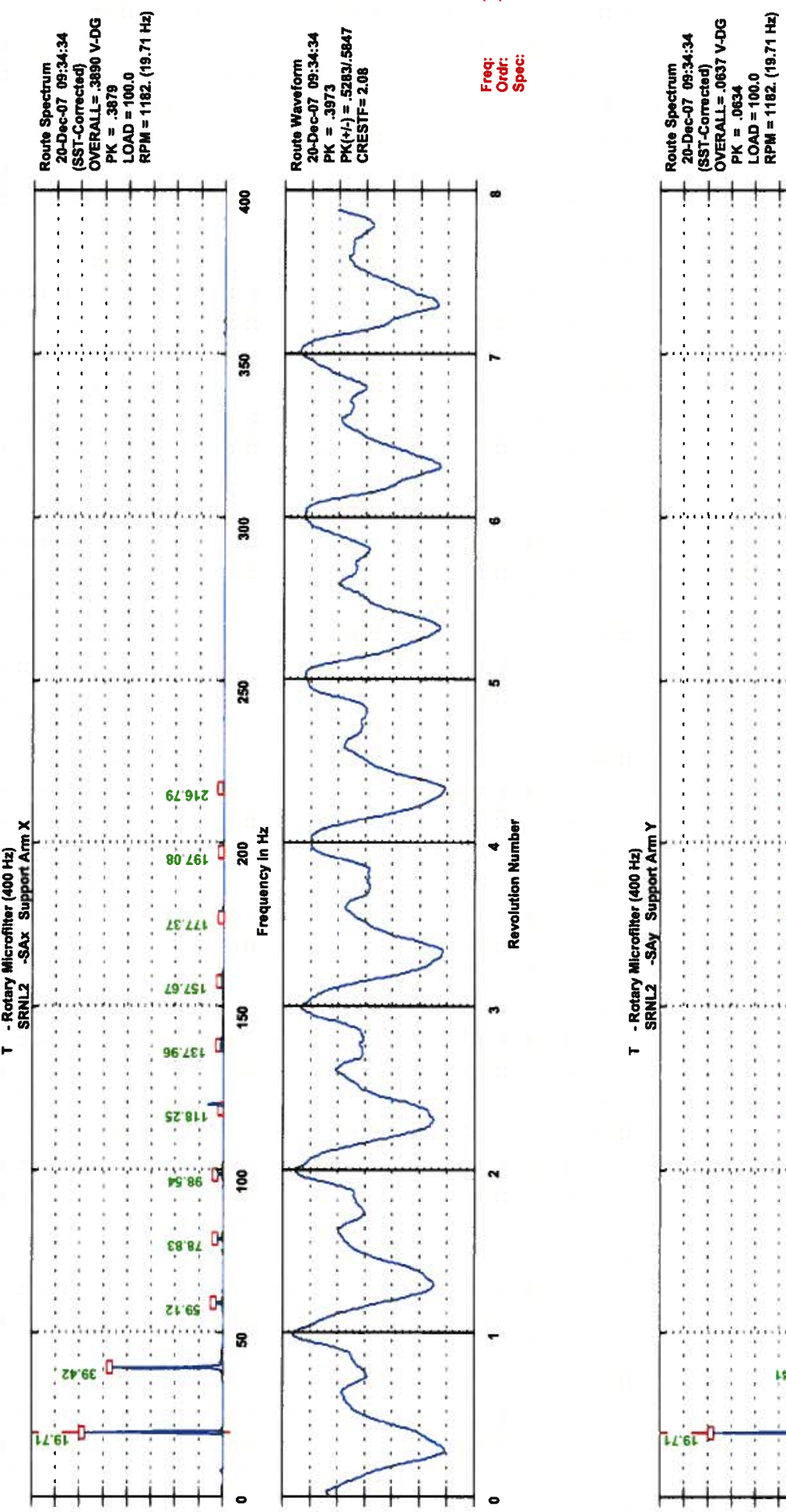

蛋影旁
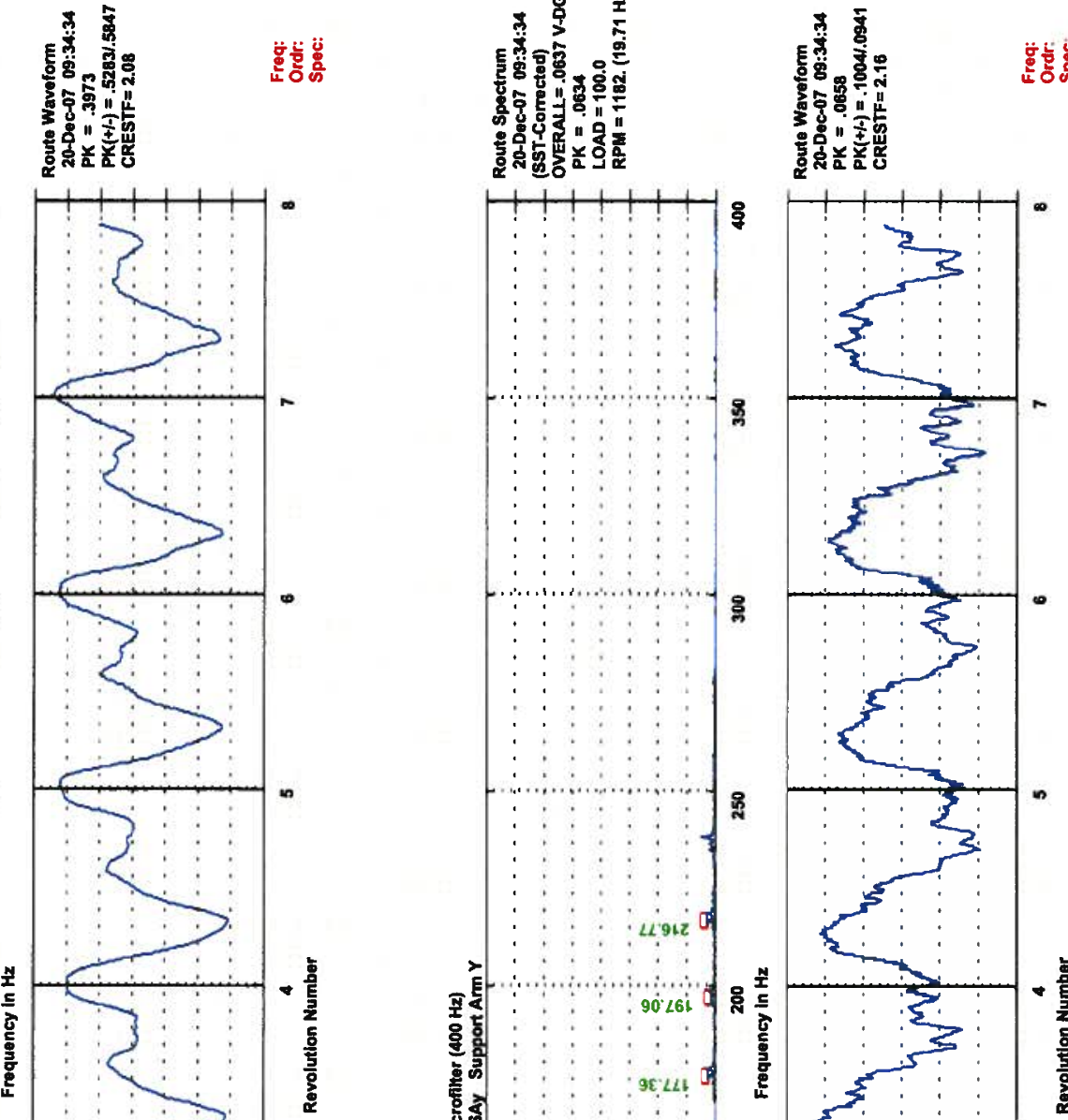

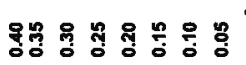

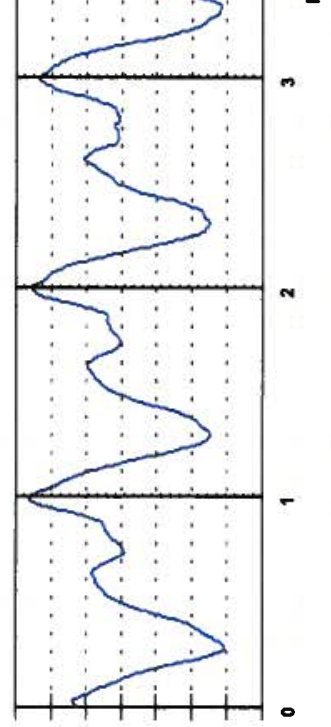

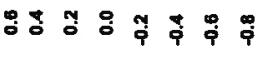

205/UI UI Alpopen Xd

905/U U 내잇ㅅ

כes/니 니 새여새 Xd

sog/u 바 사아에 
SRNL-STI-2009-00183 Revision 0

Attachment 5

Second Vibration Measurement

21 of 21

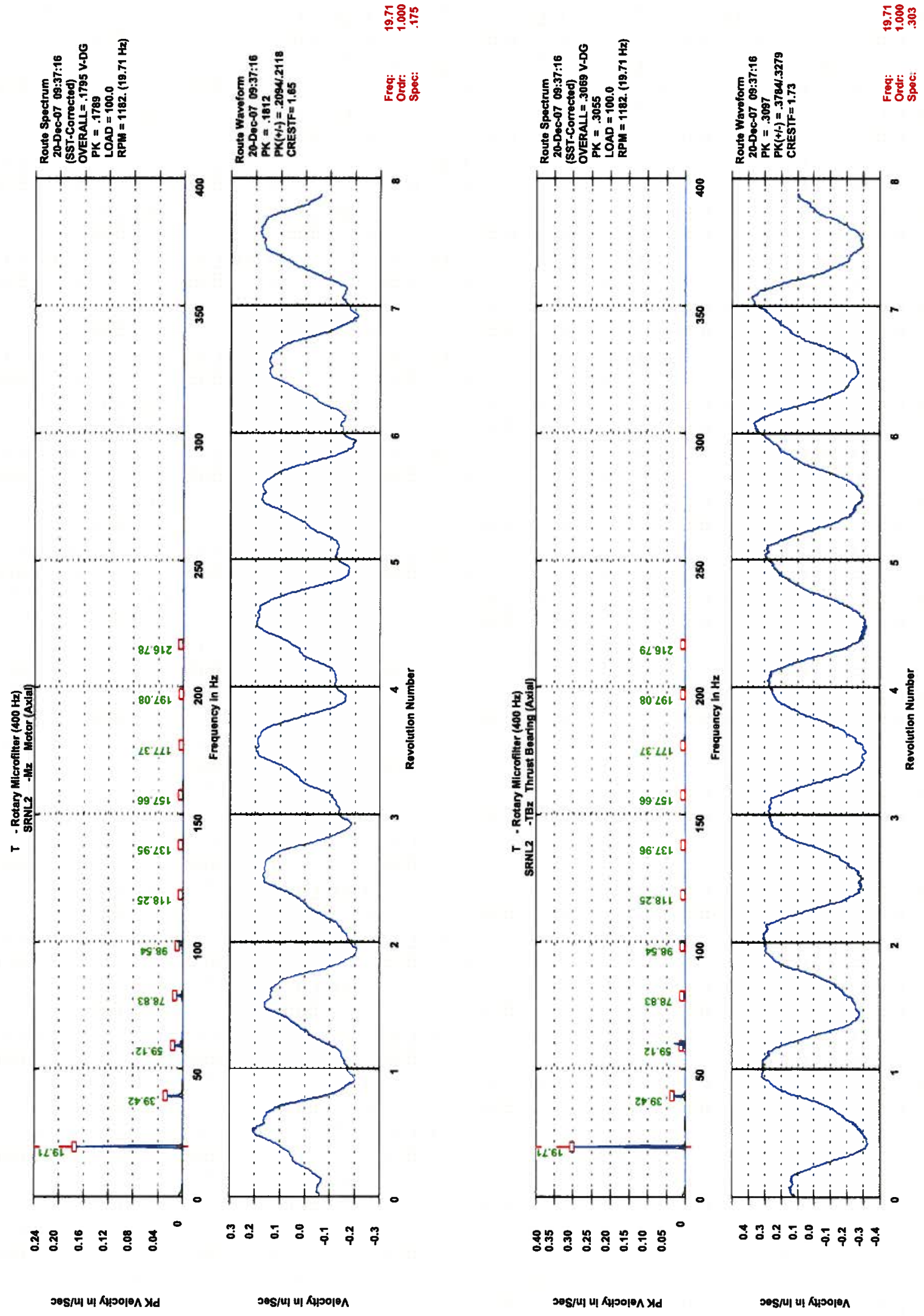

